\title{
GOVERNING CORAL REEF CONSERVATION IN \\ THE DIGITAL SOCIETY
}

EIRA C. CARBALLO CÁRDENAS

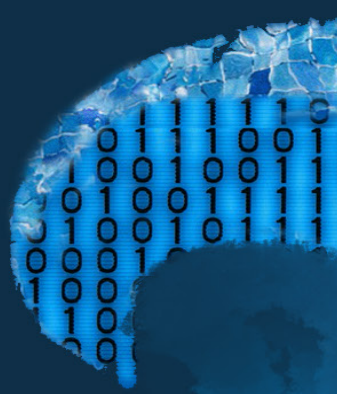

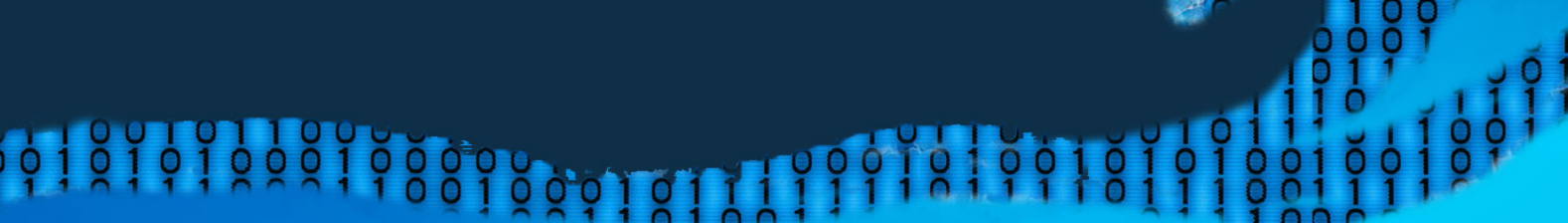

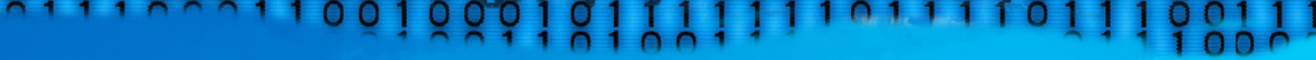

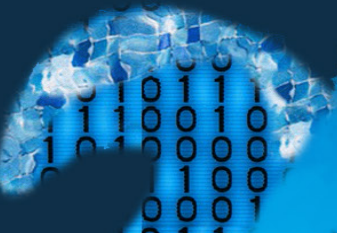




\section{Propositions}

1. For multi-actor digital conservation networks to endure, robust mechanisms that manage accountability are required. (this thesis)

2. Measures promoting lionfish consumption encroach on policy domains beyond conservation. (this thesis)

3. Global warming increases the entropy of the Earth system, but also forces order onto social systems.

4. Mitigation-driven biodiversity offsets grant developers a "license to trash nature".

5. Performance assessments of academics should incorporate their personal ecological footprint metrics.

6. The "Ph" in $\mathrm{PhD}$ implies awareness of the philosophy of science chosen.

7. Globalization triggers localization.

8. Believing that everything is possible makes new beliefs possible.

Propositions belonging to the $\mathrm{PhD}$ thesis, entitled Governing coral reef conservation in the digital society Eira C. Carballo Cárdenas 



\section{Governing coral reef conservation in the digital society}

Eira C. Carballo Cárdenas 


\section{Thesis committee}

\section{Promotors}

Prof. Dr A.P.J. Mol

Professor of Environmental Policy

Wageningen University \& Research

Prof. Dr H.J. Lindeboom

Emeritus professor of Marine Ecology

Wageningen University \& Research

\section{Co-promotor}

Dr H. Tobi

Associate professor, Mathematical and Statistical Methods, Biometris

Wageningen University \& Research

\section{Other members}

Prof. Dr A. Irwin, Copenhagen Business School, Denmark

Prof. Dr E. Turnhout, Wageningen University \& Research

Prof. Dr R. van der Wal, Swedish University of Agricultural Sciences, Sweden

Dr M. Verweij, Wing, the Netherlands

This research was conducted under the auspices of the Wageningen School of Social Sciences (WASS). 


\title{
Governing coral reef conservation in the digital society
}

\author{
Eira C. Carballo Cárdenas
}

\section{Thesis}

submitted in fulfilment of the requirements for the degree of doctor at Wageningen University

by the authority of the Rector Magnificus,

Prof. Dr A.P.J. Mol,

in the presence of the

Thesis Committee appointed by the Academic Board

to be defended in public

on Friday 8 May 2020

at 4 p.m. in the Aula. 


\section{Eira C. Carballo Cárdenas}

Governing coral reef conservation in the digital society

258 pages

$\mathrm{PhD}$ thesis, Wageningen University, Wageningen, the Netherlands (2020) With references, with summary in English

ISBN: 978-94-6395-326-9

DOI-link: https://doi.org/10.18174/516144 


\section{Acknowledgements}

As the end of my PhD journey finally comes to an end, I would like to thank those who have accompanied me along the way.

Firstly, my deep gratitude goes to my supervisors, Arthur Mol, Han Lindeboom and Hilde Tobi, for giving me the opportunity to engage in this project and for their enduring support and patience. Arthur, your feedback was always constructive and spot-on; thank you for your guidance all along, and for your indispensable role during the last stretch of the thesis. Han, your passion for marine conservation is inspiring; thank you for your valuable insights and for having shared with us the various royal visits and fascinating symposiums. Hilde, I am appreciative of your critical eye as it always benefitted my work; it was really nice getting to know you over the years. I am sincerely grateful for your support, both at the research and personal level!

Being part of the Environmental Policy group (ENP) has been a joy. ENP has provided me with a stimulating, friendly space where I feel at home. Thanks to the PhD community (and junior researchers) for all the formal and informal moments during which we have shared our ups-and-downs, with our $\mathrm{PhD}$ dinners as especially memorable: Agnes, Aisa, Alexey, Alita, Anke, Astrid, Belay, Carolina, Chaohui, Ching, Dan, Debasish, Dorien, Dung, Elisabeth, Ery, Fan, Frank, Hanne, Harry, Helena, Hilde, Ivo, Jenni, Jia, Jiaqi, Jillian, Joeri, Jordi, José, Judith F., Judith T., Kari, Karlijn, Latiful, Leah, Linde, Maíra, Mandy D., Maria, Mariska, Marjanneke, Martijn, Mekdi, Moisés, Nantamol, Natapol, Nila, Nowella, Pamela, Paul, Phatra, Quoc, Radhika, Robin, Sake, Sammy, Sarah, Sawitree, Sayel, Somjai, Tabitha, Terrence, Tracey, and Trang. My best wishes to the new PhDs: Iryna, Robert, Sussane, Usha, Violet and Yongsheng.

Special thanks to my various office-mates for the open-hearted conversations, the many moments filled with laughter and the occasional tears: Ching, Elisabeth, Harry, Hilde Toonen, Joeri, Judith Floor, Judith Tukahirwa, Karlijn, Mandy de Wilde, Natapol and Sanneke. Harry, thank you for your optimism; your big smile and laughter are still missed at ENP. Judith, I enjoyed discussing our research, and life in general, with you; thanks for your guest lectures for my courses, I'm glad that we are still in touch! Natapol, we laughed so much together!! Sanneke, it was so nice 
having you as 'seminar course buddy'; thanks for lending me two key books that helped me to frame the Introduction of this thesis.

A special word of thanks goes to Corry Rothuizen, the go-to person at ENP for matters of practical and emotional nature. Her office is, besides the central node of ENP's information network, a sanctuary where many of us go for a moment of rest, advice and reflection. Lieve Corry, hartelijk dank voor alles!! Jij bent heel bijzonder voor ons allemaal. A special mention goes to Jan van Tatenhove and Simon Bush for giving me the opportunity to transition into a post-doc and lecturer position at ENP. This filled me with new energy, insights and confidence that allowed me to re-focus on my $\mathrm{PhD}$ thesis. It was interesting and somehow humorous to balance my three identities within ENP. Jan, thank you very much for inviting me to join MERCES; I have enjoyed discovering the world of European projects, while making new friendships; go WP6 team! Simon, igracias por todo! I'm so grateful for your support during challenging times; a big thank you for the valuable conversations that helped me to conceptualize chapter 6 of this thesis, and for asking me to stay at ENP. I'm happy to be part of the new lecturers team at the group!

The interactions with many lovely and interesting people make my days enjoyable. I am grateful to the entire ENP staff for their warmth and amazing productive energy. Dear Myanna, it has been great meeting you and sharing dance, dinners and fun moments with our families and doggies; thanks for Lulu! My appreciation goes to Kris and Mattijs for their helpful advice regarding all things related to education. Kris, we love your music! Gert, I enjoy our debates; we'll miss you at ENP! Berill, I'm grateful that we have each other now that our sons are going through similar processes. Raffaele, I enjoy our chats about the world; best wishes for the time ahead. Loes, jtu energía es contagiosa!

Sake, you are a sweetheart, and so is your mom; you'll rock your PhD! Maíra and Hanne, Veerle and Renske - thank you all for your help with my courses and for always being so thoughtful. Sweet Trang, all the best to you. Mandy, Mariska and Phatra, good luck finalizing your respective theses! Moisés and Sayel, you've brought in a Mexican flavor to ENP life; jmucho éxito para ambos! Pamela and Nila, my dear office neighbors, go for it! Maartje and Emily, it feels like I've known you for a long time, you're both so likable and supportive. Maartje, thanks for your help with my courses; Em, you did a terrific job with my thesis cover! Many thanks to Susan Boonman-Berson for our inspiring sparring sessions a while back and the 
helpful pep-talks! Sam, thank you for your help with the layout of this thesis. Hugs to Dani in Brazil, Fan in China, Karin in Sweden and Peter in Norway - I'm happy our paths crossed in Wageningen. Many thanks to all the students I've had the opportunity to teach and supervise - you are a source of refreshing energy! It's been a delight to collaborate with lecturers from other chair groups (ELS, ENR, ESA, FNP, LAW, MAE, PAP) in courses and as student co-supervisors. I have enjoyed getting to know our PAP and LAW colleagues better, by sharing their respective corridors. Thanks for the coffee breaks and pleasant conversations! Ik stel de vriendelijke mensen van de kantine en receptie van de Leeuwenborch erg op prijs, vooral Jeroen en Michelle, Mirjam en Cor - altijd zo aardig en behulpzaam!

Thanks to Hilde, Jillian and Karlijn - three strong, smart, positive, brave women for accepting to be my paranymphs. Hilde, I love sharing the office and talking with you; thank you for the great vibe that you bring in every day and for your capacity to stay focused, an example I strive to emulate. Jillian, you shine like the sun! It's been a long and winding road to the $\mathrm{PhD}$ finish line, but walking the last stretch together with you has made the process easier. We will find our moment to do our dance moves and celebrate reaching our respective milestones... M\&M, girlfriend! Karlijntje, it is always so very pleasant and uplifting to talk with you, I appreciate our walks around the Leeuwenborch and the easiness with which we connect; I am sure that you'll do great within your $\mathrm{PhD}$ and beyond.

While a virus is wreaking havoc worldwide and transforming our lives overnight, a personal tragedy descending upon our dear colleague Judith van Leeuwen has had a huge impact on everyone at ENP. Judith, as my MSc thesis supervisor back in 2009, together with Peter Oosterveer, you put in a good word for me with Arthur when I applied for this $\mathrm{PhD}$ position, which was highly appreciated. My deepest sympathy go to you and your family for the loss of your little boy Jelle. In these challenging times, it is comforting to feel the sense of togetherness at ENP that has strengthened us as a group, even in times of 'social distancing'.

As John Lennon wrote, life is what happens to you when you're busy making other plans. Throughout the decade (!) that took me to complete this thesis, life happened, and life is always better with a little help from our friends. I feel blessed with several groups of wonderful friends with whom we've shared countless celebrations throughout the years, filled with fun, dancing, music and delicious food - as well as periods of hardship eased by our mutual support. They are like family to us, too 
many to name here individually, so I'd like to thank them collectively: gracias a las 'chicas de zumba' y sus familias - mis queridas amigas de Bolivia, Colombia, Ecuador, El Salvador, España, Perú, Rep. Dominicana; a toda la comunidad latina dentro y fuera de OLAH; a nuestros queridos amigos mexicano-holandeses: los Menchaca, Toonders, van der Veen y López; Nayelli, aunque lejos, siempre has estado cerca. The melting pot of diverse Latin American cultures, but also Bulgarian, Greek, Indian, Indonesian, Russian - and of course Dutch and Mexican - enriches our lives. Bedankt aan onze vrienden groep van 'de meiden pony club' voor de vele mooie ervaringen in de afgelopen $15+$ jaar samen met onze gezinnen, met de fantastische oud en nieuw feestjes als hoogtepunt! A big, special thank you to my best friend Yovita for the great conversations, laughs, good books and your medical advice. I'm always amazed by how many hours and hours we can talk in one go and yet, there is always something to say. Your friendship since day one at Wageningen University - more than twenty years ago - and your loving support during the rough periods of life, are priceless. Best wishes for you and Catrinus, die lieve man van je.

Finally, I close with these lines dedicated to my dear family. My love and heartfelt gratitude go to my parents, whose encouragement and hard work to provide their children with a good education enabled us to pursue our dreams. Sadly, my dad passed away when I was 18, but the memory of his out-of-the-ordinary personality and love has had a lasting influence in my life. My mom's innate good mood, courage and tremendous energy have been a source of inspiration. Ma, mil gracias por tu apoyo y cariño, jte quiero! Esta tésis te la dedico a tí. Thanks to my brother and sisters for putting up with their bossy big sister, and for their love and support always. Tamer, Aniux, Pris, ¡los quiero! Abrazos para mis cuñados y bellas sobrinas. Mi cariño para todos los Carballo y los Cárdenas, siempre han estado presente. Aan mijn lieve schoonfamilie, ook Truus: een dikke knuffel voor jullie allemaal! Jammer dat ik dit moment niet meer met Ria heb kunnen delen.

Although I don't say it enough, I am genuinely grateful to my lovely Dutchman, my life partner and the person for whom I moved to this, my adopted country. Lieve Ivo, ontzettend bedankt voor je steun en geduld al die jaren; het viel soms echt niet mee, maar dit boek is eindelijk af - letterlijk en figuurlijk. Ik hou van je en onze kindjes. Kyran y Melina, amores míos, ¡su mamá por fin terminó la escuela!

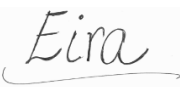

Wageningen, March 2020 


\section{Contents}

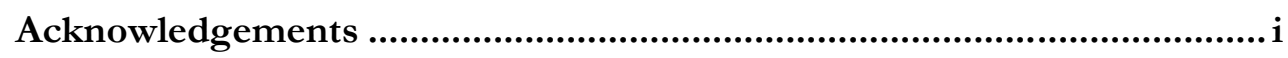

List of Figures .......................................................................................... xi

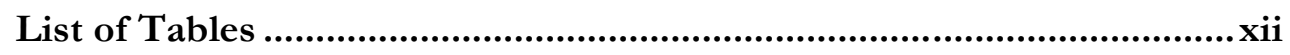

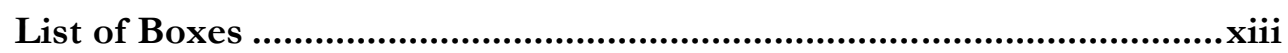

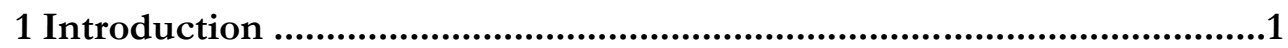

1.1 Our changing world.................................................................................... 1

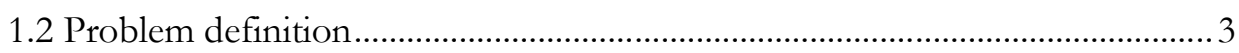

1.3 Research aim and research questions ............................................................. 4

1.4 Scoping digital conservation: a sociological perspective....................................5

1.4.1 Conceptualizing the digital in digital conservation......................................6

1.4.2 Data, information and knowledge in digital conservation ........................10

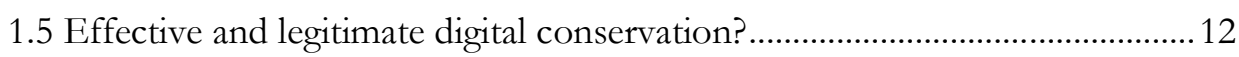

1.5.1 Effectiveness of digital conservation initiatives ........................................13

1.5.2 Participation in and legitimacy of digital conservation initiatives ............14

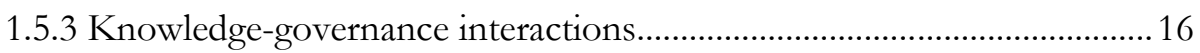

1.6 Coral reefs, MPAs and digital conservation in the Caribbean Sea .................19

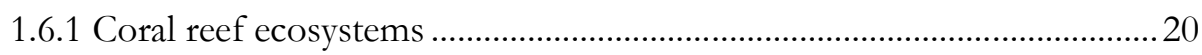

1.6.2 Marine protected areas .............................................................................22

1.6.3 Coral reef MPAs: an answer to coral reef degradation?...........................23

1.6.4 Caribbean MPAs: sites selected for this thesis .........................................25

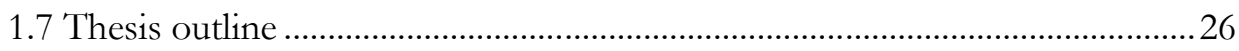

2 Research philosophy, methodology and methods..................................33

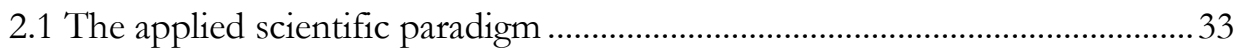

2.2 Hermeneutics: the pursuit of meaning................................................................ 35

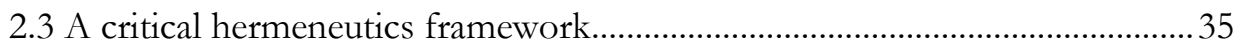

2.3.1 Pre-understanding, being-in-the world and breakdowns of meaning ....36

2.3.2 The dialectic, the hermeneutic circle and the fusion of horizons ............37 


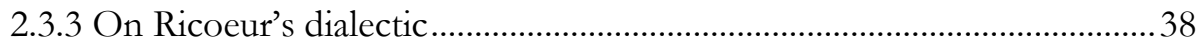

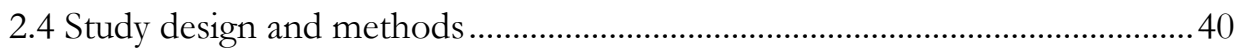

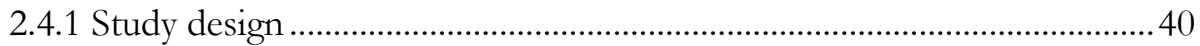

2.4.2 Methods of data collection and data analysis ..........................................40

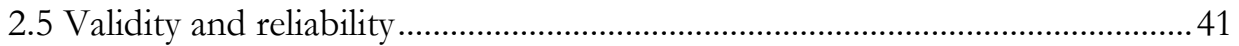

3 Information systems for marine protected areas: How do users interpret desirable data attributes? ......................................................... 47

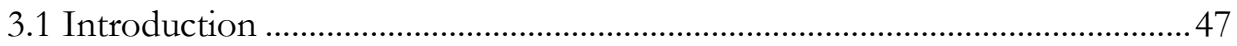

3.2 Marine protected areas and requirements of information systems users ......49

3.2.1 Marine protected areas .................................................................................4

3.2.2 Approaching information systems, users and requirements....................50

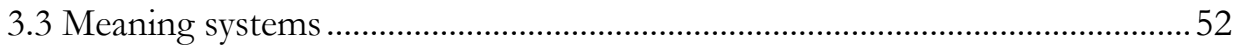

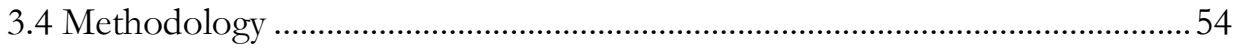

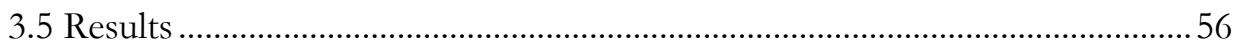

3.5.1 Domain analysis ........................................................................................56

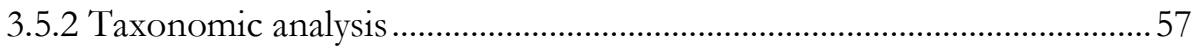

3.5.3 Componential and thematic analyses........................................................65

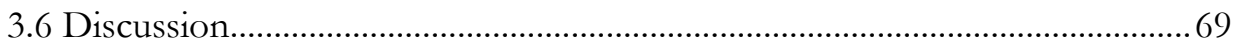

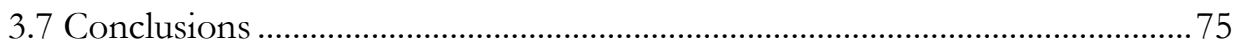

4 Controversies and consensus on the lionfish invasion in the Western

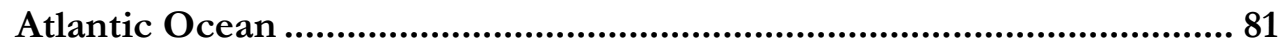

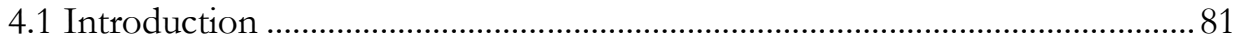

4.2 Conceptual framework............................................................................... 82

4.2.1 Constructing a biological invasion: origin, spread, impact, and control 82

4.2.2 Discourses and invasive species management............................................ 84

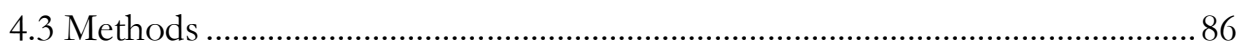

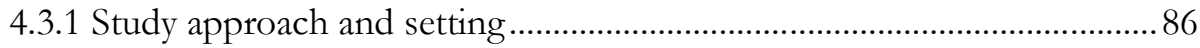

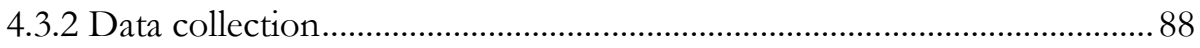

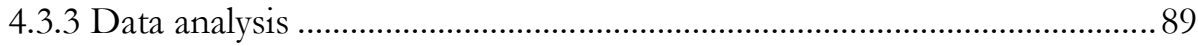




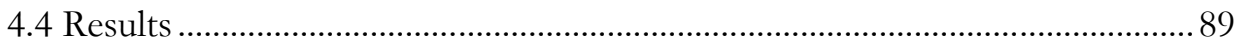

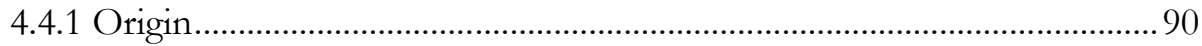

4.4.2 Spread ………………………………………….................................. 92

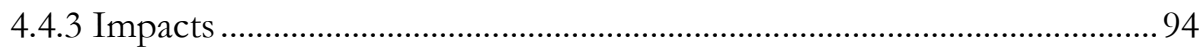

4.4.4 Lionfish control.................................................................................... 100

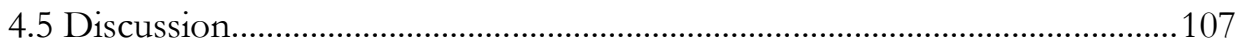

4.5.1 Scientific and media construction of the lionfish invasion ....................107

4.5.2 Stakeholder constructions of the lionfish invasion..................................109

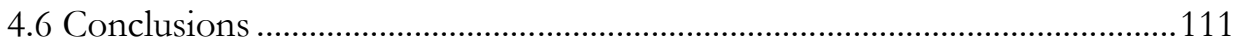

\section{Citizen science regarding invasive lionfish in Dutch Caribbean} MPAs: Drivers and barriers to participation ........................................... 117

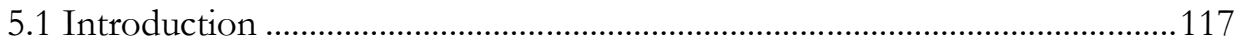

5.2 Citizen science, lionfish management in MPAs and motives to participate118

5.2.1 Defining conservation citizen science ......................................................118

5.2.2 Lionfish management in Caribbean MPAs...............................................121

5.2.3 Drivers and barriers to participation in conservation citizen science...122

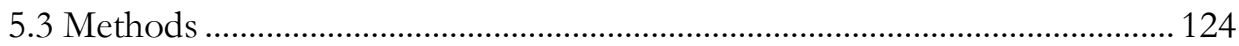

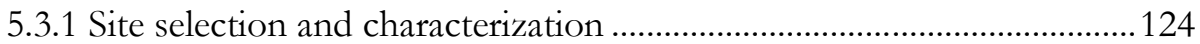

5.3.2 Informant selection and characterization................................................125

5.3.3 Data collection and data analysis...............................................................127

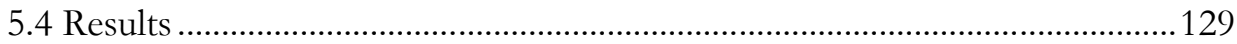

5.4.1 Participation in citizen science initiatives on lionfish .............................129

5.4.2 Enabling and constraining factors ..........................................................134

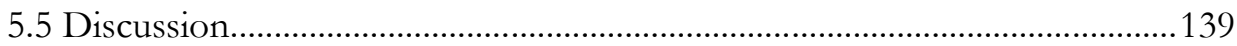

5.5.1 Multiple and changing motivations.....................................................139

5.5.2 Situated meanings of lionfish and of data collection and sharing.........141

5.5.3 Citizen science and invasive species ........................................................141

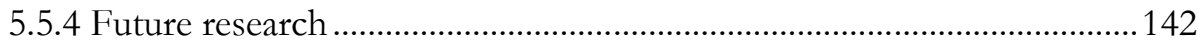

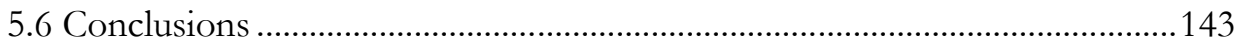


6 Chronicle of a grassroots project to monitor seawater quality on Bonaire: Unpacking legitimacy and the democratic potential of participatory sensing

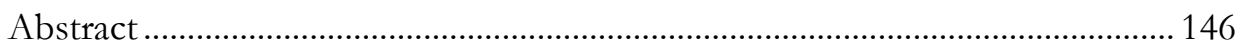

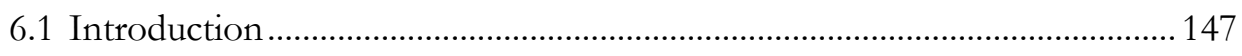

6.2 Legitimacy dynamics in participatory knowledge production for

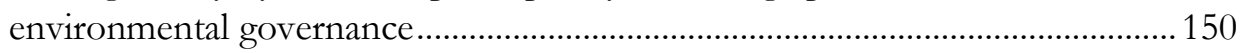

6.2.1 Citizen science: on the nature of public participation in scientific

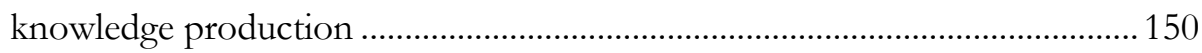

6.2.2 Legitimacy dynamics in participatory sensing projects............................152

6.2.3 Gaining, maintaining and repairing legitimacy ........................................154

6.2.4 Feedback legitimacy: on account giving .................................................154

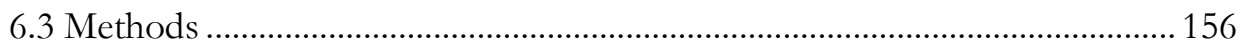

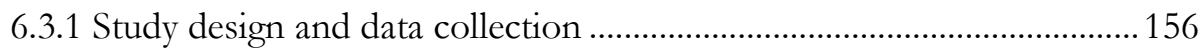

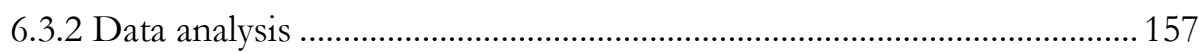

6.4 Background to the "Light and Motion Sensor Program" ..............................159

6.4.1 Coral reefs and water quality ……........................................................159

6.4.2 Bonaire's coral reefs and water quality ……………………....................160

6.5 Narratives on Bonaire's “Light and Motion Sensor Program”......................161

6.5.1 The nutrient pollution narrative .................................................................. 161

6.5.2 Gaining legitimacy for the LMSP: a story of a threatened reef and

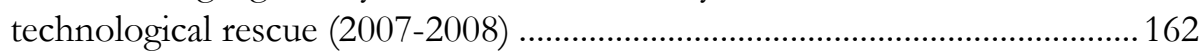

6.5.3 Maintaining legitimacy for the LMSP: approaching tipping points

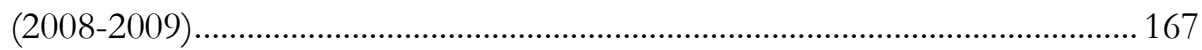

6.5.4 Repairing legitimacy for the LMSP: embarking on a new journey

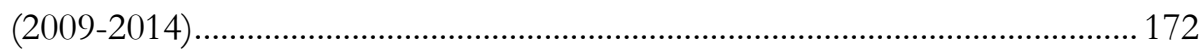

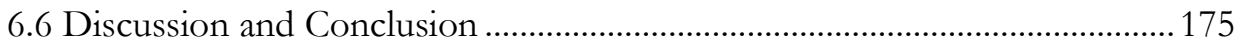

6.6.1 The LMSP and its legitimating narratives: key outcomes ......................175

6.6.2 The LMSP's internal legitimacy and the democratization of water quality monitoring ...... 
6.6.3 The LMSP's external legitimacy and the democratization of water

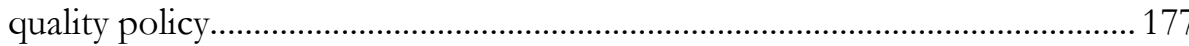

6.6.4 Conceptual lens and future research................................................. 178

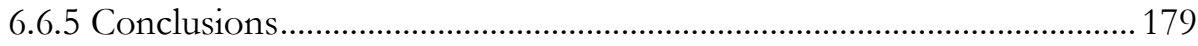

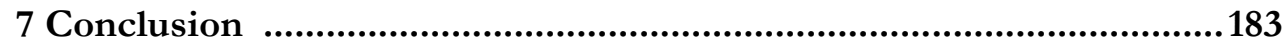

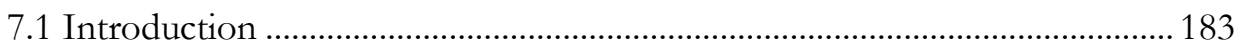

7.2 Understanding knowledge production and use by multi-actor digital

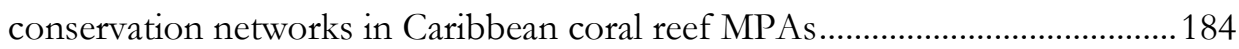

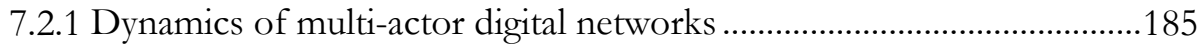

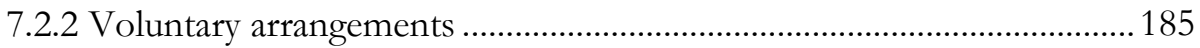

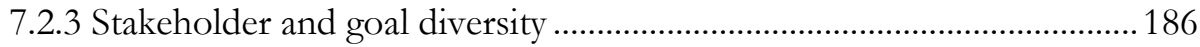

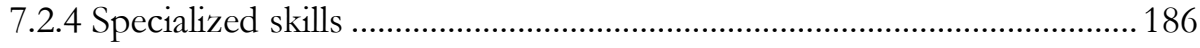

7.2.5 Type of nature conservation issue and issue polarization.....................187

7.3 Drivers and barriers for participation in multi-actor digital networks for

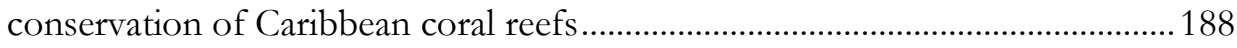

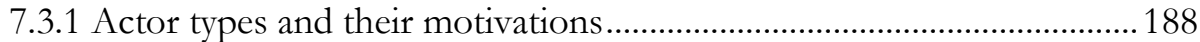

7.3.2 The various logics of participation, enabling and constraining

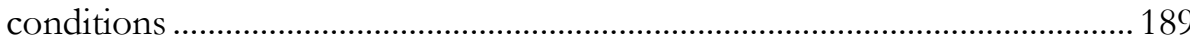

7.3.3 On the nature of participation in digital conservation networks ..........190

7.4 Effective and legitimate multi-actor digital networks for conservation of

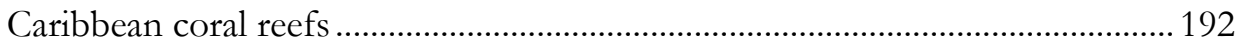

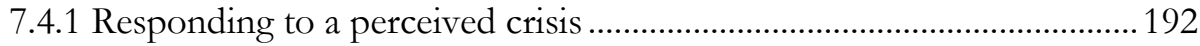

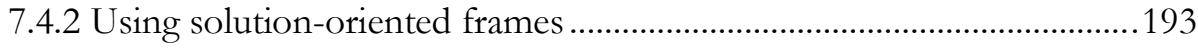

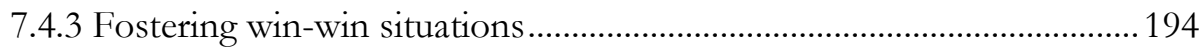

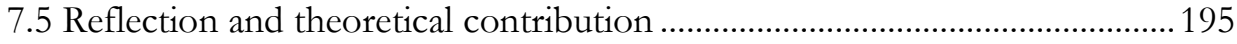

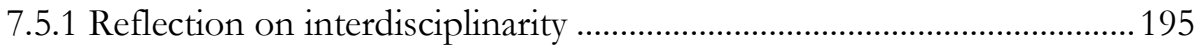

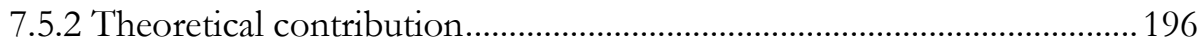

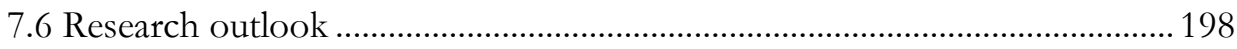

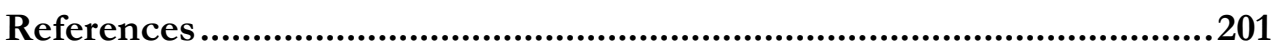


Appendices............................................................................................223

Appendix 1: Interview schedule (Chapter 3) .....................................................223

Appendix 2: Overview of informant groups, MPAs selected and interviews

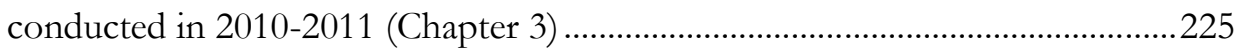

Appendix 3: Interviews with MPA stakeholders conducted in 2013

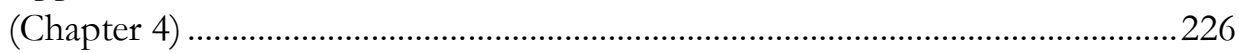

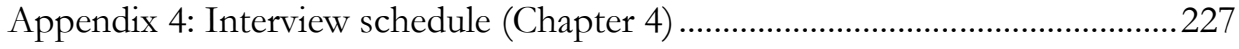

Appendix 5: Interview schedule (Chapter 5) ......................................................228

Appendix 6: Primary and secondary data sources (Chapter 6) .............................229

Summary .............................................................................................231

WASS Education Certificate .........................................................235

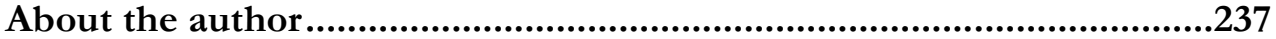




\section{List of Figures}

Figure 1.1 Assumed relations between science and practice underlying digital conservation

Figure 1.2 Conceptualization of the phases that comprise a digital conservation initiative

Figure 1.3 Different models to understand knowledge-governance interactions

Figure 1.4 The world's coral reefs at risk from individual local threats and cumulative threats

Figure 1.5 MPAs in the Caribbean Sea selected as case study sites

Figure 2.1 A critical hermeneutics research framework

Figure 3.1 Taxonomic analysis of the cover term data availability

Figure 3.2 Informants' conceptualizations of five desirable data attributes

Figure 4.1 Conceptualizations of nature and implications for nonnative species management

Figure 4.2 Lionfish in a Caribbean reef

Figure 5.1 Drivers and barriers to participation in conservation citizen science

Figure 5.2 Location of the selected MPAs in the Caribbean

Figure 5.3 Participation in lionfish-focused data collection and data sharing in Dutch Caribbean MPAs: changes of motivations over time

Figure 5.4 Enabling and constraining factors for participation in lionfish-focused data collection and sharing

Figure 6.1 Legitimacy dynamics in participatory sensing projects

Figure 6.2 Rainbow sensors at Bonaire National Marine Park

Figure 6.3 Algal growth on sensors

Figure 6.4 Timeline of Bonaire's sewerage and wastewater management program

Figure 7.1 Typology of multi-actor digital conservation networks 


\section{List of Tables}

Table 1.1 Examples of digital conservation 8

Table 1.2 Selected marine protected areas $\quad 25$

Table 3.1 Nine universal sematic relationships $\quad 47$

Table 3.2 Domain analysis of five desirable data attributes as conceptualized by informants

Table 3.3 Componential analysis: Kinds of data dissemination mechanisms

Table 3.4 In-depth componential analysis: Kinds of data dissemination mechanisms

Table 3.5 Thematic analysis: Legitimacy of practices of informant groups along the data value chain

Table 3.6 Thematic analysis: Accountability relations of informant groups and accountability mechanisms regarding practices along the data value chain

Table 4.1 Selected marine protected areas (Pterois sp.)

Table 4.3 Media discourse on Western Atlantic lionfish (Pterois sp.) (Pterois sp.) throughout the Caribbean Sea are situated

Table 5.4 Types of data collection and sharing initiatives per MPA site

Table 7.1 Overview of the case studies 


\section{List of Boxes}

Box 1 Data, Information, Knowledge, Wisdom and Science in the context of digital conservation 
CHAPTER 
Introduction 



\section{Introduction}

\subsection{Our changing world}

The world is changing in multiple and profound ways. Climate change, acceleration of biodiversity loss and widespread introduction of non-native species in new habitats are exemplary of the global environmental transformations unfolding in our planet (Bindoff et al., 2019; Rockström et al., 2009; Vitousek et al., 1996). Coral reef ecosystems - which harbor the highest biodiversity of any ecosystem on Earth - are among the most threatened ecosystems in the world and particularly vulnerable to the effects of global change (Hughes et al., 2018 and 2017; Pendleton et al., 2016). Approximately one third of the world's reefs has been permanently lost, no pristine reefs are left in the oceans and between $60 \%-99 \%$ of existing reefs are estimated to be at risk by a combination of local and global stressors (Bindoff et al., 2019; Burke et al., 2011). As providers of livelihoods for approximately 500 million people worldwide, coral reef ecosystems are regarded as an urgent conservation priority internationally (Hoegh-Guldberg et al., 2018; Bellwood et al., 2004).

Alongside the transformations of the natural world, societal changes that have been triggered by the Internet revolution and the ensuing explosion of Information and Communication Technologies (ICTs) over the last couple of decades have been so impactful that we are said to be living in the information age (Castells 1996; Mol 2008) and in the digital society (Marres 2017; Lupton 2015). This PhD thesis is set at the intersection of these two global trends: coral reef conservation in a changing world and the ongoing digitization of society.

The term digital conservation has been coined to denote the rapid spread and impacts of ICT innovations on the science and practice of nature conservation (Arts et al., 2015; van der Wal and Arts 2015). Digital conservation is an umbrella term that includes the design and deployment in the field of novel monitoring and surveillance tools and sensors; tracking technologies; citizen science and citizen sensing initiatives; mobile apps; public engagement and data collection and sharing through social media; e-learning, e-gaming, virtual reality, augmented reality, artificial intelligence and Internet of Things applications; collaborative information systems and decision-making support tools, among others (Allan et al., 2018; Bakker and Ritts 2018; Norouzzadeh et al., 2018; Arts et al., 2015; Di Minin et al., 2015; Jepson and Ladle 2015; Joppa 2015; Pimm et al., 2015). 


\section{Chapter 1}

Digital innovations are contributing not only to the generation of more and new data types, but also to new data practices and new actors engaging in these practices (Bakker and Ritts 2018; Gabrys et al., 2016; Arts et al., 2015; Volk et al., 2014; Wiggins and Crowston 2011). Emerging digital architectures are seen as having the capacity to fundamentally transform processes and practices of knowledge production and use, and through these changes, to bring about new modes of environmental governance (Bakker and Ritts 2018; Toonen 2013; Mol 2008). Here I follow the definition of environmental governance provided by Bakker and Ritts as "the set of social actors and institutions (including laws, rules, norms, customs), as well as data gathering and decision-making processes, engaged in environmental decision-making" (2018:202-03).

The rise of ICTs in the environmental governance domain has been greeted by many with great enthusiasm (Bakker and Ritts 2018; Conti et al., 2018; Joppa 2015; Pimm et al., 2015), as illustrated by the assertion that "[ $[$ ] he genius of ICT is twofold: firstly, it facilitates the collection, dissemination and analysis of data and, secondly, it radically transforms the ability of people to connect with each other" (Petrik and Raemaekers 2018:2), the latter referring to the participatory and inclusiveness affordances that digital technologies are endowed with. This quote encapsulates the essence of the key proposition that I examine in my thesis, namely, the belief that cutting-edge technologies and the collaborative approaches enabled by ICT technologies are inherently "good" or beneficial for the field of nature conservation. The two arguments often advanced to articulate the promises of novel ICTmediated, multi-actor networks to enhance environmental governance and conservation outcomes will be stated next, as well as key criticisms that nuance this optimism.

First, the unprecedented streams of environmental and ecological data made possible by ICT innovations, together with advances in computing and analytics, are enabling a boost in scientific knowledge and understanding of spatiotemporal changes in the natural world (Allan et al., 2018; Bakker and Ritts 2018). From the perspective of many environmental scientists, ecologists and conservation biologists, there is an entrenched conviction that more, better and more accessible data will result in better informed policy and governance, and therefore in biodiversity and environmental improvements (Bakker and Ritts 2018; Conti et al., 2018; Pendleton et al., 2016; Cvitanovic et al., 2015 and 2014; Conserve.iO, 2015; Joppa 2015; Pimm 
et al., 2015). This stance is based on the knowledge-deficit model, which presumes a gap between science and society that can be filled through a one-way, linear transfer of knowledge from experts to policymakers and the public about a given topic, leading to improved attitudes and changed practices (McNie 2007; Cvitanovic et al., 2015 and 2014). This model, however, has been criticized on the basis of various of its assumptions about the nature of scientific knowledge and the model's inadequacy for understanding the complex relation between science and environmental policy and governance (Turnhout 2018; Janssen 2015; Brown 2008). In sections 1.4 .2 and 1.5.3, I will go into more detail regarding my conceptualization of knowledge and alternative models proposed to understand the interactions between knowledge and action in environmental governance.

Second, from a social sciences and humanities perspective, the digitization of society is associated with higher levels of openness of, and participation in, the knowledge production process, which in turn are believed to support the democratization of knowledge and thereby the legitimacy of decisions about the environment (Marres 2017; Mooney and Corcoran 2014; Friess et al., 2011). The notion of "opening up" the closed knowledge systems of traditional scientific practices to non-scientific actors (i.e. multi-actor knowledge networks) is part of a broader discourse on the changing relation between science and society and the emergence of new modes of collaborative knowledge production deemed necessary to adequately address today's complex social-environmental problems (van der Hel 2016; Cornell et al., 2013; Hessels and van Lente 2008; Nowotny et al., 2001; Gibbons 1999; Irwin 1995; Funtowicz and Ravetz 1993). In her book entitled Digital Sociology, Noortje Marres poses the question: “Isn't the digital the harbinger of participatory knowledge, does it not enable the implementation of knowledge democracy?" (2017:166), inviting a closer scrutiny of the meaning of openness, inclusion and collaboration in digital societies given the inconclusiveness of research findings addressing this question so far. In section 1.5.2, I will return to the issue of legitimacy and the democratization of knowledge production by networks of heterogeneous actors in the context of environmental governance.

\subsection{Problem definition}

There is hence an assumed relation between innovative ICTs and multi-actor collaborative forms of knowledge production on one hand, and effective and legitimate environmental management and governance, on the other. Yet, this relation and the conditions under which it holds require further scrutiny, both 


\section{Chapter 1}

conceptually and empirically. I argue that a one-to-one relation between more and 'better' data generated collaboratively through digital technologies on one hand, and more effective and legitimate conservation governance on the other, is a simplistic view of a multidimensional and relational phenomenon. Therefore, a thorough and contextualized analysis of how actors interpret the various dimensions that comprise the knowledge and governance practices enacted through digital conservation is necessary to understand how digital conservation performs, in terms both of its perceived effectiveness and legitimacy.

In this thesis I explore and critically assess - from a sociological perspective - new types of collaborations, facilitated by ICTs, of distributed, multi-actor networks engaged in the production, interpretation, sharing, dissemination and use of data in the context of coral reef conservation. With the aim of understanding the conditions under which multi-actor networks for digital conservation deliver on their promises of effective and legitimate conservation governance, I examine the structural and individualistic factors that enable and constrain actors and their data practices in different situations. Data practices refer to the manifolds of actions that make up research and monitoring undertaken to inform conservation management and governance (see an elaboration of this concept in Section 1.5.3).

I focus my enquiry on both the processes and the outcomes of digital collaborative endeavours to govern issues affecting coral reefs, with knowledge production and use at the core of my analysis. Importantly, I am interested in the meanings that the participants of these networks assign to the various aspects of knowledge production and use in the context of digital conservation.

\subsection{Research aim and research questions}

Set in the context of governance arenas where digital technologies and collaborative approaches to knowledge production and governance increasingly play an important role, the overall research goal of this $\mathrm{PhD}$ thesis is to contribute to our understanding of multi-actor knowledge production and use in the digital conservation of coral reefs, both empirically and theoretically. This thesis pursues three objectives. The first objective is to contribute to the theorizing of the novel field of digital conservation, in order to inform further research on digital conservation design and implementation. The second objective is to understand actors' motivations to engage in practices related to various aspects of digital conservation, as well as the conditions that enable and constrain them. The third objective is to analyze how 
heterogeneous actors who engage in digital networks, construct, interpret and use knowledge about marine conservation issues, in order to better understand the perceived effectiveness and legitimacy of digital conservation initiatives and to inform their further development in practice. To this end, coral reef marine protected areas (MPAs) located in the Caribbean Sea were selected as case study sites. In order to achieve the three stated objectives, the following research questions were formulated:

1. What features of multi-actor digital conservation networks in Caribbean coral reef MPAs are essential to understand processes of knowledge production and use by these networks?

2. What motivates, enables and constrains actors to participate in practices related to digital conservation in Caribbean coral reef MPAs?

3. Under which conditions do digital conservation networks in Caribbean MPAs contribute to effective and legitimate coral reef governance?

Case studies were selected that encompassed a spectrum of digital technologies (to be) used in MPA conservation governance, including collaborative databases, digital maps, social media and a water quality sensor network. The criteria for case and site selection will be explained in section 1.6. First, I introduce the notion of digital conservation, viewed through a sociological lens, and the theoretical perspectives and concepts that informed this $\mathrm{PhD}$ thesis.

\subsection{Scoping digital conservation: a sociological perspective}

Nature conservation is a mission-driven science and practice (Soulé 1985). Novel digital technologies are pushing the frontiers of what this mission can accomplish, and in the wake of this technological revolution many interesting questions arise. In this section I delineate the contours of digital conservation and introduce the key theoretical perspectives that have informed my understanding of this phenomenon and that have helped me to articulate my research questions and search for the answers. The overall perspective in this thesis is a sociological one, which means that I look at human behavior and its relation to society as a whole. This perspective invites us to use our sociological imagination (Mills 1959, in Gane and Back 2012) to try 


\section{Chapter 1}

to understand the connections between the behavior of individual people and the structures of the society in which they live.

Specifically, I position my research within the so-called realist social constructionism paradigm (Elder-Vass 2012), which entails a distinct set of ontological and epistemological assumptions, as well as methodological choices (see Chapter 2). Positioning of my research in this paradigm suggests particular theoretical perspectives. Indeed, I draw from interpretivist streams of literature from various disciplines (i.e. sociology of knowledge, knowledge management studies, information systems studies, human-computer interaction studies, management of innovation studies and organization studies, among others) that share a concern with socially constructed meanings of the world, and that together have contributed to the elucidation of the puzzle that I have set out to solve in this thesis. Below I provide my conceptualization of key terms related to the digital in digital conservation; I show examples of digital conservation, and define the concepts of data, information and knowledge in the context of digital conservation.

\subsubsection{Conceptualizing the digital in digital conservation}

Every study of the sociology of the digital recognizes Manuel Castells' contribution to the theorizing of the social world as structured around networks that are connected, through technology, by a constant flow of information in digital form (Castells 1996). In Castells' work, processes of globalization go hand in hand with the emergence of the network society. Anthony Giddens (1990: 64) has described globalization as "the intensification of worldwide social relations which link distant localities in such a way that local happenings are shaped by events occurring many miles away and vice versa". This entails a change in the way we understand space.

Indeed, the dominant spatial configuration of Castells' network society is referred to as the space of flows, a different type of space that permits distant and synchronous interaction among members of a digital network. Traditionally, space has been considered to be a static, material entity that supports people's life in the here and now - referred to as the space of places by Castells. Digital ICTs, however, allow a decoupling from the rigid spatial-temporal limits that formerly conditioned daily activities and practices, and thereby reduce the importance of the spatial frameworks that are socially accepted and expected for the performance of such practices. For instance, e-mail has enabled a change in the organization of work practices into more dynamic ways in terms of a schedule and a location: people can work from home, 
from the office or from a park, and can alternate personal activities with these work spaces and times. Whether the consequences of these new practices can be considered positive or negative is of course open to interpretation and debate.

In science, the space of flows has paved the way for the global rise of research networks of distributed teams of scientists, a phenomenon that has attracted academic attention and has been referred to as the "science of team science" (Wagner et al., 2015; Adams 2012). Conservation science has certainly experienced a fundamental reorganization in terms of collaborative biodiversity and environmental research, augmented by the ongoing revolution in data acquisition and communication technologies (Bakker and Ritts 2018; Allan et al., 2018; Steenweg et al., 2017; Arts et al., 2015). Changing the working practices of scientists to conform to the aspirations of these new networks has not been straightforward, however, for example in relation to obstacles around data sharing practices (Costello et al., 2015; Volk et al., 2014).

Moreover, collaborative, ICT-mediated networks around nature conservation increasingly include non-scientists, for purposes that are either scientific or conservation action oriented, or both (Turrini et al., 2018; Newman et al., 2017; Gray et al., 2017; Bonney et al., 2014 and 2009; Wiggins and Crowston 2011). It is this type of networks that I explore in my thesis and refer to them as multi-actor networks. Table 1.1 shows examples of digital conservation of marine and terrestrial ecosystems based on networks of various kinds.

Opening up scientific networks to non-scientists, including natural resource managers, resource users and citizens, poses non-trivial questions around, for instance, data quality and long-term durability of volunteer-based initiatives (Chandler et al., 2017; Alender 2016; Lewandowski and Specht 2015; Rotman et al., 2014). Importantly, conservation practice does not take place in a vacuum, but often unfolds in messy and conflictual situations where power dynamics become crucial (Aswani et al., 2018; Adams 2017). This has significant implications for how these multi-actor networks may function from a governance perspective (Toonen 2013; Mol 2008). 


\section{Chapter 1}

Table 1.1 Examples of digital conservation.

\begin{tabular}{|c|c|c|c|c|}
\hline $\begin{array}{l}\text { Project } \\
\text { name }\end{array}$ & Project aim & $\begin{array}{l}\text { Role of digital } \\
\text { technology }\end{array}$ & Brief description & Reference \\
\hline $\begin{array}{l}\text { Snapshot } \\
\text { Serengeti } \\
\text { Project }\end{array}$ & $\begin{array}{l}\text { To reduce the } \\
\text { costs and time } \\
\text { needed to } \\
\text { analyze large } \\
\text { imagery } \\
\text { datasets }\end{array}$ & $\begin{array}{l}\text { Big data } \\
\text { (images from } \\
\text { motion-sensor } \\
\text { cameras) and } \\
\text { deep learning }\end{array}$ & $\begin{array}{l}\text { Analysis of the world's } \\
\text { largest dataset of wild } \\
\text { animals. Automated } \\
\text { analysis of } 3.2 \text { million } \\
\text { camera trap images of } \\
48 \text { species in Serengeti }\end{array}$ & $\begin{array}{l}\text { Norouzzadeh et } \\
\text { al., } 2018\end{array}$ \\
\hline $\begin{array}{l}\text { Virtual Reef } \\
\text { Diver }\end{array}$ & $\begin{array}{l}\text { To identify } \\
\text { areas of } \\
\text { decreasing } \\
\text { coral cover } \\
\text { and other } \\
\text { problem spots } \\
\text { on the Great } \\
\text { Barrier Reef }\end{array}$ & $\begin{array}{l}\text { User-generated } \\
\text { database }\end{array}$ & $\begin{array}{l}\text { Classification of } \\
\text { underwater images of } \\
\text { Great Barrier Reef by } \\
\text { volunteers (from } \\
\text { home) }\end{array}$ & $\begin{array}{l}\text { https://www.virtu } \\
\text { alreef.org.au/ }\end{array}$ \\
\hline FishFace & $\begin{array}{l}\text { To use data on } \\
\text { the species } \\
\text { and numbers } \\
\text { of fish caught } \\
\text { to inform } \\
\text { management } \\
\text { decisions }\end{array}$ & $\begin{array}{l}\text { Machine } \\
\text { learning device } \\
\text { using facial } \\
\text { recognition } \\
\text { technology } \\
\text { to automate } \\
\text { the collation of } \\
\text { information at } \\
\text { sea }\end{array}$ & $\begin{array}{l}\text { Fisheries monitoring } \\
\text { project developed by } \\
\text { The Nature } \\
\text { Conservancy }\end{array}$ & $\begin{array}{l}\text { https://www.natu } \\
\text { reaustralia.org.au/ } \\
\text { what-we-do/our- } \\
\text { priorities/provide- } \\
\text { food-and-water- } \\
\text { sustainably/food- } \\
\text { and-water- } \\
\text { stories/fishface/ }\end{array}$ \\
\hline $\begin{array}{l}\text { Extreme } \\
\text { Citizen } \\
\text { Science }\end{array}$ & $\begin{array}{l}\text { To empower } \\
\text { marginalized } \\
\text { communities } \\
\text { to produce } \\
\text { knowledge } \\
\text { they need for } \\
\text { conservation } \\
\text { action }\end{array}$ & $\begin{array}{l}\text { Open source } \\
\text { mobile data } \\
\text { collection } \\
\text { platform (for } \\
\text { non-literate } \\
\text { and illiterate } \\
\text { users with little } \\
\text { or no prior } \\
\text { ICT } \\
\text { experience) } \\
\text { and web GIS } \\
\text { available for } \\
\text { anyone to use }\end{array}$ & $\begin{array}{l}\text { Extreme Citizen } \\
\text { Science (ExCiteS) } \\
\text { supports several local } \\
\text { communities across the } \\
\text { globe in their aim to } \\
\text { combine their local } \\
\text { environmental } \\
\text { knowledge with } \\
\text { scientific analysis to } \\
\text { improve environmental } \\
\text { management }\end{array}$ & $\begin{array}{l}\text { https://www.geog } \\
\text {.ucl.ac.uk/researc } \\
\text { h/research- } \\
\text { centres/excites }\end{array}$ \\
\hline
\end{tabular}


In view of the above, the space of flows for nature conservation becomes an uncertain and contested space. Deborah Lupton (2015) observes, following Lash (2006), that the concept of flow in the global information society should be complemented by the notion of flux. Both terms indicate fluidity, but flow connotes unrestricted movement, whereas flux invokes mutability, instability and unrest, pointing to tensions and power struggles within networks. In other words, Lupton challenges the idea that digital data and information circulate freely through networks and problematizes the very concepts of digital technologies and data, as these objects are the product of human action and judgements.

I likewise contend that digital technologies and data are not neutral objects that can be understood separately from the people who use and produce them. Not only are technologies and data the products of human decisions and subjectivities, but also of contingencies that result in unintended consequences. Examples of the former are the choices of what to render visible as data, what to count and what not to count, how to classify, how to analyze and to represent (Marres 2015; Turnhout and Boonman-Berson 2011; Lawrence and Turnhout 2010; Tuomi 1999). Examples of the latter are the invisible, contested or unforeseen uses of the functionalities built into technological artifacts (Lupton 2015; Toonen and Bush 2018; Tim et al., 2018; Orlikowski 2007).

When I refer to the term digital technology in this thesis, I mean the hardware, the software and supporting infrastructures, and refer to both the Information (data acquisition/sensing, processing, analysis, storage, etc.) and Communication affordances of ICTs. With the term digital data, I refer to everything that is represented in digital form: different kinds of objects that are encoded, recorded and transmitted using digital technologies. Digital data hence includes numerical and written material, but also audio and visual data such as maps, photos and videos. I draw from science and technology studies, an interdisciplinary field characterized by its critical posture, in my conceptualization of data, digital technologies and people in the network as assemblages (Latour 2005; Müller 2015). According to Lupton, "The assemblage provides an approach to understanding the individual's relationship to and use of digital technologies that emphasizes that each actor, whether human or non-human, shapes the other in a mutually constitutive relationship" (2015:24).

This relational understanding of networks, where the social is inextricably bound up with the material, is useful when examining the practices and interactions among 


\section{Chapter 1}

different people, and between humans and the non-human, in the context of conservation science and practice (Orlikowski 2007; Pickering 1993). The notion of non-buman elements of the network refers to digital and non-digital technologies, the data and the objects people intend to encode as data. As we will see in the empirical chapters of this thesis, the space of flows in digital conservation is indeed a space of flux.

\subsubsection{Data, information and knowledge in digital conservation}

In the following lines I elaborate on my understanding of the elusive concepts of data, information and knowledge, and how they are interrelated. An overview of the definitions provided in different literatures shows that, typically, data are defined as symbols that represent objects and events, or "facts" of the world (Johannessen et al., 2002). According to this view, "raw data" are transformed into information after a processing step that assigns meaning to data, and information is in turn transformed into knowledge when information is placed in context (Canessa et al., 2007; Johannessen et al., 2002; Tuomi 1999). This implies a hierarchy of how these concepts relate to each other, which indeed is often portrayed as a pyramid with data at the base supporting information, information supporting knowledge, and ending with wisdom at the top.

This view of a unidirectional flow from data to wisdom in the conceptual hierarchy of knowledge has been challenged. I concur with Tuomi (1999) and Rasmus (2018), who posit that data can only emerge when a meaning system - knowledge - is already embedded into the semantic structure of our brains or of a digital technology. Furthermore, according to these scholars, knowledge is necessary for the interpretation of information, where information is conceptualized as (digital) data that has been activated through the interpreter's attention and awareness, which confer these data with the capacity to inform something (ibid). Because digital data can be copied, it can exist in two states simultaneously: active and inert. When data are not viewed or used, data assume their inert stance and may decay.

As I discussed above, moreover, data are not a neutral and objective representation of the "facts" of the world. Data are a social construction, and so is knowledge (Burnett 2015; Arts et al., 2014; Turnhout and Boonman-Berson 2011; Lawrence and Turnhout 2010). Data and knowledge are performative - that is, they have an effect not only on how we understand the world, but also on how we act, or perform, upon it (Arts et al., 2014). There is a dynamic quality to data and knowledge in that they do not simply mirror reality, but also constitute it. This insinuates that the social 
construction of data and knowledge involves the exercise of power (Turnhout 2018; Arts et al., 2014). Box 1.1 summarizes my view of the concepts of data, information, knowledge, and defines wisdom and science.

Box 1.1 Data, Information, Knowledge, Wisdom and Science in the context of digital conservation.

Data: Anything that is represented in digital or analogue form. Digital data can emerge only if a meaning structure (knowledge) is first fixed and then used to represent information. Digital data may exist in two states simultaneously: active and inert. In the absence of active engagement, data are meaningless; when not viewed or used, data become inert and "decay". The value of data is manifested when data are used. Data can only be understood in context. Data have different information potentials: low when data are "raw" and high when organized and visualized as e.g. maps or infographics.

Information: Data (in active stance) informing something through attention and awareness of the interpreter. Information is ephemeral, it only exists when an active agent, through knowledge, interprets meaning from data or takes action based on that data. Information may lead to action (action-based information) and in some cases to new knowledge (transformation).

Knowledge: Understanding of something based on rules and patterns derived from (bodily) experience, beliefs, values and previous knowledge. Unless being used, knowledge is inert. Knowledge is necessary for data to emerge and to interpret information. Knowledge can be codified (made explicit) but also exists in tacit form. Knowledge is a social construction and is performative, can reside in individuals and in collective form and can be interpreted differently. Knowledge (production) is power. Knowledge use includes conceptual, instrumental and political uses.

Wisdom: The most tacit of knowledge. Wisdom is a selection process (hence evaluative) that filters the knowledge best suited to extract the appropriate information from data. Wisdom may be transformed through the experience of its application.

Science: The pursuit of knowledge through systematic study and simplification of data (digital or analogue) about the world.

Sources: Rasmus 2018; Arts et al., 2014; Nursey-Bray 2013; Contandriopoulos et al., 2010; Tuomi 1999; Weingart 1999; Ackoff 1989; Weiss 1979. 


\section{Chapter 1}

\subsection{Effective and legitimate digital conservation?}

As I stated before, there is a belief among many conservation scientists and practitioners that a one-to-one relationship exists between innovations in conservation science and improvements of conservation practice, brought about by the twofold "genius" of ICTs: the possibility to generate more and new types of data about nature in order to improve the effectiveness of decision-making and hence benefit conservation, and the opportunity for more and diverse actors to participate in knowledge production to enhance the legitimacy of conservation governance. Figure 1.1 depicts this hypothesized relation and the assumptions underlying its mechanisms.

In what follows I will dissect each set of assumptions, explicating the concepts and the bodies of theory upon which I build throughout the thesis to study the notions of effectiveness and legitimacy of knowledge production and use by digital multiactor conservation networks. I will show that such hypothesized linear relationships between technologically enhanced conservation science and technologically enhanced conservation practice are a simplistic reduction of a complex phenomenon.

In this section I unpack the constructs depicted in Figure 1.1. I begin by examining the different levels at which effectiveness can be assessed, and the various sorts of possible outputs and outcomes of digital conservation. Then I move to the notions of opening up participation in knowledge production and legitimate conservation governance. Finally, I clarify the theoretical underpinnings that ground my understanding of knowledge-governance interactions. 


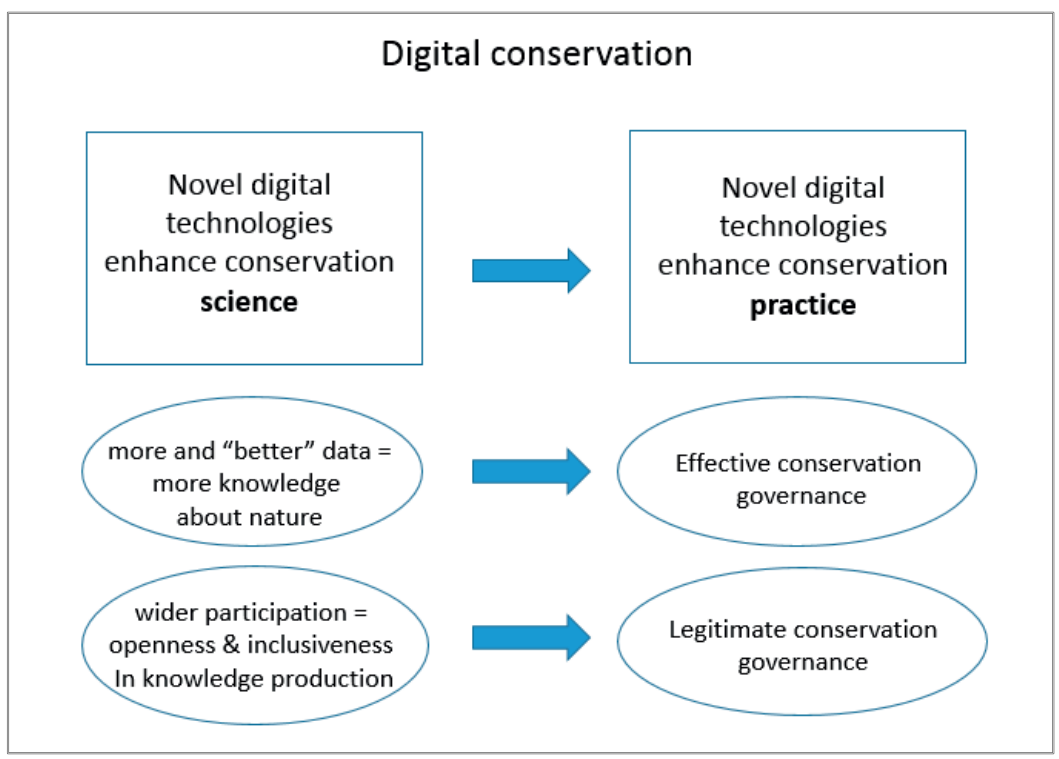

Figure 1.1 Assumed relations between science and practice underlying 'digital conservation'.

\subsubsection{Effectiveness of digital conservation initiatives}

I borrow from Shirk et al., (2012) and García-Soto et al., (2017) to conceptualize multi-actor digital conservation initiatives and their effectiveness (Figure 1.2). Multiactor networks entail the participation of scientists and non-scientists; in this thesis the former are usually natural scientists working at universities or research institutes; the latter include environmental non-governmental organization (eNGO) representatives, MPA managers and staff, policy-makers, business actors such as scuba dive operators and commercial fishers, and "citizens" at large (including recreational fishers, tourist divers, local residents), who collaborate in digital conservation initiatives mostly on a voluntary basis. The inputs from the different actors contribute, in varying degrees, to the definition of the problem that the digital conservation initiative intends to address. Also, to a variable extent, the different actor groups may co-design the project infrastructure (digital and non-digital) and co-manage the implementation of the various activities. These activities will have effects, or results, at various levels: at the output, outcome and impact level. These effects can be thought of as the "products" of a digital conservation initiative. 


\section{Chapter 1}

Outputs may encompass tangible and intangible results: a digital technology itself, intended for collaborative use, as well as data and experiences derived from participation in different activities (e.g. data collection, data sharing, data analysis). Outcomes refer to the uses of data and the meanings of experiences. Outcomes can be distinguished at the level of the actor type, but also in relation to the socio-ecological system and may be tangible and intangible as well. For instance, the primary uses of data for scientists are scientific publications as well as enhanced understanding of a phenomenon; the uses of data for non-scientists include for example NGO reports or policy reports, and the meanings of experiences include new skills, enhanced knowledge, and enhanced self-identity (Clary and Snyder 1999). The uses of data for conservation actions include measures designed to improve the socio-ecological system (e.g. legislation, management plans). Another outcome category refers to the actual adoption and use of a digital technology, and to sustained participation in the digital conservation initiative. Finally, the ultimate goal of digital conservation is to effect environmental and biodiversity improvements, referred to as impact.

Effectiveness of a digital conservation initiative can therefore be assessed at one or more of these levels. Effectiveness as understood in the policy and governance evaluation literature poses the question: "To what degree do the achieved results correspond to the intended goals?" (Mickwitz 2003; Crabbé and Leroy 2008). From this, it follows that the goals of the various actors that participate in digital conservation must be articulated by the actors or at least inferred by the analyst, and the constructs data, meanings of experiences, knowledge use and the desired state of nature must be defined and operationalized in order to be able to make some judgement regarding effectiveness. I explore each of these concepts in my thesis, emphasizing different aspects in the various chapters, as elaborated in the Thesis Outline (section 1.7).

\subsubsection{Participation in and legitimacy of digital conservation initiatives}

Besides the "products" or results-oriented evaluation approach described above, a process-oriented approach can be applied to assess a digital conservation initiative. As the name indicates, such approach focuses on procedural features, whereby the underlying assumption is that "good" processes are linked to improved quality of the results at different levels (Rauschmayer et al., 2009; Bäckstrand et al., 2010). In environmental governance, knowledge that is perceived to be credible and to emanate from a legitimate process is more likely to be accepted by all actors involved and used by decision-makers (Cash et al., 2002 and 2003). 
In Figure 1.2, the "process" refers to how the Inputs and Activities of digital conservation are organized: who is included and excluded? What kind of input does each actor type provide? In other words, are all the actors with a stake in the issue represented and do they perceive their participation to be meaningful? In this sense, legitimacy is linked to the representation dimension of participation (Newig and Kvarda 2012; Cash et al., 2002; Scharpf 1999). Various accounts of digital knowledge technologies invest these technologies with special powers of participation, equating digitization with democratization "as in the ideal of the shift from the passive audience to active participant" (Marres 2017:161). The democratization of knowledge and deliberative forms of environmental governance have been a recurrent normative theme over the last few decades (Irwin 1995; Bäckstrand et al., 2010; Berkes 2017). However, scholars from multiple disciplines have questioned the "special powers of participation" affordances of digital conservation technologies, and critique them as tools that tend to reproduce existent expert hierarchies (Bakker and Ritts 2018; Marres 2017).

Knowledge production within multi-actor networks is a collaborative endeavor, referred to in various literatures as joint knowledge production or knowledge coproduction. Berkes (2017) defines knowledge co-production as "the collaborative process of bringing a plurality of knowledge sources and types together to address a defined problem. It can be expressed as the multiple evidence base approach [...], emphasizing the advantages of combining different kinds of knowledge to approach problems. It may involve participatory research — learning together to co-produce knowledge. More broadly, it may involve emergent dialogue, whereby the meaning and value of information is co-created among the various interests." (2017:1232).

In multi-actor digital networks engaged in knowledge co-production intended to inform conservation action, mutual trust among stakeholders and in the data produced is crucial for such data to be accepted and used in decision-making (Cash et al., 2002; Edelenbos et al., 2011). Inclusion of non-scientists in the production of scientific knowledge, however, often affects the credibility of the initiative as the quality of the data is questioned by other scientists (Freitag et al., 2016) and decisionmakers (Ottinger 2010). As such, trade-offs may occur between representationbased and credibility-based forms of legitimacy (Scharpf 1999; Suchman 1995). 


\section{Chapter 1}

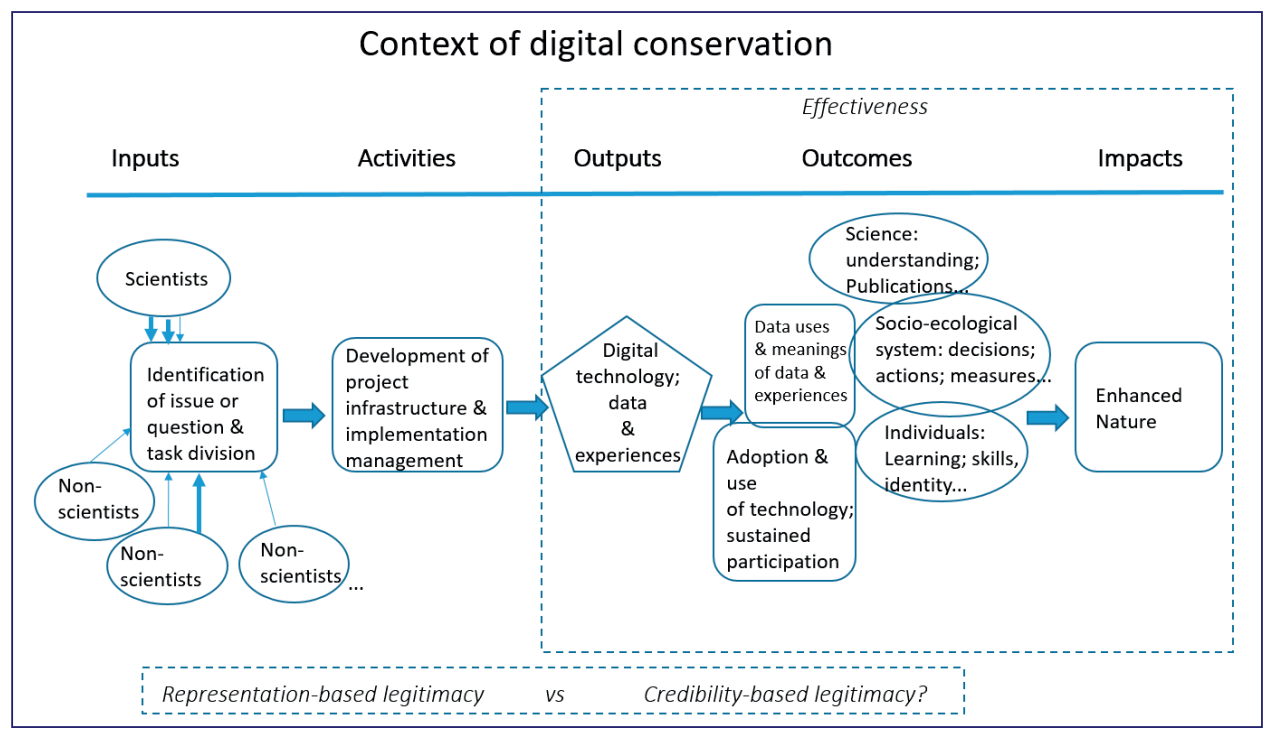

Figure 1.2 Conceptualization of the phases that comprise a digital conservation initiative (Inputs, Activities, Outputs, Outcomes, Impacts), and the levels at which effectiveness and legitimacy can be assessed. The external boundary indicates the "context" in which digital conservation unfolds. Adapted from Shirk et al., (2012) and García-Soto et al., (2017).

\subsubsection{Knowledge-governance interactions}

In section 1.1, I introduced the knowledge-deficit model, which conceives of knowledge as moving in a linear fashion from the science field to the non-science field to fill a perceived gap, and in doing so trigger change (e.g. conservation action). This model is akin to the knowledge-driven model in the literature on science-policy interactions and knowledge exchange (Weingart 1999; Contandriopoulos et al., 2010). In another variation of the linear model, referred to as problem-driven, the direction of the arrow is inverted to indicate that the policy field defines the knowledge problem and subsequently turns to science for an answer (Figure 1.3). The assumption is that the produced knowledge is used instrumentally by policymakers. Indeed, in both varieties, the linear or 'pipeline' model implies a "sciencebased fix for all societal problems" (Röling 1992;46, quoted in Janssen 2015:38). Such view is based on a Positivistic stance in science. The assumption is that knowledge production by scientists and knowledge use by policy-makers occurs 
independently from each other. The linear model depicts these two worlds as strictly separated by fixed boundaries to demarcate scientific "facts" from political "values" (Guston 1999 and 2001).

The linear science-policy model has been criticized on a number of grounds. Referring to the problem-driven variety, Weingart observes that "at least three basic assumptions underlying the [linear model do] not stand up to empirical test: the linear sequence of (political) problem definition, (expert) advice and (political) decision; the value freedom of scientific knowledge; and the disinterestedness or political neutrality of scientists" (1999:154-155). In addition, the linear model ignores the contribution of knowledge producers other than scientists, which runs counter to empirical insights from the literature on science in society (Jasanoff 2003; Nowotny et al., 2001; Gibbons 1999; Funtowicz and Ravetz 1993; van der Hel 2016; Cornell et al., 2013).

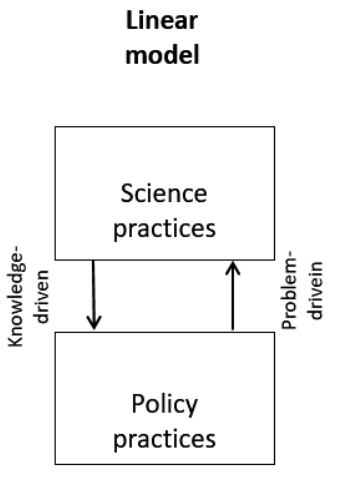

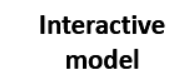

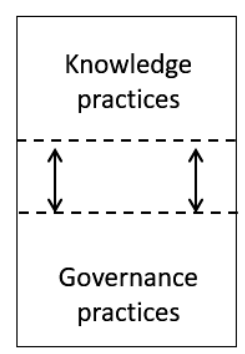

Discourse coalitions
model

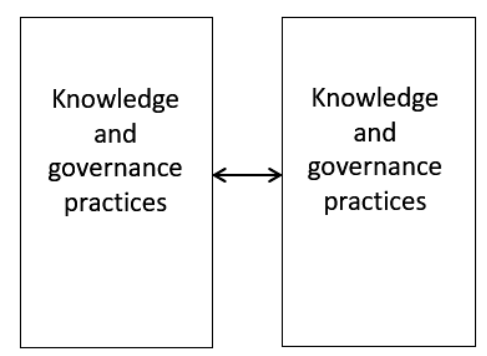

Figure 1.3 Different models to understand knowledge-governance interactions (adapted from Janssen 2015 and Floor 2018).

An alternative model to conceptualize the relation between knowledge and action is the Interactive model, also referred to as the Co-production or Intertwinement model (Contandriopoulos et al., 2010; Janssen 2015; Floor 2018). The worlds of science and policy are seen in this model not as separate, but as entwined, recognizing the political role of science in defining problems and solutions for policy-making (Jasanoff 2004; Wesselink et al., 2013; Weingart 1999). Two-way interactions take place between knowledge production and decision making, and the 


\section{Chapter 1}

boundaries between science and non-science are blurred and permeable (Guston 1999 and 2001). The model views science and knowledge as socially constructed and highlights the co-production of knowledge by various actors (i.e. expert and lay, science and non-science).

I use the terms knowledge and governance as they are broader than science and policy and indicate the multiplicity of knowledges and actors engaging in, for instance, data practices for nature conservation governance. Finally, this model asserts that knowledge is not only used instrumentally in governance arenas, but also conceptually and politically (Weiss 1979), and is useful to analyze situations in which produced knowledge is not used. This conceptualization of knowledge coproduction and (non) use in governance fits with a constructivist stance in science.

A third model of interest in this thesis is the Discourse Coalitions model, which is also based on the conceptualization of knowledge as socially constructed and coproduced by multiple actors, where the boundaries between knowledge producers and users are blurred (similar to the Knowledge Coalition or Ways of Knowing models, Janssen 2015; Floor 2018). In addition, this model introduces the notions of discourse and coalitions. A discourse can be defined as "a specific ensemble of ideas, concepts and categorizations, that are produced, reproduced and transformed in a particular set of practices and through which meaning is given to physical and social realities" (Hajer, 1995:44). A discourse coalition is an internally diverse set of actors sharing the same understanding of a phenomenon. Discourse coalitions interact with each other in an argumentative struggle, "striving for hegemony by trying to empower their definition of reality on the basis of credibility, acceptability and trust" (Arts et al., 2012:912). For the analyst, the challenge lies in combining the scrutiny of "the discursive production of reality with the analysis of the (extra discursive) social practices from which social constructs emerge and in which the actors that make these statements engage" (Hajer 2002:45).

Knowledge production and governance are understood as social practices, a concept that highlights the dialectic between social structures and human agency (Arts et al., 2014; Schatzki 2012; Shove 2012; Giddens 1984), and provides useful lenses to understand, in our case, old and new practices associated with the development and use of digital technologies for nature conservation, embedded in their particular context. The duality of structure allows us to grasp, at the theoretical level, the mutual 
relationships between societal structures and actors engaged in digital conservation (Arts et al., 2014; Giddens 1984).

In this $\mathrm{PhD}$ thesis, when I refer to data practices or knowledge practices, I mean all epistemic practices, scientific and non-scientific, related to the manifolds of actions that make up research and monitoring undertaken to inform coral reef conservation decisions. Actors' ontological and epistemological assumptions (See Chapter 2), as well as axiological positions or normativity (what is valued, considered right or socially acceptable) shape the design and use of digital technologies, actors'(mental) models of the physical and social world, knowledge production methodologies chosen and the criteria to assess knowledge (van der Hel 2016; Cornell et al., 2013; Orlikowski 2007; Nowotny et al., 2001; Mingers 2000; Gibbons 1999; Funtowicz and Ravetz 1993). I use the term governance practices to refer to the localized, smallscale routine interactions between old and new actors and discourses who strive to define and steer an environmental or nature conservation issue (Arts et al., 2014; Arts and Leroy 2006).

Combining analytical perspectives that focus on systemic and individualistic features of such practices is useful to capture the duality of structure in empirical research (Arts and van Tatenhove 2006). Systemic analyses refer to foregrounding the analysis of certain practices from a structural perspective and focusing on for instance institutions or norm circles (Elder-Vass 2012; Arts and van Tatenhove 2006), while the agency of actors is bracketed. Individualistic analyses, in contrast, start the analysis focusing on the ideas, motivations, identities or actions of agents, while placing in brackets the structural features of the context in which actors are embedded (Arts et al., 2014; Arts and van Tatenhove 2006). I combined both analytical perspectives in studying instances of digital conservation. The following section introduces the setting which provided the empirical insights for this $\mathrm{PhD}$ thesis.

\subsection{Coral reefs, MPAs and digital conservation in the Caribbean Sea}

The first step of my research consisted of an overview of different types of marine protected areas (MPAs), located in tropical and temperate regions throughout the world and established to protect diverse marine ecosystems. The aim was to examine how various actors associated with those MPAs interpret desirable data attributes in the context of collaborative information systems developed for participatory MPA management and governance. From this initial overview, I narrowed down the scope 


\section{Chapter 1}

of my study to coral reef MPAs. Instances of digital conservation were sought that focused on coral reef conservation in the Caribbean Sea.

Here I provide the justification for the delimitation of the Caribbean Sea as study region, and within this region, the selection of the specific cases that provided the empirical grounding for this $\mathrm{PhD}$ thesis. First, the Caribbean has been recognized as one of the key marine biodiversity hotspots in the world (Miloslavich et al., 2010), but it is also an area where reef biodiversity has declined significantly in previous decades due to old and new threats. Second, coral reef ecosystems are vital for the livelihoods of many people in the region, and consequently, coral reef conservation is a high-stake governance issue. Third, MPAs are important governance sites. Because they hold high biodiversity, these areas attract resource users (e.g. tourism, fisheries) and are often the stage of conflict. Moreover, due to their high conservation value, a multitude of conservation initiatives, including digital conservation, are concentrated in MPAs. The combination of these factors, coupled with a personal interest and contacts in the region, explains my choice for Caribbean MPAs as the geographical area for my research. In the next sub-sections I present a brief introduction to coral reef ecosystems and coral reef MPAs. I close the section by introducing the MPAs selected as sites for my case studies.

\subsubsection{Coral reef ecosystems}

Although coral reefs cover less than $0.1 \%$ of the seafloor globally, these ecosystems provide habitat for approximately $25 \%$ of all marine life and are therefore among the most productive and biologically diverse ecosystems on Earth (Thornhill 2012). Located in the tropical and sub-tropical oceans, reefs are vital to the social and economic wellbeing of millions of people from predominantly poor coastal areas of developing countries and of small island developing states, where alternative livelihood options are limited (Pendleton et al., 2016; Scobie 2016). Caribbean reefs span 38 countries, supporting more than 43 million people and generating between US \$3.1-4.6 billion annually from tourism and fisheries, not including other goods and services (Jackson et al., 2014; Burke et al., 2011).

Significant degradation of reefs and associated biodiversity over the last few decades has been documented throughout the world (Hughes et al., 2018 and 2017; Jackson et al., 2014). Reef ecosystems are said to be undergoing "a death by a thousand cuts" (Hughes et al., 2017) as causes for decline comprise a large variety of global and local pressures, both natural and anthropogenic, including damage by storms, destructive 
fishing practices, overfishing, water pollution, invasive species, coastal development, dredging, overharvesting, unsustainable tourism and effects of climate change that include increased incidence of coral bleaching, altered coral calcification and coral diseases (Bindoff et al., 2019; Hughes et al., 2017; Mumby and Steneck 2008). In the Caribbean Sea, a region-wide $50 \%$ reduction in coral cover has been observed since the 1960s, next to a recent decline in reef architectural complexity and reductions in Caribbean reef fish abundance (Jackson et al., 2014; Alvarez-Filip et al., 2011; Paddack et al., 2009).

Figure 1.4 shows the percentage of the world's coral reefs considered to be at risk. The figure is based on the latest assessment, to the best of my knowledge, of the main pressures, both local (overfishing/destructive fishing; marine-based pollution and damage; coastal development and watershed pollution) and global (thermal stress), as reckoned in 2011. According to this assessment, cumulative threats placed about $75 \%$ of the world's reefs at medium to high risk. After 2011, old and new pressures have continued to impact coral reefs. Between 2014-2017, a global bleaching event affected more reefs than any previous event, the effects were more severe in some areas (e.g., Great Barrier Reef, Kiribati) than ever before and it caused mass bleaching in various reefs that had never been affected (e.g., northernmost Great Barrier Reef) (NOAA 2018). Thirty percent of the coral reefs in the Great Barrier Reef died after the 9-month marine heatwave in 2016 (Hughes et al., 2018). In addition, recent research has found that plastic litter has rapidly become a new serious threat to coral reef health (Lamb et al., 2018; Debrot et al., 2013). In the Caribbean, the impact on coral reefs and coastlines of invasive species has made international news headlines in the last few years and incited a spur of research on this increasingly severe pressure affecting the region (Business Insider 2018; Willette et al., 2014; Côté et al., 2013).

According to the 2019 IPCC special report on the ocean, “...almost all coral reefs will greatly decline from their current levels, even if global warming remains below $2^{\circ} \mathrm{C}$ (very high confidence). Any coral reefs that do survive to the end of the century will not be the same because of irreversible changes in habitat structure and functioning, including species extinctions and food web disruptions; these changes are already taking place (e.g., the Caribbean reefs)" (Bindoff et al., 2019: 5.3.4). On a more positive note, the same report states that research has shown variations in sensitivity and adaptation capacity to warming and ocean acidification across coral reef species and ecosystems. Monitoring of coral reefs worldwide shows that some 


\section{Chapter 1}

areas, including in the Caribbean, "have recovered more rapidly after bleaching than the larger-scale average (medium confidence)" (ibid).

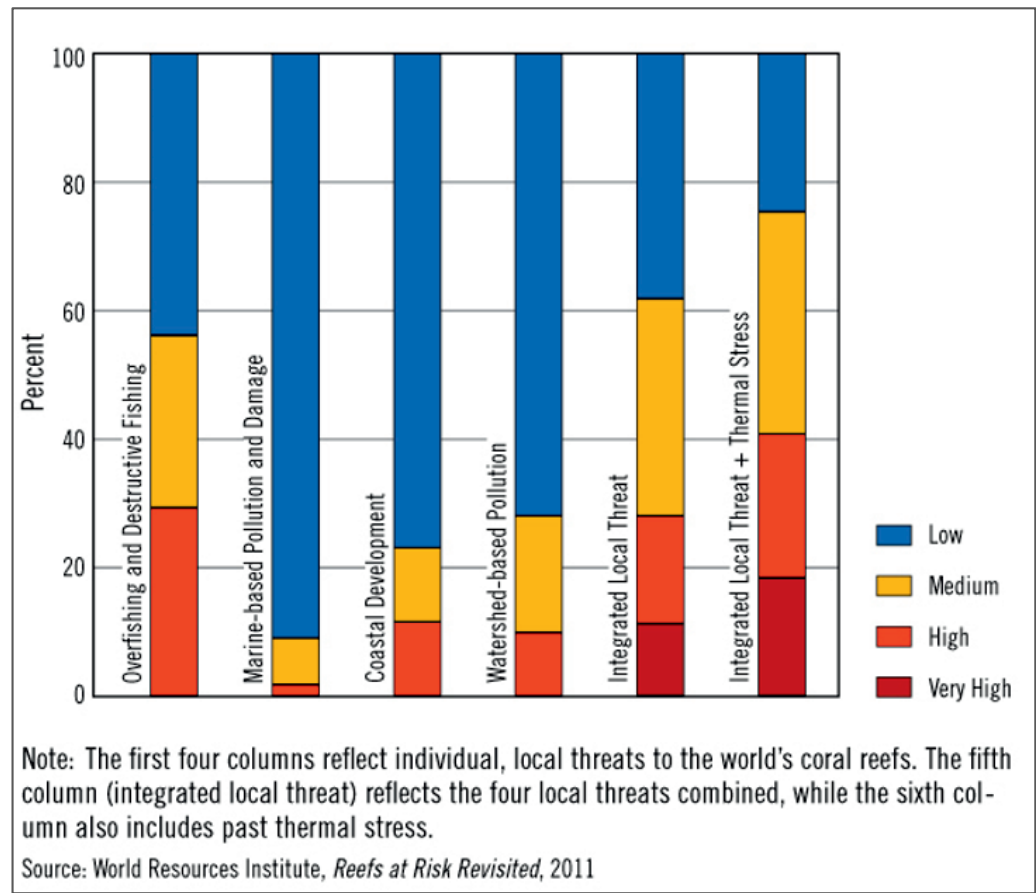

Figure 1.4 The world's coral reefs at risk from individual local threats and cumulative threats (Burke et al., 2011).

\subsubsection{Marine protected areas}

A leading strategy in international efforts for coral reef conservation has been the establishment of marine protected areas (Christie 2011; Mora 2008; Agardy et al., 2003). The most widely used definition of an MPAs, and the one I use in this $\mathrm{PhD}$ thesis, is "any area of intertidal or sub-tidal terrain, together with its overlying water and associated flora, fauna, historical and cultural features, which has been reserved by law or other effective means to protect part or all of the enclosed environment" (Kelleher, 1999). Many other definitions exist, however, each emphasizing different goals, including biodiversity conservation, fisheries management and tourism development (Hargreaves-Allen et al., 2011; Agardy et al., 2003). 
Prompted by the World Summit on Sustainable Development's 2002 targets to develop representative networks of MPAs by 2012 and the Convention on Biological Diversity's 2006 target to conserve at least $10 \%$ of the world's marine eco-regions by 2010 (extended to 2020), thousands of MPAs have been established worldwide (CBD 2017; Agardy et al., 2003). Over the last two decades, the number and spatial extent of MPAs has increased significantly. While in the year 2000, approximately $0.7 \%$ of the total extent of the world's coasts and seas was covered under MPAs, representing $2,000 \mathrm{~km}^{2}$, today, almost $7.5 \%$ of the ocean, or 27 million $\mathrm{km}^{2}$, is under some form of protection (UNEP-WCMC and IUCN, 2019). According to the world database on protected areas, there are currently 14,841 MPAs, most of them found within national waters, with a small proportion of MPAs recently established in areas beyond national jurisdiction (ibid).

MPAs come in a range of sizes, shapes and age and show various degrees of management effectiveness, from total lack of enforcement (i.e. "paper parks") to management that is regarded as effective and equitable (Gill et al., 2016; Rife et al., 2013; Selig and Bruno 2010). Management approaches range from full protection in no-take areas, where extractive activities (fishing, oil/gas winning, mining) are severely restricted or prohibited, to multiple-use areas where regulation aims at sustainable resource use. Similarly, governance arrangements vary widely, including top-down by governments, bottom-up by indigenous or local communities, and all kinds of co-management or shared governance modes (Dudley, 2008; Christie and White 2007; Agardy et al., 2003). A plethora of terms used to describe the various sorts of MPAs includes "marine park, marine reserve, fisheries reserve, closed area, marine sanctuary, MACPAs/MCPAs (marine and coastal protected areas), nature reserve, ecological reserve, replenishment reserve, marine management area, coastal preserve, area of conservation concern, sensitive sea area, biosphere reserve, no-take area, coastal park, national marine park, marine conservation area and marine wilderness area" (Agardy et al., 2003: 356). What all these nomenclatures have in common is that management interventions are spatially organized.

\subsubsection{Coral reef MPAs: an answer to coral reef degradation?}

Estimates of the world's total coral reef area $\left(527,072 \mathrm{~km}^{2}\right)$ that is protected by the global MPA system vary. Mora et al., (2006) assessed the status of the global network of coral reef MPAs. The assessment was based on a risk index of various threats to 980 MPAs. According to Mora et al.'s calculations, $18.7 \%$ of the world's coral reef 


\section{Chapter 1}

habitats lay inside an MPA in 2006, with only 1.4\% located in no-take areas and less than $0.1 \%$ within no-take areas classified as low risk (e.g. with low poaching risk). According to Mouillot et al., (2016), only 5.9\% of the world's coral reefs lie within an MPA. The discrepancy in both estimates is mostly explained by the criteria used by Mouillot et al., in building their database, which was restricted to shallow reef habitats (< $50 \mathrm{~m})$ (2016). Regarding Caribbean reefs, Mora et al., (2006) estimated that approximately $20 \%$ lay within MPAs when the assessment was conducted, and most MPAs conferred only partial to limited protection to their coral reefs. In 2018, the Caribbean Marine Protected Area Management Network and Forum (CaMPAM) Regional MPA Database listed 320 protected areas (marine or terrestrial with coastal jurisdiction) from 33 Caribbean countries and US and European territories (Bustamante et al., 2018).

Numerous studies have investigated whether a link between coral reef MPAs and ecological (conservation) and fisheries management (social) benefits can be established, with mixed results (Mellin et al., 2016; Mouillot et al., 2016; Edgar et al., 2014; Selig and Bruno 2010; Hargreaves-Allen et al., 2011; Lester et al., 2009; Mora 2008; Mora 2006; Kareiva 2006; McClanahan and Arthur 2001). Moreover, the factors that influence or favor MPA success have been examined as well, in terms of both MPA design and governance (Hargreaves-Allen et al., 2011; Christie and White 2007). Among Caribbean MPAs, co-management is the most common governance approach, whereby institutional capacity is an important factor that favors success (McConney and Pena 2012).

In general, old, large and well enforced MPAs with no-take areas lead to conservation benefits within MPA boundaries. However, the link between MPAs and both conservation and fisheries management improvements in neighboring areas (through "spillover") remains highly debatable (Halpern et al., 2009; Mellin et al., 2016). Furthermore, even when fishing and other extractive practices within MPAs are perceived to be managed adequately, the open and dynamic nature of ecosystems renders coral reefs vulnerable to impacts from activities that originate outside MPA jurisdictional boundaries (Agardy et al., 2010; CBD 2004), such as invasive species and water pollution from land. This leads me to the rationale for the selection of the sites and cases studied in this thesis. 


\subsubsection{Caribbean MPAs: sites selected for this thesis}

The selection of the specific MPAs and case studies proceeded as follows. During the initial MPA overview and interviews I conducted for my first study (described in Chapter 3), I distinguished two salient governance issues: the lionfish invasion of the Caribbean (a "new" threat for coral reefs) and water quality deterioration affecting most coral reef MPAs (an "old" threat). In addition, I identified digital conservation initiatives that addressed both issues, albeit in different ways and at different scales. While a regional digital conservation initiative was ongoing regarding the lionfish case (covering approx. 7 million $\mathrm{km}^{2}$ ) as well as local initiatives in various MPAs, the water quality initiative investigated concerned one small MPA and spanned only $200 \mathrm{~m}$ along the coast.

In total, seven MPAs were selected, representing a diverse sample in terms of sizes, governance modes, Caribbean ecoregions, digital technologies used, types of multiactor networks formed, and the governance issues studied (Table 1.2 and Figure 1.5). The precise criteria that guided site selection, the MPAs chosen for each study and the respondents approached within each MPA are described in Chapters 4 and 5, regarding the invasive lionfish case, and Chapter 6, regarding the water quality case.

Table 1.2 Selected marine protected areas.

Data from MPA Global (http://www.mpaglobal.org/) and MPAtlas (http://www.mpatlas.org/); ecoregions after Spalding et al.,(2007).

\begin{tabular}{|c|c|c|c|}
\hline $\begin{array}{l}\text { Marine Protected Area } \\
\text { (designation date) }\end{array}$ & $\begin{array}{l}\text { Total Area } \\
\left(\mathrm{km}^{2}\right)\end{array}$ & Governance & $\begin{array}{l}\text { Caribbean } \\
\text { Ecoregion }\end{array}$ \\
\hline Florida Keys National Marine Sanctuary (1990) & 9,845 & State-led & Floridian \\
\hline Sian Ka'an Reefs Biosphere Reserve (1998) & 349.3 & State-led & Western Caribbean \\
\hline Bonaire National Marine Park (1979) & 27 & NGO & Southern Caribbean \\
\hline Curaçao Underwater Marine Park ${ }^{*}$ (1983) & 10.4 & NGO & Southern Caribbean \\
\hline $\begin{array}{l}\text { St. Maarten “Man of War Shoal” Marine Park } \\
\text { (2010) }\end{array}$ & 31 & NGO & Eastern Caribbean \\
\hline Saba National Marine Park (1987) & 13 & NGO & Eastern Caribbean \\
\hline St. Eustatius National Marine Park (1996) & 27.5 & NGO & Eastern Caribbean \\
\hline
\end{tabular}

*Although this MPA is listed by international MPA databases, it has not been designated by law and lacks effective management, and is therefore considered a "paper park" (http://www.carmabi.org/naturemanagement/curacao-marine-park). 


\section{Chapter 1}

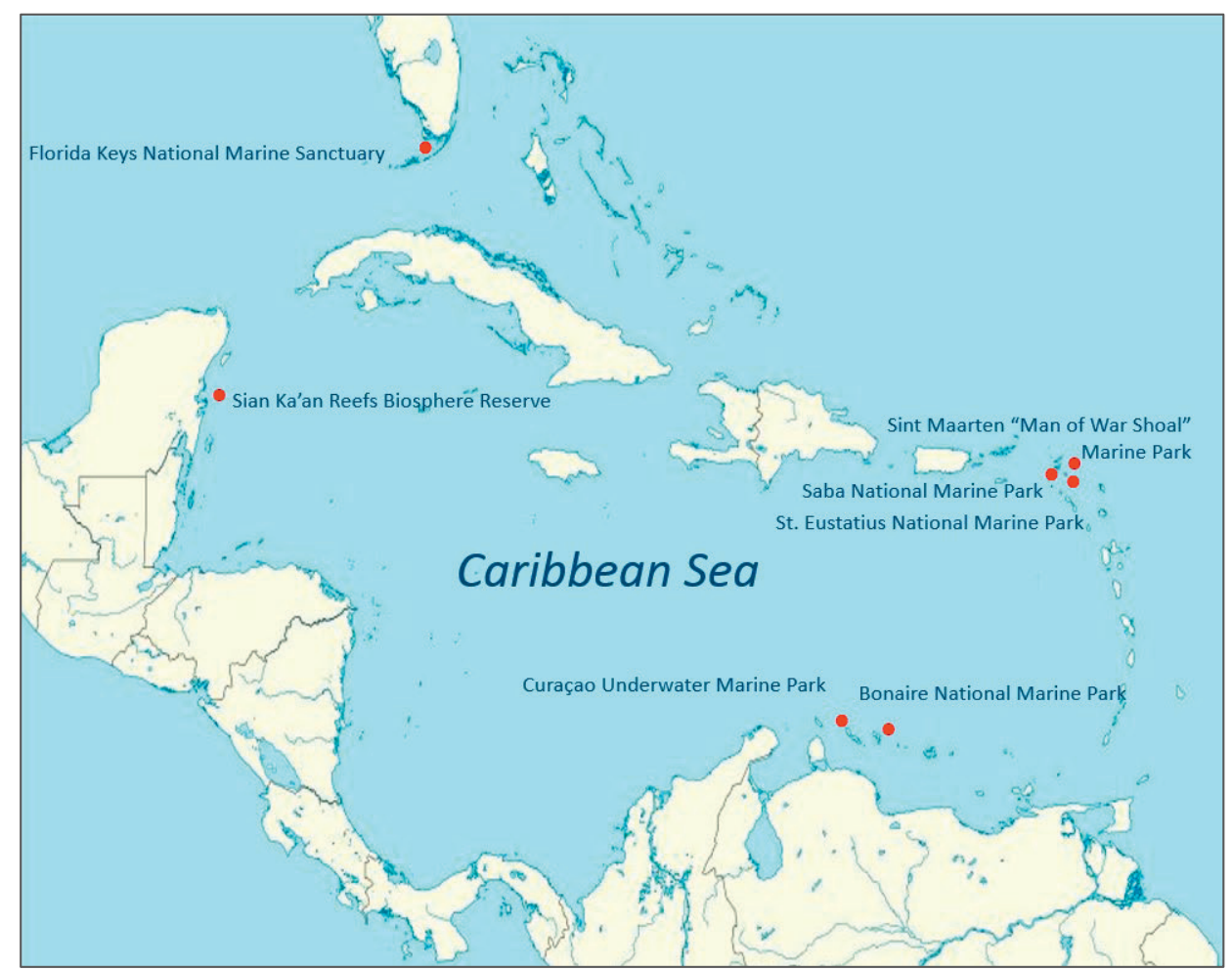

Figure 1.5 MPAs in the Caribbean Sea selected as case study sites (Source: Google maps).

\subsection{Thesis outline}

In Chapter 1, I have presented the topic of this $\mathrm{PhD}$ thesis along with the rationale for studying the phenomenon of digital conservation in coral reef MPAs; I have explained the theoretical underpinnings of this thesis, my conceptualization of the key constructs studied, and I have articulated my research aim, research questions and research strategy. In Chapter 2, I describe my research methodology. In Chapters 3 through 6, I present the empirical findings, which have been written as articles for peer-reviewed journals; these chapters are summarized below.

Chapter 3 is positioned within the information systems (IS) development literature and presents an overview of how actors associated with eleven MPAs situated in eight different countries across three continents interpret desirable data attributes (availability, accessibility, quality, consistency and security). The chapter specifically 
contributes to IS interpretive research on the field of requirements elicitation for IS design, and as such, it primarily illuminates the "Input" phase of an imagined digital conservation initiative. Because actors explicate their interpretations by drawing from the various data practices they engage with (from data production to data use), the paper is relevant to understand the "Activities" and "Outcomes" phases as well. This chapter provides insights regarding how the (knowledge management) culture of the various actors shapes their interpretations and (inter)actions regarding the production and use of data in the context of collaborative MPA management and governance. Legitimacy and accountability are identified as important themes that cut across statements from all actor groups and guide their practices.

Chapter 4 lays the groundwork for the first case study. This chapter presents a chronological overview of discourse formation regarding the lionfish, a non-native fish species that has been accidentally introduced and rapidly spread throughout the Western Atlantic and has become a serious conservation concern in many Caribbean MPAs. In focus here is how discourse coalitions draw on scientific data to make themselves persuasive, and on metaphors of nature to convey meaning. The chapter examines how science and the media, powerful meaning-making actors in society, have socially constructed the lionfish invasion. The key role herein of a regional digital conservation initiative brought about by a large multi-actor network to map lionfish distribution is highlighted. In addition, the chapter elucidates the interpretations of local stakeholders associated with seven Caribbean MPAs. Stakeholders' discourses, based on their own lionfish data and local experiences, are juxtaposed against the dominant storylines about lionfish management circulating through the region, mainly through online maps, databases, news reports, Internet forums and social media. Using Castell's terminology, the dominant discourses transmitted through the space of flows are pitted against the discourses stemming from the space of places.

Chapter 5 examines the drivers and barriers to participation in various digital conservation initiatives built around lionfish in five Dutch Caribbean MPAs. The chapter contributes to the environmental volunteering literature related to conservation citizen science. It looks at actors' motivations to engage with and remain active in these initiatives, focusing on practices of data collection and data sharing, from a sociomaterial perspective. Findings show that the personal meanings attached to both the data and the data collection experiences influenced actors' motivations to sustain or cease their participation in the various multi-actor networks 


\section{Chapter 1}

operating regionally and locally. Moreover, enabling and constraining conditions at the personal, interpersonal, organizational and technological levels are identified. The chapter sheds light on the "Activities", "Outputs" and "Outcomes" phases of digital conservation initiatives for coral reef MPA governance.

Chapter 6 presents the second case study. This chapter assesses the social processes and outcomes of a participatory sensing initiative created to monitor seawater quality around the island of Bonaire. The chapter contributes to academic research of science-society relations in digital conservation, with legitimacy dynamics and the democratization of science and policy as central themes. A conceptual framework that explicates the multiple legitimacy relations forged among heterogeneous actors in collaborative knowledge production processes is presented. The framework is applied, through a rhetoric-based narrative analytical approach, to describe and explain the processes and results of the participatory sensing initiative. The chapter offers an impression of various phases of the initiative, from "Input" to "Outcomes," along with a critical appraisal of digital technologies' promises of democratic knowledge production for use in coral reef conservation governance.

Chapter 7 concludes the thesis. The chapter combines insights from the empirical chapters to answer the research questions. Further, it provides a reflection on the interdisciplinary approach adopted in this Phd thesis and on the theoretical contributions made. Finally, the chapter closes with a research outlook for the digital conservation field. 
Introduction

1 
CHAPTER 


\section{Research philosophy, methodology and methods}





\section{Research philosophy, methodology and methods}

For a research strategy to be internally coherent, different elements should be aligned: the ontological and epistemological assumptions of the researcher - that is, her positioning within a research paradigm within the philosophy of science - should match the various theoretical perspectives that inform the study and be congruent with the study design and methods used for data collection and data analysis. Together, these elements comprise the research methodology. In this section I explicate the philosophy of science and research methodology foundations that support my $\mathrm{PhD}$ thesis.

\subsection{The applied scientific paradigm}

Ontology and epistemology are branches of philosophy that theorize, respectively, the nature of being and of knowledge. Within the philosophy of science, a key debate centres on the question whether reality exists independently of humans (ontology) and whether objective knowledge of this reality is possible (epistemology) (Willcocks and Mingers 2004; Tuomi 1999). In this debate there are two major meta-theories or paradigms, representing opposing views along a continuum, referred to as Positivism and Constructivism. Positivism holds that there is a single reality or truth about the world, that this reality exists independently from humans and it can be measured and known. This Aristotelian notion of knowledge posits that true knowledge is independent of the knower. Within Positivism, different views about the nature of reality and how to access knowledge of this reality have been developed throughout the centuries, which range from empiricism to realism (for a detailed account see Mingers 2000 and von Glasersfeld 1991). At the other end of the continuum, Constructivism holds that there is no single reality or truth, and therefore reality needs to be interpreted; in this view, the knower interprets and constructs a reality based on her interactions with the world. Such position is referred to as relativism or interpretivism. There are many varieties of Constructivist ontology and epistemology, from moderate to radical (Elder-Vass 2012; von Glasersfeld 1991), the latter expressed by statements such as 'the human mind can know only what the human mind has made' and hence the only reality that exists for humans resides in their mind (von Glasersfeld 1991:4). 


\section{Chapter 2}

Within both Positivism and Constructivism, there is a tendency to conflate ontological and epistemological statements, in other words, to take the category of that which exists to be exhausted by the category of that which is known. Critical Realism is a paradigm that criticizes such conflation, as it leads to what Bhaskar calls an epistemic fallacy (quoted in Mingers 2000:1261):

The essential mistake is in reducing the ontological domain of existence to the epistemological domain of knowledge... statements about being are translated into ones about our (buman) knowledge or experience of being. For the empiricist, that which cannot be experienced cannot be... In contrast, the realist asserts the primacy of ontology: the world would exist whether or not bumans did.

In the Critical Realist paradigm, which is positioned mid-way along the PositivistConstructivist continuum, reality exists independently of humans, but because knowledge production is the work of humans, knowledge about reality is constructed. This paradigm thus accepts the relativism of knowledge - including scientific knowledge - as socially and historically conditioned (Kuhn 1970; Mingers 2000). Critical Realism takes a realist stance ontologically and a relativist stance epistemologically. Importantly, this paradigm highlights that epistemic relativity does not correspond to judgemental relativity - the position that all views are equally valid - and maintains that choosing between different views can be accomplished based on rational grounds (Mingers 2000).

As stated in Chapter 1, I position my $\mathrm{PhD}$ research within realist social constructionism, which builds from the Critical Realist paradigm and spouses a moderate variety of constructivism and positivism within sociology (Elder-Vass 2012). This view holds that the social world is open to causal explanations and that we can make judgements between alternative constructions or interpretations (ibid). Within this paradigm, hermeneutically based research methodologies are suitable, as they focus on the interpretation of meaning. In this $\mathrm{PhD}$ thesis I followed a research approach that can best be characterized as critical hermeneutics (Gadamer 1975, 1988; Ricoeur 1973). Critical hermeneutics seeks to integrate the interpretive work of "pure hermeneutics" with a critical stance by the analyst towards her object of study (Butler 1998). In the following section I elaborate on the theoretical underpinnings of critical hermeneutics and build a critical hermeneutic methodological framework. 


\subsection{Hermeneutics: the pursuit of meaning}

Hermeneutics is the study of interpretation and understanding. The term's origin refers to Hermes, the messenger of the gods in Greek mythology, whose task was to translate the gods' messages and communicate them to humans (Butler 1998). Traditionally, hermeneutics has been associated with the interpretation of texts, such as ancient scriptures. In contemporary hermeneutics, however, text-analogues including speech events, social actions and social phenomena are also objects of study using hermeneutic concepts and methods (Roberge 2011; Ricoeur 1973). Hermeneutics is concerned with bridging the gap in understanding between the familiar and the unfamiliar; "[i]ts field of application is comprised of all those situations in which we encounter meanings that are not immediately understandable but require interpretive effort" (Editor's Introduction in Gadamer 1975: xii). For consistency purposes, I will refer here to a social phenomenon under study as an action-text to be interpreted.

Different perspectives on interpretation exist in contemporary hermeneutics (Butler 1998). I draw primarily from the work of social philosophers Hans-Georg Gadamer $(1975,1988)$, who was inspired by his teacher Martin Heidegger, and Paul Ricoeur (1973). Building on constructivist philosophy, critical hermeneutics recognizes that reality is socially constructed and acknowledges the multiple and possibly conflicting interpretations of an action-text - but it does not agree that all interpretations are equally valid (Ricoeur 1973). In adopting a critical hermeneutics perspective to study social action and social phenomena, "the researcher does not merely accept the selfunderstanding of participants but seeks to critically evaluate the totality of understandings in a given situation" (Myers 1994:189). Such 'critical evaluation' refers to a recognition of participants as situated social actors, with values and interests, wants and beliefs that color their interpretations and actions (Roberge 2011; Ricoeur 1973). Moreover, critical hermeneutics is concerned with power asymmetries in society and processes of social inclusion-exclusion, and as such has an emancipatory purpose (Roberge 2011). In engaging with the science and technology studies literature, in this thesis I adopt a critical stance towards knowledge production and use in digital conservation networks.

\subsection{A critical hermeneutics framework}

Here I will briefly introduce the main concepts developed by Gadamer $(1975,1988)$, Heidegger (discussed in Chughtai and Myers 2017; Sandberg and Tsoukas 2011; Cole 


\section{Chapter 2}

and Avison 2007) and Ricoeur (1973) that I have incorporated in my research framework.

\subsubsection{Pre-understanding, being-in-the world and breakdowns of meaning}

Gadamer argues that, instead of attempting to set aside our prejudices, we as interpreters must become aware of our views and biases emanating from our historicity and how these shape our understanding of the action-text (Gadamer 1988). By being open to what the action-text has to say and recognizing that her knowledge is incomplete, a researcher scrutinizes her prejudices or pre-opinions, through critical reasoning and a dialogic approach, and revises them if needed (ibid). This self-reflexivity is an important element of the methodological framework applied in this thesis.

The concepts of historicity and prejudice are related to Heidegger's notion of preunderstanding, or the fore-structures of understanding: our presuppositions, background and current horizon, which enable us to make sense of the unfamiliar by anticipating its meaning, to grasp that to be interpreted in a preliminary way (Chughtai and Myers 2017). Gadamer defines horizon as related to a temporal situation of understanding: "The horizon is the range of vision that includes everything that can be seen from a particular vantage point" at a given moment in time (Gadamer 1975: 269). When we start a new research, we engage with the literature by bringing in our fore-structures of understanding and research interests, which constitute our interpretive horizon and guide us in formulating our lines of enquiry (Cole and Avison 2007).

Heidegger posits that understanding unfolds as time moves forward. By virtue of being-in-the-world, we understand something, and we become familiar with it (Heidegger 1927/1996, cited in Sandberg and Tsoukas 2011). "[T] ne notion of being-in-the-world stipulates that our most basic form of being is entwinement: we are never separated but always already entwined with others and things in specific sociomaterial practice worlds" (Sandberg and Tsoukas 2011:2011). The more familiar we are with a phenomenon or a practice, the less interpretive effort it takes to understand it. However, whenever a 'breakdown' in meaning occurs - an anomalous statement, event, or behavior - we need interpretive effort to understand the new situation (Sandberg and Tsoukas 2011; Cole and Avison 2007). For Gadamer, language is the medium in which substantive understanding and agreement between people take place (1975:386). In the context of research, this requires entering into a dialogue, or dialectic, with the action-text to reach new 
understanding. Gadamer calls this process a fusion of horizons (Gadamer 1975). In our research, the breakdowns of meaning may require a reformulation of our lines of enquiry.

\subsubsection{The dialectic, the hermeneutic circle and the fusion of horizons}

The dialectic is a versatile concept in hermeneutics. It primarily refers to a dialogue that follows a metaphorical circular movement between interpreter and action-text. As explained above with respect to the interpreter's prejudices, Gadamer suggests that, in order to distinguish between 'true' prejudices that aid in understanding and 'false' prejudices that result in misunderstanding, researchers must subject their prejudices to a test. Such a test consists of establishing a dialogue, in the Socratic and Platonic sense, of engaging in a question and answer dialectic with the action-text (Butler 1998). For Gadamer, "The essence of a question is to open up possibilities [for understanding] and keep them open" (1988:77). This dialectic is primarily selfreflexive, and its main purpose is to enhance the interpreter's self-understanding.

The dialectic further entails an interpretation process whereby the action-text is deconstructed into its parts, which are then re-integrated into the whole in the hermeneutic circle or circle of understanding (Gadamer 1988). Smaller units of meaning, the parts, acquire their meaning by virtue of being part of a larger unit of meaning, the whole. The whole has meaning because of its constituent parts. The process of interpretation moves, then, between the parts and the whole and back to the parts, in order to determine the meaning of both. One round of the circle represents a partial fusion of horizons. A constant revision of our interpretations takes place as more information is considered, or old information is re-interpreted, leading to new understanding. Because the context that determines something's meaning is vast, and because breakdowns of meaning occur, various rounds of interpretation are required to arrive to a total fusion of horizons. This does not entail that understanding is perfect or complete, but that it suffices to answer the research question(s) posed through our lines of enquiry.

Gadamer states that "The task is to expand in concentric circles the unity of the understood meaning. Harmonizing all the particulars with the whole is at each stage the criterion of correct understanding. Its absence means the failure to understand" (1988:68). How is this harmonizing process carried out? The types of dialectic used in this harmonizing process are Socratic and Hegelian (Butler 1998). The Hegelian dialectic "comes into play when a particular interpretation or thesis is worked out with a competing interpretation or antithesis so as to arrive at a newer, fuller and 


\section{Chapter 2}

more informed interpretation or understanding... [it] involves an interpretive synthesis of expectation or preunderstanding with 'objective' observations in order to make sense of a phenomenon and thus attain an understanding of it" (Butler 1998:290). This type of analytical reasoning is critical in the sense that it passes judgement on the quality of alternative interpretations, where harmonizing or attaining coherence between the parts and the whole is the criterion of correct understanding, and where understanding is the ultimate aim. This type of analytical reasoning is not critical of the content of the action-text, however. Indeed, Gadamerian hermeneutics is not concerned with a critical scrutiny of what the action-text talks about nor strives to explain the implications of the new understanding acquired. For this last fusion of horizons, we turn to Ricoeur's work (1973).

\subsubsection{On Ricoeur's dialectic}

Paul Ricouer is considered to be a critical hermeneuticist, concerned with the "problem of ideology" and structures of domination in society (Roberge 2011). The dialectic that Ricoeur proposes is one between the process of explaining (erklären) and the process of understanding (verstehen), achieved through a structural linguistic analysis and a depth-semantics analysis (Ricoeur 1973). Ricoeur applies a structural analysis to an action-text, using the analogy between social action and a myth, to illustrate the dialectic between explaining and understanding. By explaining the structure of the myth, we can identify how the parts relate to each other, the myth's internal logic. By interpreting the discourse, we understand - not what it says, but what it talks about (1973: 114). We explain the syntax, but we understand the semantics of the action-text.

The structural analysis follows a reductionist approach, which involves a narrowing down of the scope of generic concepts that constitute social phenomena, identifying sets of topics and the hierarchical relations between primary and secondary sets (Ricoeur 1973). This reasoning follows "the Aristotelian method of division or repeated logical analysis of genera into species..." (Butler 1998:290) and enables us to reduce social complexity to aid in its comprehension and description. As Ricoeur observes, a structural analysis is "a stage - and a necessary one - between a naïve interpretation and a critical interpretation, between a surface-interpretation and a depth-interpretation" (1973:113). The next stage is a depth-semantics analysis, which allows a social critic to move from the appearance of the text to its in-depth understanding. It is through the critical (social) theories informing our research that we can link the structural and depth-semantics analyses in our dialectic. 
Finally, regarding the multiple possible interpretations or 'plurivocity' of the text, Ricoeur observes that "if it is true that there is always more than one way of construing a text, it is not true that all interpretations are equal" (Ricoeur 1973:108). He goes on to note that "the text is a limited field of possible constructions" and that we can base our arguments for or against an interpretation based on the logic of probability (1973:107). "To show that an interpretation is more probable in the light of what is known is something other than showing that a conclusion is true" (Ricoeur 1973:107).

Figure 2.1 shows the critical hermeneutic methodological framework describing the research process that led to this $\mathrm{PhD}$ thesis. The steps depicted by the various hermeneutic circles represent ideal abstractions, as in practice, the processes underlying the four empirical chapters followed slightly distinct patterns and multiple iterations.

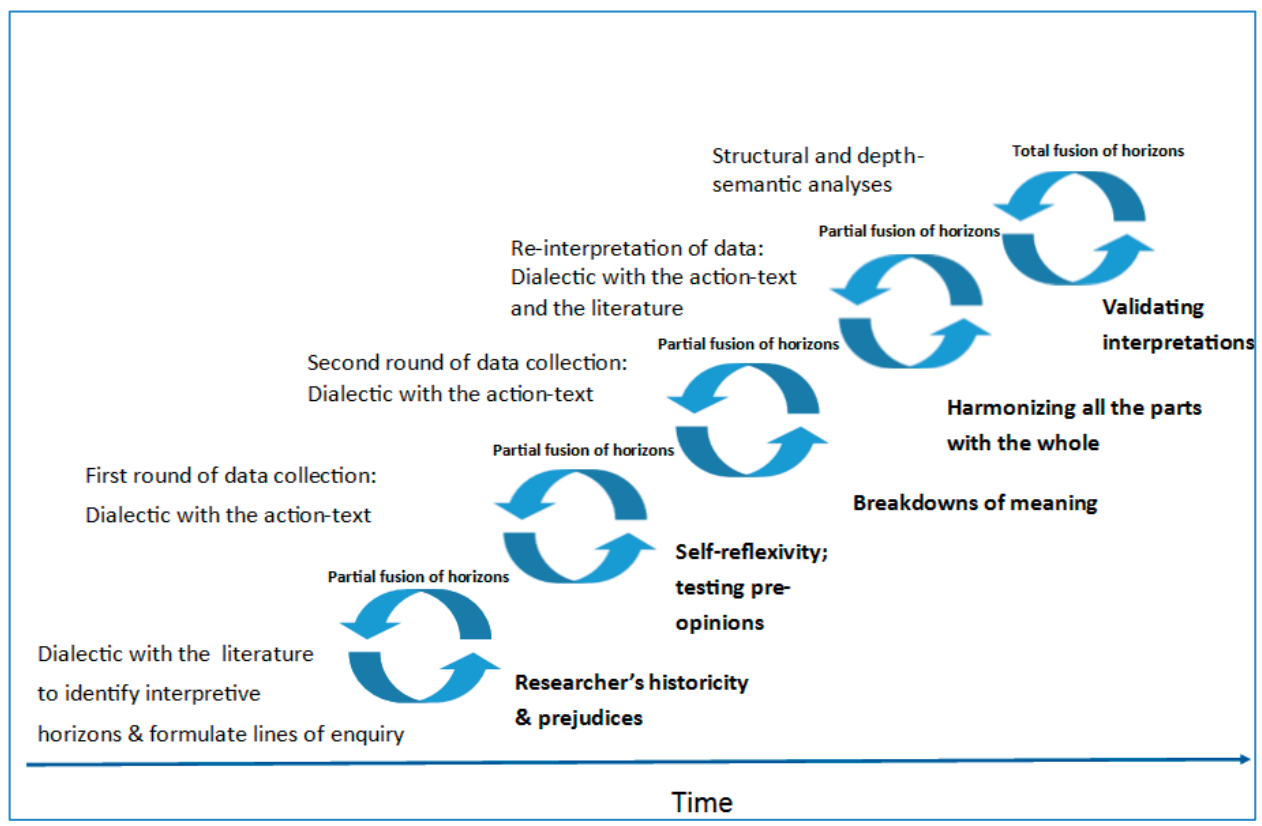

Figure 2.1 A critical hermeneutics research framework. 


\subsection{Study design and methods}

\subsubsection{Study design}

The study design of this thesis is based on a qualitative case study approach. Case study design is appropriate for answering 'what', 'how' and 'why' questions of a phenomenon studied in its real-life context and supports the use of diverse methods of data collection and analysis (Yin 2009). Case study design is labelled as an 'intensive' research approach, as it allows for an in-depth and detailed examination of a phenomenon, by focusing on a single or a handful of instances of said phenomenon, that can be followed retrospectively over time.

As already mentioned in section 1.6, as a starting point for this thesis I conducted a study that consisted of an initial overview of several MPAs located in various countries in tropical and temperate regions of the world. This exploratory study was valuable for the further delimitation of my research to one ecosystem type in one geographical region (coral reefs in the Caribbean), as well as the selection of two cases for which digital conservation instances had been developed to address salient governance issues: one focusing on invasive lionfish monitoring and management and the other on water quality monitoring. The unit of analysis in all the studies conducted in this thesis is the assemblage formed though the digital conservation initiative, while my units of observation are the individual actors interviewed and the texts selected for interpretive analysis.

\subsubsection{Methods of data collection and data analysis}

In line with critical hermeneutics, interpretive methods for data collection and analysis were employed in the empirical chapters of this $\mathrm{PhD}$ thesis (Schwartz-Shea, and Yanow 2013; Angen 2000; Klein and Myers 1999). Methods of data collection consisted of semi-structured interviews with a total of 135 respondents, (participant) observations and text analysis. Purposive sampling (Bryman 2012) was carried out; the criteria for the selection of respondents and texts as data sources for each study are described in the respective empirical chapters (Ch. 3 to 6). Texts analyzed included scientific articles, policy and MPA management documents, NGO reports, and a range of online data sources such as newspaper table of contents and articles, blogs, social media posts, databases, maps, forums and videos. Data collection proceeded based on the principle of theoretical saturation (Saunders et al., 2017). 
A range of interpretive data analysis methods was applied: domain analysis in Chapter 3 (Spradley 1974), discourse and metaphor analysis in Chapter 4 (Lakoff 1993; Hajer 1995), thematic network analysis in Chapter 5 (Attride-Stirling 2001) and a rhetoric-based narrative analysis in Chapter 6 (Lejano et al., 2013; Feldman et al., 2004). All methods are semiotic and linguistic based analyses and follow an iterative inductive-deductive coding approach to identify themes and patterns, applying the various dialectic techniques described above (Schwartz-Shea and Yanow 2013; Fereday and Muir-Cochrane 2008; Butler 1998).

\subsection{Validity and reliability}

Validity and reliability as measures of research quality are tools of a Positivistic paradigm. Because the quality of a study in each paradigm should be judged by its own paradigm's terms, validity and reliability should be redefined to fit the realist social constructionist paradigm and interpretive methodology in which my research is situated (Golafshani 2003). Measures of quality of interpretive research that encapsulate the notions of validity and reliability, are trustworthiness and defensibility of the research, based on its credibility and rigor (ibid), where rigor is defined as "the goal of making data and explanatory schemes as public and replicable as possible" (Denzin 1978:7, quoted in Onwuegbuzie and Leech 2007: 239).

External validity, or the generalizability of interpretive research, rests also on different principles than generalizability as understood in the Positivistic paradigm, which focuses on statistical generalization of findings from the sample to the population. Within interpretive research, two forms of generalizability are common: analytic generalizations and case-to-case transfers (Onwuegbuzie and Leech 2007). Analytic generalization entails generalization of "words and observations... to the population of words/observations (i.e., the "truth space") representing the underlying context" (Onwuegbuzie, 2003:400, quoted in Onwuegbuzie and Leech 2007:240). Analytic generalization is also referred to as theoretical elaboration, in which the researcher draws from her case findings as evidence "to refine, dispute, support or detail a concept, model or theory" (Jackson et al., 2007:26). Case-to-case transfer entails making generalization from one case to another, similar, case (Onwuegbuzie and Leech 2007).

The notions of 'comparability' and 'translatability' are useful measures of how generalizable the findings of a case study are, and hence whether case-to-case transfer is feasible. Comparability refers to the degree to which the study 


\section{Chapter 2}

components (such as units of analysis, concepts generated, population characteristics and settings) have been sufficiently described and defined, while translatability refers to the explication of the theoretical stance and research techniques used by the researcher (Goetz and LeCompte 1984: 228, in Schofield 2002:179). Comparing the situation in the site one wishes to draw from to the site one wishes to generalize to is possible in qualitative research. Necessary conditions are that clear descriptions are available of both sites and that the contextual and temporal similarities allow for the transferability of certain "working hypotheses" from one site to the other (Guba and Lincoln 1982: 238, in Schofield 2002: 178).

The knowledge claims that I present in this thesis do not aim to convey an objective and singular truth of the phenomenon studied, but rather a plausible and defensible account of the empirical events observed and interpreted through a process of sensemaking. This sense-making process is supported by a rigorous research design, meticulous data collection and thorough data analysis to ensure the credibility of the findings, as presented in the paragraphs above and described in a detailed and transparent way in the methods sections of the empirical chapters. This will allow other researchers to judge whether findings are generalizable to similar settings, and to support of refute the analytical generalizations discussed in Chapter 7 of this thesis. 
Research philosophy, methodology and methods 
CHAPTER 


\section{Information systems for marine protected areas: How do users interpret desirable data attributes?'}




\begin{abstract}
The purpose of this paper is to provide empirical evidence on how various user groups related to Marine Protected Areas (MPAs) interpret desirable data attributes, whether their interpretations differ and to what extent. Moreover, this study aims to make a methodological contribution to the interpretive information systems (IS) literature by showing the potential of Spradley's (1979) ethnographic methods for understanding the human context in IS research and practice. Semi-structured interviews of MPA managers, academics, government officials, and environmentalists were analyzed in four steps. Our findings show that each of the five data attributes studied encompassed more than one and often partly overlapping meanings. Commonalities and differences in interpretations between groups were observed. Users' organizational background helped to explain these differences; cross-cutting themes that seemed to guide users' interpretations and actions were perceived legitimacy and accountability of practices along the data value chain. Systematic use of ethnographically-informed methods allowed the detection of subtle differences in how users constructed meaning. As these different interpretations may lead to misunderstandings during requirements engineering, Spradley's approach could prove useful as a tool not only to elicit and analyze requirements, but also to facilitate unambiguous communication to reach mutual understanding among participants. This may help to improve IS development and thus enhance IS use for participatory governance and management in MPAs.
\end{abstract}




\subsection{Introduction}

Worldwide, participatory approaches for managing the marine environment have been promoted in the last two decades, with sustainability as overarching goal (Pomeroy and Douvere, 2008; UNCED, 1992). To realize this vision of a participatory management, adequate information provision that supports decisionmaking in complex socio-natural systems is required (McIntosh et al., 2011; Szaro et al., 1998). Significant investments to develop marine information systems (IS) and e-infrastructure that seek to integrate fragmented data and cater to various users at different scales have been undertaken recently in several parts of the world (Canessa et al., 2007; Eleveld et al., 2003; Masalu, 2008; Meiner, 2010; Tolvanen and Kalliola, 2008; Wheeler and Peterson, 2010). Despite high expectations of the potential benefits of IS for participatory governance and management of the marine environment, concerns have been raised regarding failed adoption of such systems by their intended users (Diez and McIntosh, 2011; McIntosh et al., 2011, 2008; Quinn, 2010). There are multiple explanations for the lack of adoption and use of IS in managing and governing the marine environment, but we focus on one particular - but far from marginal - cause.

Poor determination of IS requirements is recognized as a major source of adoption failure (Nuseibeh and Easterbrook, 2000; van Lamsweerde, 2000). This failure often results from inadequate involvement of future users in information system development (ISD) and/or from communication problems between participants in the requirements engineering (RE) process (Al-Rawas and Easterbrook, 1996; Anwar et al., 2011; Byrd et al., 1992; Diez and McIntosh, 2009; Fuentes-Fernández et al., 2010; Gallivan and Keil, 2003; Lyytinen, 1988; McAllister, 2006). It is acknowledged that not only technical and functional aspects but also the 'human context' (be it cognitive, organizational, political or cultural) is of vital relevance in and for the RE process and misunderstanding or ignoring that hampers IS adoption (Bergman et al., 2002; Checkland, 2000; Vidgen, 1997; Viller and Sommerville, 1999). Valusek and Fryback (1985) identified three main types of obstacles that hinder an effective elicitation process in ISD: obstacles within individual users or developers, obstacles among users, and obstacles between users and developers. Obstacles within individuals are related to cognitive constraints (Browne and Ramesh, 2002; Valusek and Fryback, 1985), whereas obstacles among users, and between users and developers, are mainly related to divergent interpretations of similar concepts that lead to miscommunication of requirements and thus to IS that fail to meet users' 


\section{Chapter 3}

needs (Byrd et al., 1992; Fuentes-Fernández et al., 2010; Hughes and Wood- Harper, 1999; McAllister, 2006; Valusek and Fryback, 1985).

This paper analyzes potential communication obstacles among users of prospective IS for marine environmental governance and management. We examine how different user groups associated with marine protected areas (MPAs) differ in defining and conceptualizing data and information attributes, and as such may prevent development and adoption of adequate IS. Our focus is on five data attributes that are considered generally desirable in IS: data/information availability, accessibility, quality, consistency and security (Panian, 2009).

MPAs are an interesting study area for marine ISD, given the current global momentum in establishing MPAs and MPA networks (Belfiore et al., 2004; UNEPWCMC, 2008; Wood et al., 2008), the conflict around managing and governing these MPAs (Jentoft et al., 2007), and the calls to develop IS on protected areas that satisfy a variety of user requirements (Bertzky and Stoll-Kleemann, 2009; Corrigan and Kershaw, 2008; UNCED, 1992; UNEP-WCMC, 2008). In analyzing how users of existing IS interpret and define data attributes, the focus should not only be on individual interpretation schemes, but also on how the 'human context' influences data attribute meanings; both should be included in designing future IS. To the best of our knowledge, no work has focused on this aspect of ISD for MPAs.

Hence, the goal of the paper is two-fold. First, we provide empirical evidence on how and to what extent various user groups interpret desirable data attributes differently. Second, this study aims to make a methodological contribution to the so-called interpretive IS literature (Klein and Myers, 1999; Walsham, 2006). By systematically and in a transparent way applying ethnographic techniques that focus on semantic analysis we show that data analysis in interpretive studies need not be “...a rather subjective and unplanned process..." (Walsham, 2006: 325).

The next section provides further background on MPAs and describes how we approach IS user requirements. The third section introduces the ethnographic techniques applied, and presents our conceptual framework for semantic analysis, to be followed by the methods used for data collection and analysis. The fifth and sixth sections present and discuss the results, respectively. The paper closes with substantive and methodological conclusions. 


\subsection{Marine protected areas and requirements of information systems users}

\subsubsection{Marine protected areas}

The most commonly used definition of a Marine Protected Area (MPA) is "any area of intertidal or sub-tidal terrain, together with its overlying water and associated flora, fauna, historical and cultural features, which has been reserved by law or other effective means to protect part or all of the enclosed environment" (Kelleher, 1999). More than 5000 MPAs have been established worldwide, ranging from 0.4 up to $41,050,000$ ha and with a wide spectrum of management goals and strategies (Wood, 2007; Wood et al., 2008). Management strategies range from full protection in notake areas, where extractive activities (i.e. fishing, oil/gas winning, mining) are severely restricted or prohibited, to multiple-use areas where regulation aims at sustainable resource use. Similarly, governance arrangements vary widely, including governance by indigenous or local communities, by government(s), by private actors and all kinds of shared governance modes (Dudley, 2008).

A key aspect to effectively manage MPAs is to follow an adaptive management approach, which requires continuous monitoring, evaluation and adjustment of management decisions in a learning cycle that builds on information of results (AIDEnvironment, 2004; Day, 2008). Hence, effective MPA management relies on a continuous flux of different types of information on bio-physical, socio-economic and legal/institutional indicators and parameters (Agardy, 2000; Pomeroy et al., 2005). Financial constraints of most MPAs (Balmford et al., 2004), and significant costs of data collection and handling, encourage strategic and coordinated efforts to effectively meet information needs (de Freitas et al., 2009; UNCED, 1992; UNEPWCMC, 2008).

In marine environments data production and handling activities are highly fragmented, owing to the large numbers and heterogeneity of individuals and organizations involved, each with their own needs and objectives (Corrigan and Kershaw, 2008; Dyer and Millard, 2002; Eleveld et al., 2003; Stojanovic et al., 2010). The data processing chain conceptualizes the flow of the various types of generated data into information (Dyer and Millard, 2002; Hansen and Wang, 1991), and 


\section{Chapter 3}

consists of three stages: data production, data handling and data consumption. ${ }^{2}$ Best practices during the production and handling stages ensure that desirable data attributes are met, such as availability, accessibility, quality, consistency and security. And such data attributes facilitate - or even precondition - data use to meet the goals of individuals and organizations involved in MPA management, governance and use.

\subsubsection{Approaching information systems, users and requirements}

Within the IS discipline no agreement exists on how to define key concepts such as "information system" (Alter, 2008), "requirements" (Hickey and Davis, 2004) or "user" (Millerand and Baker, 2010). For instance, Alter (2008) shows the great variety of IS definitions proposed in the literature, ranging from a simple data table or software directed information technologies to complex human-technology systems. The definition used by a researcher delineates the boundaries of the inquiry and underpins the selection of conceptual and methodological frameworks. This section explicates the main assumptions underlying this research and clarifies the way these three key concepts are used.

As a starting notion IS are seen "as all components that together provide the necessary information. The components are: the hardware and the software, the people and the procedures with which they work, and the data that are processed by the system" (Renkema and Berghout, 1997:2). As found in the scientific literature, existing IS are being used by various individuals and organizations to facilitate policy and management decisions in MPAs and improved/new IS are being developed to meet information needs (Bertzky and Stoll-Kleemann, 2009; de Freitas et al., 2009; UNEP- WCMC, 2008; Wood, 2007). Various sorts of IS are distinguished, including "integrated assessment models, geographic information systems and decision support systems [which] are well suited to informing environmental management and policy processes" (Diez and McIntosh, 2009:588) as well as the more ubiquitous environmental information management systems (Quinn, 2010).

The definition of "requirements" and what is considered as necessary information to be elicited from users during RE varies among IS scholars (Browne and Ramesh, 2002; Carrizo et al., 2008; Hickey and Davis, 2004; van Lamsweerde, 2000), ranging

\footnotetext{
${ }^{2}$ The term data is used throughout the paper for consistency purposes, although the terms information and knowledge may be more appropriate to refer to the second and third stages of the data processing chain, respectively (Canessa et al., 2007; Stojanovic et al., 2010).
} 
from required software functionality to "....also needs, problems, wants, desires, goals and the like" (Hickey and Davis, 2004:73). Here, we understand RE as a social process to uncover users' views of the situation including elucidation of the meanings they assign to various concepts that 'define' (data in) a future IS (Checkland, 2000; Hughes and Wood-Harper, 1999). Clearly, effective elicitation and interpretation of users' views is central to RE. However, it is not always obvious who exactly these users are or how they can best be engaged in the elicitation process (Berente et al., 2011; McIntosh et al., 2011; Millerand and Baker, 2010).

The 'user' - or IS stakeholder, client, or customer (Lin and Lu, 2000; Rowlands, 2009; Sharp et al., 1999) - is a key research subject in both applied and theoretical IS studies (Hirschheim and Newman, 1988; Lamb and Kling, 2003; Millerand and Baker, 2010). Identifying who is an IS user comes with the question of how to interpret a user. We use Lamb and Kling (2003) and Millerand and Baker (2010) in interpreting the user as a social actor. According to Millerand and Baker (2010:141) a social actor in IS "generates, exchanges and consumes information mediated by the information system in multiple social contexts and among a variety of working activities. This view focuses less on the user of the system and more on the user of the information mediated by the system". Lamb and Kling's (2003) model of the user as social actor focuses on the relevance of the user's context, characterizing the individual user according to four dimensions: the user's affiliations, environments, interactions and identities. Affiliations are the relationship networks that link individuals within and across organizations; environments are defined as "the stabilised, regulated, and/or institutionalised practices, associations, and locations that circumscribe organisational action" (ibid:206); interactions are "packages of information, resources, and media of exchange that organisation members mobilise to engage with members of affiliated organisations" (ibid:207); and identities are "avowed presentations of the self and ascribed profiles as an individual or as a collective entity" (ibid:213). For this study, users spanning a range of professional, organizational, geographical and contextual backgrounds were approached for interviews.

Users related to marine IS may not just have different interests in and requirements for IS. They may understand, interpret and give meaning to similar requirements including desirable data attributes - differently, complicating RE processes led by IS developers and leading to potentially inadequate or dysfunctional IS. In the next 


\section{Chapter 3}

section we start to build a conceptual framework for investigating interpretations and definitions of desirable data attributes of distinct users and user groups.

\subsection{Meaning systems}

Anthropologist James Spradley developed a step-wise method to elicit and analyze cultural knowledge by prompting informants to describe their culture in their own terms (Spradley, 1979). Spradley defined culture as "the acquired knowledge that people use to interpret experience and generate social behaviour" (ibid:5). Spradley's overall goal was to understand culture from an insider's point of view, by discovering how these insiders conveyed meaning to things, people, concepts, processes and actions in their everyday life. As cultural meaning is generated by the use of symbols, and language is the principal symbol system that encodes cultural meaning in all societies, Spradley focused on semantics, the analysis of meaning in linguistic expressions. In our study, we will apply his approach specifically to analyze meaning in cultures of marine IS users and their organizational setting.

Following Spradley, the starting point of our framework are salient domains identified within cultural knowledge of IS users. A domain is a symbolic category that includes other categories; hence, it is a collection of categories that share a relationship through at least one feature of meaning. Three elements of a domain are crucial. The first element is a cover term, a category of cultural knowledge that covers other terms of the domain. The second element is what Spradley called the included terms, or folk terms, which belong to the same domain but in a specific relation to the cover term. The third element of a domain is a semantic relationship, or a linguistic expression that links a cover term to all folk terms in its domain. For instance, in the domain marine life, fish is a cover term in English for various species such as cod, tuna and grouper, which are the included or folk terms. If someone foreign to the culture would ask, "What is a grouper?" a likely definition would be "A grouper is a kind of tropical saltwater fish", whereby the concept grouper is linked to the concept (tropical saltwater) fish by means of the semantic relationship is a kind of.

Spradley developed a detailed method to identify domains, cover terms and associated folk terms articulated by informants during interviews. He called this 
method domain analysis. ${ }^{3}$ The most crucial aspect of domain analysis is to select a single semantic relationship to locate concepts in the same meaning category. Systematic studies on the role of semantic relationships in the creation of meaning suggest that a limited number of these occur in all human cultures. Spradley proposed a set of nine universal semantic relationships as tools to discover semantic domains (Table 3.1).

Domain analysis is complemented by a taxonomic analysis and a componential analysis. The goal of performing a taxonomic analysis is to discover the internal structure of a domain. This is accomplished by looking for similarities between different folk terms, grouping folk terms in subsets, and then mapping the relationships between the subsets. A componential analysis aims at an in-depth study of selected terms by using various semantic relationships to find all characteristics related to these terms. It involves searching for contrasts - in our study, between meanings articulated by different IS users - to obtain greater detail of the meaning of the terms under scrutiny.

Parallel to his in-depth analysis of selected domains, Spradley aimed for an overview of the culture under study by searching general cognitive principles that bind parts together and organize cultural meaning systems. This is referred to as cultural theme analysis. A cultural theme is defined as "any cognitive principle, tacit or explicit, recurrent in a number of domains and serving as a relationship among subsystems of cultural meaning [...] A cognitive principle is something that people believe, accept as true and valid" (ibid:186). Cognitive principles may appear as assertions, folk sayings, mottos, proverbs or recurrent expressions such as "publish or perish" in academic circles. However, most cultural themes are not articulated but remain tacit knowledge. The researcher then has to uncover the cultural principles that guide interpretations and meaning across domains by (in our case) marine IS users. Cultural principles do not only guide meaning but also IS user's behaviour.

Lamb and Kling's (2003) user as social actor model can bridge the analysis of meaning and interpretation at the individual level to the cultural theme analysis at the organizational/institutional level. Bringing in the context of organizational/institutional dimensions can help to explain and understand how an

\footnotetext{
3 Although also based on semantics, domain analysis as known in library and information science (Hjørland and Albrechtsen, 1995) and software engineering (Neighbors, 1980) are distinct from Spradley's domain analysis. The usage of the term domain analysis in ISD refers to a specific knowledge area (discipline, business process, etc).
} 


\section{Chapter 3}

individual user gives meaning and interprets terms, and how groups of individuals give similar or different meanings/interpretations to cover terms.

Table 3.1 Nine universal sematic relationships (according to Spradley, 1979: 111).

\begin{tabular}{|l|l|}
\hline Name & Semantic relationship (X is folk term; $Y$ is cover term) \\
\hline Strict inclusion & $X$ is a kind of $Y$ \\
\hline Spatial & $X$ is a place in $Y, X$ is a part of $Y$ \\
\hline Cause-effect & $X$ is a result of $Y, X$ is a cause of $Y$ \\
\hline Rationale & $X$ is a reason for doing $Y$ \\
\hline Location for action & $X$ is a place for doing $Y$ \\
\hline Function & $X$ is used for $Y$ \\
\hline Means-end & $X$ is a way to do $Y$ \\
\hline Sequence & $X$ is a step (stage) in $Y$ \\
\hline Attribution & $X$ is an attribute/characteristic of $Y$ \\
\hline
\end{tabular}

\subsection{Methodology}

The employed methods for data collection and data analysis to interpret meanings of desirable data attributes follow a grounded theory approach (Glaser and Strauss, 1967) using ethnographic techniques (Spradley, 1979).

Primary data sources consisted of semi-structured interviews (average length $53 \mathrm{~min}$, range 20-97 min; conducted in the period July 2010-August 2011) of key informants that use IS related to MPAs in eight countries spread across the temperate, subtropical and tropical regions in both the developed and developing world. Most interviews were conducted by telephone, 5 interviews were conducted face-to-face (one was a group interview) and one by e-mail. The total number of informants interviewed was 35. Data collection consisted of two distinct phases. The first phase in the summer of 2010 was exploratory and served the purpose of identifying salient domains in IS by asking primarily descriptive questions (Spradley, 1979). After analysis of those interviews, the second phase (2011) targeted more specifically the 
components of the domains and the number of MPAs was narrowed down to six (in order to facilitate locating informants by a combination of snowball and theoretical sampling).

Interviews in the first phase were not taped, but summaries were sent to informants for content verification. All interviews in the second phase were taped, transcribed and the text imported into Atlas.ti, where coding was carried out to facilitate analysis. Secondary data sources included websites of the MPAs, universities, NGOs and government agencies; and scientific and grey literature (MPA management plans, policy documents and other official documents pertaining to data or IS of the MPAs). Semantic analysis was conducted on interviews alone.

Design of the data collection instrument was informed by a review of the data (quality) management literature (Panian, 2009; Pipino et al., 2002; Wand and Wang, 1996; Wang, 1998; Wang et al., 1993; Wang et al., 1995; Wang and Strong, 1996). Panian (2009) lists a set of six desirable data attributes: data availability, accessibility, quality, consistency, security and auditability. This basic set of attributes, which intuitively encapsulated the main issues related to data raised in the MPA literature, seemed more useful for the preliminary conceptual framework underpinning our interviews than categorizations provided by data quality scholars. The latter consider all conceivable desirable data attributes as components of the single domain "data quality" and list dozens of terms with varying definitions. Wang and Strong's (1996) framework classifies data quality attributes under the labels intrinsic, contextual, representational and accessibility data quality, which is useful for analytical purposes but seemed too complex to guide instrument design. Besides, our goal was to uncover informants' own mental models regarding the attributes studied without imposing our classifications or constructs a priori. Thus, as a starting point we opted for Panian's terminology, except for data auditability, which was left out in order to keep the interviews manageable (the researchers anticipated that this term would provoke some confusion or anxiety among informants). The topic list with examples of questions asked during interviews is shown in Appendix 1.

The selection of informants proceeded by convenience sampling in the first phase (found through our academic network and through Internet searches) and moved into purposeful sampling in the second phase. In the latter phase, informant 


\section{Chapter 3}

identification was carried out drawing from the literature on stakeholder analysis (Reed et al., 2009). Our aim was to select a small, but representative sample of relevant informants associated to each MPA. The approach used was an iterative one, considering both the main management issues/problems (i.e. coral reef/bird/fisheries/visitor monitoring, etc.) in each MPA and the key individuals or groups involved in each issue. The information necessary for this initial step was derived from a review of the literature and of the MPAs' official websites. Once the main informant group categories were distinguished, in this case based on sectors (academic, government, voluntary and natural resource management sectors), individuals belonging to each category were identified and approached by e-mail. A combination of this approach with snowball sampling was conducted until at least three of the four informant group categories in each MPA had at least one respondent. Appendix 2 provides an overview of group categories, the MPAs they were associated with and the total number of individuals interviewed.

\subsection{Results}

\subsubsection{Domain analysis}

The first phase interviews, and relevant literature, were analyzed to identify salient domains, selecting five desirable data attributes as cover terms of domains: data availability, accessibility, quality, consistency and security. An expanded and detailed domain analysis was conducted using all interviews with all informants, instead of analyzing interviews of each informant group separately. This analytic strategy was selected in order to uncover all meanings and conceptualizations assigned to each cover term by informants from distinct contexts.

Table 3.2 shows that all cover terms encompass more than one meaning (see third column). Semantic relationships "allow speakers of a particular language to refer to all the subtleties of meaning connected to its folk terms" (Spradley, 1979: 108). Indeed, the different semantic relationships used to link the elicited folk terms to each cover term indicate distinct meaning categories. These categories broadly delineate the internal structure of each domain, serving as basis for the taxonomic analysis. Two semantic relationships were found most useful: "is a reason for" and "is a way to". In addition, "is a characteristic of", and "is a cause of" were also useful semantic relationships. The use by informants of these semantic constructions to talk about data attributes is relevant for the thematic analysis (Section 3.5.3). 


\subsubsection{Taxonomic analysis}

The taxonomic analysis for the cover term data availability is presented as an illustration in Figure 3.1. Due to space limitations, detailed taxonomies of the other cover terms are not given in individual figures but are basically delineated in Table 3.2 and described next. Two distinct meanings of the cover term data availability emerged from the analysis: one concerning the existence or presence of data and the other referring to the obtainability of data. Regarding existing data, folk terms used referred to its amount and to factors that enable or constrain data production activities. Regarding obtainability of data, mechanisms for dissemination were mentioned. Similarly, two distinct meanings were revealed by the respondents to questions on the cover term data accessibility. The first and most commonly used was the obtainability of data (hence, overlapping with one interpretation of data availability). Folk terms used referred to the driving forces to share or not to share data. The second meaning referred to data being comprehensible. Folk terms referred, on one hand, to data organized or reported so that it can be understood and easily used, and on the other hand to data analysis capacity.

Respondents ascribed the cover term data quality with several dimensions, which collectively render data suitable for its intended use. For respondents to consider data as possessing high quality, various conditions must be met throughout data generation processes, which include the sampling design process, the production process and the interpretation process. Robust design and production processes using standard procedures for data collection, documentation and storage enhance the comprehensibility of data (hence, this meaning is linked to data accessibility). Moreover, a data collection program was considered of good quality if it produces relevant data in an efficient manner. Three meanings of the cover term data consistency could be distilled from the respondents. ${ }^{4}$ The first one referred to a lack of contradiction, and data being consistent with reality or with what is expected. The second meaning was related to data that are constant or regularly and evenly occurring, both spatially and temporally (hence, connected to the concept of availability). The third meaning referred to data achieving such a level of performance that it does not vary greatly in time, owing to the application of established methods and/or by being produced and handled by competent groups

\footnotetext{
${ }_{4}$ Various informants were unsure what the terms data consistency and data security referred to and asked for clarification during interviews. They were prompted to provide their own interpretation of the terms. Attempts to revisit the domains were made later during the interviews to elicit informants' own conceptions by asking them to provide examples related to their own experience.
} 


\section{Chapter 3}

of people. This means that data possesses consistent quality (hence, linked to the cover term data quality).

Finally, two meanings of the cover term data security were distinguished. The first relates to secure storage or the protection of the integrity and long-term preservation of data to ensure data remain obtainable (hence, partly overlapping with the terms data availability and accessibility). The second meaning refers to secure ownership, or the protection of data property. Because the underlying motivation of ensuring secure data ownership is to protect data from being accessed by others without authorization, this meaning is linked to the cover term data accessibility. Figure 3.2 shows the relationships between all the meanings assigned by informants to the five desirable data attributes.

Based on the taxonomies of each cover term, a comparative analysis was conducted across all users to identify commonalities in the conceptualizations of different desirable data attributes (cover terms) among users. Main findings are that the term data availability was used interchangeably with data accessibility and that social networks based on trust and transparency are crucial factors that enable improved availability and accessibility through more efficient data collection and exchange. Furthermore, MPA websites were referred to by most informants as important doorways to existing data. In terms of data availability, the role of volunteers was recognized as key in data collection, and limited resources as constraining data collection activities in all MPAs.

As for data accessibility, all informants recognized the value of standardized procedures for data collection, storage and analysis in improving the obtainability and comprehensibility of data. However, data producers also recognized the obstacles in their daily practices to achieve this standardization, which included lack of resources (e.g. time), lack of communication and coordination with other data providers, donor considerations (e.g. choice of monitoring protocol due to attached funding) or simply a lack of attention or forgetfulness (e.g. individual scientists forgetting to document metadata). The manner in which data are communicated, in particular scientific results, was also seen as crucial in making data comprehensible to non-scientific audiences. Finally, from the perspective of data users, access to trusted experts was considered essential for better interpretation and/or evaluation of the data. 
Information systems for marine protected areas

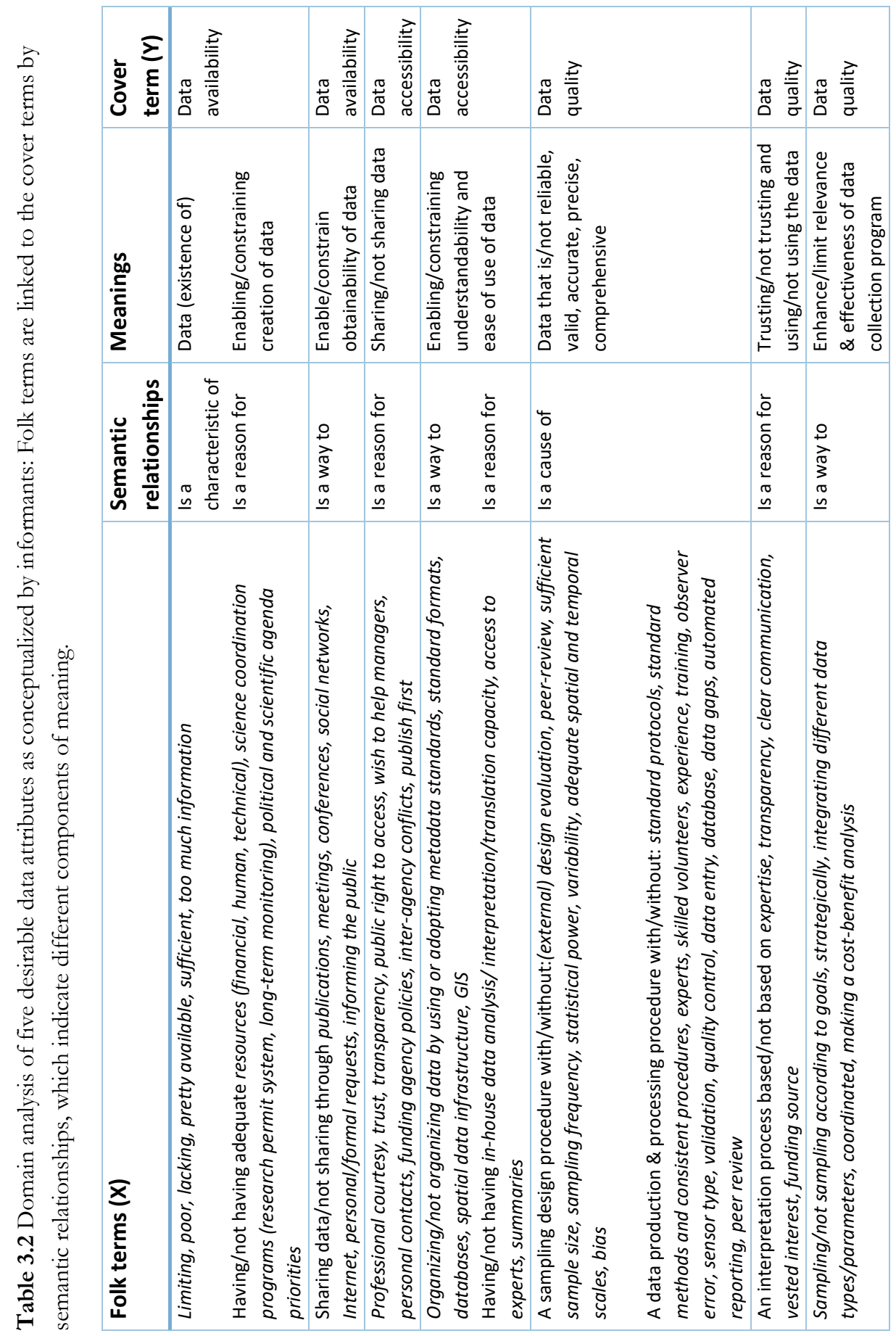


Chapter 3

\begin{tabular}{|c|c|c|c|c|c|c|c|c|c|}
\hline 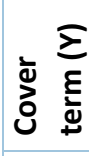 & 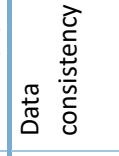 & 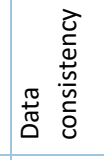 & & 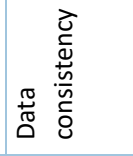 & & 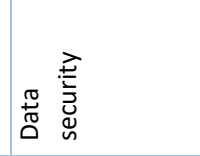 & & 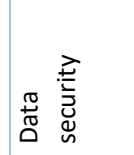 & \\
\hline 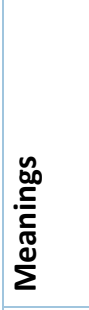 & 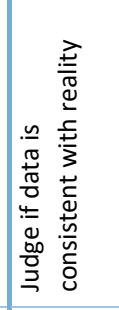 & 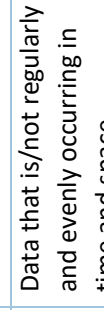 & & 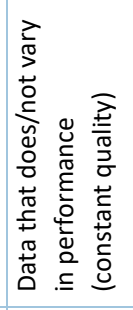 & & 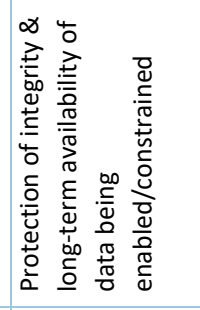 & 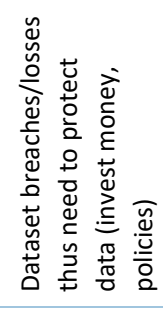 & 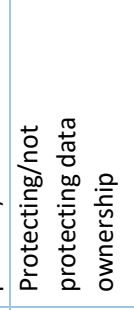 & \\
\hline 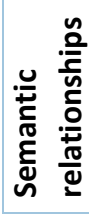 & 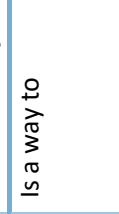 & 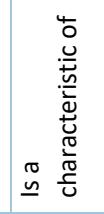 & 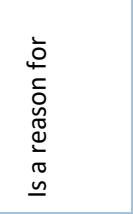 & 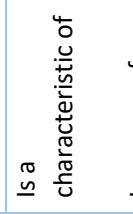 & 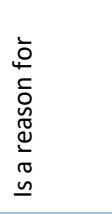 & 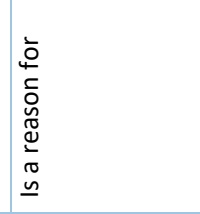 & 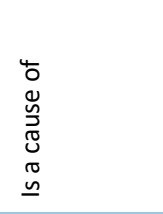 & 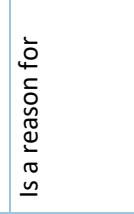 & \\
\hline 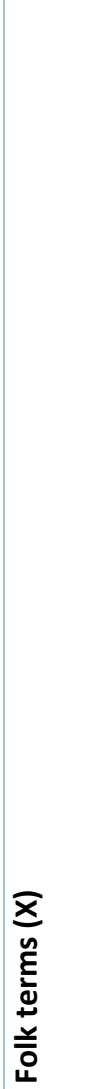 & 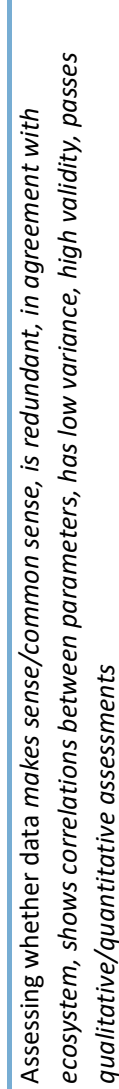 & 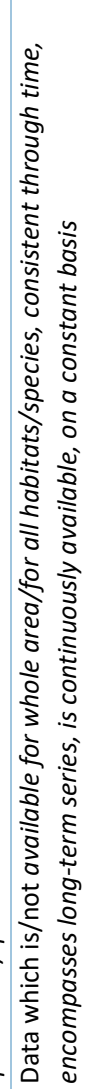 & 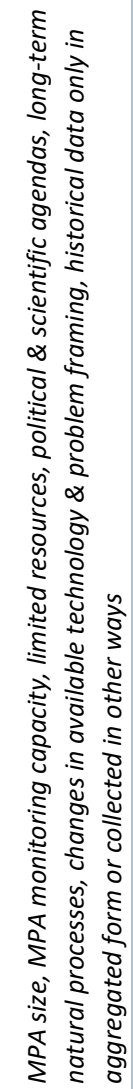 & 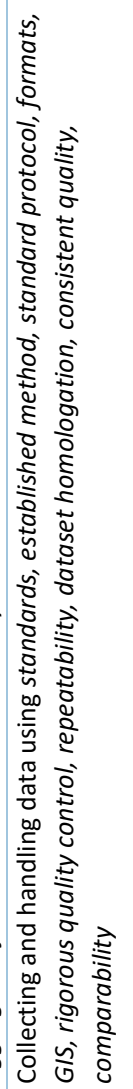 & 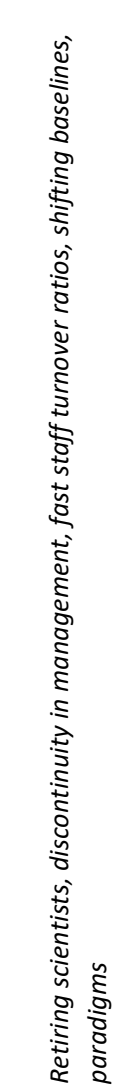 & 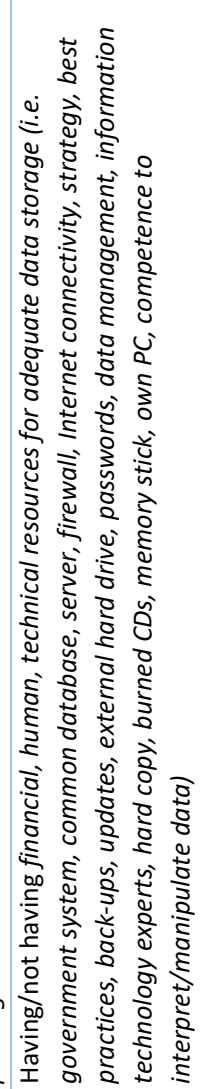 & 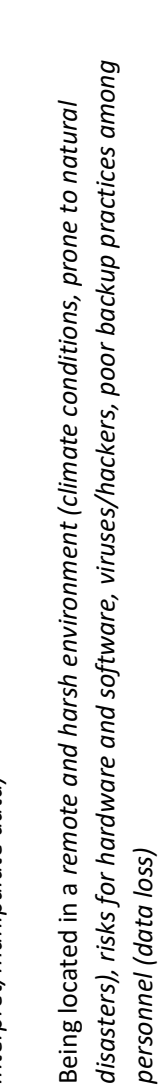 & 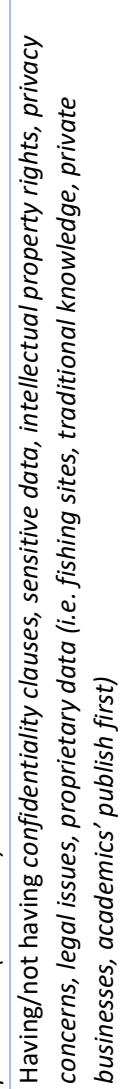 & \\
\hline
\end{tabular}


Information systems for marine protected areas

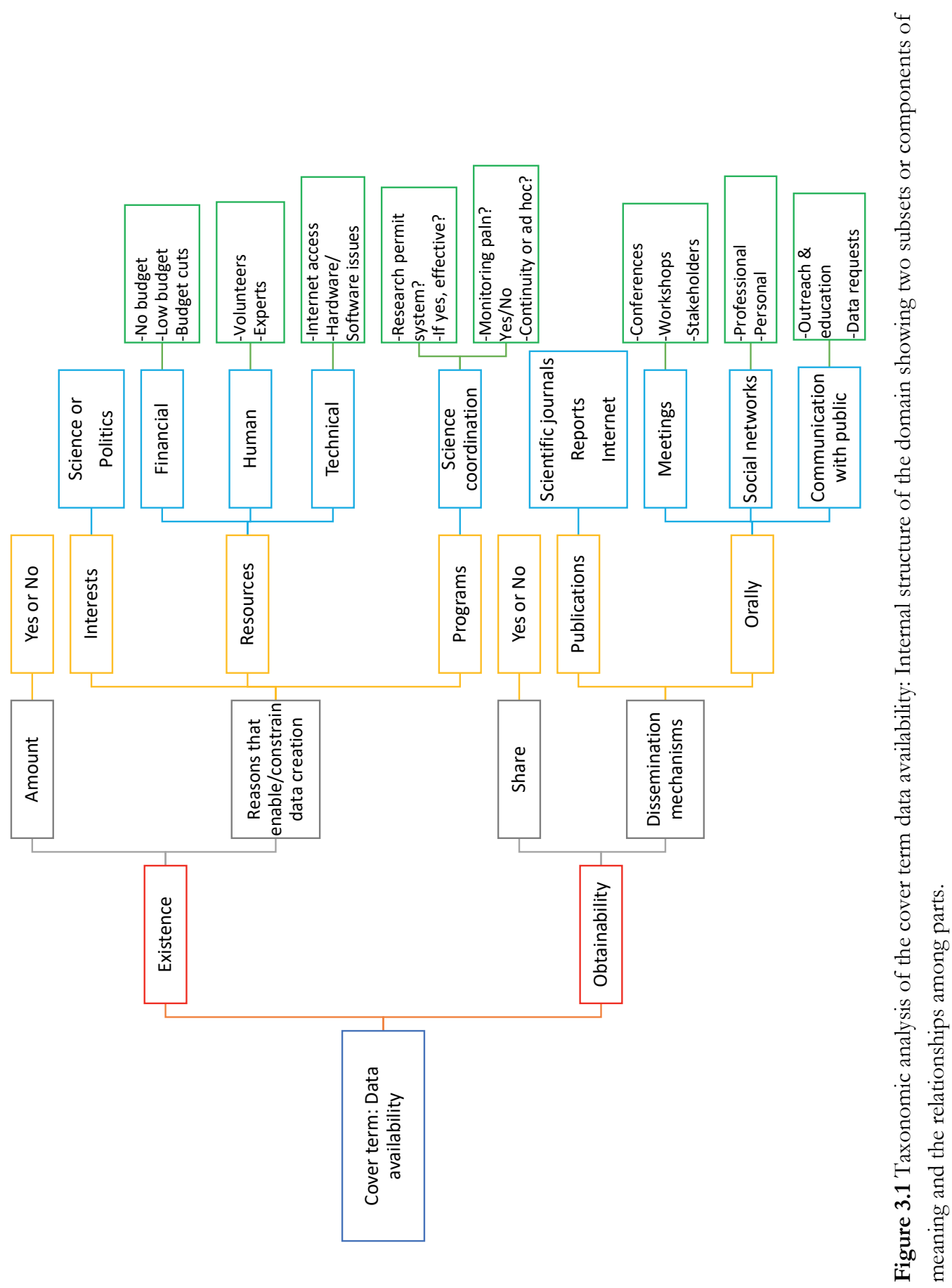


Chapter 3

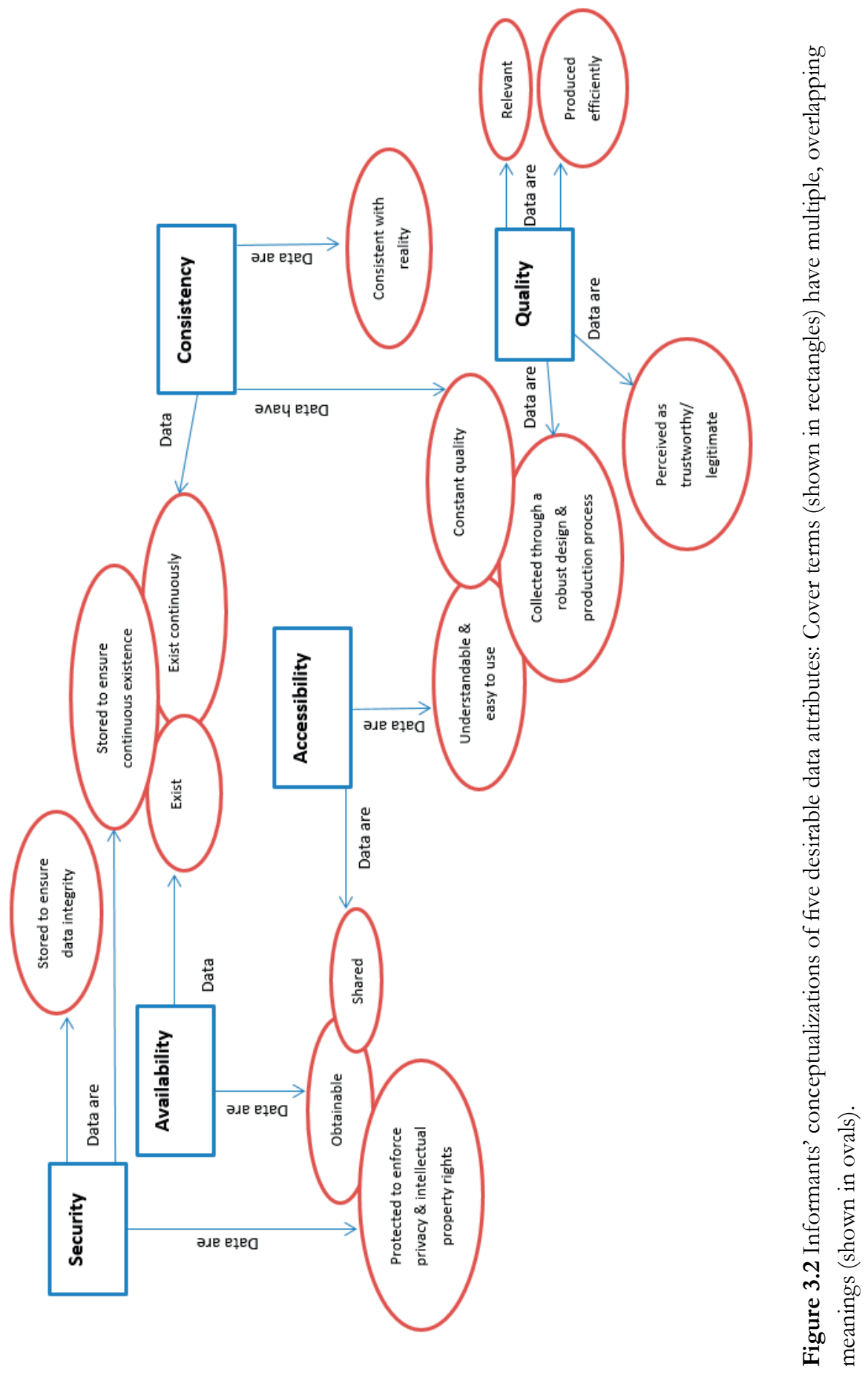


Information systems for marine protected areas

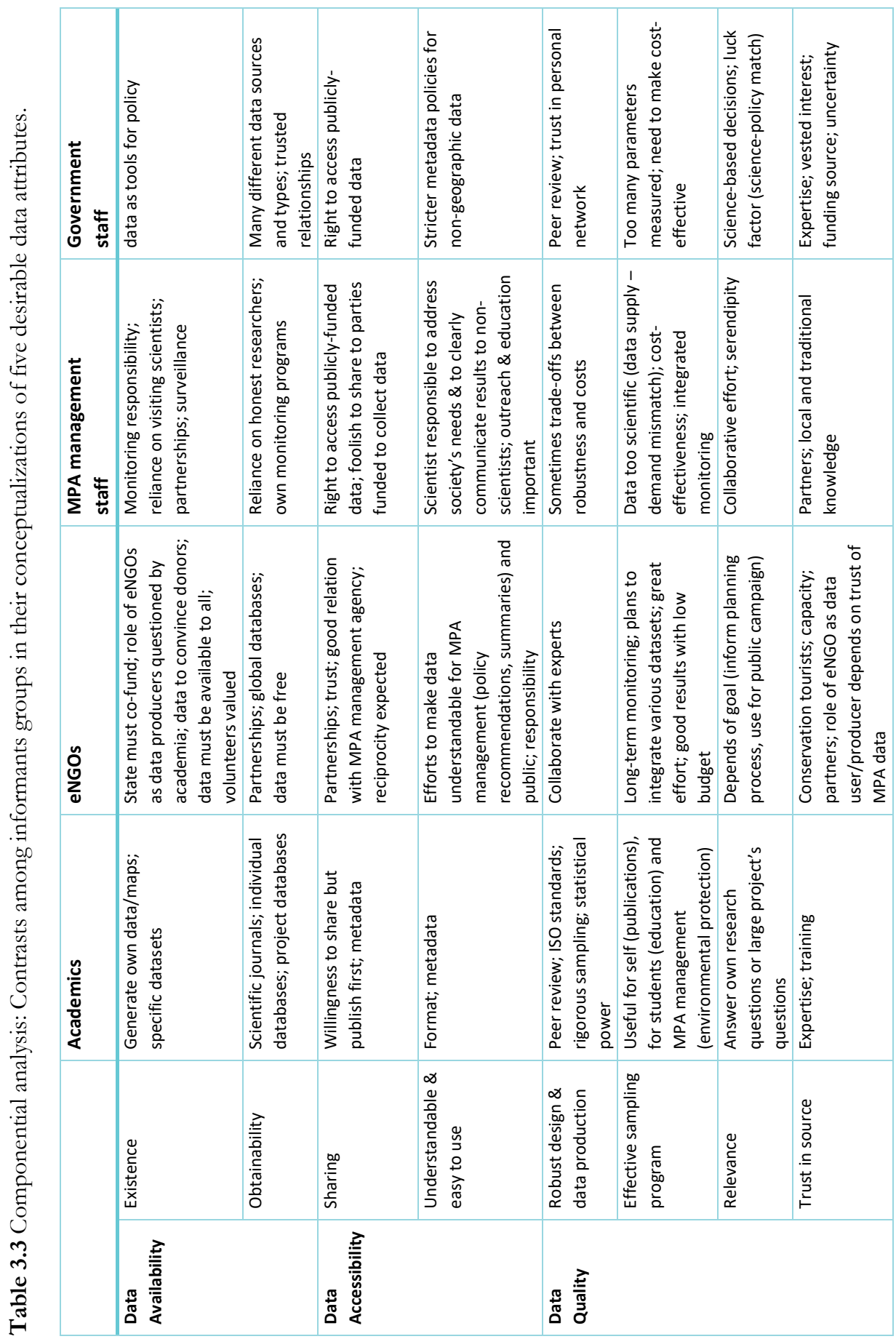


Chapter 3
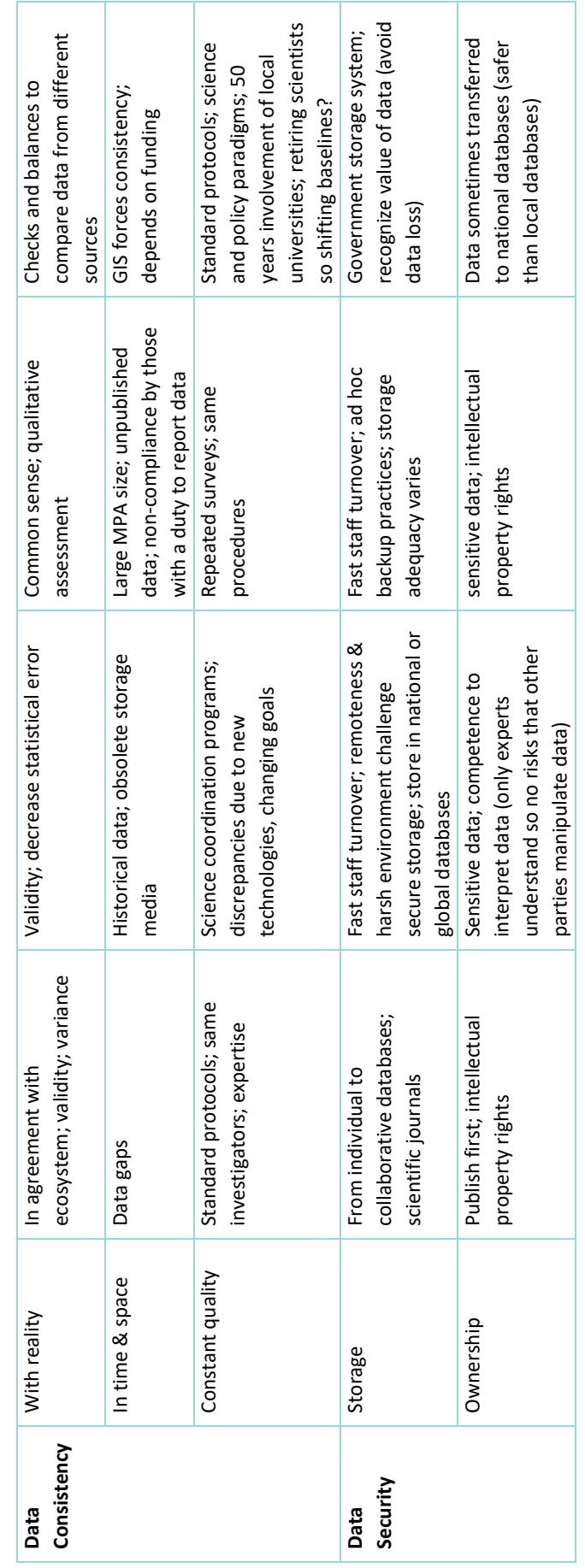
The terms data quality and data consistency were also used in overlapping ways across informant groups when referring to 'consistent quality' of the data, which according to informants depended on the use of standard protocols. A common response across informant groups when speaking of data quality was the role of mutual trust and transparency of practices along the data processing chain in conferring a status of 'good quality' to the data. Most informants conceptualized data consistency as data without gaps in time or space. The term data security was interpreted across groups as the combination of all individual practices that secure data against loss, theft, intentional or unintentional corruption, and/or unauthorized access. Making back-ups and trusting each other "in doing the right thing" were most common responses.

\subsubsection{Componential and thematic analyses}

Spradley's approach was adapted by changing the level of the componential analysis from the individual to the group level. The purpose was to analyze whether and how conceptualizations of desirable data attributes differ between user groups, which are considered to belong to distinct organizational cultures. Differences were assessed by looking closely at the folk terms elicited from all group members and determining whether a unique component of meaning could be observed that distinguished this group from the others. This means that Table 3.3 shows the entire diversity of responses and not the "most common" responses. In addition, in-depth analysis of one dimension of meaning of the cover term data availability (obtainability) is shown in Table 3.4. This example shows details of the preferred mechanisms to disseminate data by the various groups, what motivates them to do so and what the perceived challenges are. To complement and explain the findings of the componential analysis, a cultural theme analysis was carried out.

What are the conceptual themes that different user groups apply to connect the cover terms or domains? Themes can be detected by examining the dimensions of contrast recurring in several domains. Among academics, a recurring dimension of contrast had to do with the notion of scientific credibility (i.e. rigorous versus ad hoc data collection). Among MPA managers frequent dimensions of contrast were related to the relevance and cost-effectiveness of data for management (i.e. data too scientific versus useful for management goals; trade-offs between data quality and costs). For environmental NGOs contrast dimensions were the roles played by eNGOs and their responsibilities towards all different partners (i.e. eNGO as data 


\section{Chapter 3}

provider versus eNGO as data user; as contractor versus client versus equal partner). Frequent dimensions of contrast for government staff were management of uncertainty and conflict (i.e. trust versus mistrust of data source; trade-offs between socio-economic and ecological values).

Table 3.4 In-depth componential analysis: Kinds of data dissemination mechanisms (Cover term: data availability, component of meaning: obtainability)

\begin{tabular}{|c|c|c|c|}
\hline \multirow{2}{*}{$\begin{array}{l}\text { Contrast set: Folk } \\
\text { terms related to data } \\
\text { dissemination } \\
\text { mechanisms }\end{array}$} & \multicolumn{3}{|c|}{ Dimensions of contrast } \\
\hline & Mainly done by & Motivations & Challenges \\
\hline $\begin{array}{l}\text { Publication in science } \\
\text { journals }\end{array}$ & Academics & $\begin{array}{l}\text { Credibility; career } \\
\text { requirement }\end{array}$ & $\begin{array}{l}\text { Mentioned by MPA managers: } \\
\text { Data 'too scientific' }\end{array}$ \\
\hline Publication in reports & $\begin{array}{l}\text { NGOs; MPA } \\
\text { managers }\end{array}$ & $\begin{array}{l}\text { Transparency; reporting } \\
\text { obligations }\end{array}$ & $\begin{array}{l}\text { Mentioned by MPA managers: } \\
\text { may take long to obtain data, } \\
\text { may be too scientific }\end{array}$ \\
\hline Publication on Internet & $\begin{array}{l}\text { NGOs; MPA } \\
\text { managers }\end{array}$ & $\begin{array}{l}\text { Transparency, efficiency, legal } \\
\text { requirement }\end{array}$ & $\begin{array}{l}\text { In remote places: inadequate } \\
\text { Internet connectivity }\end{array}$ \\
\hline Orally in conferences & Academics & $\begin{array}{l}\text { Career requirement; } \\
\text { credibility }\end{array}$ & $\begin{array}{l}\text { Mentioned by MPA managers: } \\
\text { Data 'too scientific' } \\
\text { Mentioned by Academics: low } \\
\text { participation by decision-makers }\end{array}$ \\
\hline Orally in workshops & All groups & $\begin{array}{l}\text { Transparency; trust; } \\
\text { evaluation }\end{array}$ & \\
\hline $\begin{array}{l}\text { Orally in stakeholder } \\
\text { meetings }\end{array}$ & All groups & $\begin{array}{l}\text { Transparency; trust; } \\
\text { effectiveness (participatory } \\
\text { approach) }\end{array}$ & $\begin{array}{l}\text { Match between way data is } \\
\text { communicated and audience } \\
\text { (i.e. scientific jargon) }\end{array}$ \\
\hline Professional networks & All groups & $\begin{array}{l}\text { Data provider perspective: } \\
\text { Data collection and handling } \\
\text { is costly hence collaboration } \\
\text { is efficient; }\end{array}$ & $\begin{array}{l}\text { Retiring scientists; fast staff } \\
\text { turnover }\end{array}$ \\
\hline Personal networks & All groups & $\begin{array}{l}\text { Data user perspective: access } \\
\text { to trusted experts }\end{array}$ & \\
\hline $\begin{array}{l}\text { Communication to } \\
\text { public: outreach \& } \\
\text { education } \\
\text { (summarized) }\end{array}$ & $\begin{array}{l}\text { MPA managers; } \\
\text { NGOs }\end{array}$ & Transparency; advocacy & $\begin{array}{l}\text { Historic data in obsolete carriers; } \\
\text { limited resources; } \\
\text { data sharing obstacles } \\
\text { (proprietary data, etc) }\end{array}$ \\
\hline $\begin{array}{l}\text { Communication to } \\
\text { public: } \\
\text { Raw data requests }\end{array}$ & $\begin{array}{l}\text { Academics; } \\
\text { government } \\
\text { scientists }\end{array}$ & $\begin{array}{l}\text { Transparency; legal } \\
\text { requirements }\end{array}$ & \\
\hline
\end{tabular}


Lamb and Kling's (2003) user as a social actor model, where the user is characterized by his/her interactions, environment, affiliations and identities, was useful to guide the thematic analysis. A common thread in the interviews was that informants legitimized their data practices by referring to their environments or context, especially organizational and institutional factors, which enabled or constrained them in their daily data work. The frequent semantic relation "is a reason for" and "is a cause of" indicate a preoccupation of informants with justifying their actions and interactions. For instance, limited financial, technical and human resources were mentioned as main obstacles for adequate data production and handling, which in the case of some MPAs translated in reliance on volunteers, eNGOs or visiting scientists to fulfil or complement MPA management information needs.

These interactions and the dimensions of contrast named above reflect the inherent tensions within and between different institutional/organizational settings in which informants are embedded through their various affiliations. For example, an informant belonging to an eNGO that acts as data provider for the governmental MPA management agency in country A was challenged by a university scientist, who claimed that conducting research was the remit of universities and not of NGOs. The university scientist in fact questioned the capacity of eNGOs to produce unbiased, good quality data for the MPA. An informant from an eNGO with the mandate to provide scientific information for MPA management in country $B$ expressed the tensions of fulfilling various responsibilities:

It's difficult for us because we have a double role - as a scientific institution we should be able to publish and continue to produce useful, relevant data but at the same time we're in an auxiliary position when you need to continuously be available to address any particular questions or problems going on at the [MPA] and be very flexible, and all under a very restricted funding environment... (pers. comm., 2011).

Further, informants held themselves and each other accountable for (not) meeting their responsibilities towards desirable data attributes. For example, academics had high regards for data that meet requirements of peer-reviewed publications, considering this as a measure of data quality and thus of their own scientific quality. From the point of view of government officials or MPA managers, on the other hand, the quality of the data depended on trust of the source, its relevance to addressing the problem and whether data were succinctly and timely communicated to non-scientists. With these interpretations and claims, informants sought to 


\section{Chapter 3}

validate their identities and preserve the identity of the organizations they represented.

The main common themes distilled from the thematic analyses were the management of legitimacy by informants and their accountability relations. Legitimacy is defined as "a generalised perception or assumption that the actions of an entity are desirable, proper or appropriate within some socially constructed system of norms, values, beliefs and definitions" (Suchman, 1995:574). Two key questions are usually addressed regarding legitimacy: legitimacy for what and legitimacy in the eyes of whom (ibid). Suchman (ibid) posits that the main reason why an organization seeks legitimacy is to ensure its continuity and credibility, and that the legitimation dynamics of an organization can be understood by examining both the internal perspective, so the views of its own members regarding their legitimation efforts, and the external perspective, so the viewpoint from external observers. Table 3.5 illustrates how informants in each user group viewed their own actions and the actions of others in the context of legitimate data practices.

An organization's legitimacy is influenced by its accountability (Slim, 2002). Accountability is the "responsibility to answer for particular performance expectations to specific stakeholders" (Brown and Jagadananda, 2007:9). Because organizations may be subjected to accountability claims from different types of stakeholders in various performance settings, a relational element links those held accountable to those who have the right to hold to account. For instance, eNGOs may owe accountability upward to donors and legislators who endorse them, downward to beneficiaries including local communities and future generations who may benefit from a protected environment, outward to peers and partners who collaborate in projects, and inward to staff and volunteers who dedicate their time and talents to the organization (Brown and Jagadananda, 2007; Jepson, 2005). Four core mechanisms have been identified in the literature to manage accountability claims: transparency, participation, evaluation and complaints and redress mechanisms (ibid). Table 3.6 illustrates the relations and mechanisms used by the different informant groups to manage accountability claims in the context of data practices. 


\subsection{Discussion}

A large variety of definitions and interpretations of desirable data attributes exists in the IS literature. Panian (2009) asserts that data availability, accessibility, quality, consistency and security are desirable data attributes for a firm, but the definitions he provides are somewhat narrow and circular (ibid:1065). Others have provided multi-dimensional definitions of the encompassing domain data quality; for instance Pipino et al., (2002) list sixteen dimensions of data quality including accessibility, appropriate amount of data, consistent representation and security, and Wand and Wang (1996) list twenty-six dimensions based on a literature review. Our study moved beyond the variation in scientific definitions of data attributes in investigating how different users of existing IS in different locations/contexts interpret desirable data attributes and what that means for future IS developers.

Wang and Strong (1996) elicited 179 terms associated to "data quality" from users within the academic (M.B.A. students in the United States) and business sectors; their study diligently captures data users' perspectives, but it does not address the issue of ambiguities or overlapping meanings, nor does it examine the influence of users' backgrounds on their interpretation schemes. The findings of our study show that each cover term studied - each desirable data attribute - has multiple dimensions according to the individual data users themselves and that "organizational" cultures shape how users interpret and give meaning to these terms. At first glance, the often subtle differences between the meanings may seem innocuous. However, during the interviews the ambiguity of these cover terms sometimes led to communication lapses between informants and researchers. It was also clear that informants emphasized different meaning dimensions of the domains and cover terms discussed, depending on his/her role in the data processing chain, the organizational culture she/he belongs to or the MPA context. The assumption of the informant was always that we as researchers shared his/her understanding of the terms. It can be argued that such ambiguities could lead to misunderstandings during requirements elicitation in a realworld ISD project.

A rich picture has been painted of the numerous affiliations between individuals and organizations related to MPAs, all concerned with preserving their identities and 


\section{Chapter 3}

legitimating their activities regarding data, as indicated in Table 3.5. This picture becomes more complex when considering the multiple roles that actors play simultaneously (such as being data producer within one organization and user of data/information generated by other organizations), and the fact that certain organizations with multiple mandates are accountable to a variety of parties, some of which may have incompatible goals or interests, as illustrated in Table 3.6. Potts and Hsi (1997) coined the term contextualism to refer to the necessity to understand the particularities of the context of use and users of IS before deriving the requirements. This study has shown that such a broader (contextual) interpretation of requirements information, akin to a social or ethnographic analysis, could be enacted through the systematic, transparent method that we used. But how credible and transferable are results from such ethnographic and qualitative approaches into desirable data attributes?

Ethnographically-informed methods have been applied in RE studies for decades. Field observations and rich, detailed ethnographic descriptions have proven useful in understanding requirements of users in various work settings (Bentley et al., 1992; Sommerville et al., 1993; Viller and Sommerville, 1999). Systematic reviews of empirical studies on effectiveness of elicitation techniques in gathering information found that both structured and unstructured interviews are the most effective elicitation methods compared to e.g. thinking aloud techniques or prototype-based discussions (Carrizo et al., 2008; Davis et al., 2006). Interviews following ethnographic and grounded theory principles can also best foster the informants' use of their own terms to construct meanings of those terms reflecting their own experiences (Hughes and Wood-Harper, 1999). By using Spradley's techniques to systematically analyze the interviews, valuable and credible insights could be obtained of how distinct meanings are attached to similar cover terms, at both individual and organizational levels. This study also showed that telephone interviews, informed by Spradley's ethnographic interview principles, are a useful method of collecting such data on and from informants in various geographical locations. Sufficient depth and breadth could be obtained for the analysis, which was also confirmed by de Leeuw (1992) in finding no difference between data collection via face- to-face and via telephone surveys (de Leeuw, 1992). 
Information systems for marine protected areas

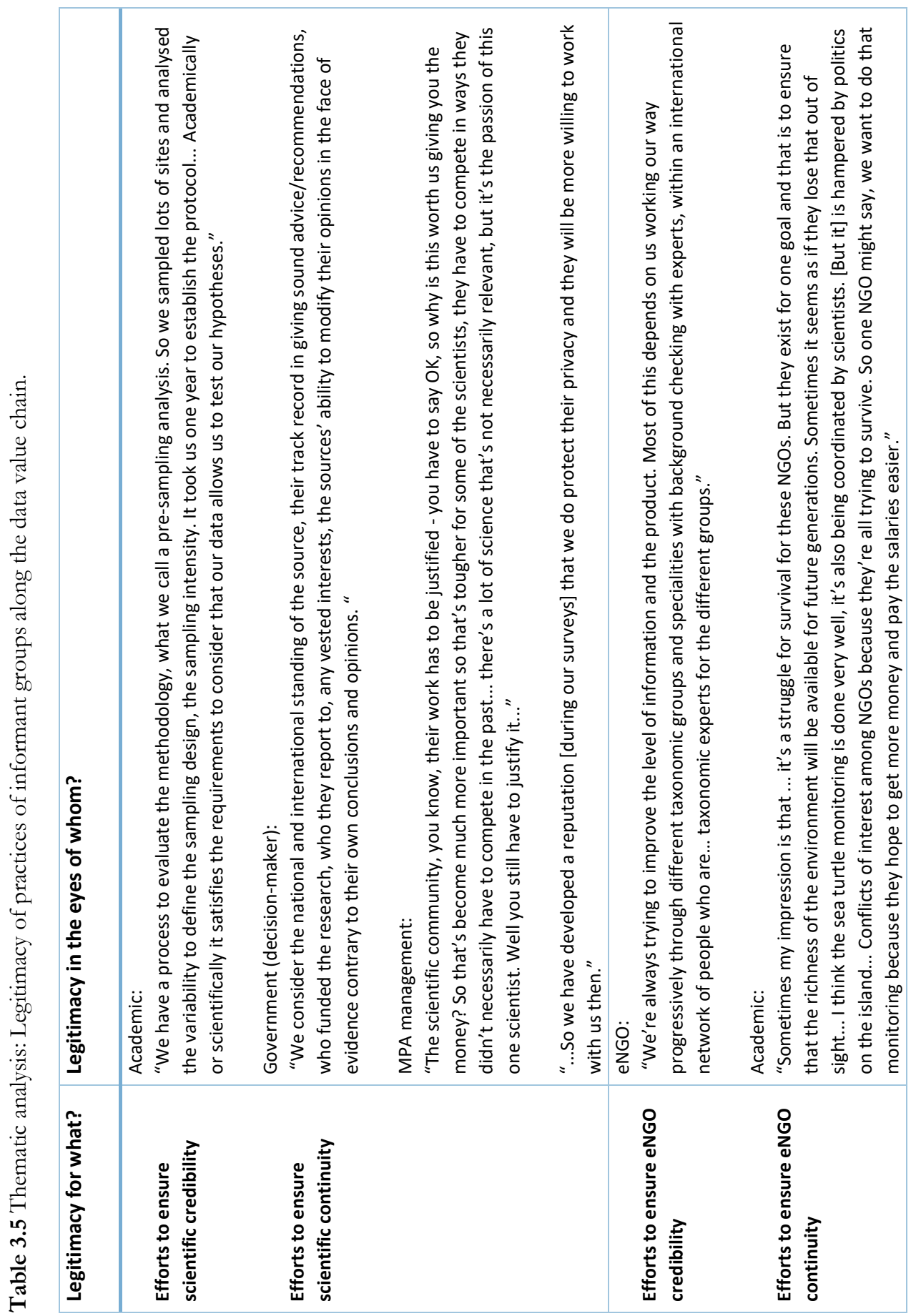


Chapter 3

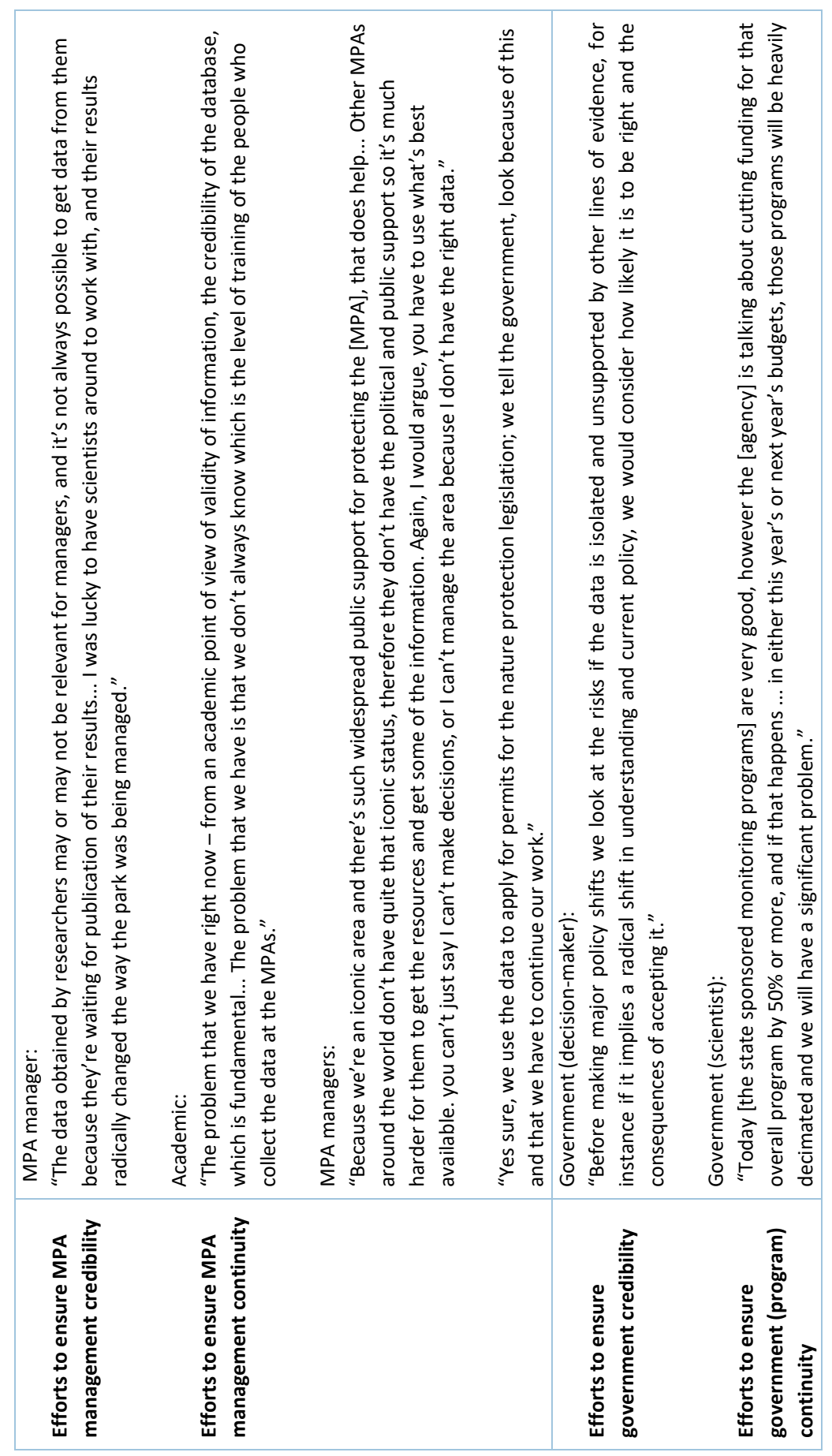


Information systems for marine protected areas

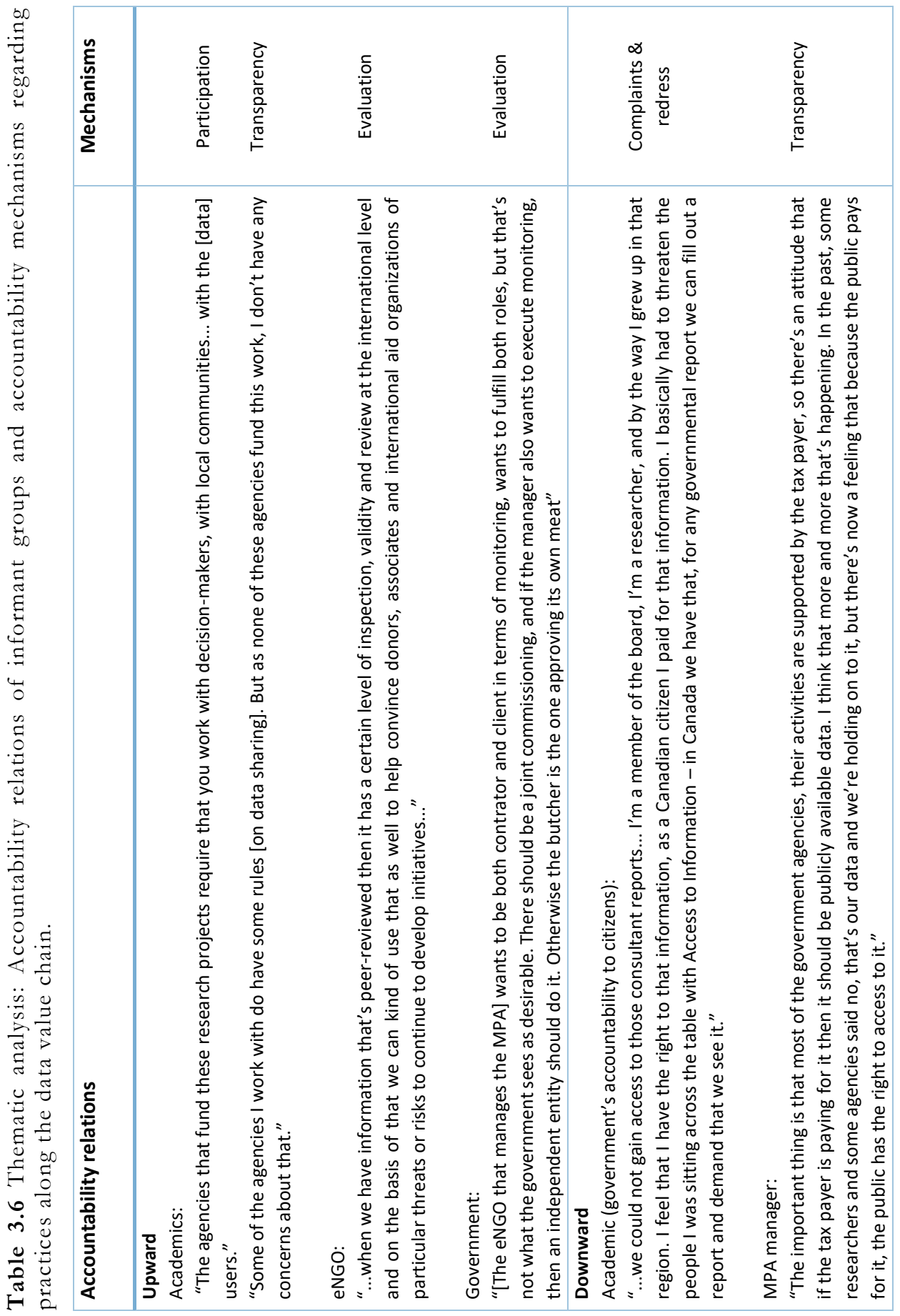


Chapter 3

\begin{tabular}{|c|c|c|c|c|c|c|}
\hline 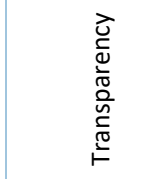 & 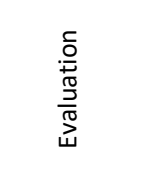 & 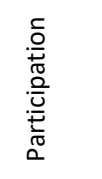 & 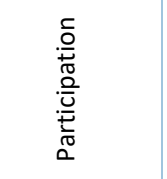 & 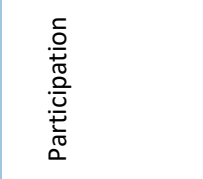 & 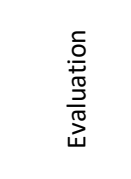 & 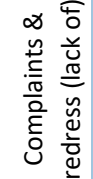 \\
\hline 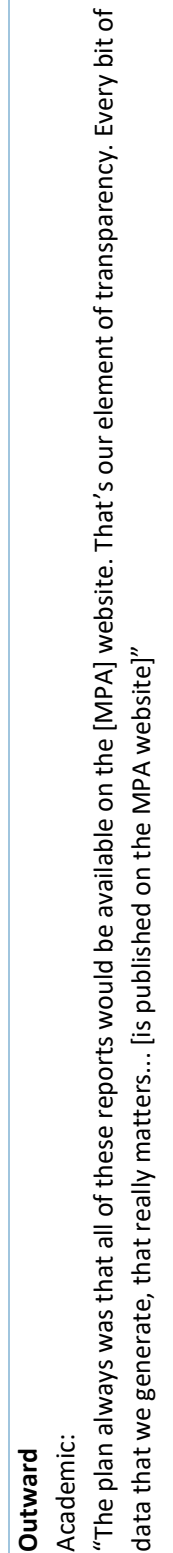 & 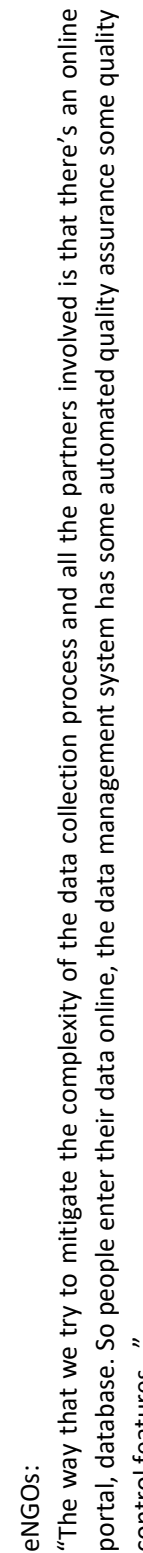 & 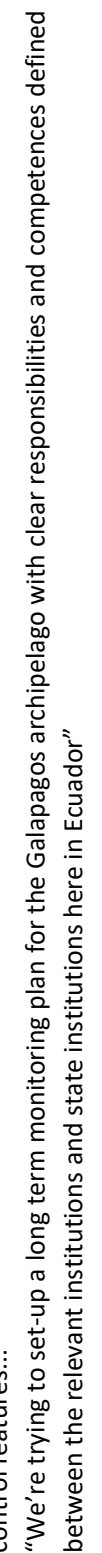 & 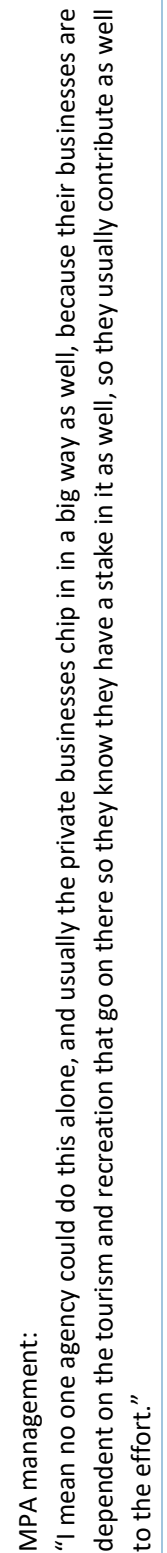 & 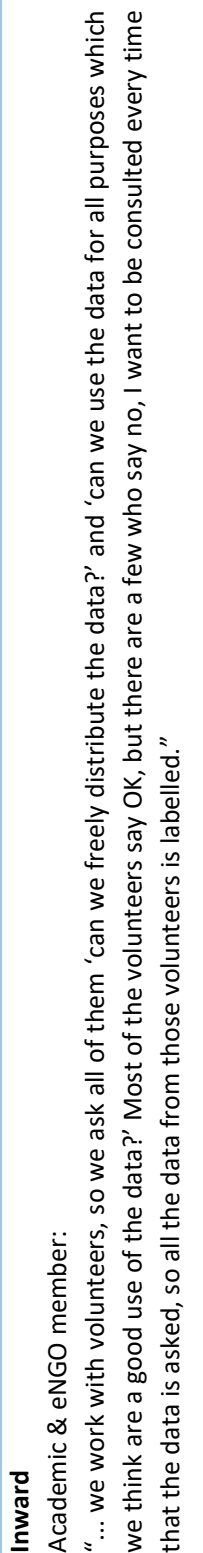 & 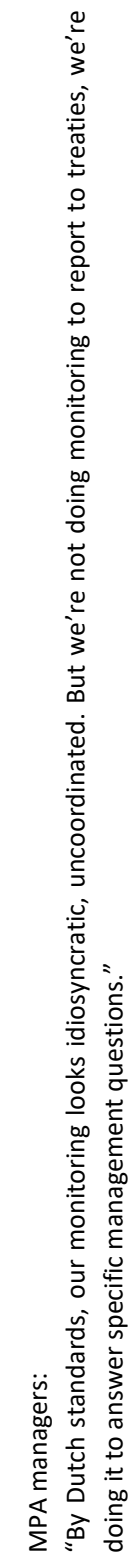 & 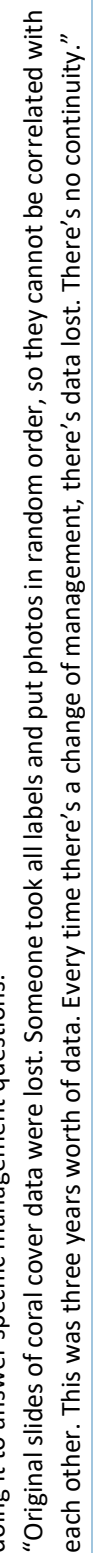 \\
\hline
\end{tabular}


Given the variability in users and the variability in contexts (different MPAs, with different challenges, and different IS) covered in this study, the qualitative findings in interpretations and meaning of desirable data attributes can be considered quite robust and transferable to settings not included in our study. Of course, the specific situation in each MPA ISD project will vary, but despite wide differences in users and in location, size and context of MPAs, various data aspects and requirements yielded consistent responses across informant groups and locations (such as limited resources, importance of volunteers in data collection, standardized procedures in data collection and handling activities, trust and transparency in the human component of IS). Furthermore, our findings pointing to the different knowledge management cultures between groups resonate with what has been reported in the literature on data production and use for natural resource management and governance, notably the science-policy and science-management gaps (McNie, 2007; Roux et al.,2006; van Wyk et al., 2008; Welp et al.,2006) and the IS design-use gap (McIntosh et al., 2011, 2008). In investigating other MPA ISD processes we might find different emphases locally, but not different conclusions on the meaning and interpretation confusions of desirable data attributes, and the roles of legitimacy and accountability as central themes in how users approach data in relation to IS.

The pursuit of "good governance" in natural resource management has prompted calls for more collaborative and participatory approaches to decision-making, including in ISD (Matthews et al., 2011; McCall and Dunn, 2012; McIntosh et al., 2011, 2008). For these attempts to result in adequate IS that are adopted and used satisfactorily, understanding the diversity of user needs, values and perceptions is crucial (Checkland, 2000; Lawrence and Stewart, 2011). Spradley's techniques have been applied in knowledge elicitation for expert systems designed for water management, among other purposes (Bharwani, 2006; Kemp-Benedict et al., 2010), and this study shows that these techniques offer great potential for application in RE for ISD in MPAs as well.

\subsection{Conclusions}

This paper makes two contributions to ISD studies, a substantial and a methodological one. First, substantially the study showed that terms used to express data attributes which are commonly considered as desirable in IS, are interpreted in various ways by different users and user groups. Data availability, accessibility, quality, consistency and security all have multiple and overlapping meanings among users (and user groups). The cultural thematic analysis shed light on the underlying 


\section{Chapter 3}

motivations and preoccupations of the user groups regarding data practices, as explained by their organizational/contextual backgrounds. Legitimacy and accountability were recognised as important principles that steer their actions and interpretations with respect to data attributes.

This ambiguity in the interpretation of data attributes has practical implications for ISD, as misunderstandings both among users and between developers and users easily arise if the terms are not defined and agreed upon during early RE stages. This is even more relevant for MPAs, which have often complex governance settings rife with conflict, where information plays a crucial role in decision-making. As such, conflicting claims on IS goals, boundaries and functionality are to be expected. Clearly, unambiguous communication and interpretation of user needs is the first step towards negotiation of ISD by all groups with a stake in the MPA.

As a second contribution, this paper exemplified the application of Spradley's ethnographic techniques to elicit and analyze informants' interpretations of abstract terms. The study demonstrated that the use of semantic relationships in domain analysis is a powerful tool to map informants' conceptualizations. By performing taxonomic and componential analyses, similarities and differences in conceptualizations among user groups could be systematically uncovered. The series of analyses used created a fuller picture of user group needs than other techniques that tend to focus on finding the most common responses or majority voices among the various user groups (Gallivan and Keil, 2003). The limited componential analysis as applied in this study (i.e. without card sorting or triads), yielded sufficient granularity to identify differences between informant/user groups. Future work using Spradley's contrast elicitation methods could profit from computer-based elicitation techniques, including laddering and RepGrid methods (Crudge and Johnson, 2007; Farinha and DaSilva, 2011; Schultze and Avital, 2011). Finally, including the organizational/ institutional context in the thematic analysis, based on Lamb and Kling's (2003) user as social actor model, helped to understand the responses from individuals.

Globally, focus on MPA establishment is shifting from single sites towards comprehensive MPA networks (UNEP-WCMC, 2008) and this is accompanied by the need to develop governance frameworks, including for ISD, that are everincreasing in scope and complexity. Given the multiple challenges faced by MPA practitioners today (Davis, 2011; Miller-Taei and Kostka, 2012), closer collaboration 
and better communication among all groups involved is indispensable if global sustainability goals are to be met. Regional IS are being developed to meet some of these challenges, i.e. Dutch Caribbean Biodiversity Data (Verweij and Vermaas, 2012), and these settings offer ideal opportunities to apply and extend our findings. Further research could examine whether facilitation of RE processes informed by Spradley's elicitation and analysis techniques effectively and efficiently aid participants to communicate unambiguously and reach mutual understanding of their IS needs and goals. In environmental ISD, teams of scientists, who are main data producers and users, take up the role of IS developers as well (McIntosh et al., 2011, 2008). Our findings should be useful to sensitize this key group regarding the different interpretation schemes and knowledge management cultures of other groups involved in ISD. 
CHAPTER 


\section{Controversies and consensus on the lionfish invasion in the Western Atlantic Ocean ${ }^{5}$}




\begin{abstract}
This study investigates how the lionfish (Pterois sp.) invasion of the Western Atlantic Ocean has been socially constructed by natural scientists, the media, and stakeholders associated with various marine protected areas in the Caribbean. By examining the use of data and metaphors by these actors, I identify where invasion discourses converge and diverge. Although consensus exists regarding the non-nativeness, introduction vector, and successful establishment of lionfish throughout the region, I also identify uncertainty surrounding lionfish impact and controversies regarding lionfish management and control. The dominant discourse frames lionfish as a threat, and control efforts as a war to keep the enemy at bay, promoting lionfish hunting and consumption by humans: the "ultimate predators." However, this view is challenged by a coalition that questions the safety, effectiveness, and morality of the practices promoted by the kill-and-eat lionfish coalition. A nascent discourse that frames lionfish as fulfilling the role of overexploited native species, primarily expressed in socioeconomic terms, is shifting lionfish impact perception from negative to positive among some stakeholder groups. Whereas the dominant discourse views humans as helping nature to regain balance through lionfish hunting, a minority coalition views lionfish as part of the ecosystem, where a new equilibrium will be reached. This study shows that scientific data and metaphors, amplified by the media, facilitated initial understanding of the lionfish phenomenon and are used to legitimize claims. In time, however, local knowledge and societal values have intermingled with scientific data, sometimes challenging scientific discourses, and contributing to a richer understanding of the invasion as a social-ecological phenomenon.
\end{abstract}




\subsection{Introduction}

Species introductions, their impacts, and their management are among the most salient biodiversity conservation issues globally (Vitousek et al., 1996; Mack et al., 2000; McGeoch et al., 2010; Davis et al., 2011). When a species is introduced to a new environment, it engages in complex interactions with the biotic, abiotic, and human components of the recipient ecosystem and may become categorized as invasive (Boonman-Berson et al., 2014). No consensus exists on what a biological invasion is, not even among invasion scientists (Richardson et al., 2000; Valéry et al., 2008; Heger et al., 2013). This lack of consensus is reflected by competing discourses in scientific and public debates on invasive species. Note that the term "invasive" is used throughout the paper for consistency purposes, while recognizing the contested meanings of this expression. See the section titled "Constructing a biological invasion: origin, spread, impact, and control."

At the crux of controversies among invasion ecologists are disparate perspectives on the criteria and terminology used to classify a species as invasive (Colautti and MacIsaac 2004). Also debated are the risks that such species represent for native species (Gurevitch and Padilla 2004; Clavero and García-Berthou 2005) and the acceptable degree of subjectivity and advocacy when ecologists communicate about biological invasions in the public arena (Colautti and Richardson 2009; Young and Larson 2011). Moreover, ecologists have debated with social scientists and philosophers on the rhetoric of ecologists (Simberloff 2003). The latter have been harshly criticized for their use of metaphors that frame invasive species issues in militaristic and xenophobic terms (Subramaniam 2001; Chew and Laubichler 2003; Larson 2005, 2007a, 2007b; Warren 2007).

Media coverage of biological invasions has similarly been criticized for its hyperbolic language and alarmist metaphors (Gobster 2005; Larson et al., 2005). Recognized as powerful areas of meaning-making in society, science and the media ultimately shape public views, policy, and management of invasive species (Stromberg et al., 2009; Lavoie 2010). As a growing literature has highlighted, a species labelled as invasive is often perceived and valued differently by different people, and these divergent constructions usually lead to management disputes (Perry and Perry 2008; Weeks and Packard 2009; Marshall et al., 2011; Shine and Doody 2011; Dickie et al., 2014). Therefore, understanding stakeholders' plural views and values of the focal species is acknowledged as key for workable management strategies and to minimize conflict (García-Llorente et al., 2008; Schüttler et al., 2011; Estévez et al., 2015). 


\section{Chapter 4}

Increasingly, local communities are participating in invasive species management (Foster and Sandberg 2004; Bryce et al., 2011; Shine and Doody 2011; FordThompson et al., 2012). This is the case for the recent lionfish invasion in the Western Atlantic Ocean (Morris 2012). The present study is a contribution to the body of literature on the management implications of competing discourses on invasive species, with the lionfish Caribbean invasion as case. An ever-increasing number of academic publications on Atlantic lionfish exist from a natural science perspective (Côté et al., 2013; GCFI 2014), but only minor attempts have been made to understand stakeholders' views on this species and its management (Ali 2011; Moore 2012; Scyphers et al., 2014).

This study sets out to investigate how the lionfish invasion has been socially constructed and defined by natural scientists, the media, and local stakeholders associated with various marine protected areas (MPAs) in the Caribbean, by examining the use of data and metaphors by these actors. The goal is to ascertain where discourses on lionfish converge and diverge, and whether competing discourses have been implicated in management disagreements. The study is relevant given the growing importance of the lionfish invasion as a conservation and development concern in the region, the participatory nature of lionfish control efforts, and the recognition of MPAs as priority control locations given their high ecological value and conservation-oriented character (Morris 2012; Gómez Lozano et al., 2013; GCFI 2014).

\subsection{Conceptual framework}

\subsubsection{Constructing a biological invasion: origin, spread, impact, and control}

The analysis of lionfish discourses is positioned against the backdrop of key debates on biological invasions, for which the definition of invasive species is crucial. Classifying a species as invasive is important given the practical consequences that ensue, such as control or eradication programs to mitigate perceived negative impacts. Discussions regarding the definition of invasive species center around the so-called native versus non-native duality, where the biogeographic or origin criterion is paramount in classifying a species as invasive (Richardson et al., 2000; Warren 2007; Valéry et al., 2008). In other words, the species being novel to a region is the only factor considered to classify it as invasive. The rationale is that a nonnative species, by virtue of its lack of coevolutionary history within the native environment, possesses traits, e.g., lack of predation, competition, parasitism, that 
may confer it advantage over local species and facilitate its domination in local communities (Simberloff 2005). Advocates of the origin criterion are concerned with the unprecedented rate at which humans redistribute species because of increased human travel and globalized trade and transport (Carlton and Geller 1993; Vitousek et al., 1996). Evidence to support the origin criterion primarily consists of data that establish the species identity, its origin, and the vector of introduction. Terminology used to designate this foreignness includes terms such as nonindigenous, alien, foreign, exotic, and immigrant (Wong 2002; Falk-Petersen et al., 2006).

Various ambiguities complicate the categorization of a species as invasive based solely on its origin. Variable spatial and temporal scales are applied in deciding where and when a species is invasive (Richardson et al., 2000; Hall 2003; Donlan and Martin 2004). Moreover, according to the origin criterion, native species that become dominant and 'encroach' in their native environment do not qualify as invasive. To account for these perceived limitations, the "spread" and "impact" criteria have been advanced to complement the definition of invasive species.

The potential of a species to spread over a long distance rapidly and colonize a large area is viewed by proponents of this criterion as a defining characteristic of an invasive species, regardless of its origin (Richardson et al., 2000; Daehler 2001). The logic is that because populations of most non-native species do not or only minimally expand beyond their sites of introduction, they do not meet the spread criterion and hence should not be classified as invasive. Rapid distribution of a species, through population growth and expansion over a large area, is thought to occur at the expense of other (native) species. In this way, spread is associated to the notion of harm and linked to the impact criterion. Opponents to this line of thinking claim that long-distance spread may have negligible impact on the new environment; in other words, they think that spread is not correlated to impact (Ricciardi and Cohen 2007). Data that underpin the spread criterion include species numbers and location (how many? where?), reproduction rates, growth rates, and in the case of fish, larval dispersal and recruitment rates. Terminology used in relation to the spread criterion include militaristic metaphors like colonizer, invader, and natural enemy (Chew and Laubichler 2003).

Environmental and societal costs, including human health and economic loss, associated with a number of successful invaders are widely acknowledged (Vitousek et al., 1996; Pimentel et al., 2005). Nonetheless, the impact criterion has been 


\section{Chapter 4}

strongly criticized by a group of scholars for its nebulous, undefined, and subjective nature (Daehler 2001; Sagoff 2005), because qualifying and quantifying the effects of invasive species both in ecological and social terms ultimately rest on value judgments. Evidence regarding impact in ecological terms includes data on distribution, density, and in the case of animals, per capita effect of the individual invader, for which "effect" remains difficult to establish (Parker et al., 1999). Data that demonstrate impact in socioeconomic terms include opportunity costs due to invasive species-driven population decline or extinctions of commercially exploited species, and data on the costs of control programs. Terminology used for harmful species include pest, transformer, biological pollution, and infestation (Davis and Thompson 2000; Wong 2002; Larson 2008).

Although ecological damage caused by an introduced species classified as invasive may be recognized, the same species may also provide food, ornamental benefits, or recreational benefits as well as other ecological services (Robbins 2004; Weeks and Packard 2009; Dickie et al., 2014). This ambiguity confounds the use of the impact criterion, with its negative connotation, in classifying a species as invasive. Moreover, perceptions of a species as "good" or "bad" may change through time and across stakeholder groups, with implications for management decisions (García-Llorente et al., 2008; Stromberg et al., 2009). Control of invasive species may trigger controversies because of high economic costs, uncertainties, divergent stakeholder interests, and ethical concerns (Messing and Wright 2006; Haider and Jax 2007; Evans et al., 2008; Nuñez et al., 2012). Data sought to justify specific control methods include cost-benefit analyses and assessments of potential efficacy and side effects. Control metaphors used include war, anti-immigration, epidemic, and catastrophe (Wong 2002; Larson et al., 2005; Zinken 2007; Nerlich and James 2009).

\subsubsection{Discourses and invasive species management}

Discourse is defined as "a meaning of a phenomenon shared by a small or large group of people on the local, national, international or global level" (Arts et al., 2012:912). Referred to as a discourse coalition, a group sharing the same meaning of a phenomenon is an internally diverse set of actors that "strives for hegemony by trying to empower its definition of reality on the basis of credibility, acceptability and trust" (Arts et al., 2012:912). A storyline is a central idea that condenses a discourse in a simple, succinct way and sometimes replaces complex debates by clustering knowledge. As use of storylines increases, they acquire a ritual character 
and become a discursive cement that keeps a coalition together. A discourse coalition draws on scientific evidence, i.e., data, to make itself persuasive and legitimate, and draws on metaphors to convey meaning (Hajer 1995).

Data play a key role in substantiating claims in invasive species debates (Wilcove et al., 1998). However, practices of data production, interpretation, and use are also contested (Stromberg et al., 2009; Crall et al., 2010; Lavoie 2010, Davis et al., 2011; Boonman-Berson et al., 2014). For instance, different interpretations of the same data sets have led to opposing assessments of the impact of invasive species on native species (Gurevitch and Padilla 2004; Clavero and García-Berthou 2005).

Metaphors allow people to conceptualize the unfamiliar in terms of the familiar (Lakoff 1993; Maasen et al., 2001). Metaphors are mental models that aid, through a linguistic expression, our understanding of one mental domain in terms of another. Metaphors are ubiquitous in science (Maasen et al., 2001), and in ecology, metaphorical frames are used to conceptualize nature and interpret invasive species (Cuddington 2001; Chew and Laubichler 2003; Keulartz and van der Weele 2008).

Two metaphors, nativism and cosmopolitanism, represent extreme positions with respect to how invasive species and their management are viewed according to core beliefs and values in conservation (Callicott et al., 1999; Keulartz and van der Weele 2008). Nativism conceptualizes nature as pure and in harmony if consisting of species that originate in or belong to a certain space and if these species' composition and numbers remain roughly constant (Cuddington 2001). Nature is believed to be fragile and vulnerable to humans' destructive influence, and hence in need of protection to preserve its biological integrity and balance (Peretti 1998; Callicott et al., 1999; Cuddington 2001; Davis et al., 2011). Restoration in nature is analogous to restoration in the visual arts, with the aim of resembling as much as possible the "original composition" of a pristine landscape/seascape, in which non-natives are unwelcome (Keulartz and van der Weele 2008). Hands-on management is thus necessary to prevent the introduction of foreign species, or if that fails, to eradicate them. Cosmopolitanism, on the other hand, sees non-natives as a component of an inexorable process of change and recombination of a robust nature, and calls for acceptance of these novel ecosystems (Soulé 1990; Keulartz and van der Weele 2008; Davis et al., 2011; Graham et al., 2014; Graham and Hicks 2015). A hands-off management stance is advocated here, with human intervention not warranted except for elimination of "the most offensive exotics" (Soulé 1990:235). 


\section{Chapter 4}

Between these two poles, other metaphors exist along a continuum such as nature as a patient that can be cured (rehabilitation) or nature as a machine/factory that can be repaired (reparation), where the role that the species plays in the whole is what counts, therefore conferring more flexibility regarding non-natives. Although in the rehabilitation metaphor, the criterion of biological integrity is important to the health concept, the function of the species in the ecosystem is emphasized, not its origin. The ritual and communal character of the "healing art" (a euphemism for elimination of invasive species through sacrificial rituals) distinguishes this view from the reparation metaphor, which regards nature as a set of resources with cash value, where foreign species are "so to speak, entitled to a green card as long as they do their job" (Keulartz 2008:249). Figure 4.1 depicts the conceptualizations of nature through these metaphors and implications for non-native species management.

\subsection{Methods}

\subsubsection{Study approach and setting}

Discourse analysis (Hajer 1995) was applied to various linguistic data sources (Wetherell et al., 2001): scientific literature, online media, lionfish management documents, and interviews. The scientific construction of the invasion was taken as a starting point of the analysis. Then an examination of how the media reported on the issue and how local stakeholders interpreted the invasion was conducted. MPAs located in the Caribbean, a "major global marine biodiversity hot spot" (Miloslavich et al., 2010:1), were selected as setting because they exemplify the tensions between conservation efforts and invasive species. Purposive sampling (Bryman 2012) was used to identify the specific MPAs for the study. MPA selection proceeded as follows: academic/grey literature and online material (MPA websites, press releases) provided an overview of the MPAs where lionfish was a management issue. Sites were selected based on (1) existing contacts with MPA staff/stakeholders, which facilitated access to these and other informants, (2) first lionfish sightings were reported around the same period, and (3) spread in geographic location, sizes, and governance modes to ensure a diverse sample (Table 4.1). Sites selected are multipleuse MPAs. 
Controversies and consensus on the lionfish invasion

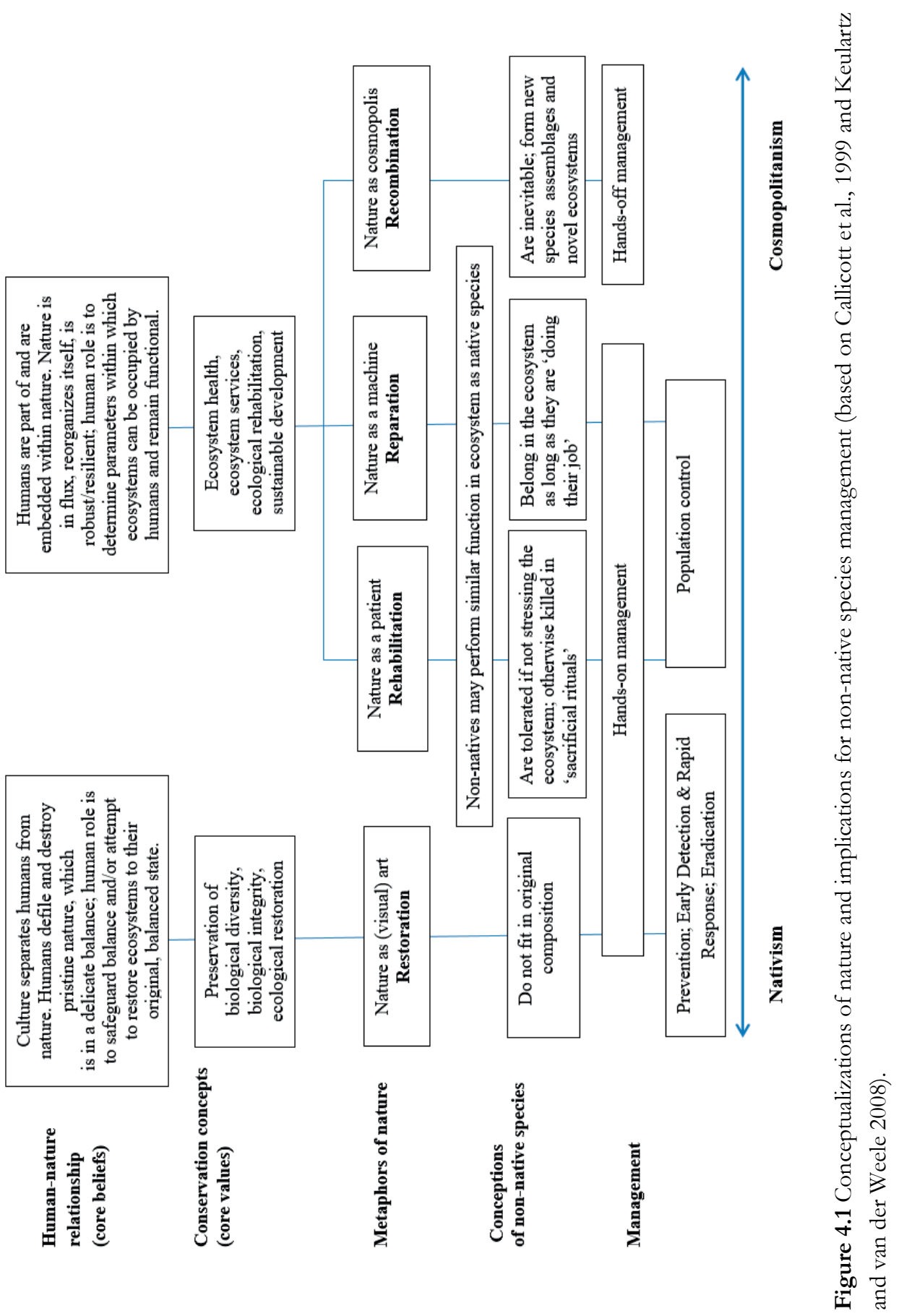


Table 4.1 Selected marine protected areas. Data from MPA Global (http://www.mpaglobal.org/), MPAtlas (http://www.mpatlas.org/); ecoregions after Spalding et al., (2007).

\begin{tabular}{|c|c|c|c|c|}
\hline $\begin{array}{l}\text { Marine Protected Area } \\
\text { (designation date) }\end{array}$ & $\begin{array}{l}\text { Total } \\
\text { Area } \\
\left(\mathrm{km}^{2}\right)\end{array}$ & Governance & $\begin{array}{l}\text { Caribbean } \\
\text { Ecoregion }\end{array}$ & $\begin{array}{l}\text { Lionfish } \\
\text { first } \\
\text { sighted }\end{array}$ \\
\hline $\begin{array}{l}\text { Florida Keys National Marine Sanctuary } \\
\text { (1990) }\end{array}$ & 9,845 & State-led & Floridian & 2009 \\
\hline $\begin{array}{l}\text { Sian Ka'an Reefs Biosphere Reserve } \\
\text { (1998) }\end{array}$ & 349.3 & State-led & Western Caribbean & 2009 \\
\hline $\begin{array}{l}\text { Bonaire National Marine Park } \\
\text { (1979) }\end{array}$ & 27 & NGO & Southern Caribbean & 2009 \\
\hline $\begin{array}{l}\text { Curaçao Underwater Marine Park } \\
\text { (1983) }\end{array}$ & 10.4 & NGO & Southern Caribbean & 2009 \\
\hline $\begin{array}{l}\text { St. Maarten "Man of War Shoal" Marine } \\
\text { Park (2010) }\end{array}$ & 31 & NGO & Eastern Caribbean & 2010 \\
\hline $\begin{array}{l}\text { Saba National Marine Park } \\
\text { (1987) }\end{array}$ & 13 & NGO & Eastern Caribbean & 2010 \\
\hline St. Eustatius National Marine Park (1996) & 27.5 & NGO & Eastern Caribbean & 2010 \\
\hline
\end{tabular}

\subsubsection{Data collection}

Primary data sources were semi-structured interviews conducted between January and March 2013. Relevant informants were those with a stake in the MPA and potentially engaged in lionfish management. Referred to as local MPA stakeholders, the sample included MPA staff, government officials, nongovernmental organization (NGO) representatives, scientists, dive tourism operators, recreational and commercial fishers, and other resource users (Appendix 3). After locating potential respondents through a mix of online searches and snowball techniques (Bryman 2012), interview appointment requests were sent by e-mail. On Bonaire and St. Maarten, opportunistic sampling was carried out by walking along the beach and requesting interviews from staff present at the encountered dive shops. On St. Eustatius and Saba, a few fishermen at work were also interviewed on-site. For this reason, the length of some unplanned interviews was short, but the interviews provided rich data from key stakeholders. Telephone and face-to-face interviews (average length of 36 minutes, range of 8-95 minutes), based on the topic list shown in Appendix 4, were taped and transcribed. Participant observation of a lionfish removal activity organized by a dive operator was performed on Curaçao. 
Scientific articles were selected based on their contribution to the origin, spread, impact, and control components of the analysis, using Google Scholar citation numbers and cross-referencing patterns as indication of the article's influence in the debate. Online news reports were selected based on geographical spread, representing the studied ecoregions; language, i.e., English, Spanish, or Dutch as spoken in the selected MPAs; and scope, including large news media broadcasters with an international audience as well as small, local news providers. In selecting scientific and media data sources, attention was given to the period covered to provide an overview of discourse formation in time, up to 2013. Also, during the interviews, stakeholders were prompted to provide a chronological sequence in their lionfish accounts.

\subsubsection{Data analysis}

Data sources were imported into Atlas.ti for deductive and inductive coding (Fereday and Muir-Cochrane 2008). Inductive coding is a data-driven process that entails careful reading and rereading of the data to identify themes, i.e. discourses, whereas deductive coding applies a code template "as a means of organizing text for subsequent interpretation", i.e., distinguishing discourse coalitions based on argumentations and teasing out arguments to identify their constituent data and metaphors (Fereday and Muir-Cochrane 2008:83). In total, 167 documents were coded: 50 scientific articles, 7 lionfish assessment and management plans, 58 online news reports, and transcripts of 52 interviews, including group interviews (80 respondents in total).

\subsection{Results}

Ecologists and the media univocally define lionfish as invasive based on the three criteria of origin, spread, and impact, characterizing lionfish as a threat and calling for population control through targeted removals. Most MPA stakeholders interviewed aligned themselves with this dominant discourse, but some divergence was revealed in respondents' views of spread, impact, and the defensibility of control measures - including human consumption of lionfish -, with implications for management in some of the MPAs studied. 


\subsubsection{Origin}

Storyline: Indo-Pacific lionfish most likely introduced through aquarium releases in Florida Scientists from the U.S. National Oceanic and Atmospheric Administration (NOAA) published the first scientific article on the occurrence of lionfish in the Western Atlantic Ocean (Whitfield et al., 2002). This article qualified the lionfish as invasive based on its foreignness and dispersal throughout the U.S. East Coast and Bermuda. The non-nativeness of lionfish in the Western Atlantic Ocean was quickly accepted as a fact, because this fish was known to occur in the Western Pacific and Indian oceans (Schultz 1986) but was never observed in Atlantic waters before the 1980s. This absence of data on lionfish sightings prior to the 1980s in the Western Atlantic Ocean was equated to non-nativeness.

Lionfish are conspicuous in their coloration patterns, fleshy tentacles above eyes and around the mouth, large pectoral fins, and venomous spines, and are thus easily recognizable by scientists and resource users (Figure 4.2). In early investigations from 2000 to 2004, visual identification and description of morphology and meristics (quantification of fish traits such as fin spines) were the primary data used to establish lionfish identity. In subsequent stages, genetic data were used to distinguish between the two-sister species, Pterois volitans and P. miles, caught throughout their novel range to reconstruct lionfish expansion and to trace the origin of the parent populations to Indonesia and the Philippines (Hamner et al., 2007; Freshwater et al., 2009).

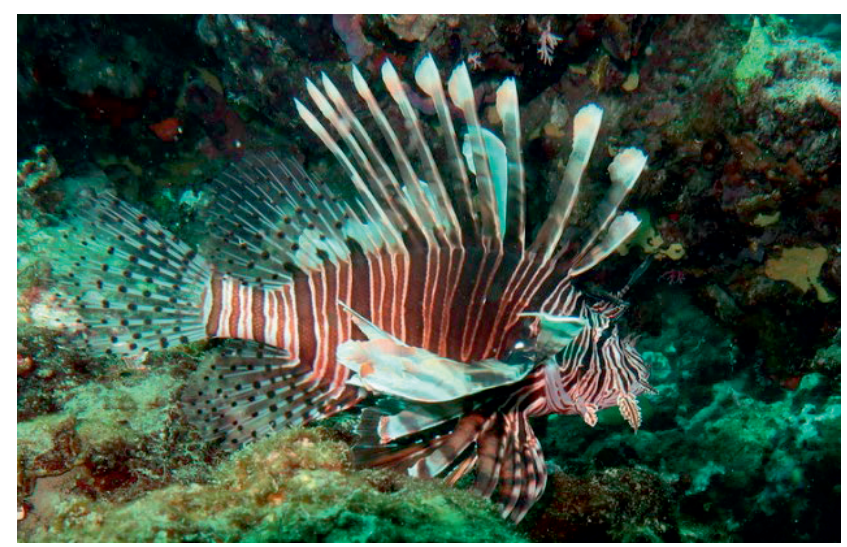

Figure 4.2 Lionfish in a Caribbean reef (Used with permission from L. Alvarez-Filip). 
How did the lionfish arrive at the Western Atlantic Ocean in the first place? Various explanations were considered by scientists (Hare and Whitfield 2003). Initial hypotheses of natural dispersal through the Panama Canal or across the Atlantic from the Mediterranean Sea, where lionfish had also been sighted (Golani and Sonin 1992), were soon discarded because the distance was deemed too large and the ecological barriers, insurmountable. Moreover, later studies showed that genetic data did not match the data from those areas.

Concurrently, evidence pointing to a human-mediated introduction accumulated. Ship ballast water is the most common introduction vector of marine species and was a logical candidate. Nonetheless, aquarium trade was eventually identified as the most likely vector for lionfish and other marine tropical fish introductions. This claim was substantiated by multiple data sources, including "a large spatially explicit marine fish database to show that there are a surprising number of non-native fishes on the reefs of southeast Florida, USA.... Data on international shipping patterns and marine fish imports were used to evaluate the culpability of these 2 vectors. Our results suggest that the introductions are the result of aquarium releases" (Semmens et al., 2004:239). The marine fish data used have been compiled by the Reef Environmental Education Foundation (REEF), an NGO based in Florida, through its sport diver volunteer fish surveys since 1993 and its online "exotic species reporting page" since 2002 (http://www.reef.org).

The National Geographic News of June 2004 (Pickrell 2004) was the first to feature a story that linked the aquarium and ornamental species industry to non-native species introductions worldwide, including the lionfish case. The story summarized two scientific articles published that year (Padilla and Williams 2004; Semmens et al., 2004) that encouraged measures to prevent further non-native species introductions into aquatic ecosystems, in line with nativism. In subsequent reports on lionfish, the media consistently referred to its non-nativeness in headlines such as "Lionfish: Born in the Wrong Sea," "New Pirate of the Caribbean Invades from Pacific," and "Unwelcome Visitors."

The full mechanism through which lionfish were introduced into the Western Atlantic Ocean will probably never be known, but a combination of intentional and accidental releases from Florida aquariums are the most plausible explanations according to scientists and the media. Intentional releases refer to pet owners who 


\section{Chapter 4}

no longer wish to keep lionfish in their tanks. Accidental releases refer to a popular account that links a few lionfish sighted in 1992 in Biscayne Bay, Florida, to Hurricane Andrew's destruction of a beachside aquarium. However, the first documented lionfish sighting dates from 1985 in Dania Beach, Florida (Morris and Akins 2009), with the specimen being preserved by the U.S. Geological Survey (Betancur-R et al., 2011) The first time a link was suggested between Hurricane Andrew and lionfish was in 1995 (Courtenay 1995), but Courtenay said to a reporter in 2010 that he would like to "put this idea to rest.... It was second-hand information...which unfortunately continues to spread, so that Andrew is often mentioned as the reason for the catastrophic lionfish invasion" (Morell 2010).

MPA stakeholders were cognizant of the foreign origin of lionfish, often referring to the time when "this fish arrived here," a period characterized by fear of the new species. Respondents reported that they gradually got used to the presence of lionfish in their waters. The introduction vector and mechanism did not feature prominently in respondents' accounts.

\subsubsection{Spread}

\section{Storyline: Lionfish are everywhere}

Semmens et al., (2004) were "surprised" by the large numbers of non-native fishes they found because before that time establishment of introduced marine fishes was considered rare. Lionfish sighting data indicated that lionfish had the potential to survive and reproduce in their new environment and to rapidly colonize a large area. After the first lionfish sightings in eastern Florida, several years passed before verified reports were received. Between 2000 and 2002, lionfish observations were documented along the U.S. eastern seaboard in Florida, Georgia, North Carolina, and New York, and in Bermuda, about $1000 \mathrm{~km}$ from Cape Hatteras, North Carolina. In 2004 lionfish were observed in the Bahamas, more than $1500 \mathrm{~km}$ south of Bermuda, and in less than a decade lionfish expanded into the rest of the Caribbean and reached South America (Schofield 2009, 2010).

The most crucial data used by scientists to underpin their application of the spread criterion were sighting data sets, predominantly the U.S. Geological SurveyNonindigenous Aquatic Species Database (Schofield et al., 2015). This publicly accessible database, accompanied by a real-time point distribution map, includes a total of 5609 sightings from scientists and non-scientists from the entire region where lionfish have been observed as of August 20, 2015. The database, with REEF 
as important data contributor, enabled tracking lionfish expansion as it unfolded, for the first time documenting the rapid spread of a non-native fish in a novel range. Combined with this distribution data set, abundance and density estimates at various sites illustrated the extent of lionfish invasiveness.

The media attested that "lionfish ... [were] showing up everywhere" (Associated Press 2008). A respondent from Florida stated: "As soon as the first one was seen it was very big news... through Florida." In Sian Ka'an, the Research and Monitoring Coordinator stated:

In just one year, the lionfish has established and prospered throughout the coast and islands of the states of Quintana Roo and Yucatan, including...Sian Ka'an Reefs Biosphere Reserve... Just for the Ascencion Bay area..., there are records of more than 2120 dead specimens, ranging from 3 to $32 \mathrm{~cm}$ in length, plus 1000 sightings. (Gómez 2010)

Data on sightings (numbers and location), captured lionfish, size, and stomach content were collected in all MPAs studied. MPAs' data sets were made possible through the participation of local divers and fishers in data and specimen collection.

The reproductive characteristics of lionfish have been identified by ecologists as key to its rapid and wide-ranging spread: lionfish may become sexually mature within their first year of life, present yearlong spawning at a frequency of more than two million eggs annually and reproduce by releasing free-floating egg masses that are dispersed by ocean currents and subsequently develop into planktonic larvae (Morris and Whitfield 2009). Ecologists investigated other factors that enabled this rapid dispersal: those inherent to lionfish biology, such as antipredatory defences, distinctive predatory behavior, low parasitism, and ecological flexibility including a generalist diet, and those inherent to the recipient ecosystems, such as prey naïveté, weak competitors, and overfished native predators possibly naïve to lionfish (Côté et al., 2013).

For the media, the fecundity and ubiquity of lionfish were integral to their portrayal of this species as invasive. All media stories examined either allude to scientific studies or directly quote scientists and numbers, albeit with some variation from the original data source, in describing lionfish spread to their audience, for instance: 


\section{Chapter 4}

"The facts about lionfish are frightening. A female can produce 30,000 eggs every four days" (Ecott 2011).

Next to fact reporting, vivid imagery is used such as in this quote from a scientist: "It's like an oil spill that keeps reproducing and will keep reproducing forever" (Shogren 2013). Most respondents had also witnessed a rapid increase in lionfish numbers and size in their waters. However, some dive operators from Saba and St. Eustatius asserted that, based on their own daily observations, lionfish populations in those MPAs were not surging as in other areas. These individuals suggested that lionfish were controlled by local environmental conditions and, possibly, native predators.

\subsubsection{Impacts}

\section{Storyline: That fish eats everything; the lionfish is a formidable foe}

Because establishment of non-native marine fishes in new ranges was considered uncommon up to 2004, effects of newcomers on marine ecosystems were largely unstudied and unknown. Given the ecological role of lionfish as predator, scientists expressed their concern about possible effects on populations of potential prey and competitors since the first studies on Atlantic lionfish were published. Lack of detailed data on lionfish diet, however, precluded any assessment at that point. The tone of the discourse between 2002 and 2006 was still speculative. During this period negative effects on the ecosystem were considered limited because of the small lionfish numbers observed in locations where lionfish had been sighted (Whitfield et al., 2002; Ruiz-Carus et al., 2006).

After 2007 the tone of the scientific discourse shifted from cautious to alarmist following reports that in some sites along the U.S. coast lionfish were starting to dominate native communities and, in the Bahamas, "record lionfish densities" were documented (Whitfield et al., 2007; Green and Côté 2009). Also, data from stomach content analysis and foraging studies showed the wide variety of fish and crustacean prey ingested by lionfish, including ecologically and economically important species (Morris and Whitfield 2009). Higher feeding rates and growth rates were measured in Atlantic lionfish relative to lionfish in their native range. The study by Albins and Hixon (2008) in experimental reefs in the Bahamas affords what has become perhaps the most referred-to ecological impact data in the lionfish discourse, by scientists and non-scientists alike: 


\section{Controversies and consensus on the lionfish invasion}

Lionfish caused significant reductions in the recruitment of native fishes by an average of 79\% over the 5-week duration of the experiment. This strong effect on a key life stage of coral-reef fishes suggests that invasive lionfish are already having substantial negative impacts on Atlantic coral reefs. (Albins and Hixon 2008:233)

Although no studies have quantified the effect of lionfish on native fish recruitment in natural reefs, an American expert interviewed for a popular TV show in the United States used Albins and Hixon's data to claim that:

In our waters these fishes are consuming everything. They eat everything on a reef. You have a beautiful little patch reef covered with a rainbow of fish and you come back, after a lionfish has been there for five weeks and 80\% of those fish are gone. (CBS 2013)

Two other Bahamas studies linked lionfish to a reduction of native fishes' biomass and diversity in coral reefs, which in the latter case preceded a shift to algal dominance (Lesser and Slattery 2011, Green et al., 2012). Meanwhile, data accumulated on various aspects of lionfish biology. The fish were observed in a great variety of habitats (reefs, mangroves, rocky bottoms, seagrass beds, estuaries), showing high range tolerance to depth ( $1 \mathrm{~m}$ up to $>300 \mathrm{~m}$ ), temperature, and salinity (Kimball et al., 2004; Claydon et al., 2012; Jud et al., 2015). From 2008 onward, various scientific studies called for action in the form of lionfish removals to control populations, calls that were echoed by REEF and the governmental agencies with remit on protected areas in Mexico (Comisión Nacional de Áreas Naturales Protegidas, CONANP) and the United States (NOAA), which have led efforts to develop a regional management strategy (Morris 2012). Lionfish were now perceived as a threat to stock-rebuilding and reef conservation efforts, with possible repercussions for the fisheries and tourism sectors. Moreover, the fish's venomous spines were considered a public health risk for fishers, swimmers, snorkelers, and divers.

Marine managers, in collaboration with scientists, initiated campaigns to inform the public about "The lionfish invasion!" with warnings such as "Look but don't touch!" (Ali 2011, NOAA 2011). Overall, the message conveyed by scientists and the media was gloomy and expressed through a vocabulary of calamity. In the media's militaristic terms, the war was declared on lionfish, "a formidable foe" (Cocking 2013). Table 4.2 shows the time course of the scientific discourse, and Table 4.3 shows examples of media headlines. 


\section{Chapter 4}

Whereas the observed and potential negative impacts attributed to lionfish by ecologists and the media were considered alarming and used to incentivize removal programs, MPA stakeholders were more nuanced in their construction of lionfish impacts. In all MPAs some degree of lionfish research and/or monitoring had been conducted; however, site-specific ecological impact data were not yet available. The novelty of the issue and its inherent uncertainties were acknowledged by an MPA manager:

It takes time for the ecological consequences of this type of invasion to actually be noticeable, whether it is through analysis of fisheries landings, or other studies that are done in an annual basis... Some of those may take a while for a signal to be observed, and after that...what's the correlation of that signal to the presence of lionfish?

About $80 \%$ of respondents aligned themselves with the discourse that views lionfish as a threat. The majority likewise recognized high densities and voracity of lionfish as the main factors that could impact ecosystems and services local communities depend on. However, although agreement seemed to exist on the nature of the impacts of lionfish, stakeholders had divergent views regarding the extent of these impacts in specific sites, recognizing local differences. An MPA manager with a science background for instance questioned the generalizability of available impact data:

Lionfish has been demonized endlessly but the truth is that the science bebind those statements is quite thin. There are very few studies that show to what extent lionfish influences the fish population on a reef. These are old studies...it is said that lionfish can reduce recruitment by $80 \%$ in five weeks - that's the classical speech. That's work done... in the Bahamas. What happens is, those are patchy reefs... Lionfish gets there and empties the reef... because there's little shelter due to low rugosity. So, reeffish... cannot bide. Here...the reef is different; fish populations are totally different and their behavior is also different, so I don't know in how far those results can be extrapolated [to our reefs].

A geographical difference in lionfish perceptions could be observed: about half of the respondents from the Eastern Caribbean MPAs considered lionfish a threat or problem, whereas more than $90 \%$ of respondents at the other MPAs did so. As mentioned in the Spread section, some respondents from Saba and St. Eustatius stated that lionfish were not observed in high numbers in their dive sites and therefore thought that lionfish were not impacting those areas. 
Controversies and consensus on the lionfish invasion

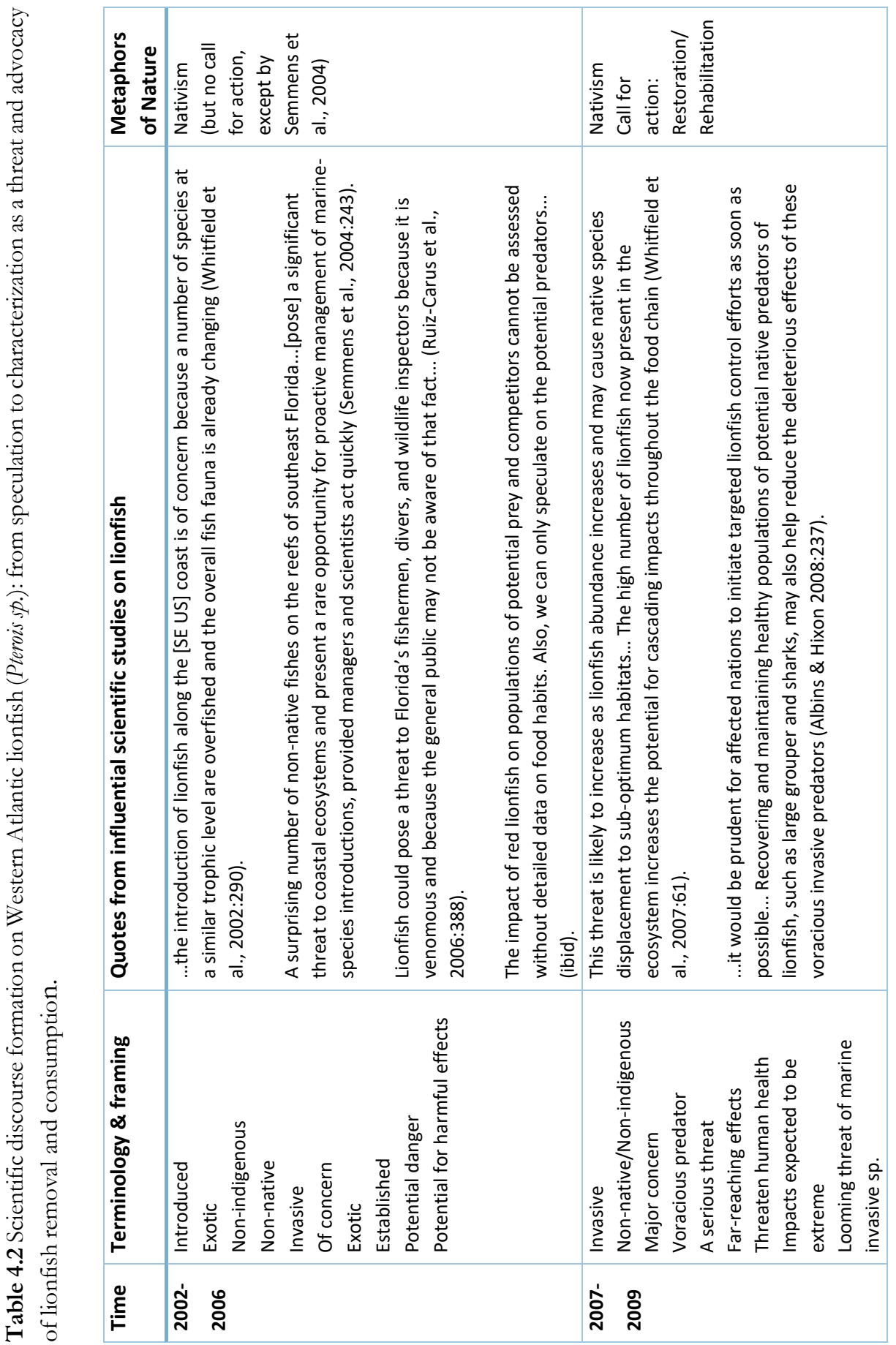




\section{Chapter 4}

\begin{tabular}{|c|c|c|c|c|}
\hline 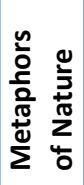 & 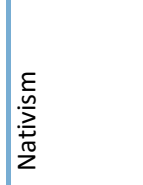 & 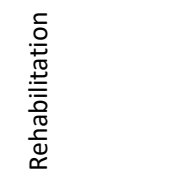 & 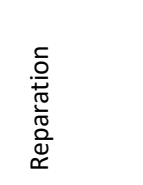 & \\
\hline 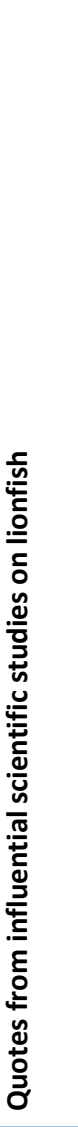 & 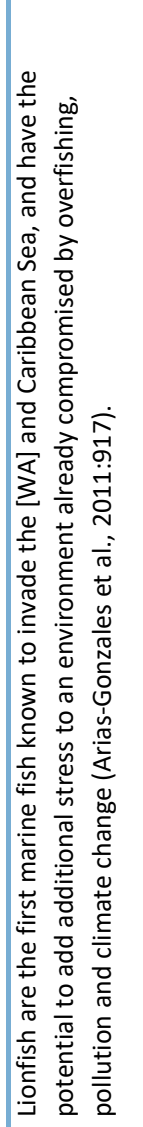 & 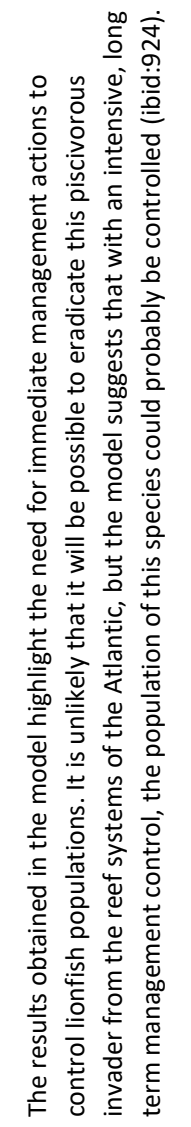 & 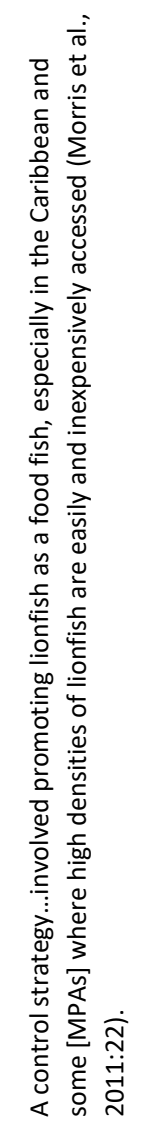 & 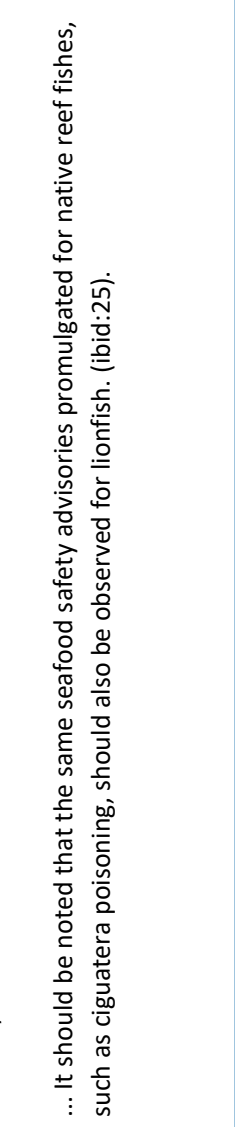 \\
\hline 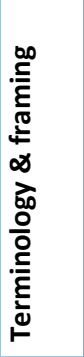 & 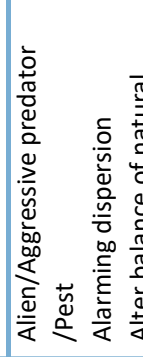 & 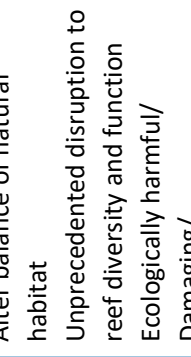 & 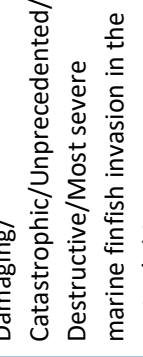 & 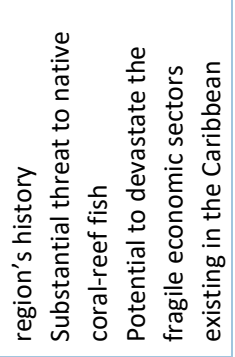 \\
\hline$i^{\prime}=$ & 올 & & & \\
\hline
\end{tabular}




\section{Controversies and consensus on the lionfish invasion}

Table 4.3 Media discourse on Western Atlantic lionfish (Pterois sp.).

\begin{tabular}{|c|c|}
\hline Examples of media headlines on lionfish & Source and publication date \\
\hline Freed Pet Fish Threaten Native Species, Study Says & $\begin{array}{l}\text { National Geographic } \\
\text { 01.06.2004 }\end{array}$ \\
\hline $\begin{array}{l}\text { A Spiny Invader Proliferates in L.I. Waters, and Scientists Wonder } \\
\text { About Its Impact }\end{array}$ & $\begin{array}{l}\text { The New York Times } \\
\text { 08.09.2006 }\end{array}$ \\
\hline Lionfish: Born in the Wrong Sea & $\begin{array}{l}\text { Turks and Caicos Weekly News } \\
\text { 13.12.2008 }\end{array}$ \\
\hline Poisonous Lionfish Invade Caribbean, Head Up Eastern Seaboard & $\begin{array}{l}\text { Fox News } \\
14.08 .2008\end{array}$ \\
\hline Newcomer to Keys is unwelcome, uncouth & $\begin{array}{l}\text { Miami Herald } \\
18.01 .2008\end{array}$ \\
\hline $\begin{array}{l}\text { Beautiful but Lethal Lionfish: Wanted Dead or Alive } \\
\text { (in Spanish) }\end{array}$ & $\begin{array}{l}\text { Mundo Náutico } \\
\text { 24.03.2009 }\end{array}$ \\
\hline Influx of Lionfish a Threat to Native Marine Life, Experts Say & $\begin{array}{l}\text { St. Croix Source } \\
\text { 23.08.2009 }\end{array}$ \\
\hline New Pirate of the Caribbean Invades from Pacific & $\begin{array}{l}\text { Inter Press Service News Agency } \\
02.12 .2009\end{array}$ \\
\hline Fighting Lionfish Necessary for Coral (in Dutch) & $\begin{array}{l}\text { Radio Nederland Wereldomroep } \\
\text { 06.01.2010 }\end{array}$ \\
\hline $\begin{array}{l}\text { Red Lionfish (Pterois sp). A New Threat for the Mesoamerican Reef } \\
\text { (in Spanish) }\end{array}$ & $\begin{array}{l}\text { Sian Ka'an Tours.com } \\
13.01 .2010\end{array}$ \\
\hline Florida Keys Declare Open Season on the Invasive Lionfish & $\begin{array}{l}\text { New York Times } \\
22.11 .2010\end{array}$ \\
\hline U.S. coast battles the lionfish & $\begin{array}{l}\text { Wall Street Journal Online } \\
\text { 15.08.2010 }\end{array}$ \\
\hline How to conquer the invasive lionfish? Saute it & $\begin{array}{l}\text { Washington Post } \\
07.07 .2010\end{array}$ \\
\hline 'Godzilla' Lionfish Threatening Cayman Paradise & $\begin{array}{l}\text { BBC } \\
07.05 .2011\end{array}$ \\
\hline Changing seas, alien invaders & $\begin{array}{l}\text { WPBT PBS } \\
06.07 .2011\end{array}$ \\
\hline Answer for Invasive Species: Put It on a Plate and Eat It & $\begin{array}{l}\text { The New York Times } \\
\text { 09.07.2011 }\end{array}$ \\
\hline Taming the Lionfish: Florida Fights Back Against Invasive Species & $\begin{array}{l}\text { CNN } \\
26.04 .2012\end{array}$ \\
\hline Scourge of the Lionfish, Part 3: The Newest Fish in the Kitchen & $\begin{array}{l}\text { The New York Times } \\
10.10 .2012\end{array}$ \\
\hline $\begin{array}{l}\text { Lionfish Researcher Looks at Invasive Species. Dispels Fears, Tells of } \\
\text { Lionfish as Non-Poisonous Delicacy }\end{array}$ & $\begin{array}{l}\text { The Anguillian } \\
07.12 .2012\end{array}$ \\
\hline Lionfish: Invasive species devastating reefs, expert says & $\begin{array}{l}\text { CBS NEWS } \\
21.02 .2013\end{array}$ \\
\hline Lionfish Attacking Atlantic Ocean Like a Living Oil Spill & $\begin{array}{l}\text { WLRN } \\
18.04 .2013\end{array}$ \\
\hline Even Sharks Are No Match for Invasive Lionfish & $\begin{array}{l}\text { NBC News } \\
12.07 .2013\end{array}$ \\
\hline Lionfish Infestation in Atlantic Ocean a Growing Epidemic & $\begin{array}{l}\text { CNN } \\
19.10 .2013\end{array}$ \\
\hline
\end{tabular}




\section{Chapter 4}

\subsubsection{Lionfish control}

Storyline: Kill lionfish to protect Caribbean reefs

Although the potential costs and benefits of lionfish removal programs have been debated (Frazer et al., 2012), there is consensus among scientists that local lionfish control is necessary to mitigate negative effects on the ecosystem and the economy. Lionfish removals are carried out manually by scuba divers or fishers using hand nets or small spearguns; hence, this activity is constrained by (wo)manpower and depth limits. Scientists have focused on seeking optimum removal rates through modelling and field studies, acknowledging that high levels of uncertainty due to data gaps make generalized predictions difficult. Whereas total eradication has been deemed unfeasible (Arias-González et al., 2011; Barbour et al., 2011) because of lionfish high reproduction, efficient larval dispersal, and depth constraints, a few studies provide data that substantiate claims that local control efforts yield positive results in terms of decreased lionfish biomass (Frazer et al., 2012; de León et al., 2013).

Lionfish removal events, also called safaris, derbies, or fishing tournaments, are organized in various locations, and bounties are provided as participation incentives. In addition, self-organized volunteers, who call themselves lionfish hunters, are active throughout the region. The media casts a positive light on lionfish removal events, with some headlines such as "Divers to Be Honored for Lionfish Kills" glorifying those who participate (Barlow 2012).

In some MPAs, debates emerged regarding the trade-offs of allowing/promoting spearfishing because of poaching concerns. A respondent from Curaçao noted: "You have some people on the island who are taking advantage of that law and they're spearing lobster, parrotfish, mullet...." Also, MPA managers are being called to relax regulations to allow removals in no-entry or no-take zones. These areas epitomize the nativist view of a pristine nature free of human interference, but also free of non-native species. Notwithstanding the expressed uncertainties, all MPA staff and government officials interviewed promoted lionfish removal efforts in their waters, albeit with some restrictions in terms of access because of zoning, gear use, and training requirements for licensed individuals, asserting that lionfish represent yet another risk factor to already-stressed reefs.

As stated in the Impact section, approximately $80 \%$ of respondents viewed lionfish as a threat and supported control measures. Within this coalition, a small group of 
respondents did not consider lionfish as a risk in their dive sites anymore because of a combination of active hunting and what they thought was natural control of lionfish populations. This argument was supported by personal observations of low lionfish numbers and the presence of large reef fish that were considered potential lionfish predators. For this group, nature is resilient but needs human intervention to restore health, their views best fitting with the rehabilitation metaphor.

\section{Storyline: Don't kill lionfish; nature will balance itself}

About $20 \%$ of respondents, all professional divers, positioned themselves within a coalition that challenges the dominant "Kill lionfish" discourse. Different arguments were provided in support of this position. A small group within this coalition acknowledged the risk that the lionfish represents for native ecosystems but refused to kill them on moral and safety grounds. This group expressed animal rights and fear-based arguments as deterrents to engage in lionfish removals. Safety/liability concerns for both staff and clients included fear of being stung by lionfish, of injuries by spearing gear, and of being bitten or followed by large predators in search of speared lionfish: "In early November one of our guides got bitten by a shark. So unfortunately, this has curtailed us from hunting them because we cannot risk that the sharks are associating divers with dead lionfish." Also, some individuals considered killing lionfish against the philosophy of scuba diving, i.e., take only pictures, leave only bubbles. Personal observations that native predators were starting to feed on lionfish were advanced to support the argument that human intervention is neither necessary nor sufficient to control lionfish populations: "Divers are diving one tenth of one percent of the reefs that are out there so there's no way they're going to have an impact [on lionfish populations]. Stop fishing those predators and let them have a balanced ecosystem."

Another small group was identified that opposed killing lionfish based on the explicit acceptance of this new species in the ecosystem, as long as lionfish numbers did not increase. These respondents also thought that native predators were keeping lionfish numbers in check, which accordingly renders human intervention unnecessary. Finally, a group expressed ambiguity toward the presence of lionfish and toward control efforts. Various individuals stated that initially they had been alarmed and engaged in lionfish removals, but subsequently their interest waned as they became accustomed to the presence of lionfish in their waters, implicitly accepting the novel species in their ecosystem. The position of these various groups fit with the 


\section{Chapter 4}

cosmopolitanism view of recombination and hands-off management. Table 4.4 shows quotes illustrating stakeholders' discourses.

Table 4.4 Stakeholders' discourses on Western Atlantic lionfish (Pterois sp.).

\begin{tabular}{|c|c|}
\hline Quotes from stakeholders associated to Cari & $\begin{array}{l}\text { Metaphors of } \\
\text { Nature }\end{array}$ \\
\hline $\begin{array}{l}\text { I've never heard or seen an invasive species that has done anything right for the system that } \\
\text { they're introduced to... I would tend to stay on the cautious side and would worry about it. } \\
\text {..when they're gonna shoot it they explain look, they're not supposed to be outside the Pacific } \\
\text { and Indian Ocean and they go "OK." } \\
\text { When it first came out ... they were scaring us to death "it's going to destroy your reefs, you're } \\
\text { going to have } 50 \text { of these on every dive." }\end{array}$ & $\begin{array}{l}\mathrm{m}: \\
\text { ation }\end{array}$ \\
\hline $\begin{array}{l}\text { So we had two management strategies, that is the direct control by physically eliminating the } \\
\text { lionfish from the reef... and the second...would be the introduction of two No Fishing Zones that } \\
\text { we hope that maybe natural predators of the lionfish could establish themselves and multiply - } \\
\text { since the lionfish came in Curaçao in a damaged ecosystem by overfishing. } \\
\text { A lot of people think that what we're doing is very cruel. And I want to make it very clear as well }\end{array}$ & $\begin{array}{l}\text { Restoration/ } \\
\text { Rehabilitation }\end{array}$ \\
\hline $\begin{array}{l}\text { On the other hand...[lionfish can] potentially remove the impact or shift impact away from some } \\
\text { species...it can provide an added source of income for subsistence fishermen. } \\
\text { we need to get [lionfish]off the reef and I would probably just kill them to get them off the reef } \\
\text { because it's damaging our reefs but... giving it to the restaurants, they'll use it. }\end{array}$ & $\operatorname{Re}$ \\
\hline $\begin{array}{l}\text { Whether you like it or not, [lionfish] are part of the ecosystem now. Like we are, we're invasive } \\
\text { species. Especially me [foreign dive operator]. } \\
\text { It's an invasive species but nature finds its balance, it finds its way. }\end{array}$ & $\begin{array}{l}\text { Cosmopolitanism: } \\
\text { Recombination }\end{array}$ \\
\hline
\end{tabular}

The argument for focusing attention on species that, through predation, could become a natural control mechanism of lionfish, e.g., sharks, large groupers, and snappers, resonates with the enemy-release hypothesis in ecology, which maintains that invasive species can thrive in novel ranges because their populations are not controlled by enemies. A debate has emerged around biocontrol of lionfish (Bruno et al., 2013; Mumby et al., 2013), with one coalition stating that native predators are already consuming lionfish, a claim substantiated by a couple of reports from the scientific literature (Maljković et al., 2008; Pimiento et al., 2013) and numerous personal observations by divers and fishers. It is argued that populations of these large native reef fishes, which are overexploited in the Western Atlantic Ocean, should be restored and better protected from overfishing. Some individuals have 
attempted training potential predators to recognize lionfish as prey by feeding them dead or injured lionfish from their spear tips, a practice criticized as unsafe because it conditions large predators to associate divers with food. Also, sceptics state that although anecdotal evidence of native predators consuming lionfish may exist, their effect on lionfish populations is negligible. This coalition tends to recommend lionfish removal and consumption: man-as-ultimate-predator.

\section{Storyline: Eat lionfish}

Lionfish is edible and considered tasty. NOAA scientists launched a campaign in 2010 in line with the imagery of war: "Eat them to beat them." This campaign has been supported by scientific studies seeking to legitimize claims that the lionfish meets nutritional and safety requirements for human consumption, by REEF, and by celebrity chefs who promote lionfish as sustainable seafood (Morris et al., 2011). In the media this campaign was translated as a "do-good dish that helps balance ocean ecology" (Glader 2010). In 2010, NBC News aired a piece entitled "Do Your Civic Duty, Eat This Fish!” (Huus 2010).

Respondents from Bonaire and Curaçao reported catching lionfish for their own consumption or sale to local restaurants. Lobster fishermen in the Florida Keys and Sian Ka'an were increasingly harvesting lionfish as by-catch in their traps and started to capitalize on the new species. Calls to further commercialize lionfish are being voiced by various stakeholder groups throughout the region. However, the discourse that advocates lionfish removal and consumption is been challenged by a coalition that questions safety for harvesters and consumers, and points to possible ecological and social side effects of an established lionfish fishery.

\section{Storyline: Don't eat lionfish}

Concerns about ciguatera poisoning through lionfish consumption were raised in various locations (Note: Ciguatera fish poisoning is a foodborne illness caused by consumption of the flesh of tropical marine fish that carry a toxic dinoflagellate). On November 22, 2011, the blog Green Antilles published a report titled "More data emerges about ciguatera toxin in lionfish" (Green Antilles; http:// www.greenantilles.com/2011/11/22/more-data-emerges-about-ciguateratoxin-inlionfish/). This report and a press release by the NGO that manages the MPA on St. Maarten warned the population not to eat lionfish caught in North-eastern Caribbean waters, a known ciguatera region: "We tested several samples of lionfish 


\section{Chapter 4}

meat and have found that unfortunately an uncomfortably high percentage showed the presence of ciguatoxin" (Nature Foundation 2011). Although no specific numbers were mentioned, the "data" in this press release initiated the to-eat-or-notto-eat lionfish debate. A government official interviewed stated that "one of the biggest bottlenecks or barriers to lionfish control is the ciguatera issue."

Various respondents from the Eastern Caribbean challenged the validity of the data based on the quality of the test kit used, which was according to MPA staff members from Saba and St. Eustatius, respectively, a "very basic test" and "like a home-made kit...very sensitive...it can pick up other stuff as well.... And then the discussion waswas it really ciguatera or was it showing something else? There's really no answers." St. Maarten's MPA staff acknowledged the disputed quality of the test results: "We just had a positive or negative assay that we used so it's probably, you know, it can be that it was minuscule amounts, but as a conservation organization we were not comfortable promoting the fish as edible."

In contrast, a highly placed MPA staff member from St. Eustatius said they promoted lionfish consumption on the island: "We eat them here all the time, all the staff. I've eaten like 150 of them. We have not had any [ciguatera poisoning] incidents here, absolutely not." The local population in St. Eustatius was not used to the new fish but according to the MPA representatives, many people had tasted lionfish dishes during an MPA outreach event. Of the three fishermen interviewed in St. Eustatius, one declared that he ate lionfish.

Tests conducted by the U.S. Food and Drug Administration (FDA) in the U.S. Virgin Islands added to the ciguatera debate (Robertson et al., 2013). The NBC News of June 2012 positioned the two U.S. federal agencies against each other: NOAA promotes lionfish consumption whereas the FDA "certainly do[es]n't promote any campaign like that since we have found levels above our guidance," according to lead author Robertson (Aleccia, 2012). Referring to these data, which were still unpublished when NBC featured the story, a Florida stakeholder observed:

There was a report that was pretty damaging - a few months ago-about ciguatera poisoning and lionfish in bigh frequency... I thought it was fairly irresponsible to release that. I believe where they did the research was in a high ciguatera poisoning area anyway, so the groupers and snappers probably have just as high a level as the lionfish.... So, when you're trying to create a level of demand for [lionfish] consumption here in the States, where 
there's no high levels of ciguatera poisoning, they create a situation where the demand goes away because people read that " $40 \%$ of lionfish have ciguatera poisoning."

A few days after the NBC News story appeared, the Florida Keys News cited the FDA's spokesman seeking "to walk the agency back from Robertson's remarks," explaining that none of the lionfish tested in the study originated from the Keys (Silk 2012). The spokesman added nonetheless that "the Keys, along with several Caribbean islands, are known ciguatera zones." Staff from NOAA and the MPA responded by stressing that ciguatera is present in a variety of reef fishes, not only lionfish. The same week the Florida Sea Grant Program, a large research funding body, had issued a statement in response to the FDA data:

$[D]$ espite the fact that $N O A A$ has an ongoing program to teach people how to catch and cook lionfish, given this new information, under no circumstances should any person affiliated with Florida Sea Grant advocate consuming these fish, regardless of the location from which they are taken. If someone tells you it is $O K$ to eat lionfish, tell them that the latest FDA science indicates that there is a significant risk, and it is recommended that they DO NOT eat them. (Gill 2012)

The eat-them-to-beat-them coalition contends that "whatever small risk there is, is outweighed by the benefit [to the ecosystem]" and that "legitimate concerns about ciguatera should be balanced by responsible sourcing" (Aleccia 2012).

The FDA results were published in 2013 and, interestingly, the paper concludes that there are no data to suggest that lionfish outside of known ciguatera-endemic regions would be ciguatoxic (Robertson et al., 2013). However, the paper does not specify where these regions are, nor does it show where the toxic fish in their samples originated from within the U.S. Virgin Islands. Traditionally, ciguatera hotspots have been identified through local knowledge of fishers and residents. Respondents in this study indeed referred to some of these areas such as the Saba Bank, sometimes called the "poison bank" because of high ciguatera prevalence. Whereas the position of Saba's MPA staff and dive operators interviewed regarding lionfish consumption was ambivalent (hesitation because of "the tests they did at St. Maarten"), Saba fishermen have reported eating locally caught lionfish. Respondents from Bonaire, Curaçao, and Sian Ka'an did not seem to consider ciguatera a risk given the absence of this topic in their lionfish consumption stories. 


\section{Chapter 4}

Envenomation through a sting from lionfish spines is another risk mentioned by individuals sceptical of the eat-lionfish discourse. Although its spines are venomous, lionfish flesh is not poisonous, a distinction that if not understood causes apprehension among potential consumers (Anguillian, 2012). Venomous organisms deliver or inject a toxin directly, usually from an internal gland. Poisonous organisms typically secrete a toxin externally and may be harmful when touched or ingested. Lionfish is thus venomous but not poisonous, and the highest risk of being stung hence accrues to those who harvest or process the fish. The eat-them-to-beat-them coalition emphasizes that once the spines are removed (or cooked), eating the fish is safe. Also, this coalition stresses that no fatalities have been reported from envenomations. Respondents from Sian Ka'an report a shift from the initial stages of the invasion, when people were scared to get stung, to a situation where eating lionfish has become widely accepted in neighboring Cozumel, which is profiling itself as a culinary touristic destination, with lionfish as key attraction (Cruz 2013).

Promotion of invasive species consumption to control populations is not new, but the trend has intensified in recent years and has been picked up by the media, using the term "invasivores" to refer to "those who eat non-native (invasive) species" (Gorman 2010). The Mexican agency CONANP released a documentary entitled Lionfish: From Threat to Opportunity that showcases a fishing cooperative harvesting lionfish in Sian Ka'an both for the local and international seafood markets (CONANP 2012). Media headlines in various Caribbean sites provide a similar message: "Scourge of the Lionfish, Part 3: The Newest Fish in the Kitchen" (Safina 2012a) and "Lionfish: Profitable Danger" (Avila 2013). This stance fits with the reparation metaphor.

Caveats about mitigation efforts that rest on consumption of the invasive species are recognized. The New York Times warned that marketing invasive species may make them so popular that people "raise or release the fish where they did not already exist... potentially exacerbating the problem" (Rosenthal 2011). Respondents from Curaçao and Bonaire contend that some individuals purposefully leave the small lionfish in the reef to grow larger:

It started out pretty good, now that there's a market and people can make money out of it, people are getting greedy.... For example, they would leave the small fish behind and would go back a couple of weeks later so that [the lionfish is] big enough so that they can make money. 
Among ecologists, the dominant discourse is that lionfish consumption is a promising control strategy. Only one article was found where a marine biologist questioned the effectiveness of lionfish commercialization, in particular if regulatory aspects are not addressed simultaneously. The author's arguments are in line with those of The New York Times. Further, he criticizes the way lionfish commercialization has evolved in Mexico, which he calls a disorganized market with "malicious incentives to either monopolize markets or even prevent benevolent people to make a living of the new market" (Aguilar-Perera 2012:318). For some respondents, harvesting lionfish manually for food is not worth the trouble because of the effort, costs, and risk involved in capturing and processing lionfish, and because the flesh yield is limited. Within the eat-lionfish coalition, development of a specialized lionfish trap is advocated, but the counterarguments are that, besides being expensive to develop, traps are not as species specific (hence sustainable) as manual removals. A spear lionfish versus trap-lionfish debate has emerged on the grounds of cost-effectiveness and sustainability of removal methods, but thus far no data had been brought forward to substantiate claims.

\subsection{Discussion}

\subsubsection{Scientific and media construction of the lionfish invasion}

The use among ecologists of subjective and normative terms to refer to the lionfish and its management is similar to how other introduced species considered harmful are conceptualized and portrayed in scientific studies, a practice that has been constantly debated (Brown and Sax 2004; Colautti and MacIsaac 2004; Cassey et al., 2005; Colautti and Richardson 2009; Young and Larson 2011). The shrub Tamarix, for instance, considered invasive in the western United Sates, has been referred to as "evil" by scientists who argue for its removal (Stromberg et al., 2009). Expressions of subjectivity and advocacy by scientists are disapproved of by some scholars, who argue that these expressions undermine scientific credibility, while being defended by others as a logical result of the values that guide people toward a career in ecology and conservation biology (Barry and Oelschlaeger 1996; Brown and Sax 2004; Cassey et al., 2005; Larson 2007a; Colautti and Richardson 2009).

These tensions are illustrated by a survey among 422 invasion biologists, which showed that $94 \%$ agreed with the statement: "The role of scientists in studying invasive species should be to gather, interpret, and communicate information as 


\section{Chapter 4}

accurately and objectively as possible" (Young and Larson 2011:895). However, responses were split regarding the statement "Any characterization that nonindigenous species are good or bad is a value judgment, not science" (49\% agreed, 40\% disagreed; Young and Larson 2011:895), which suggests that some scientists may not recognize the underlying values they communicate along with their findings. The scientific discourse on Atlantic lionfish is clear in its characterization of this species as a threat, hence bad for native ecosystems, based on measured and assumed impacts (but see Elise et al., 2015), and this characterization reflects the values and beliefs encapsulated by nativism.

News reports' uptake of the scientific message on lionfish echoes other studies on the conceptualization and framing by the media of invasive species as enemies (Larson 2008). Media reports consistently quoted lionfish scientists and experts, a common journalistic practice to ensure empirical validity and enhance media credibility (Pan and Kosicki 1993). Also, various news items built their story around recently released scientific studies, including data and interviews with the authors. In this study I found that scientists' language use when interviewed by the media was more emotive than that in their academic reports. Wong (2002) similarly showed that invasion scientists in the United States admit communicating with other scientists through journals differently than they communicate with the public through journalists. Despite their recognition that terms such as invasive, alien, or exotic are loaded, scientists use them to capture public attention (Wong 2002).

A study on the social construction of purple loosestrife, an invasive plant in North American wetlands, found that the media attributed more negative impacts to the plant than scientists did (Lavoie 2010). In contrast, media and scientific reports portrayed a comparable image of lionfish, although the media's language use was more inflated. Militaristic metaphors, for instance, were more widespread and explicit in media reports than in scientific writings on lionfish. Social scientists commonly criticize the practice of appealing to the fear factor through use of war and catastrophe metaphors related to invasive species. As such, a sense of urgency and need for action are created, but these can result in paralysis or counteraction instead of the hoped-for action (Gobster 2005, Nerlich and James 2009).

During the initial stages of the lionfish invasion, warnings by scientists, management agencies, and the media instilled fear among marine resource users. By using not only catastrophe frames, however, but also solution-oriented frames such as lionfish 
removal and consumption, the dominant discourse on lionfish has been successful in its call for action, as demonstrated by the findings of this study and by multiple reports of divers and fishers engaged in lionfish control throughout the region (Morris 2012; Festa 2014), as well as the August 2014 import ban of live lionfish into the state of Florida (Talbot 2014). Solution frames are consistent with the rehabilitation and reparation metaphors, with the latter's emphasis on the function of lionfish not only as a new commodity but also as a green seafood choice, contributing to a win-win rhetoric.

\subsubsection{Stakeholder constructions of the lionfish invasion}

Although the majority of the respondents perceived lionfish as a threat and engaged in lionfish control, about $20 \%$ of respondents diverged from this dominant discourse, their views best fitting with the recombination metaphor. On the Eastern Caribbean islands, divergent positions had proportionally larger implications for lionfish management than in the other MPAs studied because of the smaller number of stakeholders available to participate in lionfish removal activities. For instance, whereas only two dive operators exist on St. Eustatius and three on Saba, managers and/or staff from one dive shop at each site refused to engage in lionfish removals. From the perspective of MPA goals, this position is in conflict with the intended aims to control lionfish at the local scale.

Among stakeholders within the "Kill lionfish" coalition, lionfish perceptions seemed to be influenced by the lionfish numbers that respondents personally observed underwater, in particular when there was a rapid increase in numbers, coupled to factual understanding of the species' voraciousness. Among opponents of removals, willingness to engage in this activity was expressed by certain individuals only if lionfish numbers would increase in their area. In a survery conducted by Scyphers et al. (2014) among spearfishers in the Gulf of Mexico, 75\% of respondents perceived lionfish as harmful or very harmful for marine ecosystems. Scyphers et al., showed that perceived harmfulness was correlated to spearfishers' reported encounters with lionfish during their dives and that these perceptions were a powerful predictor of individuals' willingness to participate in control initiatives (ibid). The findings of my study, although not based on a quantitative approach, are consistent with the survey results reported by Scyphers et al. (2014). 


\section{Chapter 4}

The eat-them-to-beat-them discourse, based on the view that fishermen are capable of exploiting fish almost to extinction (Moore 2012), is challenged by a coalition that questions the safety and effectiveness of the practices promoted by this campaign. Potential side effects could backfire because incorporating lionfish into local cuisines could undermine desired ecological outcomes. Indeed, a nascent discourse on lionfish as fulfilling the role of overexploited native species, primarily expressed in economic terms but possibly in the cultural sense as well (Nuñez et al., 2012; Festa 2014), is shifting lionfish impacts from negative to positive among various stakeholder groups.

Competing discourses regarding the consumption of lionfish emerged because of ciguatera risk perceptions. At a meeting in November 2013, the kill-and-eat-lionfish coalition argued that lionfish should be treated like other reef fish with regards to ciguatera by the seafood industry and seafood health regulators (Bogdanoff et al., 2014). Renewed research interest on the topic is generating new data and feeding the debate, such as the recent finding that false-positive tests for ciguatera may be occurring because of the similarity between ciguatoxins and lionfish venom (Wilcox and Hixon 2014).

The balance of nature was a recurrent trope in many stakeholders' discourses. Whereas in ecology, perceptions of ecosystems have shifted from static entities in equilibrium to dynamic, complex, and unpredictable systems (Wu and Loucks 1995), the balance metaphor persists among many ecologists (Cuddington 2001) and in lay people's beliefs about nature (Buijs 2009). The role of predators, including humans, in maintaining lionfish populations within some balance threshold is a key discursive element herein and a source of debate. Regarding biocontrol, four scientific studies have addressed the question of whether natural predators are preying on healthy lionfish and/or affecting their populations in Caribbean reefs, with mixed results (Mumby et al., 2011; Hackerott et al., 2013; Diller et al., 2014; Valdivia et al., 2014). In 2014, Saba fishermen reported frequent observations of lionfish in snappers' stomachs trapped at 100-m depth, a finding that a local manager wanted to confirm through a scientific approach (Spalburg 2014). Anecdotal evidence of lionfish being preyed upon have become "scientific" data when these observations were verified and reported in academic journals (Maljković et al., 2008; Pimiento et al., 2013).

Lionfish control by humans is controversial for various reasons, including doubts of the effectiveness of spearfishing (Côté et al., 2014) and concerns that some 
individuals could abuse amendments made to spearfishing gear use and no-take zone regulations in various MPAs to target other species. On Bonaire and Curaçao, for instance, spearfishing is illegal and special permits are issued for lionfish capture only (de León et al., 2013), but enforcement is difficult. Moreover, moral considerations play a role among a minority who opposes killing lionfish. Animal rights discourses have dominated the debate in other cases of invasive species management, particularly when species are considered charismatic. For example, plans to eradicate the American grey squirrel in Italy because of concerns about its competitive exclusion of the native red squirrel were halted because of public opposition (Genovesi and Bertolino 2001).

Studies have shown that public attitudes to species management are influenced by how target species are perceived (Bremner and Park 2007). For instance, perceptions differ between "hated invasives" such as rats and "attractive invasives" as birds and certain plant species (Bremner and Park 2007). Also, people tend to have negative perceptions of predators (Kellert 1985). In the case of lionfish, many stakeholders reported mixed feelings toward this species. A New York Times science writer reflects: "It's a sad commentary about how we're changing the world that killing and eating one of the world's most beautiful fish-as long as they're from the Caribbean or Atlantic Ocean—actually helps" (Safina, 2012b).

\subsection{Conclusions}

The lionfish invasion of the Western Atlantic Ocean has driven two significant shifts in scientific discourses on marine fish invasions and their vector. Initially considered rare and low risk, now marine fish invasions are believed to be potentially common and high risk. Secondly, the aquarium industry, which was previously not recognized as an important introduction vector, is now subject to scrutiny and public pressure.

Current scientific understanding of Atlantic lionfish is characterized by a discourse that conceptualizes lionfish as a threat and that advocates lionfish removal programs to mitigate its negative impacts on vulnerable ecosystems and human communities. The media have taken over and amplified this message, adding some balance on the invasivore issue, while MPA stakeholders incorporate their own experiences into their lionfish accounts, resulting in some divergence from scientific claims. In building their arguments about lionfish, actors use data and information that substantiate their views, and do so using particular metaphorical lenses. Stakeholders challenge the validity of scientific data by drawing from their own experience, as in 


\section{Chapter 4}

the ciguatera risk or the biocontrol debates. In some cases, systematic observations by stakeholders to test their own hypotheses in pseudo experiments arguably approach scientific methods, e.g., eating "150 lionfish and getting no ciguatera."

Discourses may converge in the future on the biocontrol debate. Despite numerous incidents of large reef fish and lobsters preying on lionfish reported by fishers and divers, this "citizen data" or local knowledge is not yet considered scientific and hence is put aside in the current discourse. If data accumulate on direct and indirect observations of lionfish being preyed upon to levels that could control their numbers, the enemy-release hypothesis could be challenged at least in particular sites.

This study illustrates that biological invasions should be understood as a socialecological phenomenon. Scientific data and metaphors, amplified by the media, proved instrumental to gain initial understanding of the new lionfish phenomenon and to legitimize claims. In time, however, local knowledge and societal values have intermingled with scientific data, sometimes challenging scientific discourses, and always contributing to a richer understanding of the invasion in all its facets. 
Controversies and consensus on the lionfish invasion 
CHAPTER 


\section{Citizen science regarding invasive lionfish in Dutch Caribbean MPAs: Drivers and barriers to participation ${ }^{6}$}




\begin{abstract}
Understanding the drivers and barriers to participation in citizen science initiatives for conservation is important if long-term involvement from volunteers is expected. This study investigates the motivations of individuals from five marine protected areas (MPAs) in the Dutch Caribbean to (not) participate in different initiatives around lionfish. Following an interpretive approach, semi-structured interviews with seventy-eight informants were conducted and analyzed using thematic network analysis. Approximately $60 \%$ of informants indicated that they had participated in citizen science initiatives at the outset of the invasion. From this group, almost half said that they still participated in some type of data collection, but only a few did so within a citizen science context. Many informants were initially motivated to participate in lionfish detection and response initiatives due to concern for the environment. Personal meanings attached to both the data collection experiences and to the data influenced informants' motivations to sustain or cease data collection and/or sharing. In time, the view of lionfish as a threat changed for many informants as this species' recreational and/or commercial value increased. Enabling and constraining factors for data collection and sharing were identified at the personal, interpersonal, organizational and technological levels. Our findings have implications for the design of future citizen science initiatives focused on invasive species.
\end{abstract}




\subsection{Introduction}

Public participation in recording observations of the natural world has a centurieslong history (Lawrence and Turnhout, 2010; Miller-Rushing et al., 2012). Over the past few decades, involvement of citizens in the production of data to address environmental management and biodiversity conservation issues, referred to as environmental-based or conservation citizen science, has grown considerably worldwide (Catlin-Groves, 2012; Roy et al., 2012; Silvertown, 2009; Wiggins and Crowston, 2011). Although a vast literature has investigated the benefits of involving citizens in science for conservation (Section 5.2), there is relatively limited research that explores what drives, and limits, citizen participation in such initiatives.

Management of invasive lionfish relies on public participation (Morris, 2012; Harvey and Mazzotti, 2015). Because lionfish eradication is regarded as unlikely, scientists and managers emphasize that long-term commitments to control lionfish populations at the local scale will be required (Arias-González et al., 2011; Gómez Lozano et al., 2013). Reporting and documentation are considered valuable components of lionfish control strategies as sightings and capture data help to direct removal efforts and assess their effectiveness (Morris, 2012). It follows then that sustained participation in both lionfish capture and reporting of sightings and removals is seen as important for lionfish management. Understanding what drives, enables and constrains individuals to participate is essential not only to engage volunteers, but also to ensure sustained participation in lionfish management.

The aim of this qualitative study is to elucidate what compels people to, and deters them from, collecting and sharing data related to invasive lionfish in various marine protected areas (MPAs) in the Caribbean. The focus is on the personal values and meanings attached to participation in such activities. The research questions are i) What motivates individuals to participate in lionfish-focused data collection and sharing initiatives? ii) (How) do motivations change in time? and iii) which factors enable and constrain participation?

In the next section the conceptual framework that guided our analysis of the drivers and barriers to participation in lionfish-focused citizen science is developed. Section 5.3 explains the research approach and methods used. Sections 5.4 and 5.5 present and discuss the findings, respectively. The concluding section considers the implications of these findings for conservation citizen science in general, and for lionfish management in the Caribbean, in particular. 


\subsection{Citizen science, lionfish management in MPAs and motives to participate}

\subsubsection{Defining conservation citizen science}

Numerous definitions and typologies of citizen science have been offered in the literature (Irwin, 1995; Bonney et al., 2009a; Wiggins and Crowston, 2011; European Commission, 2013). In the United States, the term citizen science is predominantly used to describe large-scale and scientist-led data collection initiatives in ecology studies (Bonney et al., 2009b). In Europe, citizen science is mostly understood within social studies of science as "a philosophy of engaging public perspectives and knowledges in science discourse and policy making” (Shirk et al., 2012:2).

Many different terms that partly overlap with these two conceptualizations of citizen science are employed to describe voluntary public participation in research or monitoring for conservation. Examples include community science (Carr, 2004), community- based environmental monitoring (Conrad and Hilchey, 2011), volunteer biological monitoring (Lawrence, 2006), locally-based monitoring (Danielsen et al., 2005), participatory monitoring (Bell et al., 2008), participatory research (Almany et al., 2010), volunteered geographic information (Haklay, 2013), public participation in scientific research (Shirk et al., 2012), public participation GIS (Newman et al., 2010), recreational monitoring (Goffredo et al., 2010), research ecotourism (Bell et al., 2009), and crowdsourcing (Wiggins and Crowston, 2011).

In this paper conservation citizen science is understood as encompassing community-based monitoring and management, which is defined as "a process where concerned citizens, government agencies, industry, academia, community groups, and local institutions collaborate to monitor, track and respond to issues of common ... [environmental] concern" (Conrad and Hilchey, 2011:274). Participatory initiatives for detection and control of invasive lionfish illustrate this approach. Table 5.1 provides an overview of lionfish-focused citizen science programs throughout the Caribbean.

Several trends are contributing to the recent proliferation of citizen science programs for conservation. Such trends include a shift towards more participation in the provision of knowledge for biodiversity and environmental governance (Rauschmayer et al., 2009; Bell et al., 2008; Roy et al., 2012), and declining funds for 
resource managers, who increasingly rely on local communities to carry out monitoring and management tasks (Parfitt, 2013; Danielsen et al., 2009). In marine environments, such tasks can be particularly costly as underwater research and monitoring require specialized equipment and skills, including scuba certification (Cuthill, 2000).

Table 5.1 Examples of citizen science initiatives focused on lionfish throughout the Caribbean Sea (Google search 1 Sept. 2015 using keywords: lionfish AND monitoring).

\begin{tabular}{|c|c|c|c|c|}
\hline $\begin{array}{l}\text { Initiators and } \\
\text { program name }\end{array}$ & Stated goal & Target group & Location & Reference \\
\hline $\begin{array}{l}\text { Cape Eleuthera } \\
\text { Institute: Lionfish } \\
\text { research program }\end{array}$ & $\begin{array}{l}\text { To conduct research, } \\
\text { outreach and } \\
\text { education on lionfish }\end{array}$ & $\begin{array}{l}\text { Local community } \\
\text { (spearing) \& } \\
\text { school children } \\
\text { (citizen science } \\
\text { programs) }\end{array}$ & Bahamas & $\begin{array}{l}\text { http://www.ceibahamas.or } \\
\text { g/research/lionfish/ }\end{array}$ \\
\hline $\begin{array}{l}\text { Blue Ventures: } \\
\text { Invasive lionfish } \\
\text { monitoring \& } \\
\text { research } \\
\text { expedition }\end{array}$ & $\begin{array}{l}\text { To contribute to } \\
\text { research and remove } \\
\text { invasive lionfish }\end{array}$ & Tourist volunteers & Belize & $\begin{array}{l}\text { https://blueventures.org/e } \\
\text { xpeditions/belize/lionfish- } \\
\text { dive-trips/ }\end{array}$ \\
\hline $\begin{array}{l}\text { TIDE: } \\
\text { Lionfish research }\end{array}$ & $\begin{array}{l}\text { To understand } \\
\text { lionfish behaviour } \\
\text { and instigate effective } \\
\text { control methods }\end{array}$ & Local community & $\begin{array}{l}\text { Port Honduras } \\
\text { Marine Reserve } \\
\text { (PHMR), Belize }\end{array}$ & $\begin{array}{l}\text { http://www.tidebelize.org/ } \\
\text { article/sep-2014/lionfish- } \\
\text { research }\end{array}$ \\
\hline $\begin{array}{l}\text { Ocean Support } \\
\text { Foundation: } \\
\text { Lionfish spearing } \\
\text { initiative }\end{array}$ & $\begin{array}{l}\text { To spear lionfish and } \\
\text { report data }\end{array}$ & $\begin{array}{l}\text { Resident \& } \\
\text { visiting divers }\end{array}$ & Bermuda & $\begin{array}{l}\text { http://www.oceansupport. } \\
\text { org/what-we-do }\end{array}$ \\
\hline $\begin{array}{l}\text { Caribbean Marine } \\
\text { Institute: Dive with } \\
\text { a researcher }\end{array}$ & $\begin{array}{l}\text { To monitor and catch } \\
\text { lionfish }\end{array}$ & Tourist volunteers & $\begin{array}{l}\text { Little Cayman, } \\
\text { Cayman Islands }\end{array}$ & $\begin{array}{l}\text { http://www.greentravelgui } \\
\text { des.tv/videos/the_cayman } \\
\text { islands-lion_fish }\end{array}$ \\
\hline $\begin{array}{l}\text { Dutch Caribbean } \\
\text { Nature Alliance: } \\
\text { Lionfish control } \\
\text { application }\end{array}$ & $\begin{array}{l}\text { To help monitor and } \\
\text { control this invasive } \\
\text { species by providing } \\
\text { insight into lionfish } \\
\text { distribution and } \\
\text { success of removal } \\
\text { efforts }\end{array}$ & $\begin{array}{l}\text { Lionfish hunters \& } \\
\text { the public }\end{array}$ & $\begin{array}{l}\text { Dutch Caribbean } \\
\text { (Bonaire, } \\
\text { Curacao, Aruba, } \\
\text { St. Maarten) }\end{array}$ & $\begin{array}{l}\text { http://www.lionfishcontrol. } \\
\text { org/ } \\
\text { and } \\
\text { http://www.denanature.or } \\
\text { g/lionfishcontrolapplication } \\
\text {-2/ }\end{array}$ \\
\hline $\begin{array}{l}\text { Florida Fish and } \\
\text { Wildlife } \\
\text { Conservation } \\
\text { Comm.: } \\
\text { Report lionfish }\end{array}$ & $\begin{array}{l}\text { To raise awareness of } \\
\text { the dangers facing } \\
\text { Florida waters by } \\
\text { lionfish }\end{array}$ & $\begin{array}{l}\text { Divers, } \\
\text { snorkelers, fishers }\end{array}$ & Florida & $\begin{array}{l}\text { http://myfwc.com/reportli } \\
\text { onfish }\end{array}$ \\
\hline $\begin{array}{l}\text { Reef Monitoring } \\
\text { Inc.: } \\
\text { Lionfish Roundup! }\end{array}$ & $\begin{array}{l}\text { To remove as many } \\
\text { lionfish as possible } \\
\text { while continuing to } \\
\text { find better control } \\
\text { methods }\end{array}$ & Sport divers & Florida & $\begin{array}{l}\text { http://www.reefmonitoring } \\
\text {.org/lionfish-roundup.html }\end{array}$ \\
\hline
\end{tabular}




\section{Chapter 5}

\begin{tabular}{|c|c|c|c|c|}
\hline $\begin{array}{l}\text { Initiators and } \\
\text { program name }\end{array}$ & Stated goal & Target group & Location & Reference \\
\hline $\begin{array}{l}\text { Reef } \\
\text { Environmental } \\
\text { Education } \\
\text { Foundation (REEF): } \\
\text { Lionfish invasion } \\
\text { research program }\end{array}$ & $\begin{array}{l}\text { Sightings data used to } \\
\text { track exotic species } \\
\text { introductions, } \\
\text { document spread and } \\
\text { serve as an early } \\
\text { warning system }\end{array}$ & $\begin{array}{l}\text { Recreational } \\
\text { divers \& } \\
\text { snorkelers }\end{array}$ & $\begin{array}{l}\text { Florida and rest of } \\
\text { Caribbean }\end{array}$ & $\begin{array}{l}\text { http://www.reef.org/progr } \\
\text { ams/monitoring }\end{array}$ \\
\hline $\begin{array}{l}\text { Caribbean Reef } \\
\text { Buddy: } \\
\text { Lionfish monitoring } \\
\text { and culling } \\
\text { program }\end{array}$ & $\begin{array}{l}\text { Hunt, record catch } \\
\text { data, stomach } \\
\text { content analysis }\end{array}$ & $\begin{array}{l}\text { Tourists (certified } \\
\text { PADI Open Water } \\
\text { divers) }\end{array}$ & $\begin{array}{l}\text { Grenada, West } \\
\text { Indies }\end{array}$ & $\begin{array}{l}\text { http://www.caribbeanreefb } \\
\text { uddy.org/lionfish.html }\end{array}$ \\
\hline $\begin{array}{l}\text { Roatan MPA: } \\
\text { Lionfish program }\end{array}$ & $\begin{array}{l}\text { To reduce the impact } \\
\text { of lionfish }\end{array}$ & Local community & Honduras & $\begin{array}{l}\text { http://www.roatanmarinep } \\
\text { ark.com/research/lionfish- } \\
\text { program/ }\end{array}$ \\
\hline $\begin{array}{l}\text { Marine Institute of } \\
\text { Martinique }\end{array}$ & $\begin{array}{l}\text { To map lionfish } \\
\text { spread and follow } \\
\text { individuals' removal } \\
\text { rates }\end{array}$ & $\begin{array}{l}\text { Divers, } \\
\text { snorkelers, fishers }\end{array}$ & $\begin{array}{l}\text { Martinique, } \\
\text { French West } \\
\text { Indies }\end{array}$ & (Trégarot et al., 2015) \\
\hline $\begin{array}{l}\text { Yucatán } \\
\text { Autonomous } \\
\text { University: Mayan } \\
\text { diver/fishers as } \\
\text { citizen scientists }\end{array}$ & $\begin{array}{l}\text { To map lionfish } \\
\text { spread by collecting } \\
\text { location data and } \\
\text { specimens } \\
\text { To build local capacity } \\
\text { and awareness }\end{array}$ & $\begin{array}{l}\text { Mayan lobster } \\
\text { fishers }\end{array}$ & $\begin{array}{l}\text { Alacranes Reef } \\
\text { MPA } \\
\text { Yucatan, Mexico }\end{array}$ & López-Gómez et al 2014 \\
\hline $\begin{array}{l}\text { Tropical } \\
\text { Conservation } \\
\text { Consortium: } \\
\text { Lionfish control \& } \\
\text { management }\end{array}$ & $\begin{array}{l}\text { To develop a lionfish } \\
\text { control and } \\
\text { monitoring program }\end{array}$ & Local community & Panama & $\begin{array}{l}\text { http://www.tropicalcc.org/l } \\
\text { ionfish-control- } \\
\text { management/ }\end{array}$ \\
\hline $\begin{array}{l}\text { Gulf Coast Lionfish } \\
\text { Coalition: } \\
\text { Education, } \\
\text { mitigation } \\
\text { utilization }\end{array}$ & $\begin{array}{l}\text { To monitor and } \\
\text { enhance reef health } \\
\text { by identifying lionfish } \\
\text { hot spots }\end{array}$ & $\begin{array}{l}\text { Researchers, } \\
\text { divers, fishermen } \\
\text { \& lionfish hunters }\end{array}$ & $\begin{array}{l}\text { U.S. Gulf of } \\
\text { Mexico (Alabama, } \\
\text { Florida, Louisiana, } \\
\text { Texas) }\end{array}$ & $\begin{array}{l}\text { http://www.gulfcoastlionfis } \\
\text { h.com/lionfish_map.html }\end{array}$ \\
\hline $\begin{array}{l}\text { C.O.R.E. } \\
\text { Foundation: } \\
\text { Community lionfish } \\
\text { response }\end{array}$ & $\begin{array}{l}\text { To report sightings or } \\
\text { extract lionfish }\end{array}$ & $\begin{array}{l}\text { Fishers, divers, } \\
\text { marine users, } \\
\text { CORE members }\end{array}$ & $\begin{array}{l}\text { U.S. Virgin } \\
\text { Islands, British V.I. } \\
\text { and Puerto Rico }\end{array}$ & $\begin{array}{l}\text { http://www.corevi.org/com } \\
\text { munity-lionfish- } \\
\text { response.html }\end{array}$ \\
\hline $\begin{array}{l}\text { Joint Nature } \\
\text { Conservation } \\
\text { Committee: The } \\
\text { Caribbean lionfish } \\
\text { project }\end{array}$ & $\begin{array}{l}\text { To focus and develop } \\
\text { efforts to monitor } \\
\text { and control lionfish }\end{array}$ & The public & $\begin{array}{l}\text { U.K. Overseas } \\
\text { Territories } \\
\text { (British Virgin Is., } \\
\text { Cayman Is., Turks } \\
\text { and Caicos) }\end{array}$ & $\begin{array}{l}\text { http://jncc.defra.gov.uk/pa } \\
\text { ge-5396-theme=default }\end{array}$ \\
\hline
\end{tabular}


Converging with these governance and management shifts are the rise of the Internet and mobile information and communication technologies (ICTs), as well as the development of sophisticated data analysis tools. These technologies and tools enable collection, processing and dissemination of large amounts of data, spanning wide spatial and temporal scales, by numerous and diverse individuals (Devictor et al., 2010; Bonney et al.,2014; Arts et al., 2015). For instance, over the past several years thousands of lionfish sightings have been reported by concerned citizens to a publicly accessible database that maps lionfish distribution in the entire invaded region, encompassing more than 7 million $\mathrm{km}^{2}$ (Schofield et al., 2015; Côté et al., 2013).

\subsubsection{Lionfish management in Caribbean MPAs}

The appearance and rapid expansion of Indo-Pacific lionfish throughout the Western Atlantic Ocean has been a topic of concern for scientists, marine managers, resource users and policy makers during the past decade (Morris, 2012). Lionfish are considered a severe threat due to their high predation rates of ecologically and economically important native species (Green et al., 2012; Albins and Hixon, 2008) and their apparent resistance to predation (Valdivia et al., 2014; Mumby et al., 2013). This has prompted a group of international scientists to declare the lionfish invasion as one of the world's top fifteen issues that could affect biodiversity conservation goals (Sutherland et al., 2010).

In the Caribbean, where coral reef ecosystems generate more than US $\$ 3$ billion from fisheries and tourism yearly, reefs have declined by $50 \%$ in less than fifty years due to a suite of local and global stressors including overfishing, pollution, coastal development and global warming (Jackson et al., 2014). Lionfish effects and climate change are expected to contribute to persistent decline of Caribbean reefs and their associated biodiversity (Carpenter et al., 2008; Paddack et al., 2009). MPAs, including no-take reserves, are the most commonly used tool for coral reef conservation and management (Selig and Bruno, 2010), and thereby priority locations for lionfish control (Morris, 2012).

Region-wide, the chief lionfish management strategy currently focuses on targeted manual removals, carried out by spearing or netting the venomous fish (Morris, 2012). These tasks are usually conducted by MPA staff, fishers and/or divers, including professional and recreational divers. Two field studies (de León et al., 2013; 


\section{Chapter 5}

Frazer et al., 2012), four modelling studies (Johnston and Purkis, 2015; Morris et al., 2011; Barbour et al., 2011; Arias-González et al., 2011) and one study combining both approaches (Green et al., 2014) have investigated the efficacy of lionfish control efforts. These studies concur that eradication is not feasible because of lionfish high reproduction rates, efficient larval dispersal and depth constraints for divers. But suppression of lionfish below densities that cause environmental harm is possible, according to these studies, through frequent, coordinated, comprehensive and sustained lionfish removals. Despite some knowledge gaps and debates about costs and benefits of control efforts, scientists agree that these efforts are necessary to mitigate the actual and potential negative effects of lionfish on the ecosystem and the economy.

Lionfish detectability is low (Green et al., 2013) and lionfish behavior changes as a result of repeated culling, i.e. after a failed hunting attempt, lionfish adapt to make future encounters with hunters less likely (Côté et al., 2014). Hence, sustained participation of a highly skilled group of volunteers is deemed important for effective community-based lionfish monitoring and management. Throughout the invaded region, including many MPAs, people are encouraged to submit their sightings and capture data as shown in Table 5.1. This brings us to the question of what drives and limits individuals to engage in such participatory initiatives for conservation.

\subsubsection{Drivers and barriers to participation in conservation citizen science}

The environmental volunteering literature has identified various factors that motivate people to contribute their time and energy to nature-based programs, including citizen science (Jacobson et al., 2012). Drawing on functionalist theorizing about the motivations underlying human behavior, various psychological functions have been identified that are potentially served by volunteering (Clary and Snyder, 1999). In the context of environmental volunteering these functions include: expressing or acting on important values (i.e. helping the environment), learning about the natural world, socializing with other volunteers, improving natural areas used for recreation, gaining career experience and developing skills which enhance self-esteem (Bruyere and Rappe, 2007). This functional perspective suggests that different underlying motivational processes may result in similar actions. In other words, people may participate in the same activity for different reasons (Clary and Snyder, 1999). 
Main activities in conservation citizen science are collection of field data and sharing of those data. The functional approach proposes that participation in an activity, as well as sustained participation over extended periods of time, depends on whether an individual's motivations are fulfilled by the experiences derived from participation (Clary and Snyder, 1999). In a conservation citizen science context this process is not linear, however, as lived experiences during data collection may result in changes of personal values (Lawrence, 2006). Research has shown that people's motivations to participate in conservation citizen science and other nature-based volunteer programs changed in time (Rotman et al., 2014; Ryan et al., 2001). Furthermore, the values, meanings and motives involved in data collection may influence participants' willingness to share their data (Lawrence and Turnhout, 2010). Therefore, sustained participation is likely influenced by the degree to which values, meanings and experiences match the specific motivations important to the individual at different stages. Finally, other factors such as time availability, trust among participants and access to equipment or digital technology have been found to enable or constrain participation in conservation citizen science (Rotman et al., 2014). Figure 5.1 depicts the conceptual framework developed to investigate the personal motivations, experiences and factors that may enable or constrain participation in lionfishfocused citizen science.

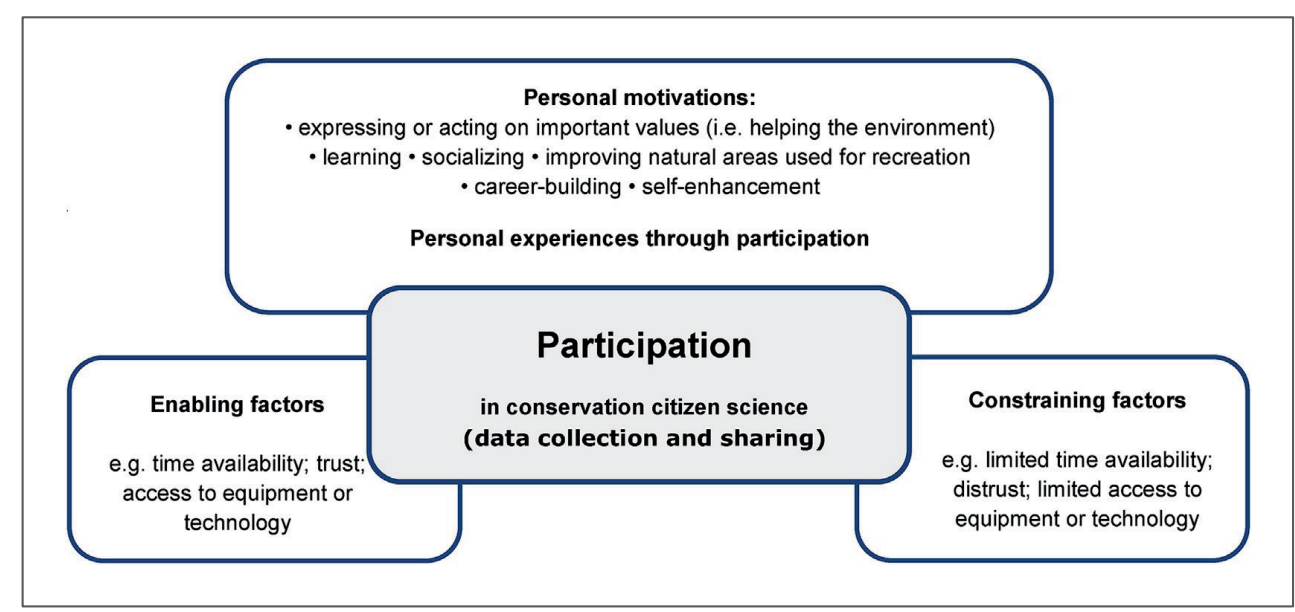

Figure 5.1 Drivers and barriers to participation in conservation citizen science. Based on Clary and Snyder (1999), Bruyere and Rappe (2007), Rotman et al., (2014), Lawrence (2006), Lawrence and Turnhout (2010). 


\subsection{Methods}

\subsubsection{Site selection and characterization}

A scan of the academic literature and online material (MPA websites, press releases, lionfish action plans) provided an overview of the Caribbean MPAs where lionfish was a management issue. MPA sites were selected based on a combination of relevance and pragmatic criteria: i) existing contacts with MPA staff, which facilitated access to these and other informants, ii) past or running citizen science initiatives about lionfish as indicated by the literature/Internet searches and e-mail correspondence with key informants, and iii) feasibility of conducting fieldwork within time and budget constraints.

This purposive sampling strategy resulted in the selection of five MPAs, all of which cover small surface areas, are managed by local non-governmental organizations (NGOs), are located in islands that comprise the Kingdom of the Netherlands and that reported first lionfish sightings between 2009 and 2010. Figure 5.2 shows the MPA locations in the Southern Caribbean (Bonaire, Curaçao) and Eastern Caribbean (Saba, St. Eustatius or Statia, St. Maarten).

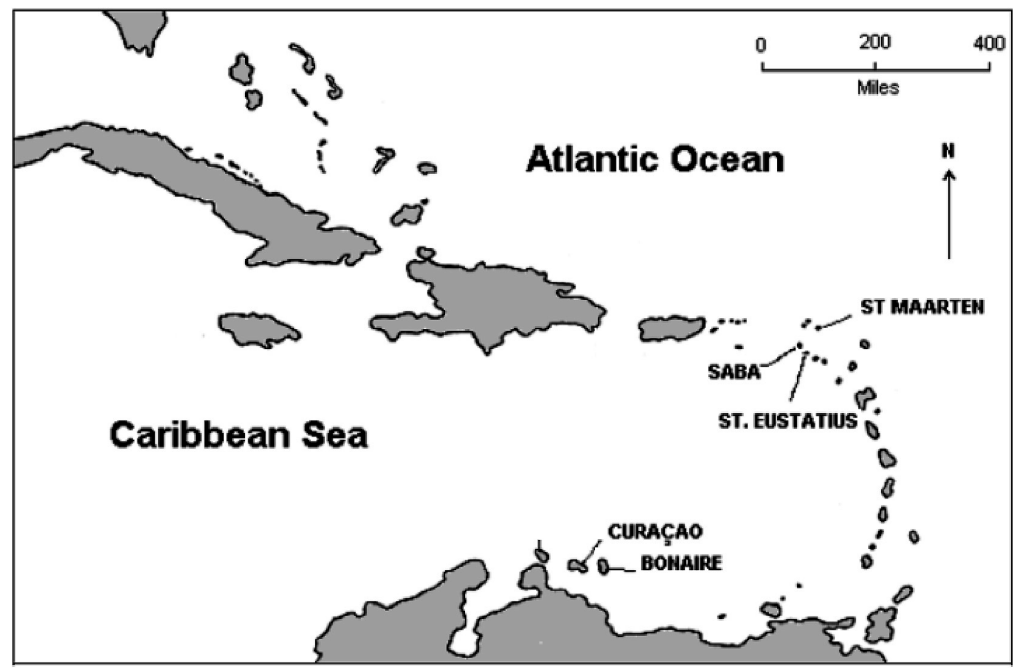

Figure 5.2 Location of the selected MPAs in the Caribbean (De Meyer and MacRae, 2006). 
In all five islands tourism represents a significant income source and activities related to the marine environment are important (Table 5.2). Bonaire and Saba host a higher number of dive shops and dive professionals, in proportion to their resident populations, than the other islands. On Bonaire, $60-75 \%$ of stay-over tourists (i.e. not arriving by cruise) are divers, whereas the other islands have a more diversified tourism sector. Historically, small-scale fisheries have been important economic and cultural activities, although the number of fishers has declined in recent decades. No systematic fisheries records have ever been kept, but recent studies have attempted to reconstruct catch data for each island for the period of 1950-2010 and to estimate the value of fisheries to the economy of Bonaire, Saba and Statia. According to these preliminary data, Saba's fisheries have a proportionally higher economic importance than fisheries in the other two islands.

A Lionfish Response Plan was developed by one MPA manager and used in all Dutch Caribbean sites for education and outreach campaigns, mainly targeting divers, snorkelers and fishers (Bervoets, 2010). The Lionfish Action Protocol included a lionfish sighting form, specimen collection and lionfish processing data sheets (ibid:23-27). These campaigns provided information on how to handle this venomous fish. At first, nets were used as removal tools, but soon the lionfish became too numerous and too large. Then, use of a modified speargun known as the ELFTM (Eradicate Lion Fish) was introduced. Spearfishing is either tightly regulated or banned in all five islands. Hence, individuals who wished to collect lionfish were required to complete a training in order to receive a spearfishing permit and a registered ELF (except on Statia, where only MPA staff was authorized to spear lionfish at the time of the interviews). "Lionfish specialty courses" were developed on Curaçao and Bonaire, where tourists were allowed to spot or spear lionfish, respectively, while supervised by a dive professional.

\subsubsection{Informant selection and characterization}

The target group consisted of individuals who played key roles in local lionfish management. Given that lionfish spearing and reporting require presence underwater, informants who were able to scuba dive were sought. Informants belonged to three diver categories. The first category encompassed professional divers: private actors in the dive tourism industry, including dive shop managers and staff. The second category encompassed those who dive as a means to accomplish certain job-related tasks - but not related to the tourism industry - including MPA 


\section{Chapter 5}

Table 5.2 Characterization of the islands where the selected MPAs are situated (all websites last accessed on February 2016).

\begin{tabular}{|c|c|c|c|c|c|c|}
\hline \multirow[b]{2}{*}{$\begin{array}{l}\text { Island } \\
\text { (date first } \\
\text { lionfish } \\
\text { sighting) }\end{array}$} & \multirow{2}{*}{$\begin{array}{l}\text { Marine } \\
\text { Protected Area } \\
\text { (designation } \\
\text { date; area in } \\
\left.\mathbf{k m}^{2}\right)^{\mathrm{a}}\end{array}$} & \multirow{2}{*}{$\begin{array}{c}\text { Resident } \\
\text { population }\end{array}$} & \multicolumn{2}{|c|}{ Tourism } & \multicolumn{2}{|c|}{ Fisheries } \\
\hline & & & $\begin{array}{l}\text { Value in } \\
\text { million } \\
\text { USD per } \\
\text { year }\end{array}$ & $\begin{array}{l}\text { No. of dive } \\
\text { professionals } \\
\text { (dive shops per } \\
\text { island) }\end{array}$ & $\begin{array}{l}\text { Value in } \\
\text { million } \\
\text { USD per } \\
\text { year }\end{array}$ & $\begin{array}{l}\text { No. of fishers } \\
\text { (full-time; part- } \\
\text { time) or number } \\
\text { of vessels }\end{array}$ \\
\hline $\begin{array}{l}\text { Bonaire } \\
\text { (Oct. 2009) }\end{array}$ & $\begin{array}{l}\text { Bonaire } \\
\text { National } \\
\text { Marine Park } \\
(1979 ; 27)\end{array}$ & $17,400^{c}$ & $125^{\mathrm{e}}$ & $\begin{array}{l}120^{\mathrm{j}} \\
\text { ( } 25 \text { dive } \\
\text { shops) }\end{array}$ & $1.1^{\mathrm{n}}$ & $80(30 ; 50)^{j}$ \\
\hline $\begin{array}{l}\text { Curaçao } \\
\text { (Oct. 2009) }\end{array}$ & $\begin{array}{l}\text { Curaçao } \\
\text { Underwater } \\
\text { Marine Park } \\
(1983 ; 10.4)\end{array}$ & $153,821^{d}$ & $778^{f}$ & $\begin{array}{l}130^{\mathrm{j}} \\
(17 \text { dive shops })^{\prime}\end{array}$ & no data & $200(50 ; 150)^{j}$ \\
\hline $\begin{array}{l}\text { Saba } \\
\text { (July 2010) }\end{array}$ & $\begin{array}{l}\text { Saba National } \\
\text { Marine Park } \\
(1987 ; 13)\end{array}$ & $2,000^{c}$ & $6^{g}$ & $\begin{array}{l}\text { ca. } 18^{\mathrm{m}} \\
\text { ( } 3 \text { dive shops) }\end{array}$ & $1.3^{\circ}$ & $\begin{array}{l}\text { Saba Bank: } \\
\text { 9-10 active } \\
\text { vessels }^{q}\end{array}$ \\
\hline $\begin{array}{l}\text { St. Eustatius } \\
\text { (July 2010) }\end{array}$ & $\begin{array}{l}\text { St. Eustatius } \\
\text { National } \\
\text { Marine Park } \\
(1996 ; 27.5)\end{array}$ & $3,900^{c}$ & $14^{\mathrm{h}}$ & $\begin{array}{l}\text { ca. } 13^{\mathrm{m}} \\
\text { ( } 2 \text { dive shops) }\end{array}$ & $0.19^{p}$ & $\begin{array}{l}15-24 \\
(3 \text { full- time })^{p q}\end{array}$ \\
\hline $\begin{array}{l}\text { St. Maarten } \\
\text { (July 2010) }\end{array}$ & $\begin{array}{l}\text { St. Maarten } \\
\text { "Man of War } \\
\text { Shoal" Marine } \\
\text { Park }(2010 ; 31)\end{array}$ & $36,607^{d}$ & $871^{i}$ & $\begin{array}{l}\text { ca. } 50^{\mathrm{m}} \\
\text { (8 dive shops) }\end{array}$ & no data & $\begin{array}{l}50 \text { fishers; } \\
7 \text { active vessels }^{q}\end{array}$ \\
\hline
\end{tabular}

a Data from MPA Global (http://www.mpaglobal.org/) and MPAtlas (http://www.mpatlas.org/)

b Listed by international MPA databases but lacking legal status and effective management

(http://www.carmabi.org/nature-management/curacao-marine-park).

c CBS 2013 (http://www.cbs.nl/en-GB/menu/themas/bevolking/publicaties/artikelen/archief/2013/2013-

3917-wm.htm)

d Word Bank data 2013, mid-year estimates (http://data.worldbank.org/indicator/SP.POP.TOTL)

e (Schep et al., 2012b)

f http://www.indexmundi.com/facts/cura\%C3\%A7ao/international-tourism

g (Van de Kerkhof et al., 2014)

h http://www.wolfscompany.com/wp-content/uploads/2014/05/Tourism-value-Statia.pdf

$\mathrm{i}$ http://www.indexmundi.com/facts/sint-maarten-(dutch-part)/international-tourism

$\mathrm{j}$ (Johnson and Jackson, 2015)

k http://www.tourismbonaire.com/bonaire-tour-operators/dive

I http://www.curacao.com/en/directory/do/dive/dive-operators/

m first author's estimations based on fieldwork in 2013 (See also:

http://www.sabatourism.com/diveoperators.html; http://www.statiatourism.com/diving.htm;

http://worldsbestdives.com/diving-destinations/scuba-diving-caribbean/st-maarten-dutch-st-martin-french/)

n (Schep et al.,2012a)

o http://www.wolfscompany.com/wp-content/uploads/2014/05/Total-economic-value-of-Saba.pdf

p (Cado Van Der Lely et al.,2014)

q (Lindop et al.,2015) 
Table 5.3 Site of selected MPAs, number of informants and demographic information.

\begin{tabular}{|c|c|c|c|c|c|c|c|c|}
\hline \multirow[t]{3}{*}{ MPA site } & \multirow{3}{*}{$\begin{array}{l}\text { Informant } \\
\text { numbers }\end{array}$} & \multicolumn{7}{|c|}{ Demographic information } \\
\hline & & \multirow{2}{*}{$\begin{array}{l}\text { Age } \\
\text { range }\end{array}$} & \multirow{2}{*}{$\begin{array}{c}\text { Foreign- } \\
\text { born* }\end{array}$} & \multicolumn{2}{|c|}{ Sex } & \multicolumn{3}{|c|}{ Diving category** } \\
\hline & & & & Male & Female & $\begin{array}{l}\text { Professional } \\
\text { (\# of dive } \\
\text { shops) }\end{array}$ & Rec. & $\begin{array}{l}\text { Job- } \\
\text { required }\end{array}$ \\
\hline Bonaire & 34 & $16-68$ & $91 \%$ & 22 & 12 & $18(12)$ & 11 & 5 \\
\hline Curaçao* & 13 & $27-63$ & $69 \%$ & 13 & 0 & $10(6)$ & 2 & 1 \\
\hline Saba & 6 & $42-50$ & $100 \%$ & 3 & 3 & $4(3)$ & 0 & 1 \\
\hline $\begin{array}{l}\text { St. } \\
\text { Eustatius }\end{array}$ & 11 & $26-48$ & $64 \%$ & 7 & 4 & $4(2)$ & 0 & 5 \\
\hline $\begin{array}{l}\text { St. } \\
\text { Maarten }\end{array}$ & 14 & $29-50$ & $93 \%$ & 7 & 7 & $13(7)$ & 0 & 1 \\
\hline Total & 78 & $16-68$ & $85 \%$ & 52 & 26 & $49(30)$ & 13 & 13 \\
\hline
\end{tabular}

*This MPA is listed by international MPA databases, but it has not been designated by law and lacks effective management (http://www.carmabi.org/nature-management/curacao-marine-park).

**Three fishers who did not dive but occasionally reported lionfish catches were also interviewed.

staff (monitoring, buoy maintenance), scientists (research, monitoring), NGO representatives (conservation projects), a teacher at a secondary school that provides scuba training for local youth (education) and one pot fisherman who engaged in spearfishing for own consumption and to complement his income (subsistence and commercial fishing). The third category encompassed recreational divers, including local residents and government officials. Table 5.3 provides informants' numbers and demographic characteristics per site.

\subsubsection{Data collection and data analysis}

An interpretive research approach informed the methods of data collection and analysis (Schwartz-Shea and Yanow, 2013). After locating potential informants through online searches and snowball techniques, interview appointment requests were sent by e-mail prior to fieldwork. Pre-arranged semi-structured interviews were conducted face-to-face in all five sites in March 2013; moreover, one e-mail and one telephone interviews took place. In addition, opportunistic sampling was carried out by walking along the beach or the harbor and requesting spontaneous interviews 


\section{Chapter 5}

from staff present at the encountered dive shops or fishermen at work. During these interactions on-site, little probing was possible due to time limitations, hence these interviews focused on a sub-set of the questions shown in Appendix 5.

During the pre-arranged interviews, extensive probing allowed for elaborations of people's motivations to engage (or not) in lionfish data collection and/or sharing ( $\mathrm{n}=65$ informants). Altogether, 45 interviews were conducted, including various group interviews, with a total of 78 individuals and saturation was achieved with this sampling strategy (Mason, 2010). Also, participant observation of lionfish spearfishing and educational activities organized by two different dive operators on Curaçao took place. The first author speaks three of the most common languages in the Dutch Caribbean (Dutch, English and Spanish), which facilitated access to informants and building rapport during the interviews. For privacy reasons, only the profession/affiliation of informants is revealed in the results section. Additional data obtained from these and other interviews were analyzed separately for other purposes and reported elsewhere (Carballo-Cárdenas, 2015).

All pre-arranged interviews and most spontaneous interviews were audio-recorded. Recorded interviews were transcribed, and data summaries were made of nonrecorded interviews. Transcripts and summaries were analyzed using thematic network analysis (Attride-Stirling, 2001), a systematic method for qualitative analysis of text. Interview data were first analyzed across all sites and subsequently within sites.

Thematic network analysis uncovers the salient themes of a corpus of data at different levels of abstraction and depicts these visually through a web-like representation that illustrates the relationships between themes. The first-order themes are called basic themes, which are grouped and categorized at a middle-order level into organizing themes. The latter are in turn summarized at the super-ordinate level into global themes. Coding and theme development were achieved by iteratively applying an inductive approach to identify basic themes emerging directly from the data and a deductive categorization of these basic themes into organizing themes. The global themes were deduced based on elements that were cross-cutting through all thematic clusters. Then, networks were built for exploration and interpretation. 
Citizen science regarding invasive lionfish in Dutch Caribbean MPAs

\subsection{Results}

The results are organized in two sections. The first section presents informants' motivations to participate in lionfish-focused data collection and sharing, including the changes in context and in motivations over time. The second section presents the factors that enabled and constrained participation.

\subsubsection{Participation in citizen science initiatives on lionfish}

\section{Initial motivations}

Initially spurred by the notion - promoted in outreach campaigns and the media that lionfish is a threat to the environment (Figure 5.3, top), approximately $60 \%$ of the informants said that upon arrival of this species to their respective islands they had participated in an early warning program. This citizen science initiative, informally referred to as the cork-and-ribbon system, was devised by MPA authorities to collaboratively gather data of locations where lionfish had been spotted by a diver, fisher or snorkeler. Only MPA staff were allowed to capture lionfish back then (on Curaçao, the local government and research institute CARMABI fulfilled this role). Citizens who saw a specimen were asked to attach the ribbon to a hard structure at the bottom whereby the wine cork would remain floating on the surface. Next, they would notify MPA authorities who would go to the indicated location to capture the lionfish, which are known for their site fidelity.

The main motivations to engage in data collection and sharing at this stage were the desire to track and respond to lionfish and thereby to help the environment. Many informants referred to the "disastrous stories in the Bahamas", where the invasion had been the most severe, according to outreach campaigns and media reports throughout the region. Fears about the potential effects of lionfish on the reefs were common, as illustrated by this dive operator's comment:

The first sightings were pretty scary. We don't want our reefs to end up like the Bahamas, so as soon as everyone knew that lionfish were on the island they started to pay close attention to $[M P A$ authority $]$.... then is when everyone got alerted about the lionfish program.

The program consisted of reporting sightings data and subsequently of lionfish captures as explained in section 5.3.1. This entailed collection of lionfish specimens as data (e.g. for genetic or stomach content analysis) for studies conducted by visiting researchers or by MPA staff. 


\section{Chapter 5}

\section{Personal experiences and meanings of participation}

The initial motivations to track and remove an invasive species from the reefs became intertwined with benefits that people derive from spearfishing lionfish. When the interviews were conducted, most informants perceived lionfish not only as a threat, but also as an opportunity to carry out new activities that were not feasible or known prior to the arrival of this novel species (Figure 5.3, middle). These new activities included: eating lionfish, spearfishing as a new sport, selling lionfish or related products and services such as specialized gear and specialty dive courses, participating in social activities around lionfish (including in the context of research projects), learning about nature and developing new skills.

The following quote by an MPA staff member reveals the multiple and dynamic meanings attached to the experience of collecting lionfish:

It's a mix. I like bunting, spearfishing, I have always liked it ... it's the first time in my life that I go spearfishing without remorse. Of course, I do it for the environment, it is my responsibility, it's my job. I think it's incredible that I get paid to do it, but that's how it is. The motivations are those, I like it and it's my job. And lately even financial motivations, because when the lionfish doesn't fit in the freezer anymore, I sell it.

The new meanings ascribed to collecting lionfish influenced many individuals' willingness to sustain (or not) their participation in lionfish data collection and/or sharing, as will be shown in the following sections.

\section{Changes of motivations over time}

Approximately $30 \%$ of informants was collecting lionfish data when the interviews were held (Figure 5.3, bottom left). From this group, thirteen individuals were doing so within a citizen science initiative and nine independently. Concern for the environment was still mentioned by some individuals but other motivations surfaced and played important roles in driving participation: learning, socializing, improving/using the area for recreation, self-enhancement and commercial motives. On the other hand, about $30 \%$ of informants lost their motivation to collect or share lionfish data. The types of lionfish initiatives as well as modes and levels of participation differed among islands as will be described next. 
Citizen science regarding invasive lionfish in Dutch Caribbean MPAs

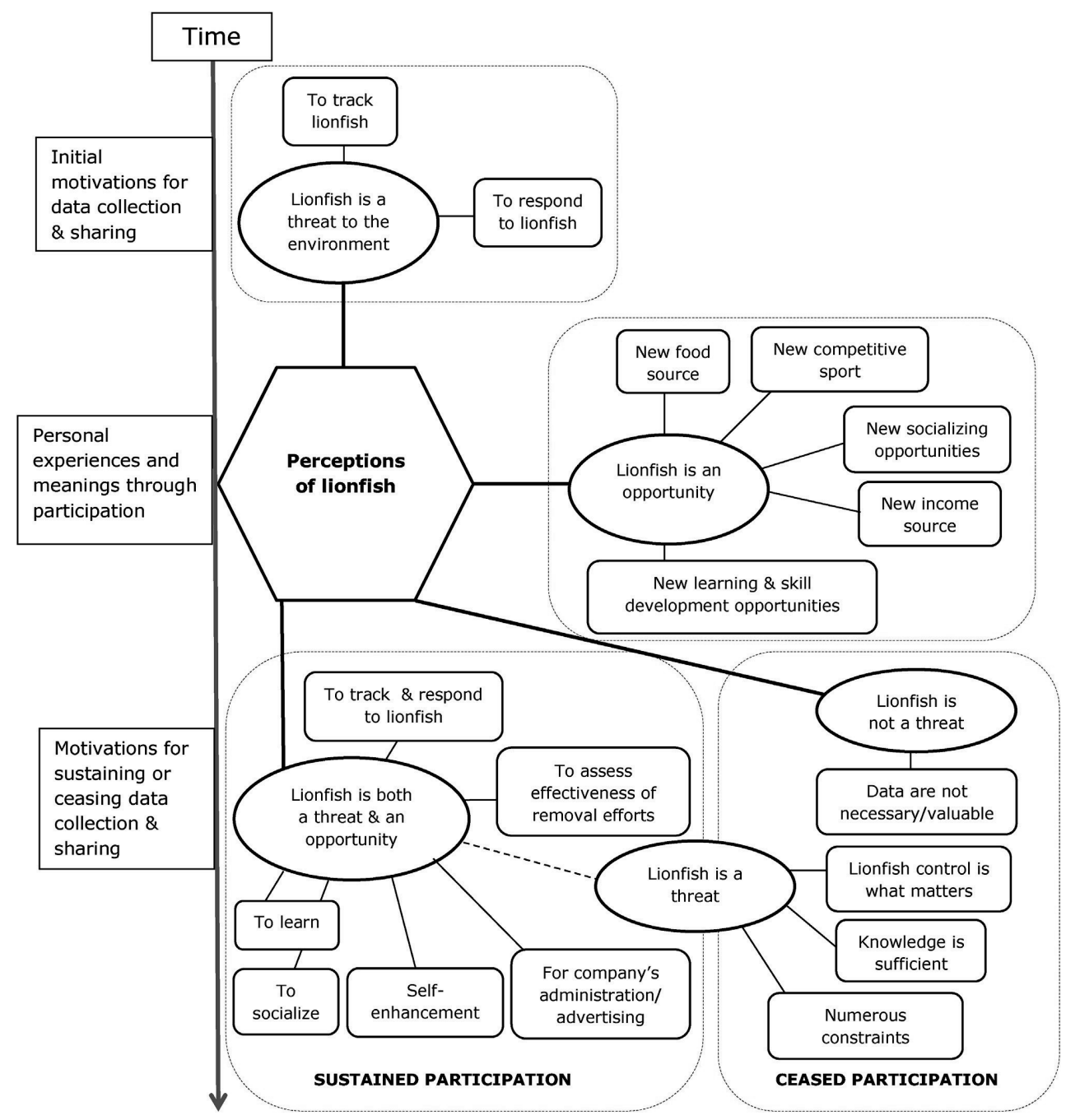

Figure 5.3 Participation in lionfish-focused data collection and data sharing in Dutch Caribbean MPAs: changes of motivations over time (Legend: Global themes shown in hexagons, organizational themes in ovals and basic themes in rectangles. Read figure from left to right and top to bottom). 


\section{Chapter 5}

On Statia and Saba the cork-and-ribbon system was replaced by written reports. Here, MPA authorities invited dive operators to fill out written forms and the data were then stored in simple databases. On Saba no one was participating anymore, but on Statia a few informants said they were still contributing their data. For one MPA staff member, an important motivation to do so was to assess the effectiveness of removal efforts and underlying this was a desire to help the environment. Another motivation was her personal interest in learning about this biological invasion.

On Bonaire, Curaçao and St. Maarten lionfish data reporting was not required after the early warning program stopped. On these islands lionfish monitoring was conducted by biologists and/or MPA staff, "to know what's going on with lionfish" in an effort to help the environment. On St. Maarten and Bonaire, foreign science students affiliated to the MPA authority and the local research station, respectively, initiated citizen science projects that included lionfish collection. On St. Maarten the project was short-term and had already finished, after which most informants seemed to lose interest in lionfish. On Bonaire several informants were still participating as volunteers in a project led by a United Kingdom (UK)-based $\mathrm{PhD}$ student.

Conserving the biodiversity of the Bonairean reef motivated many volunteers, whose lifestyle was largely defined by diving. They wanted to help the natural area used for recreation both for its intrinsic and aesthetic value. Also, the socializing aspects of hunting and eating lionfish together were recurrent topics in these informants' stories. Self-enhancement seemed a common motivation to collect and share data on lionfish. According to the UK-based researcher, her volunteers made use of their "bragging rights" about who had captured the most or the largest specimen. Informants from all sites expressed pride in being (one of) the first to have seen a lionfish in their waters or having located the largest so far. Several individuals recalled the exact date and location of their first lionfish sighting or capture. Many kept mental or written records of captured lionfish, as this dive operator from Curaçao: "I still track what I take out of the water, right now it's about 6000 lionfish."

An online database and associated map had been set up on Bonaire where citizens could enter their lionfish sightings and capture data, including locations. This database, locally referred to as the "digital map", contained data since October 2009. According to the NGO which sponsored this citizen science initiative, about forty users were actively sharing data on the island and plans for developing similar maps 
for Curaçao and St. Maarten were underway. On Bonaire, several informants had contributed data to the map at some point, but only three were still participating. Their main motivations to continue using the map were to track lionfish.

Further, some individuals on Bonaire and Curaçao were collecting data independently, this is, out of personal curiosity and for their own use. These independent data collectors expressed that learning about the novel species and assessing the effectiveness of removal efforts were motivations to collect data. One dive guide on Curaçao, for instance, recounted his interest in recognizing female lionfish. He reasoned that by targeting females his control efforts would reduce the number of baby lionfish. He decided to investigate by dissecting the captured fish at home. By correlating external physical features to what he thought were male or female reproductive organs, he claimed that, while diving, he could distinguish males and females in a group.

Another motivation for independent data collection was a commercial interest. Informants said that data were valuable for their company's administration and advertising. For instance, lionfish location data were useful for dive operators who offered lionfish hunting or spotting courses. Lastly, weight data appeared important to those selling their lionfish catch.

Among informants who had participated in data collection initially, there were some for whom data were not valuable or "did not make sense anymore". Various individuals did not perceive lionfish as a threat anymore and hence for this group data were not necessary (Figure 5.3, bottom right). Others acknowledged that data had served important functions in the past but asserted that lionfish removal "is what matters now". As illustration, an informant from Curaçao recounted that he had gathered capture data from his peers in order to lobby for the dispensation of the spearfishing ban on the island, which was realized on October 2012. Many considered that available knowledge on lionfish was sufficient. Indeed, an MPA staff member highlighted the need for action, not for data: "For me the most important is to get lionfish out of the sea, not their scientific value." Finally, a portion of the informants considered that data could be valuable but enumerated multiple constraints to explain why they did not collect or share their data. These constraints are presented in section 5.4.2. 


\section{Chapter 5}

Summing up, the sense of urgency associated to the arrival of lionfish drove informants to participate in early detection and rapid response initiatives. In doing so they acted on their values, namely helping the environment. Over time selfdirected motivations such as learning, socializing, improving the area used for diving, self-enhancement and a commercial interest became important drivers to collect data. Main reason for not collecting data was the perceived lack of value of these data given the presumed state of lionfish control in individual dive sites and the available knowledge about this species.

\subsubsection{Enabling and constraining factors}

Several factors were identified that enabled and constrained individuals to engage in data collection and/or sharing. These factors can be classified as operating at the personal, interpersonal, organizational and technological levels (Figure 5.4). Some general factors were found while others were site-dependent.

\section{Enabling factors}

In general, a factor that enabled participation in the early stages of the invasion was the outreach campaign using the Lionfish Response Plan and training provided to the target groups. The training allowed people to identify, report and/or handle lionfish properly. At the organizational level, MPA authorities facilitated the process and provided the necessary equipment. Differences in how the lionfish issue was followed-up were evident in the various islands as explained in section 5.4.1 (and summarized in Table 5.4).

Informants from Bonaire, Curaçao and Statia were still collecting and/or sharing data and the factors that enabled this are described next. Independent shore diving is permitted on Bonaire, Curaçao and St. Maarten, which made public participation possible (on Statia and Saba recreational divers are only allowed to dive if accompanied by dive professionals). However, as one informant observed, "diving is an expensive hobby". On Bonaire, the personal circumstances of many volunteers enabled participation in the UK-based project. Mostly retired expats, this group had the time and financial resources to pursue their interests and express their values, namely protecting the natural area used for recreation. For these volunteers, their good relationship with the researcher enabled sustained participation in the project. 
Table 5.4 Types of data collection and sharing initiatives per MPA site.

\begin{tabular}{|c|c|c|c|c|c|}
\hline Type of initiative; type of data collected & Bonaire & Curaçao & $\begin{array}{c}\text { St. } \\
\text { Maarten }\end{array}$ & Saba & $\begin{array}{c}\text { St. } \\
\text { Eustatius }\end{array}$ \\
\hline $\begin{array}{l}\text { Early detection and rapid response; sightings } \\
\text { data, later capture data and lionfish } \\
\text { specimens }\end{array}$ & $\sqrt{ }$ & $\sqrt{ }$ & $\sqrt{ }$ & $\sqrt{ }$ & $\sqrt{ }$ \\
\hline $\begin{array}{l}\text { Data forms for MPA authority: sightings data } \\
\text { (numbers, location, depth, size). On Saba: } \\
\text { specimens }\end{array}$ & & & & $\sqrt{ }$ & $\sqrt{ }$ \\
\hline $\begin{array}{l}\text { Researcher-led project involving volunteers: } \\
\text { specimens and ancillary data (numbers, } \\
\text { location, depth, etc) }\end{array}$ & $\sqrt{ }$ & & $\sqrt{ }$ & & \\
\hline $\begin{array}{l}\text { Digital map: } \\
\text { sightings, captures, location data, missed } \\
\text { attempts (Since Oct. 2009) }\end{array}$ & $\sqrt{ }$ & $*$ & $*$ & & \\
\hline $\begin{array}{l}\text { Independent data collection: } \\
\text { e.g. sightings and captures, missed attempts, } \\
\text { other fish species, etc. }\end{array}$ & v & $v$ & & & $\sqrt{ }$ \\
\hline $\begin{array}{l}\text { Independent data sharing (through } \\
\text { Facebook): e.g. sightings, captures, missed } \\
\text { attempts, other fish species, etc. }\end{array}$ & v & $v$ & v & & \\
\hline
\end{tabular}

Organizational factors were also identified that supported participation. For these volunteers, having additional diving (i.e. recreation) opportunities was an incentive to participate in the project, which provided structured and periodic spearfishing moments through scheduled boat trips to the islet of Klein Bonaire. There, volunteers collected lionfish for the researcher to count, weigh and dissect. Participation also involved collecting specimens in volunteers' own time and taking them to the research station for further processing. Access to dive equipment enabled participation as well. A local dive shop provided these volunteers free air tanks in reciprocity for their help with customers.

The physical act of turning in the lionfish caught was considered by some informants as data sharing. When asked whether she had shared her lionfish data, one active lionfish hunter said that she only shared her lionfish when it was requested, or in the context of a specific organized event: "No not really, only when someone asks for a specific reason, such as the hunt this weekend in the reserve, we must bring fish back so [MPA authority] can count them." 


\section{Chapter 5}

Enabling factors were distinguished that were technological in nature. Many informants from Bonaire and Curaçao identified themselves as lionfish hunters during the interviews, and self- enhancement was a strong motivation to share their data and their stories. Access to social media allowed the showcasing of hunting trophies in the form of numbers of lionfish caught, their sizes and pictures or videos to prove the deed. When asked whether they shared lionfish data and how, many informants said that they did so through Facebook, because it's "fast" and "easy to share". The PhD researcher communicated with her project volunteers mainly through Facebook. At first, lionfish location data were shared through social media, where reciprocity was important, but later on this changed as will be explained in the next section (Constraining factors).

On Statia the physical proximity that characterizes this small island was reported as facilitating data collection and sharing. The MPA authority's office is located two buildings away from the fisheries office and across the street from the island's two dive shops. According to one dive operator this facilitated data reporting to the MPA authority. This proximity also enabled lionfish data to be shared orally and good interpersonal relationships were important in this respect. A dive guide said that he was providing the sightings data to an MPA intern, not out of concern for the reefs, but due to the friendly relationship they had with each other. Finally, trust was an enabling factor. An MPA staff member said that a family member, who was working for the fisheries department, shared lionfish data with her that he obtained from the fishermen.

\section{Constraining factors}

Two groups of informants are distinguished: those who had never participated in citizen science initiatives (about 30\%) and those who did in the past, but not anymore (see section Changes of motivations over time). Among the former group, several informants had recently arrived in the Caribbean, and the lionfish phenomenon was relatively new to them. Approximately half of those who had never collected data considered that lionfish was not a threat and therefore data were not perceived as valuable. The other half thought that lionfish was a threat but did not collect data because they claimed that lionfish removal was what matters.

Among the informants who had participated in the past and who held views that data could be valuable, multiple barriers to collect or share their data were mentioned. In general, personal costs in terms of time, energy (i.e. effort) and 
financial resources to be spent were seen as an obstacle. Several professional divers said that participation would impinge on their work time. Some admitted being lazy or not having the patience to fill out data forms, either paper or digital, which was seen as a burden and incompatible with (post) diving routines.

Various risks were associated with tracking and removing lionfish. Concerns for diving accidents affected sustained participation in lionfish initiatives on Saba and St. Maarten. On Saba, one MPA staff member suggested that the reason why dive operators stopped collecting and sharing lionfish data was that one dive guide was bitten by a shark while spearing lionfish. Moreover, informants from Saba, St. Maarten and Statia alluded to concerns about ciguatera poisoning through lionfish consumption, possibly resulting in lessened interest in this species. At the interpersonal level, accountability for clients was an important factor that deterred dive professionals across all sites from focusing on lionfish, given the perceived risks. Only a few dive shops offered "lionfish specialty courses", which allowed tourists to interact with lionfish and dive operators to be released from liability.

On Bonaire and Curaçao the competition among hunters was a barrier to sharing location data: "People don't want to give up the information of where the lionfish are because they want to catch them ... there are people who are still in competition: "I want to get the biggest, I want to get the most"... In both islands, lack of trust on the quality of the data was voiced as deterrent to participate in collaborative databases and to use such data. Various informants suggested that others were either over-reporting their lionfish catches or under-reporting their sightings, again linked to the competitive aspects of the data. For one scientist and one MPA manager "volunteer data are ... completely useless" due to these and other uncertainties.

Furthermore, non-collaboration by others discouraged some informants. One dive guide from Statia stopped sharing data with the MPA after realizing that "no one else was doing it". Volunteers from Bonaire provided similar reasons for discontinuing their use of the digital map. They argued that the value of data depended on high levels of participation. Lack of collaboration led to antagonism when reciprocity was expected. For instance, an individual who helped the UKbased researcher refused to share those data through the digital map developed by the local NGO. He considered that the NGO members did not reciprocate when asked to participate in the UK-led research project. 


\section{Chapter 5}

\section{ENABLING}

CONSTRAINING

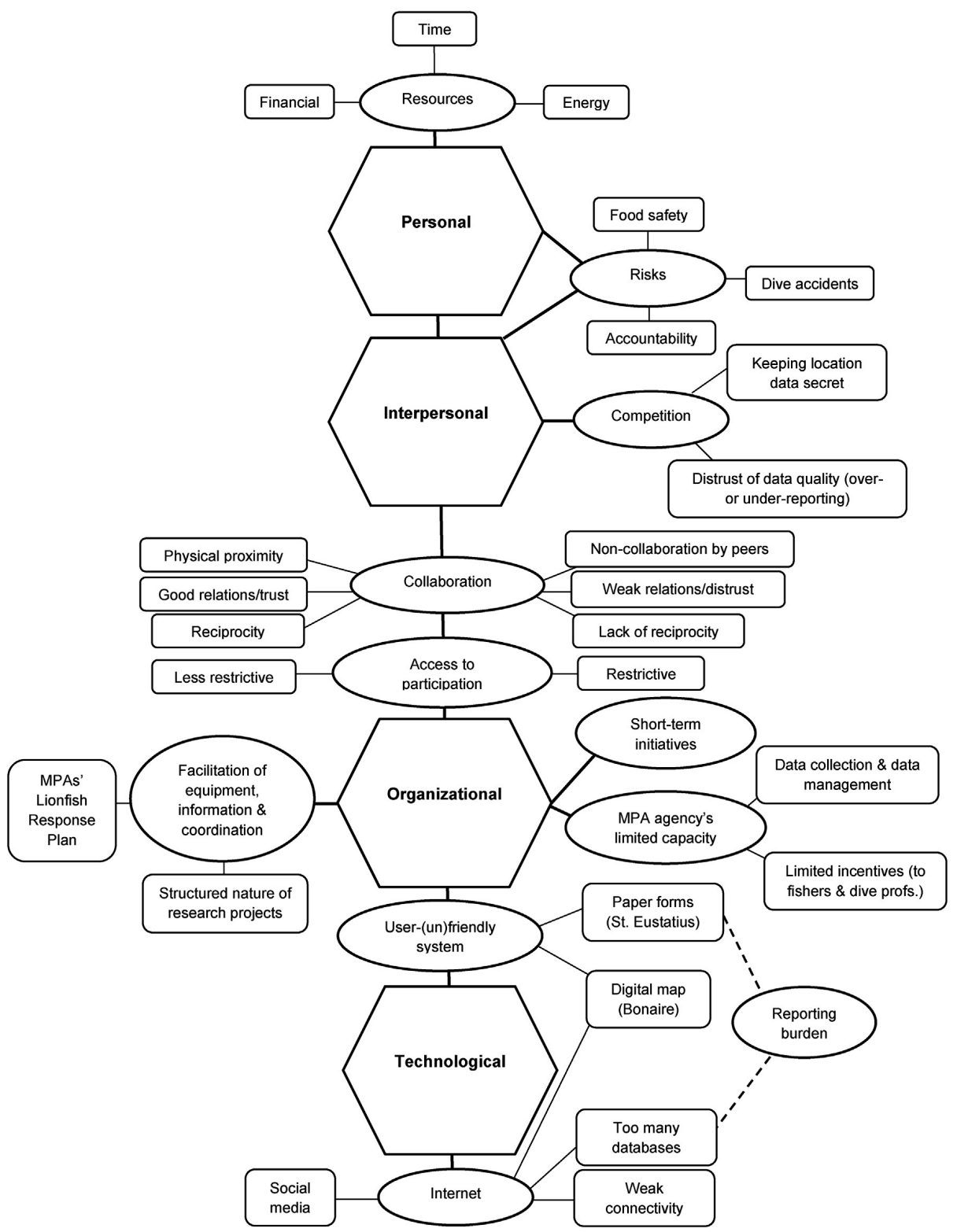

Figure 5.4 Enabling and constraining factors for participation in lionfish-focused data collection and sharing. 
Restrictions on independent shore diving and speargun use limited participation on Statia and Saba. The short-term nature of some initiatives, such as a student project on St. Maarten, was also reported as a reason why collection of lionfish and data were discontinued. From the MPA authority's perspective, limited capacity was recognized as an important constraining factor both for data collection and data management:

What happened at the beginning stages of the invasion, we collected all the data that we could find, size, stomach content, capture location, who captured them, GPS points, etc... But as the invasion progressed, it was stressing our capacity a little bit too much so now we just do simple locations where the animals have been captured ... we would be busy mostly with lionfish instead of the other things that we have to do.

Across sites, various professional and recreational divers pointed to a lack of incentives, e.g. a bounty, to sustain participation. Some informants expressed distrust or antagonism toward the MPA authority. As mentioned, dive professionals on Statia were asked to fill out various data forms by the MPA authority. One dive operator complained about the user-unfriendly format, which he perceived as a reporting burden. Similarly, some informants said that there were too many initiatives requesting lionfish data, or as one MPA staff member phrased it: "You have list servers, you have databases. You should add it here you should add it there, there .... You don't. Because after a while you just get fed up ..."

Lastly, constraints for data sharing were identified at the technological level. A number of informants from Bonaire had explored the digital map but experienced it as user-unfriendly. On Saba and Statia weak Internet connectivity was mentioned as a limiting factor to contribute to online databases.

\subsection{Discussion}

\subsubsection{Multiple and changing motivations}

The present study sought to uncover what drives individuals to participate in lionfish-focused citizen science initiatives, whether and how motivations have changed in time and which factors enable and constrain participation. Concern for the environment initially drove many individuals to participate in initiatives to collaboratively track and respond to the unfamiliar species. However, unexpected benefits and risks from spearing lionfish emerged and influenced people's 


\section{Chapter 5}

motivations to sustain or cease data collection and/or sharing. Sustained data collection was mainly driven by self-interest and to a lesser extent, the desire to help the environment. These results are in contrast with Rotman et al., (2014) who found that "self-directed motivations, such as personal interest" initially drove people to get involved in ecology-related citizen science projects, while "long-term participation is more complex and includes both self-directed ... and collaborative motivations" (ibid: 110).

Our results largely agree with findings in the environmental volunteering literature, which have identified, besides "helping the environment", various motivations that drive volunteers' participation (Bruyere and Rappe, 2007; Clary and Snyder, 1999). Motivations include learning, socializing with other volunteers, using the natural area for recreation, working in a well-organized project and developing skills to enhance self-esteem. We did not find "gaining career experience," a common motivation expressed by student volunteers, probably because most of our informants were either already employed or retired. The finding that various informants were motivated to collect data for their company's administration/advertising or for competition/trophy hunting highlights the switch from collaborative to individualistic motivations. Indeed, promoting commercial or recreational harvest of invasive species as a management strategy may result in shifting the focus from collective control efforts to the pursuit of personal gains, with potentially unintended consequences such as creating dependency on the novel species (Nuňez et al., 2012).

While $60 \%$ of informants initially engaged in lionfish detection initiatives, only about $15 \%$ remained involved in some citizen science program and another $15 \%$ collected data autonomously. We suggest the term "independent data collectors" to refer to individuals who collect data for their own interests and use, independently of professional scientists or MPA authorities. Relatively few ecology-related citizen science programs succeed in maintaining people's continued involvement over extended periods of time (Rotman et al., 2014). Estimates of attrition rates among volunteers found in the literature vary greatly, ranging between 15 and $95 \%$ (Baltais, 2013; Rotman et al., 2014). Although we did not measure attrition in specific citizen science projects, our findings also showed a decreasing participation pattern. 


\subsubsection{Situated meanings of lionfish and of data collection and sharing}

Local differences in motivations and meanings were observed among informants from the five sites studied. Spearing lionfish became the prime interest for a significant proportion of the informants from the Leeward Islands (Bonaire, Curaçao). There, concerns that lionfish represents a threat to the ecosystem and the economy were relegated to the background as the commercial and/ or recreational value of lionfish moved to the fore. This motivation shift influenced the type of data that informants were interested in collecting (i.e. catch data), the data they were willing to share (i.e. size data) and not to share (i.e. location data).

In the Windward Islands (Statia, Saba, St. Maarten), lionfish management did not seem a priority issue, except for just a few individuals. In this region, ciguatera risk perceptions associated to lionfish consumption (Foundation, 2011; Carballo Cárdenas, 2015) may have decreased dive operators' motivations to remain engaged in lionfish detection and control. Fishermen may increasingly become active participants of conservation citizen science in such islands, for instance by helping to test lionfish-specific traps or report lionfish consumption by their target species (Today, 2013; Spalburg, 2014).

Overall, most informants from St. Maarten were unconcerned about lionfish and competitiveness prevailed on Curaçao. Although on these islands "no one was asking" for data when the interviews were held, a few months later citizen science initiatives were launched in both sites (Table 5.4). Modelled after Bonaire's digital map, users can enter lionfish sightings, location, capture and hit-and-miss data (http:/ / www.dcnanature.org/lionfishcontrolapplication-2/). On July 2014, statistics for Bonaire showed a total of 10, 548 records, 32 for Curaçao and 5 for St. Maarten. Based on our findings, low levels of participation for the latter two sites could have been anticipated. Indeed, on June 2016, no new entries had been made for Curaçao and only 2 for St. Maarten, whilst on Bonaire the number of records had increased with 843 to 11,391 (www. lionfishcontrol.org).

\subsubsection{Citizen science and invasive species}

Invasive species are an issue of public interest, and as such there is increasing support for citizen science programs on this topic (Crall et al., 2012). In the United States alone, almost 250 citizen science initiatives have been established for invasive species monitoring (Crall et al., 2010). In Scotland, "one of the largest-scale invasive alien species projects worldwide targeting a carnivore species" relies on community-based 


\section{Chapter 5}

monitoring and trapping of American mink (Bryce et al., 2011; Arts, 2013). Regarding marine invasions, data collected by citizens have been useful to map the distribution of crabs, molluscs, macrophytes, tunicates and fish (Liao et al., 2010; Thiel et al., 2014; Bodilis et al., 2014; Delaney et al., 2008), including lionfish (Scyphers et al.,2014; López-Gómez et al., 2013). Despite the growth in numbers and types of citizen science programs, little research has been conducted on the motivations and retention levels of the volunteers who participate in these programs.

\subsubsection{Future research}

In citizen science, project initiators are often scientists, who work together with volunteers in various ways. Our study garnered views from both types of participants but did not distinguish between them. Shirk et al., (2012:1) observe that "particularly in conservation and natural resource management contexts, where research often addresses complex social-ecological questions, the emphasis on and nature of [citizen] participation can significantly affect both the way that projects are designed and the outcomes that projects achieve". Further research which discerns motivations of these two groups would enhance our understanding of how scientific and public goals are negotiated and integrated to enhance project outcomes for scientific research, individual participants and the socio-ecological system where the project is embedded.

A limitation of this study was that fishermen, a key stakeholder group, were underrepresented due to the difficulty in identifying and obtaining access to willing respondents under time constraints. Future studies should pay attention to this group, particularly in the Windward Islands, where the role of fishermen as citizen scientists may be gaining importance. Furthermore, as Table 5.3 on the informants' demographics shows, interesting questions arise as to who counts as a "local" participant when speaking of community-based citizen science initiatives for conservation. Future research could explore the motivations of local and foreignborn participants to engage in such programs, as well as perceived enabling and constraining factors. Another interesting topic that could be explored is the relation between outreach campaigns (e.g. content, frequency), motivations and participation levels.

Our findings have generated insights which can be used to inform the development of quantitative methods of data collection for follow-up studies. For instance, a standardized questionnaire among registered users of the lionfish digital map on 
Bonaire, Curaçao and St. Maarten could be applied to study the factors that distinguish active contributors from the non-users. Results could then guide the improvement of such technologies to attract and retain users or inform the development of alternative citizen science initiatives more attuned to the local circumstances. Finally, given rapid technological innovations and the growing significance of digital ICTs in conservation (Van der Wal and Arts, 2015), future research should consider the potential benefits of using social media platforms, which could be directly targeted for citizen science initiatives (Di Minin et al., 2015).

\subsection{Conclusions}

This study was, to our knowledge, the first to explore the motivations that drive people to participate in data collection and sharing on invasive lionfish in the region. We focused on five MPAs, but these MPAs are not unique in their need to manage invasive species (Otero et al., 2013) nor in their reliance on volunteers for data collection (Mumby et al., 1995; Koss et al., 2009). Our findings should be useful for stakeholders associated with MPAs where similar initiatives are being planned or implemented.

Implications of our study are threefold. First, design of citizen science initiatives should consider both the initial motivations that compel people to become involved in such initiatives, as well as the changing motivations over time. Community-based programs on invasive species with a harvest potential, in particular, must consider and respond to the changing values and meanings of participation. In the lionfish case, marine managers may need to emphasize the response (i.e. spearfishing) over the tracking (i.e. data reporting) component of the community-based program, depending on the local context. Second, identification of enabling and constraining conditions for data collection and sharing at the appropriate level (personal, interpersonal, organizational, technological) and differentiating among types of participants, is equally important in designing initiatives. For instance, in lionfishfocused programs where professional divers are a key target group, liability issues that may limit their participation should be considered (interpersonal factors). Finally, care must be taken to avoid placing excessive demands on participants, such as overstretching reporting tasks of marine resource users in MPAs (organizational factors). To ensure enduring engagement in community-based programs for conservation, participation that is intrinsically motivated, rather than experienced as a personal risk or burden, must be pursued. 
CHAPTER

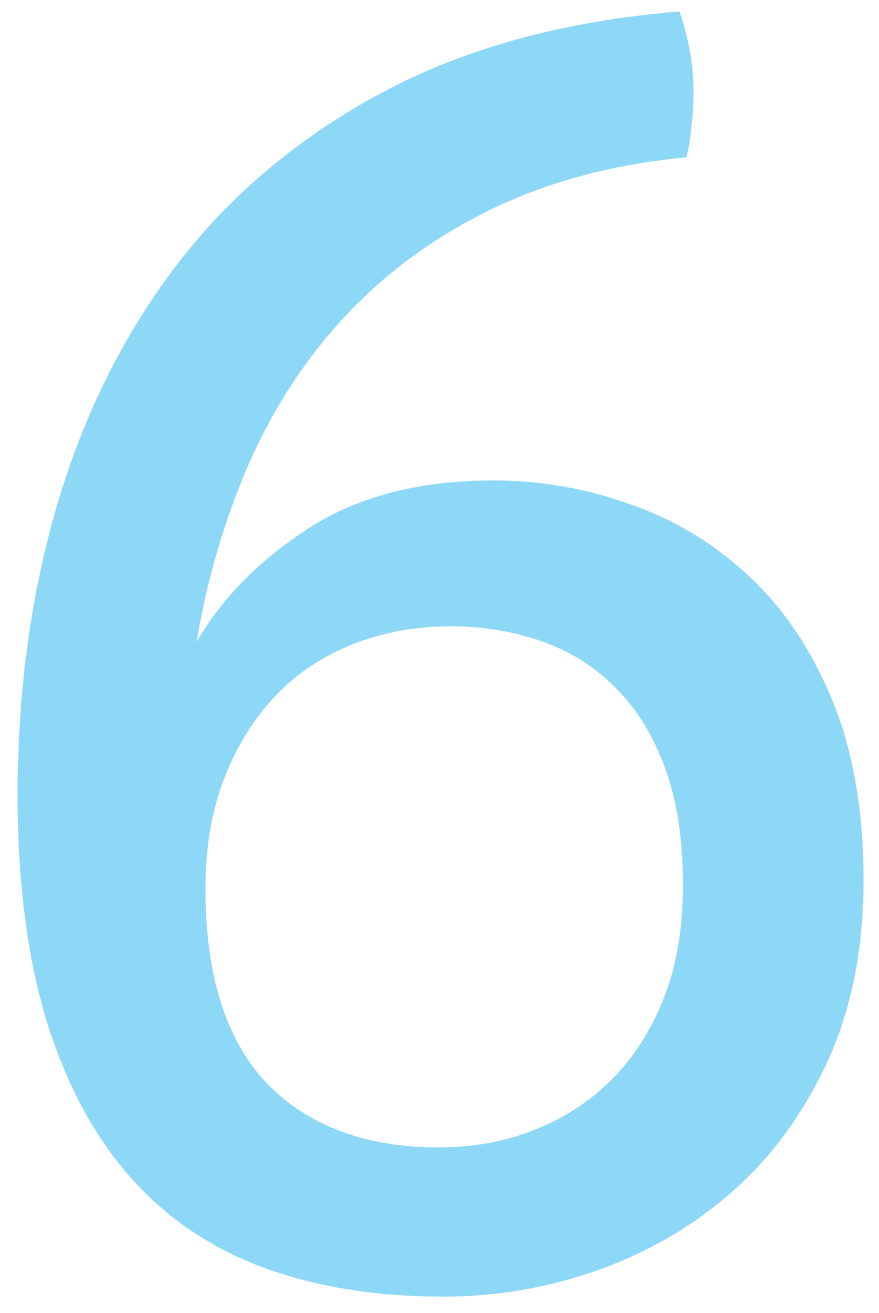




\section{Chronicle of a grassroots project to monitor seawater quality on Bonaire: Unpacking legitimacy and the democratic potential of participatory sensing ${ }^{7}$}




\begin{abstract}
Participatory sensing (PS) refers to the use of low-cost sensing technologies by local communities to monitor environmental threats, in order to gather evidence to influence policy debates. These emerging monitoring practices hold promises of democratizing the production of policy-relevant scientific knowledge. Claims about the democratic virtues of PS rest on the premise that such initiatives are perceived as legitimate by various audiences. However, there is limited understanding of the various legitimacy dimensions and perspectives relevant for the democratization aspirations of PS. To address this knowledge gap, I examined the legitimacy dynamics of a PS project established to monitor seawater quality around Bonaire. This small Caribbean island is highly dependent on scuba diving tourism and hence on its coral reefs. I applied a rhetoric-based narrative analysis on semi-structured interviews, newspaper items and key documents to understand how actors constructed meaning about Bonaire's water quality issues and of the PS project throughout the years. Findings revealed that project initiators were successful in collectively framing the problem of reef decay as stemming from anthropogenic wastewater pollution, and in garnering support and credibility from internal and external audiences for their suggested solution, i.e. long-term monitoring along the island's developed coastal strip. Notwithstanding the departure of the project scientists and the lack of formal data use, public pressure contributed to the adoption of an emergency plan by the local government to reduce sewage discharges into the reef. This case showed that, despite their emancipatory promises, PS initiatives can reproduce expert-lay hierarchies and dependencies of communities on (foreign) experts. Moreover, it showed that there are indirect pathways through which these initiatives may exert influence on policy debates. Unpacking the legitimacy dynamics of a PS initiative enhanced understanding of the democratic opportunities and pitfalls of these emerging monitoring practices.
\end{abstract}




\subsection{Introduction}

Environmental monitoring has traditionally fallen within the purview of government agencies and is typically conducted by credentialed experts. Yet, ordinary people are increasingly using low-cost sensor technologies to detect and monitor environmental threats in their communities (Irwin 2018; Austen 2015). Neologisms like 'participatory sensing' and 'citizen sensing' denote the growing trend of nonprofessionals gathering environmental data to generate evidence of environmental harm with the aim of confronting decision-makers and polluters (Carton and Ache 2017; Gabrys et al., 2016). This trend has been fuelled by innovations in sensor technologies, along with developments towards open data/open source and do-ityourself (DIY) science and technology, which enable the collection and dissemination of environmental data by non-professionals (Ferretti 2019).

The term participatory sensing is used throughout this paper to refer to a range of emerging monitoring practices that are community-based and revolve around lowcost/DIY sensing technologies. Participatory sensing initiatives have addressed anthropogenic environmental hazards with risks for human health and safety, including urban air pollution from vehicles and industry (Austen 2015), air and freshwater pollution from hydraulic fracturing for gas extraction (Gabrys et al., 2016; Jalbert and Kinchey 2016), air pollution from oil refineries (Ottinger 2010), noise pollution from airports and human-induced earthquakes by gas extraction (Carton and Ache 2017).

These emerging monitoring practices are in line with views of citizen science - which broadly speaking involves the participation of laypeople in scientific research - as a movement to democratize environmental research, with presumed emancipatory benefits for affected communities, who engage in scientific practices and discourse in an attempt to influence policy debates (McCormick 2007; Irwin 1995). Indeed, low-cost sensing technologies are celebrated as tools that empower communities by opening up spaces for participation in environmental monitoring and politics, bearing the promise of democratizing science, and thereby policy (Gabrys and Pritchard 2018; Carton and Ache 2017).

Claims about the democratic virtues of citizen science and participatory sensing rest on the premise that such initiatives are perceived as legitimate by various audiences. As is the case for other societal undertakings with a change agenda, participatory sensing projects need to build legitimacy from the start and maintain it throughout 


\section{Chapter 6}

the project (Ruebottom 2013), both internally (i.e. to recruit participants and partners) and externally (i.e. to attract donors, to be accepted as credible by decisionmakers, scientists and the public at large). In this paper I refer to these perspectives of legitimacy as the internal and external legitimacy of a participatory sensing initiative, where the former entails perceptions of the initiative as necessary and meaningful by its members and the latter encompasses perceptions of the initiative as credible and acceptable by external audiences (Suchman 1995).

With respect to internal legitimacy, there is a belief that participatory sensing initiatives, because of their grassroots nature and empowerment potential, will enjoy broad and continuous support from community members (Balestrini et al., 2015). That is, that these initiatives will be considered legitimate in the eyes of communities, who will commit to the cause through their long-term, voluntary participation. However, the legitimacy of a participatory sensing initiative may be questioned by (potential) participants, leading to conflicts within the community, or between the community and partners, and eventually to the abandonment of the project (Pritchard and Gabrys 2015).

Regarding external legitimacy, there is an often-held assumption that technologies that produce "objectivized data" perform as legitimating tools in the eyes of decision-makers, who would otherwise dismiss lay knowledge as irrelevant, biased or unscientific (Carton and Ache 2017; Jalbert and Kinchey 2016). While research indeed shows that the use of certain technologies and methods enables concerned communities to enhance the epistemological status of their knowledge claims and gain policy influence (Jalbert and Kinchey 2016; Ottinger 2010), other studies have demonstrated that citizen-datasets tend to be discredited by decision-makers and polluters, thereby pre-empting their use in policy debates (Pritchard and Gabrys 2015; Ottinger and Zurer 2011).

Despite the importance of legitimacy as a condition to fulfil the democratization promises of participatory sensing, there is little understanding of the legitimation dynamics at play in such initiatives, which span the science-society-policy interface. Legitimacy is a multi-dimensional concept (Suchman 1995), but often only one dimension is articulated in citizen science and participatory sensing studies - namely, the procedural dimension of external legitimacy that focuses on the credibility of the data, i.e. are the methods used to produce the monitoring data scientific? And by extension, are the data of good quality? (Freitag et al., 2016; Hyder et al., 2015). 
Studies that provide a comprehensive analysis of both internal and external legitimacy dynamics - and how these dynamics are related to the democratization of science and policy - are lacking in the citizen science and participatory sensing literatures.

This paper aims to fill this gap by exploring the multiple dimensions and perspectives of legitimacy concerning a participatory sensing project established for seawater quality monitoring on Bonaire. Referred to as the "Light and Motion Sensor Program" (LMSP), the project took place between 2007-2014. To enhance understanding of the legitimacy and democratic potential of participatory sensing projects, a diachronic analysis of the LMSP and its outcomes was carried out. The paper's objectives are to examine how legitimacy was built for the LMSP, how internal and external audiences responded, what these legitimacy dynamics reveal about the democratization virtues of the LMSP, and what this case teaches us with respect to legitimacy in a wider set of citizen science projects. The paper contributes to the science-society and science and technology studies (STS) literatures on citizen science and participatory sensing that focus on public participation in the production of policy-relevant knowledge about environmental issues.

Bonaire is a small island located in the southern Caribbean Sea, surrounded by a coral reef marine protected area (MPA). As the MPA lacked a water quality monitoring program and commercial sensors are expensive, the aim of the LMSP was to establish a network of low-cost optical sensors for long-term water quality monitoring. An underlying motive underpinning the monitoring effort was to produce evidence of water pollution that could be used by the island's environmentalists to advocate for policy measures around wastewater, and ultimately protect Bonaire's reef ecosystems from land-based nutrient pollution.

Historically, few opportunities have existed for community-based monitoring of seawater quality because the nature of the marine environment places high demands on the sensors and the participants involved in monitoring (Lockridge et al., 2016; de Freitas et al., 2009). The design of sensing instruments for marine environments is an engineering challenge, as sensors are required with sufficient accuracy and precision that can withstand dynamic and corrosive conditions at sea, that are durable, deployable at various depths and which minimize costs and power consumption (Lockridge et al., 2016). To the best of my knowledge this is the first study of a participatory sensing initiative established for seawater quality monitoring. 


\subsection{Legitimacy dynamics in participatory knowledge production for environmental governance}

Participatory sensing is conceived of as part of the broader field of citizen science, hence in this section I draw from the science-society and STS literatures on participation and citizen science to start building a conceptual framework regarding the relation between public participation in research and the democratization of environmental science and policy (Kimura and Kinchey 2016; Carrozza 2015; McCormick 2007; Irwin 1995). Further, I incorporate insights on legitimacy from the organizational studies, policy studies and environmental governance literatures to understand legitimacy dynamics and the democratization potential of participatory sensing projects (Newig and Kvarda 2012; Black 2008; Suchman 1995). This section is organized as follows: First, I introduce the various modes of public participation in citizen science and clarify what is meant by democratization of scientific knowledge and policy in this context. Subsequently, I lay out the various legitimacy dimensions that are relevant to understanding the democratization potential of participatory sensing.

\subsubsection{Citizen science: on the nature of public participation in scientific knowledge production}

Citizen science encompasses diverse types of collaborative arrangements established between scientists and societal actors to produce knowledge about the natural world (Shirk et al., 2012). Citizen science projects are driven by different goals. On one end of the spectrum lie the scientific-driven projects, which focus on answering research questions posed by academics (Bonney et al., 2016). On the other end of the spectrum lie the community-driven projects that arise due to public concerns related to an environmental or nature conservation issue (Wilderman et al., 2007).

Public participation in knowledge production about the natural world is not new. Almost 2500 years ago, local fishermen from the island of Lesbos assisted Aristotle, the 'father of marine biology', with his empirical research at the Aegean Sea (Voultsiadou et al., 2017). Today, millions of volunteers collaborate with scientists by collecting, processing and/or interpreting data (Bonney et al., 2016). The nature of this collaboration and the level of public participation vary according to the project type. Projects range from merely contributory - where scientists design the 
project and citizens contribute data - to the more democratic forms including socalled collaborative and co-creation projects - where scientists and citizens work together, sharing tasks and responsibilities (Bonney et al., 2009), or where citizens lead the knowledge production process, referred to as community-driven projects (Wilderman et al., 2007). Participatory sensing projects may belong to all types above. The case examined in this paper fits best within the collaborative category of participatory sensing projects.

Many forms of environmental harm can be detected through the human senses and bodily experiences of local inhabitants. This form of evidence, however, is often dismissed by decision-makers as unscientific (Jalbert and Kinchey 2016). By producing monitoring data to support their claims about environmental harm, concerned communities are responding to what Habermas referred to as the 'scientization of politics', a process by which governmental decision-making is controlled by scientific experts and bureaucrats (Weingart 1999; McCormick 2007). In this technocratic model of decision-making, those with expert knowledge are empowered while laypeople's concerns are often dismissed as biased and hence illegitimate (McCormick 2007).

The STS literature often equates "deep and active participation in scientific knowledge making" with high knowledge democracy and empowerment (Kimura and Kinchey 2016:333). According to Wilderman et al., (2007), community-driven citizen science is considered the most democratic model, as communities have control over the problem definition, project design and implementation. By gaining control of the knowledge production process about matters that concern their wellbeing, communities seek liberation from dependencies and inequalities, in this case of perceived knowledge and power asymmetries as in "experts vs laypeople" (Burke and Heynen 2014; Irwin 1995). As such, these projects are seen as empowering involved communities, through scientific knowledge production, in order to level the field in decision-making about environmental threats.

The aim of democratizing scientific knowledge for use in environmental governance implies that there is a democratic deficit that requires correction. The line of argumentation is that, by adopting scientific methods and technologies to produce environmental data, the community's knowledge becomes credible in the eyes of policymakers and other scientists, which legitimizes its use in decision-making. The assumption is that, by gaining access to the decision-making process through the 
knowledge they produce, communities are able to exert some influence on the decision; this in turn makes the decision-making process more democratic and legitimate in their eyes. The deficit is thus a deficit in legitimacy (Cash et al., 2003). But, what is legitimacy and when is a knowledge-governance process perceived as legitimate by all relevant audiences?

\subsubsection{Legitimacy dynamics in participatory sensing projects}

Suchman defines legitimacy as "a generalized perception or assumption that the actions of an entity are desirable, proper, or appropriate within some socially constructed system of norms, values, beliefs, and definitions" (1995:574). The entity here is a participatory sensing project. Legitimacy involves both attitudinal approval and behavioral consent related to an entity, where consent varies from passive acceptance to active participation.

Legitimacy is a multifaceted, relational concept that requires us to ask "legitimacy for what, and legitimacy in the eyes of whom?" (Biermann and Gupta 2011; Suchman 1995). Regarding the question of "legitimacy for what?", credibility and continuity are two reasons why entities seek legitimacy. A participatory sensing project requires credibility because the project's goal is to elicit behavioral responses based on the produced knowledge. The continuity of a participatory sensing project depends on the active and enduring support from its participants, who engage in the project on a voluntary basis. In the case of the LMSP, this support entailed volunteer divers servicing the sensor arrays and retrieving the data weekly for several years. As to the question "legitimacy in the eyes of whom?", a distinction can be made between an internal and external perspective (Biermann and Gupta 2011), as already indicated.

\section{Three broad types of legitimacy: pragmatic, cognitive and moral legitimacy} There are various reasons why people may accept or support an entity and its actions. These reasons lie in the congruence between what the entity does and people's interests, beliefs and expectations (Black 2008). The reasons can be grouped in three major categories: legitimacy may be pragmatically based, cognitively based or morally based (Suchman 1995). Pragmatic legitimacy refers to the perceptions by a person or social group that the entity pursues their interests directly or indirectly; cognitive legitimacy is based on perceptions that the entity is necessary or inevitable; moral or 
normative legitimacy is based on the perceptions that the entity's goals and procedures are appropriate (ibid).

Pragmatic legitimacy involves exchanges or interdependencies between the entity and its most immediate audiences. Cognitive legitimacy occurs when there is such a high degree of acceptance between the entity and a social group, that the entity's existence is unquestioned and perceived as inevitable and taken-for-granted. Moral legitimacy entails a positive normative evaluation of the entity and its activities. Typically, moral legitimacy concerns entities that claim to promote social welfare or environmental sustainability, such as participatory sensing projects. Thus, in what follows I focus on this legitimacy type and its various dimensions.

\section{Participatory sensing projects and their moral/normative legitimacy}

Moral or normative assessments of whether an entity should be regarded as legitimate fall into different types of legitimacy "claims". Two types are relevant for participatory sensing projects: democratic and functional/performance claims (Black 2008). Democratic claims concern the questions of who participates and how in the knowledge production process (Wilderman et al., 2007). In the environmental governance literature, these claims refer to the analytical categories of imput and throughput legitimacy (Newig and Kvarda 2012) and are mostly relevant for the community members themselves. Input legitimacy relates to the democratic principle of participation understood as representation, and is therefore concerned with questions of inclusion and exclusion in processes of knowledge production for environmental governance. Throughput legitimacy looks not only at who has been involved, but how, emphasizing the nature of participation as perceived by project participants (Newig and Kvarda 2012). In other words, how "fair" or appropriate is the knowledge production process in their eyes (Wilderman et al., 2007; Cash et al., 2003)?

Functional/performance-based legitimacy claims involve the outcomes and consequences of what the entity does. The environmental governance literature refers to this analytical category as output legitimacy (Newig and Kvarda 2012). In output-oriented legitimacy, the main criterion is the project's problem-solving capacity or achievement of results (e.g. whether the desired technology or data/knowledge are produced and used as intended). Moreover, "the extent to which [an entity] operates in conformance with professional or scientific norms...” (Black 
2008: 146) plays a crucial role in this type of claims, which correspond to what Suchman calls procedural legitimacy (1995). Functional or performance-based legitimacy claims are relevant for both internal and external audiences, but play a more prominent role in evaluations by external audiences.

\subsubsection{Gaining, maintaining and repairing legitimacy}

Suchman's analysis of how entities manage their own legitimacy identifies three stages: gaining legitimacy, maintaining it and repairing it once/if it is lost (1995). Strategies for gaining legitimacy entail devoting a substantial amount of energy “....to creat [e] objectivity and exteriority, a sense that the new endeavors define a [project] that exists independently of particular incumbents..." (ibid 1995:586). Maintaining legitimacy entails an entity's responsiveness to shifting conditions. As participatory sensing projects rely on voluntary participation, a strategy to maintain legitimacy in the face of challenges includes "stockpiling goodwill and support" (Suchman 1995:596), especially from volunteers. In case an unforeseen "crisis of meaning" occurs within the project, legitimacy will need to be repaired (Suchman 1995: 597). Suchman observes that "the initial task in mending a breach of legitimacy usually will be to formulate a normalizing account that separates the threatening revelation from larger assessments of the organization as a whole" (Suchman 1995: 597-8). Such an account will try to eliminate moral responsibility and may be followed by a re-legitimating account through a strategic restructuring/rebranding of the project.

\subsubsection{Feedback legitimacy: on account giving}

Feedback-legitimacy refers to the accountability mechanisms through which actors give each other account about project procedures and outcomes (van Tatenhove 2011). Bovens defines accountability as a specific social relation where "the obligation to explain and justify conduct" is central (2007:450). Accountability relationships may be vertical or horizontal, and accountability mechanisms - the procedures by which account is given - may be formal or informal (Emilsson 2017). When hierarchical relations between actors are established, vertical accountability relations and the mechanisms that mediate these relations are usually explained by principal-agent theory (Guston 1996). In these types of relationships a principal delegates work to the agents, whose goals may not be congruent with those of the principal, and hence formal accountability mechanisms are necessary to manage the agents' behavior (Emilsson 2017; Guston 1996). Formal mechanisms include official 
performance evaluations based on contractual obligations, formal control and monitoring of performance, and formal rewards and sanctions (Blagescu et al., 2005).

Participatory sensing projects, however, are collaborative endeavors established on a voluntary basis in order to pursue common goals. The assumption is that there is no hierarchy between actors and hence horizontal accountability relations prevail (Emilsson 2017). This type of accountability is referred to as mutual compact accountability (Brown and Jagadananda 2007), where members are bound by shared values, aspirations and social identities. Informal mechanisms mediate these accountability relations: unofficial performance evaluations, informal rewards and sanctions related to reputation and recognition (Emilsson 2017), as well as trust and transparency (Brown and Jagadananda 2007).

So far I have discussed the internal accountability structures of a collaborative project and its internal accountability mechanisms (i.e. internal feedback legitimacy). However, the project as a whole owes accountability to external forums (i.e. external feedback legitimacy). Because actors who engage in participatory sensing projects are also engaged in accountability relationships with actors or organizations external to the project, project participants are accountable to different forums, which may place conflicting demands on them. For instance, an environmental organization involved in a participatory sensing project not only owes account to the volunteers who dedicate their time and skills to the project (inward accountability), but it also may owe accountability upward to donors, downward to beneficiaries and outward to project partners (Brown and Jagadananda 2007). Scientists may have to render account to their academic institutions and to their funding bodies (upward) and to the scientific community who judges the quality of the project's scientific or technological outputs (outward) (Ladd et al., 2009).

According to Black, "to give account is to construct and present a narrative of past events or actions" and actors "can construct multiple narratives in the context of multiple accountability relationships in an attempt to meet the divergent legitimacy claims of multiple legitimacy communities" (2008:151). Through interpretive and discursive schemas manifested through their narratives, actors make sense of their own and each other's roles in the "tangled web of legitimacy and accountability" (Emilsson 2017) relations in participatory sensing projects. Figure 6.1 shows the 
Chapter 6

legitimacy dynamics at play in participatory knowledge production and environmental decision-making processes in the context of participatory sensing.

Legitimacy of the knowledge production process in the eyes of decision-makers

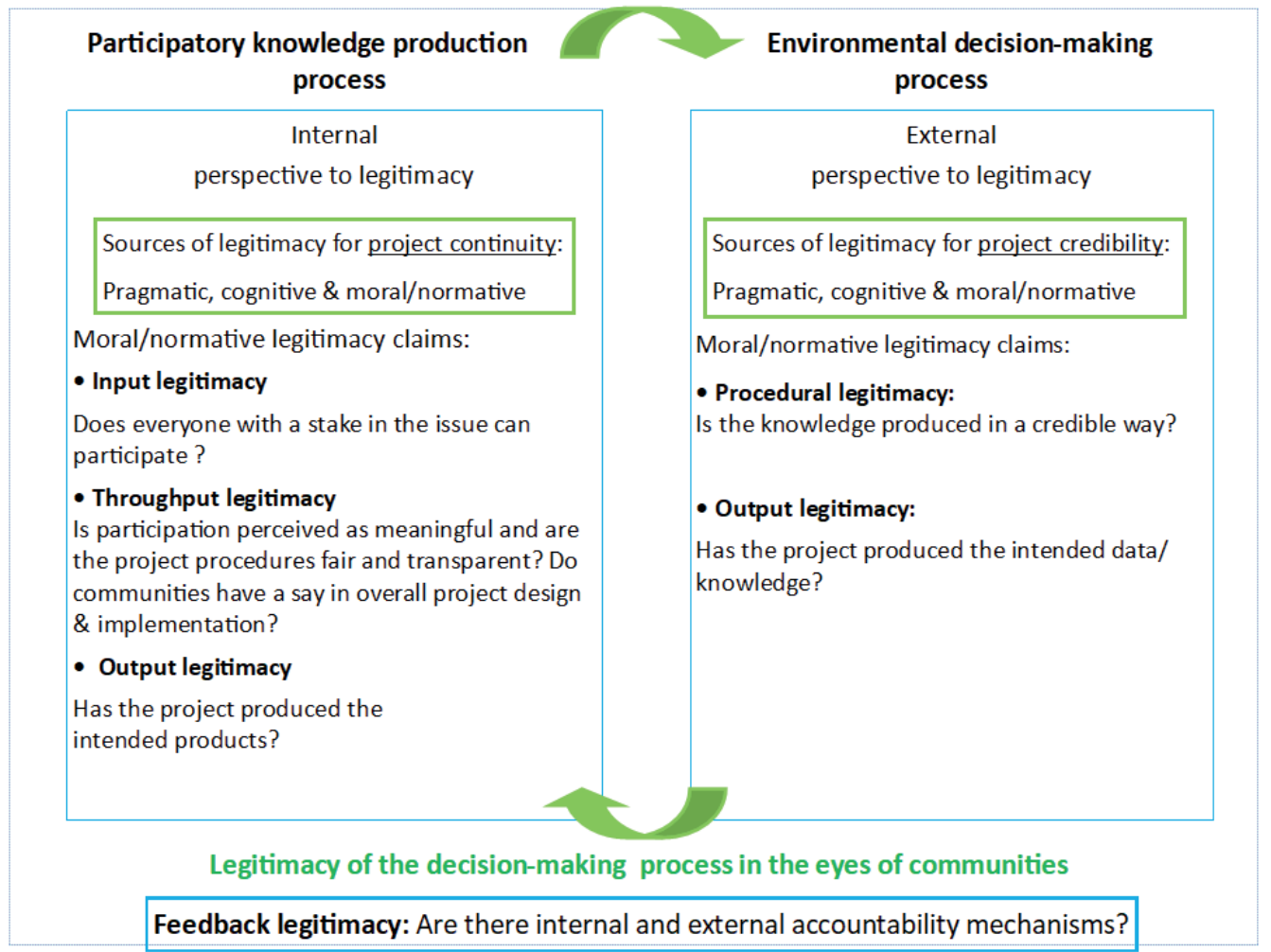

Figure 6.1. Legitimacy dynamics in participatory sensing projects.

\subsection{Methods}

\subsubsection{Study design and data collection}

The study design consisted of a qualitative case study based on an interpretive methodology (Schwartz-Shea and Yanow 2013). The "Light and Motion Sensor Program" was selected as case after an exploratory phase that identified water quality as a governance issue in a number of coral reef MPAs, and surveyed whether and how digital innovations in monitoring were implemented, by whom and to what effect. 
Data collection took place through purposeful sampling (Bryman 2012). Main data sources were newspaper reports and semi-structured interviews. All the (online) newspaper issues covering the period 2007-2019 of The Bonaire Reporter (TBR), a local newspaper issued bi-weekly in paper and digital form, were surveyed to look for stories related to the topic of water quality by scanning each issue's index (ca. 120 issues). Thirty issues containing 35 relevant items were identified. Twelve semistructured interviews were conducted with project participants and non-participants who had a stake in Bonaire's water quality science and/or management (Appendix 6). Also, several key reports pertaining to nutrient loads, the sensors and the sewerage and wastewater system were selected as data sources (marked with asterisks in the Reference list). Other data sources included websites, online forums, videos and blogs.

\subsubsection{Data analysis}

\section{Narratives and rhetoric}

Data analysis was informed by narrative and rhetoric concepts and methods. Persuasive communication - through the use of rhetoric devices embedded in narratives - plays an important role in the ways actors construct legitimacy for the organization they represent, and in how they render account to different audiences (Ruebottom 2013; Samkin and Schneider 2010; Black 2008; Golant and Sillince 2007). Narrative analysis draws from literary theories to discern how people create meaning about their world through the stories that they tell (Lejano et al., 2013; Feldman 2004). Narrative analysis is recognized as a useful analytical tool to understand phenomena from actors' perspectives, as storytelling is a basic means that participants use to create understanding of their organization or project and the roles that people play within them (Lejano et al., 2013; Feldman et al., 2004). Moreover, narratives have been studied to analyze how political actors make sense of and articulate highly uncertain and complex issues in the context of environmental governance (Hajer and Laws 2006; Roe 1989). Rhetoric is the practice of using persuasive language and symbols in oral and written communication (Higgins and Walker 2012). To be persuasive, narratives make use of rhetorical strategies and devices, appealing to the credibility of the speaker (ethos), reason or logic of the argument based on rationality, facts and figures (logos), and emotion (pathos) of the audience from which support is sought or to whom account is rendered (ibid). 
A narrative can be defined "as a sequence of events, experiences, or actions with a plot that ties together different parts into a meaningful whole" (Feldman et al., 2004:148). In their book The power of narrative of environmental networks, Lejano et al. (2013) present the concept of a "narrative-network" to denote the shared ideas and ideals that bind informal networks together in collaborative governance arrangements. A narrative-network is a social network that has built an overarching narrative about a certain environmental or nature conservation issue and comes into action to address that issue. A participatory sensing project can be viewed as part of a narrative-network, which according to Lejano et al. (2013) acts as a community of narrators, where every actor is both a narrator and a listener. The terms narrative and story are used interchangeably in this paper. Both narratives and stories include a setting (a place where the story unfolds), a chronology (beginning, middle and end), characters (heroes, victims, villains), events, plots, and breaches or twists in the plot. The context includes the history and the social, political, cultural and economic environment of the narrative-network (Lejano et al., 2013; Feldman et al., 2004).

In this paper I examine two commonly used rhetorical strategies: characterization the portrayal of protagonist $v$ s. antagonist - and the construction of syllogisms to structure causal explanations about events (Ruebottom 2013; Feldman et al., 2004). Rhetorical devices used in characterization include highlighting oppositions or contrasts, theorizing and problematizing, and alignment through the use of evaluative statements (Ruebottom 2013; Hajer and Laws 2006; Feldman et al., 2004). Through characterization of protagonists $v s$. antagonists, narrators seek to create tension and subsequently dissolve this tension by their proposed solution, in this way creating legitimacy for the protagonists of their stories.

In classical rhetoric, syllogisms are logical arguments comprised of a major premise, a minor premise and the conclusion. An enthymeme is a syllogism which lacks one of the premises or the conclusion. According to Feldman et al., narrators often embed enthymemes in their stories in order to avoid polemical topics: "leaving unspoken the potentially controversial or not taken-for-granted aspects of the argument, the speaker may stave off disagreement" (2004:152). Moreover, by using an enthymeme, the narrator expects that the audience will supply some of the information needed to make the argument complete. Feldman and Sköldberg (2002:277) explain that "Presumably what the audience supplies, the audience also believes or will be 
induced to believe" (cited in Feldman et al., 2004:152). This persuasive quality of enthymemes is useful when actors construct legitimacy and render account to their forums, wishing to avoid contentious issues, in order to appear unbiased.

\section{Analytical steps}

Data sources were analyzed based on a combination of inductive and deductive coding (Fereday and Muir-Cochrane 2008). First, inductive coding was applied to identify relevant stories in each text examined. A relevant story was one which, following a distinct arc from beginning to end, provided understanding about a specific aspect related to Bonaire's water quality issues, and the role of the LMSP herein. The second step applied deductive coding to elucidate the characterization strategy and rhetoric devices used by the narrators, as well as the syllogisms and enthymemes, and their functions in the story. The third step discerned the most conceptually powerful stories in providing understanding of the LMSP process - in terms of the various legitimacy dimensions and perspectives - as well as the LMSP's democratization outcomes. Several iterations were conducted to understand how the different stories, and their context, fit into a meaningful whole.

\subsection{Background to the "Light and Motion Sensor Program"}

\subsubsection{Coral reefs and water quality}

Coral reefs are among the most productive and vulnerable ecosystems on Earth. Located in the tropical and sub-tropical oceans, these ecosystems are vital to the social and economic wellbeing of almost half a billion people, predominantly from poor coastal areas of developing countries and of small island states, where alternative livelihood options are limited (Hoegh-Guldberg et al., 2019). Significant degradation of reefs and associated biodiversity over the last decades has been documented worldwide. In the Caribbean, a 50\% reduction in coral cover has been observed since the 1960s (Jackson et al., 2014). Causes for decline comprise a variety of local and global factors, both natural and anthropogenic, including overfishing, pollution, coastal development and the effects of climate change (Hoegh-Guldberg et al., 2019). Marine protected areas (MPAs) are the most common strategy for coral reef conservation globally (Christie and White 2007). Although MPAs can be effective in managing human activities within their boundaries, coral reefs remain vulnerable to impacts from activities that largely occur outside MPA jurisdictional boundaries (Agardy et al., 2011). Land-based water pollution is a case in point. 
Water quality deterioration due to coastal development is recognized as one of the top chronic local pressures on reefs (De'ath and Fabricius 2010). Corals, which thrive in clear, nutrient-poor waters, are particularly sensitive to eutrophication - the over-enrichment of water with nutrients originating from agriculture and sewage discharges (Fabricius 2011). Point source pollution entails discharges at a single location, such as from industrial or sewage outflow pipes. Non-point source pollution involves multiple and diffuse sources of pollutants which are transported by rivers, urban runoff, groundwater draining into the sea or ocean currents (Patterson et al., 2013). Abatement of non-point source water pollution is regarded as a 'wicked policy problem' due to the high levels of uncertainty and complexity involved in the knowability and governability of this phenomenon, which spans spatial, sectoral, jurisdictional and scientific discipline boundaries (ibid).

\subsubsection{Bonaire's coral reefs and water quality}

The small Southeastern Caribbean island of Bonaire is located off the coast of Venezuela in the Leeward Antilles. Bonaire's marine ecosystems include mangroves, seagrass meadows and fringing coral reefs that are accessible from the shore. Since the 1960s, Bonaire has established a strong dive-tourism niche (Parker 1999), and the island is consistently rated as one of the best dive locations worldwide. Tourism is the basis of Bonaire's economy, contributing $80 \%$ of GDP (van der Lely et al., 2013). A former Dutch colony, Bonaire became a special municipality of the Netherlands on October $10^{\text {th }}, 2010$, together with the islands of St. Eustatius and Saba.

Bonaire National Marine Park was established in 1979 as a response to reef degradation ascribed to unregulated marine tourism during the 1960s-70s (Parker 1999). Reef fish decline was observed due to spearfishing and there was anchor damage to corals. The marine park, a multiple-use MPA, includes all waters surrounding the island, beginning from the high-tide mark up to $60 \mathrm{~m}$ in depth and $200 \mathrm{~m}$ off the coast. The National Parks Foundation STINAPA (Stichting Nationale Parken), a non-governmental, non-profit organization, is mandated with park management. Bonaire's reefs are considered among the best protected and best remaining reefs in the Caribbean (Jackson et al., 2014). 


\subsection{Narratives on Bonaire's "Light and Motion Sensor Program"}

This Section presents the analysis of how legitimacy for the LMSP was constructed and how internal and external audiences responded. The first part of the analysis provides a brief historical overview of Bonaire's wastewater management issues leading up to LMSP establishment. The second part shows how characterization and the construction of syllogisms and enthymemes revealed actors' understanding of the project, their roles within it and the political context regarding Bonaire's wastewater issue.

\subsubsection{The nutrient pollution narrative}

On Bonaire, water pollution has been associated with tourism growth since the late 1980s, through direct and indirect wastewater release into the sea (Parker 1999). STINAPA and other environmentalists advocated for wastewater management for over two decades. Building a wastewater treatment plant and a sewerage system was initially proposed in the early 1990s, but plans were continuously postponed due to high financial costs, disagreements regarding the proposed design and wastewater treatment standards, as well as fraud allegations (TBR 2008 Vol. 15:20; van Kekem et al., 2006; Gijzen and van der Steen 2004). A feasibility study for the wastewater plant conducted around 2003 considered up to secondary treatment only, which was not acceptable to the island's environmentalists. The reason was that after secondary treatment high nutrient loads remain in the treated water. Because treated water would be reused in seafront hotel irrigation, and Bonaire's soil is porous, this nutrient-rich water would percolate into the groundwater and eventually reach the reefs (Gijzen and van der Steen 2004).

In 2006, a scientific team from the United States visited Bonaire to present the results of a study conducted to assess the status of the coral reefs. Within this team, a Florida-based scientist linked reef decline to high nutrient loads entering the reef from untreated sewage runoff. Wastewater from septic tanks and cesspools from hotels and households was thought to leach into the groundwater and drain into the coastal waters. The recommendations made included "immediate implementation of tertiary sewage treatment" in order to remove phosphates and nitrates before water discharge or reuse (Littler and Littler 2006).

The MPA manager at the time became a key node in the narrative-network that advocated for immediate sewage treatment, and an important LMSP character. 


\section{Chapter 6}

Together with two California-based scientists and a local diver and environmentalist, the MPA manager initiated the LMSP. Because the MPA manager relied on visiting scientists to provide data about water quality, and the projects were short-term, one of the main goals of the LMSP was to establish a 10-year seawater quality monitoring program, implemented locally. The pilot project was conducted between May and August of 2007, and Phase 1 of the project began in August of that year.

The analysis presented below follows a chronological order and is organized according to the stages of gaining, maintaining and repairing legitimacy (Suchman 1995), which reflect the development of the LMSP over the period between 2007-2014.

\subsubsection{Gaining legitimacy for the LMSP: a story of a threatened reef and technological rescue (2007-2008)}

During the second half of 2007, The Bonaire Reporter (TBR) provided wide coverage of the launching of the LMSP's Phase 1. The pilot phase, which consisted of testing the sensors, was touted as a success. The sensors not only remained operational under water, but they also recorded temperature differences during an upwelling event in June-July 2007, providing proof of concept that the novel sensors worked. The sensors "passing the test" granted output legitimacy to the pilot phase. This supported the decision by the project initiators to deploy a series of sensor arrays along Bonaire' leeward coast to monitor seawater quality in the 'sensitive zone', a $200 \mathrm{~m}$ strip parallel to the coast where most hotels are situated. Active support from participants was sought: donors who would fund the purchase of more sensors and volunteer divers who would service them weekly.

The following quote from TBR encapsulates the essence of the narrative constructed to acquire legitimacy for the LMSP in this initial phase:

Bonaire strives to maintain its leadership role in the conservation of coral reefs, its precious natural resource, by using modern technology to produce scientific data to study sea water quality around the island to be able to provide early warning of ecologically threatening situations (TBR 2008: Vol. 15, Issue 2:8).

Below, I show the rhetorical strategies and devices used by the project's initiators to generate active support and acceptability of the project, communicated through the stories published by TBR. 


\section{Characterization through appeals to ethos, logos and pathos}

The main characters featured in the newspaper were the California-based scientists who developed the sensors and their diving buddy, an ex-pat living on Bonaire, who assisted during the pilot phase and took the role of volunteer coordinator. These three men were also the principal storytellers on TBR during the summer of 2007, and during public presentations that the foreign scientists gave while visiting Bonaire in August of that year. The MPA manager remained in the background during this initial phase of the project.

Appeals to the credibility of the scientists and their technologies (ethos) were a common characterization strategy. The scientific credentials of the foreign researchers were highlighted, in particular of the principal investigator (P.I.), "a towering figure" in oceanographic research internationally. Positive evaluative statements about the foreign scientists, the sensors and the scientific data that the sensors would generate were abundant in the stories that introduced the LMSP. This contributed to building the project's legitimacy, based on the normative approval by internal and external audiences - of the scientific procedures and novel technology used. The development and deployment of the optical sensors was told as a success story in which various obstacles were overcome:

The idea first popped up four years ago but the costs, logistics, support and permissions to deploy sensors were formidable. A breakthrough in the design and production of an array utilizing a $\$ 50$ sensor (commercial units cost between $\$ 8,000$ to 220,000) by [P.I.] was key (TBR 2007, Vol. 14, Issue 30:3).

The contrast between the low-cost and expensive sensors was a rhetorical device frequently used to persuade audiences of the importance of this breakthrough for a small, financially constrained island as Bonaire. The researchers who achieved this feat were characterized as heroes in the story. The sensors - which measured light and temperature fluctuations, hence the 'light and motion' reference - featured prominently in all newspaper stories written about the LMSP during its first year. Dubbed as the "rainbow sensors" because of the different color wavelengths at which they absorbed light depending on water depth (an indirect assessment of organic content), these sensors were also characterized as protagonists (Figure 6.2). 
Chapter 6

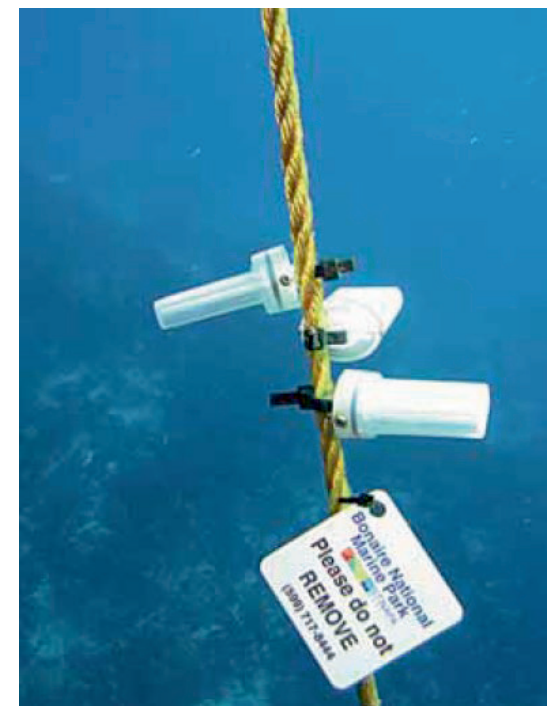

Figure 6.2. Rainbow sensors at Bonaire National Marine Park (Reproduced with permission from TBR).

Legitimacy building during the early stages of Phase 1 was strengthened by stories that showcased project achievements, which enhanced output legitimacy. These achievements were self-set goals of time-bound fundraising targets and ensuing additions of sensor moorings to the monitoring network. The terms "cost-effective" and "long-term monitoring" were frequently used in these sensor-centered stories.

Appeals made to reason (logos) were key elements of the coral reef conservation narrative. The scientific rationalization of the environmental problem faced by Bonaire's reefs was a core element that supported the LMSP enterprise. Water quality had been identified as a chief variable influencing reef health by the Floridabased and California-based experts. The rhetorical devices of theorizing and problematizing were used to persuade the audience that the protagonists - the rainbow sensors and associated data - would achieve positive outcomes. Plotted data were shown in graphs on several newspaper issues about the LMSP and during public presentations by the scientists.

The P.I. "explained that scientific data is a necessary prelude to political action" and referred to the Florida scientist's nutrient study, which "provided appropriate scientific data and, according to Bonaire National Marine Park Manager [...], the data 
was instrumental in his insisting on lower nutrient levels in the treated wastewater than was previously envisioned" (TBR 2007, Vol. 14, Issue 30:3). These arguments attempted to convince the audience that scientific data mattered, as in the past, data had enabled the environmentalists to steer policy decisions towards desired outcomes regarding water treatment standards.

Further, the storytellers built the project's legitimacy based on emotional grounds (pathos). They presented Bonaire's reefs as some of the best protected and healthiest reefs in the world, but threatened by water pollution and already showing signs of deterioration. Bonaire is known internationally for its leading role in reef conservation, hence an appeal was made to the environmentalists' pride and love for the reef in order to uphold Bonaire's strong reputation and identity as a "divers' paradise". Here, the protagonist was the reef (as victim) and the antagonist was nutrient pollution from (tourism) development (as villain). Cautionary tales of the fate of reefs in Miami and Jamaica - degraded due to wastewater pollution stemming from rapid coastal development - were told to legitimate the need for action, in the form of a monitoring program. Contrasting was used as a device to distinguish Bonaire's history of healthy reefs against reef decay elsewhere, with photographs of dead reefs to underscore the message.

The storytellers' audience was Bonaire's population, in general, and Bonaire's environmentalists in particular. The environmentalist community consisted mostly of ex-pats from North America who were experienced recreational divers and lived on the island part of the year. This group was called upon to supply material and symbolic resources to the LMSP. The project's actions were congruent with these divers' goals of protecting Bonaire's marine environment, hence, alignment between protagonist and supporters was created. A story of reef decline due to water pollution justified the need for action, and the sensors provided the means to identify the culprits of such decline: "The optical sensors can indicate decreases in water clarity that could be caused by a number of processes, including the seepage of dumped wastewater" (TBR 2007, Vol. 14, Issue 30:9).

A recurring syllogism used to argue for the monitoring program was built as follows: because nutrient pollution is a threat to coral reefs, monitoring to identify where this pollution comes from is necessary. The argument is an enthymeme, as it leaves out 
a controversial element which is already (tentatively) accepted by the audience: the seafront hotels and businesses as main pollution sources.

Summing up, the overarching narrative constructed to gain legitimacy for the LMSP presented Bonaire's coral reefs as protagonists threatened by water pollution, and the scientists and the rainbow sensors as heroes who would help to remedy the situation. This strategy worked, as active support was provided by dozens of donors and volunteer divers who joined the monitoring effort in Phase 1.

\section{Rendering account through The Bonaire Reporter and the Sea Monitoring Foundation}

In subsequent months, the volunteer divers who joined the project were given a voice through TBR to tell their stories. Next to cleaning the ropes and the sensor arrays (consisting of nine sensors each, grouped in sets of three at three different depths: 5, 12 and $20 \mathrm{~m}$ ), the volunteers were asked to report on their observations of marine life gathered around the moorings. These stories appealed to the emotional attachment of divers to the marine fauna they encountered during their dives. Moreover, TBR served as a platform that facilitated informal accountability mechanisms such as public recognition, through media attention, of the volunteers' contribution to the project. Progress reports by the volunteer coordinator about the number of sensors purchased - mentioning amounts of money donated and donor names - also served as an informal (financial and procedural) accountability mechanism towards internal and external audiences.

As an attempt to formalize roles and responsibilities within the LMSP, project initiators established the Sea Monitoring Foundation. This foundation would serve as a financial accountability mechanism regarding donations made to the project, which were tax deductible and hence required adequate financial accounting. The roles and responsibilities were as follows. Divers' weekly tasks included downloading the data from the sensors using a recording reader, checking if the sensors were functioning properly, and scrapping off algae growing on sensors and ropes. Subsequently, the divers took the reader to the local research station, where the data were uploaded to the station's computers and sent by e-mail to the scientists in California. There, data would be analyzed by the scientists and undergraduate students. The data would be sent back in processed form to STINAPA, to be 
displayed on their website, so that "anyone with Internet access [could] know of the precise quality of Bonaire's surrounding water" (TBR 2007 Vol.14, Issue 30:9).

\subsubsection{Maintaining legitimacy for the LMSP: approaching tipping points (2008-2009)}

By January 2008, thirteen sensor arrays had been deployed and were serviced weekly by a team of volunteers. Several dozen volunteers were named in the newspaper to recognize their efforts. A core group composed of the volunteer coordinator and a dozen dedicated individuals did most of the work, while the rest contributed more sporadically.

Through the newspaper, narrators openly and insistently invited all interested individuals - locally and abroad - to support the project either by active diving/data collection activities or by providing donations to purchase sensors and spare parts for repair and maintenance. Arguably, the LMSP can be considered as an inclusive project and its input legitimacy high, insofar as those interested in participating possessed a scuba diving certificate and financial resources. Regarding the project's throughput legitimacy, volunteers seemed to perceive their roles as appropriate and commensurate with their skills and interests. In terms of control over the project, the MPA manager was instrumental in shaping the problem definition and both he and the volunteer coordinator had contributed to site selection for the moorings and in sensor array deployment. According to the volunteers, the volunteer coordinator was the motor of the project; he serviced his own assigned sensors assiduously and those of other volunteers during their stays abroad (TBR 2014, Year 21, Issue 2:6,12). The Sea Monitoring Foundation functioned as an instrument for internal and external feedback legitimacy, enabling project implementation and ensuring financial transparency.

The (internal and external) legitimacy of the LMSP was strengthened by events occurring in early 2008. Volunteers started to report accelerated algal growth on the sensors, ropes and buoys (Figure 6.3). This theme appeared repeatedly in the newspaper stories published during the first months of 2008. Algal growth is associated with excess nutrient concentrations in the water, and algae are therefore characterized as a feared antagonist that can "choke the reef to death." The nutrient pollution problem seemed to become increasingly urgent and approaching a perceived tipping point, compounded by incidents of wastewater dumping by a 
Chapter 6

number of cruise ships and aircrafts into Bonaire's sewage trenches. A cruise ship was suspected of dumping water with toxic compounds (TBR 2008, Vol. 15, issue 1:15).

In March 2008, the California scientists visited Bonaire once more, taking with them "highly sophisticated" equipment on loan from the P.I.'s university for calibration. Once calibrated, the sensors would provide "verified legitimate data" which would be made available not only on STINAPA's website, but also on the Sea Monitoring Foundation's website and the P.I.'s business website (TBR 2008 Vol. 15, Issue 5:8). The reprogrammed sensors recorded data every minute, instead of every eight minutes as they did previously. The first results after calibration were shown in graphs and explained on TBR. An argument not presented before was articulated, which appealed to reasons grounded on pragmatic legitimacy, and spoke directly to the resident and tourist diving community:

...in addition to being able to detect the by-products of contamination, the sensors provide the basic information every diver coming to Bonaire wants to know: How clear is the water and what's the temperature for each dive site (TBR 2008, Vol. 15, Issue 6:8).

The scientists published a scientific paper describing the sensors, their working principle and preliminary results, which were presented during a coral reef conference (Jones et al., 2008). During this conference, other scientists and marine managers were invited to collaborate in further sensor development.

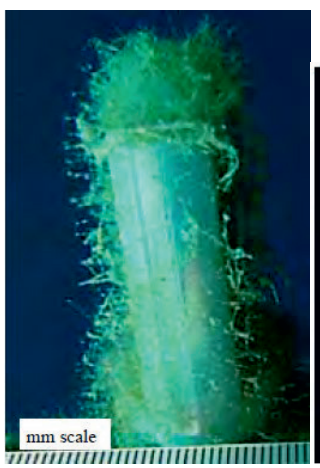

a)

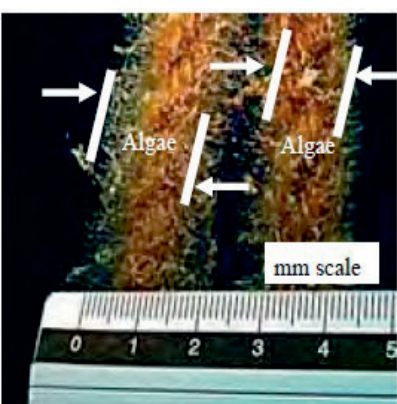

b)

Figure 6.3. One-week algal growth a) on a sensor and b) on a rope (Reproduced with permission from TBR). 
A few months later, the newspaper reported that the data flow from the LMSP was turning "into a data torrent", as data were recorded every minute. Although this technological achievement was initially seen as another testimony of the LMSP's output legitimacy, it eventually rendered data analysis unmanageable for the scientists. Both the data analysis capacity and the funding capacity of the project seemed to be approaching a tipping point. An appeal was made through TBR, in which additional donations were sought in order to hire experts - Matlab programmers - to help analyze the data. The MPA manager requested funding through other grants as well. While financial costs were a recurrent preoccupation and challenge for the LMSP, up till then the narrative had been that this antagonist could be overcome by lowcost sensors and support by donors and volunteers.

There was optimism that the project could start its Phase 2 "to expand sensor sites, provide finer details of water quality and add new types of sensors" (TBR 2008, Vol. 15, Issue 18:9). Additional volunteers and additional donations were sought to achieve this goal. The new types of sensors would measure salinity, to detect freshwater discharge from land. The scientists and the MPA manager thought that the combined sensors could detect anthropogenic nutrient pollution unambiguously. Again, the enthymeme constructed in this story left out a direct accusation to the seafront hotels and businesses. Although the narrators never explicitly named the presumed culprits while in their roles within the project (a scientific enterprise), some of them did in their roles as activists.

In August 2008, the MPA manager sent a letter to TBR urging for immediate action to stop unsustainable wastewater management practices by properties in the sensitive zone (TBR 2008, Vol. 15, Issue 16:7). He referred to various scientific studies that supported his arguments, using scientific terminology and data, as well as the rhetorical devices of contrasting (reefs in Hawaii and Bahamas being destroyed by nutrient pollution) and alignment of the protagonist and supporters (the reef, Bonaire's population). His was also a story of an impending tipping point:

As Manager of the Bonaire National Marine Park, it will be irresponsible if I do not warn you: "our wastewater management practice is no longer sustainable. This practice is killing our reef". We need to buy time; my suggestion is to truck more sewage water away from the shore-line. We have to start today! (TBR 2008, Vol. 15, Issue 16:7). 


\section{Chapter 6}

A campaign called "SOS Bonaire" (Stop Our Sewage) was launched simultaneously by the environmentalist group "Friends of Bonaire," which included some LMSP volunteers as members. These activists pushed for immediate treatment of wastewater generated by hotels, businesses and households located along Bonaire's sensitive zone and called for a boycott of seafront hotels and businesses that did not take measures to stop runoff of their wastewater. Citizen deliberations about the causal link between unregulated tourism development and reef decay, with a focus on nutrient pollution, were carried out through columns and Letters to the Editor that appeared in TBR in subsequent months.

This campaign and rising public pressure resulted in a debate regarding Bonaire's wastewater policy plans. Moreover, a temporary measure was adopted by the local government in 2009, referred to as the "Action Plan". Under this plan, wastewater generated at the sensitive zone was transported by trucks to a small treatment plant on the leeward side of the island. This side of Bonaire has no accessible reefs and hence no tourism development. According to a story that appeared in TBR on January 2009,

It's been proven that the trace nutrients in waste water are harmful to Bonaire's surrounding coral reef. These findings were reported to the government and published in The Reporter. In November, formal discussions were held with Bonaire's business community and environmental organizations to adapt the existing sewage treatment plan and adjust the capacity of the treatment plant... An interim "Action Plan" to cut sewage discharge by trucking away wastewater that would otherwise percolate into the sea is set to begin this year (TBR 2009, Vol. 16, Issue 1:2).

The above suggests that the LMSP was successful in gaining external legitimacy, in the eyes of the public and of Bonaire's decision-makers. Infrastructure works to build the wastewater and sewerage system, financed by the $9^{\text {th }}$ European Development Fund, finally began in 2009 and started operations in 2015, after decades of debate and pleas by Bonaire's environmentalist network (Slijkerman et al., 2019; van Kekem 2006). Figure 6.4 shows the timeline of Bonaire's sewerage program and monitoring efforts.

After TBR's issue that featured both the MPA manager's letter and the launching of the "SOS Bonaire" campaign, only one more story related to the LMSP appeared in the newspaper, in which the narrators appealed for support to launch Phase 2. 
Afterwards, the narrators did not speak though the newspaper anymore and no new data appeared on the STINAPA website. The water pollution narrative continued being told, through letters to the Editor and other columns, where the focus was the construction of the wastewater and sewerage system. A turn of events occurred in the LMSP's plot: Phase 2 was never launched, no funds could be raised to hire experts to analyze the data, the salinity sensors did not work and the California scientists, who filed a patent application for the rainbow sensor technology in June 2009 (Reynolds and Jones 2013), left the LMSP. Nevertheless, the core set of volunteer divers continued their weekly data collection activities for almost six more years. How can this unanticipated turn in this narrative be explained?

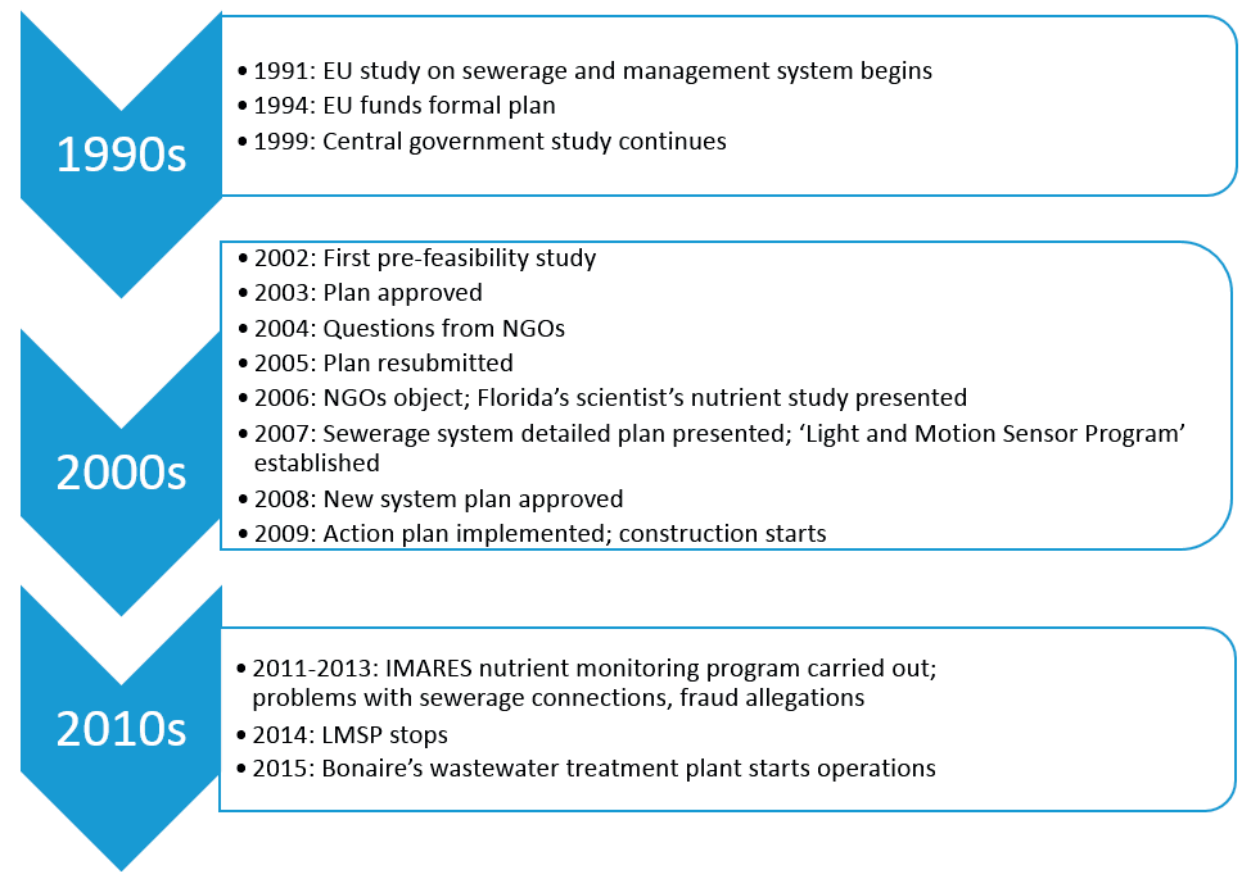

Figure 6.4. Timeline of Bonaire's sewerage and wastewater management program, including nutrient monitoring efforts (Sources: Gijzen and van der Steen 2004; van Kekem et al., 2006; TBR 2008, Vol. 15, Issue 20:3; Slijkerman et al., 2012; TBR 2013, Year 20, Issue 20:2; Davis 2016). 


\subsubsection{Repairing legitimacy for the LMSP: embarking on a new journey (2009- 2014)}

Information on the LMSP's goal and activities remained on STINAPA's website long after the scientists left the project, giving the impression that the LMSP was still on-going and that data would be "added soon" to the website. This can be interpreted as an attempt to uphold the LSMP's external legitimacy.

During an interview, the MPA manager admitted that a personal conflict had occurred between himself and the California scientists regarding the intellectual property of the sensors. He claimed that developing cheap sensors with simple color metrics had been his idea. He was disappointed when the scientists patented the sensor technology and one of them established a monitoring program in an Indonesian MPA (mostly to provide water clarity and temperature data to recreational divers) after it became apparent that no extra funding could be raised on Bonaire to pay for data analysis. The scientists, on the other hand, who were accountable to their home university and graduate students, were unable to justify to these forums the additional time and resources that data analysis for the LMSP would require.

After the departure of the scientists, one would presume that the LMSP would lose its purpose, and hence its legitimacy in the eyes of the volunteers, as the raw data would decay in the local station's computer without being analyzed or used. However, the project's internal legitimacy persisted, based on both moral/normative and pragmatic legitimacy grounds. First, the MPA manager formulated a normalizing account to repair the LMSP's moral/normative legitimacy. The account involved a story of unsuccessful efforts to raise the funds necessary to hire specialists for data analysis. High financial costs, presented as an antagonist that had been confronted successfully so far, became too strong for the LMSP. However, the project was not completely defeated. As Suchman (1995) observes, narratives used in repairing legitimacy are often followed by a re-legitimating account through a strategic restructuring/rebranding of the project.

Indeed, the MPA manager's narrative included a twist: NOAA, a large and wellknown U.S. governmental research organization had expressed interest in the temperature data detected by the sensors. Given NOAA's work in studying seawater 
temperature related to coral bleaching, this story seemed plausible. The promise of future data use provided the volunteers with a sense of purpose and justification to continue servicing the sensors. A new direction for the LMSP was established. However, the question of how, whether and by whom the sensors would be calibrated was not part of the new narrative.

The MPA manager and the organization he represented, STINAPA, had a good reputation and were trusted by the volunteers, who collaborated with the marine park in other conservation projects. One of these projects, which became an urgent conservation priority in large part of the Caribbean Sea, involved invasive lionfish monitoring and control efforts (Carballo Cárdenas and Tobi 2016). The first lionfish was spotted on Bonaire in 2009 and many of the volunteers who participated in the LMSP also joined the citizen science projects established around lionfish, combining both activities during the same dive. Eventually, spearing of lionfish became a key aim of the dives - a pragmatic source of legitimacy for continuing servicing the sensors. Lionfish became a new antagonist in the narrative-network and lionfish spearing practices became rapidly engrained in the diving routines of many volunteers. Also, socializing during and after the dive was important for participants, including their interactions with inquisitive tourists. These interactions provided for awareness raising opportunities and narratives that granted moral legitimacy to their efforts, in which the volunteers characterized themselves as environmental stewards:

Most of the Americans who volunteer on Bonaire are retired and we made this a social event. We always ran into people we knew and chit chatted. Tourists would often ask what we were doing and we always took the time to explain the LMSP as well as why we bunt lionfish. We enjoy educating people about marine ecology and the importance of what many volunteers were doing on Bonaire to protect the reef. Most people wanted pictures with the lionfish, not the [water quality data] reader [langhter]. My husband, [...], is a retired chemist and loves to explain how things work.

Moreover, several benefits derived through participation in the LMSP conferred pragmatic legitimacy to the project in the eyes of volunteers. Namely, they received free air for their tanks from a number of dive operators who agreed to support the LMSP. In exchange for free air, the volunteers in turn assisted the dive centers by helping cruise tourists who needed to gear up for scuba diving activities. Furthermore, volunteers gained access to areas of the marine park that they would 


\section{Chapter 6}

normally not be able to enter, where they could engage in recreational dives after servicing the sensors:

...We just went out to clean the sensors and collect data, about 15 - 20 minutes each site. Typically though we went on a nice long dive after since we had free tanks... [smile]. Doing the sensors also gave us access through dive resorts such as Black. Durgon, with no public access; this was excellent for lionfish bunting.

Given that many of them had provided donations to purchase the sensors they were servicing, the volunteers felt ownership of the LMSP project. Importantly, they had a close relation with each other and with the volunteer coordinator based on frequent face-to-face interactions, reciprocity and trust. Strong horizontal accountability ties regarding the LMSP developed among this close-knit diving community. The official announcement that the LMSP stopped was made after the volunteer coordinator passed away unexpectedly in January 2014 (TBR 2014, Year 21, Issue 2:6).

\section{Epilogue}

In 2011, the MPA manager approached IMARES, a Dutch research institute, to conduct a new short-term nutrient study and provide an estimate of the financial costs for a long-term monitoring program (Slijkerman et al., 2012, 2014). Negotiations to fund a new monitoring program were started between the Dutch and Bonaire governments, but remained unresolved. In 2018, the Bonairean government approached the Dutch branch of the WWF with a request to establish a seawater quality monitoring program for the island, without success (personal communication, WWF). Also in 2018, the new research station on Bonaire announced its intention to revive the LMSP, by analyzing the data still stored in their computers, aiming to use the results to evaluate the management effectiveness of the wastewater treatment plant (iSustain 2018). As of January 2020, no processed seawater quality data collected by the rainbow sensors have been made available and the status of the plans for a new monitoring program on Bonaire is unknown. 


\subsection{Discussion and Conclusion}

This paper aimed to illuminate the legitimation dynamics concerning a participatory sensing project established on Bonaire, by examining both internal and external legitimacy perspectives and the multiple dimensions of legitimacy at play. Moreover, the paper sought to provide insights regarding how these dynamics relate to the extent of democratization of water quality science and policy enabled by the project. In this section I critically discuss the most relevant findings and draw conclusions.

\subsubsection{The LMSP and its legitimating narratives: key outcomes}

The LMSP's narrators were successful in collectively framing the problem and their solution to reef degradation. While land-based nutrient pollution is recognized as one of the top local stressors for coral reefs (Fabricius 2011), eutrophication, its sources and effects on Bonaire's reefs were not unequivocally established by the Florida scientist's report. LSMP's narrators ignored other possible causes of reef deterioration, such as overfishing of herbivores (Steneck et al., 2009), and ascribed the problem solely to nutrient pollution. Simplification of the complexity surrounding the persistent environmental problem of coral reef decline was a useful narration strategy: it strengthened perceptions of the urgency to address water pollution to save the reef and justified the creation of the LMSP. The procedural dimension of legitimacy - the LMSP's scientific underpinning and its source of credibility - was crucial in creating attitudinal approval and behavioral consent from both internal and external audiences. Characterization of the sensors and the scientists who designed them as heroes who would provide scientific data to fight water pollution was fruitful in creating "objectivity and exteriority" for the LMSP (Suchman 1995:586). The use of enthymemes contributed to this sense of objectivity. The LMSP narrators avoided controversial statements that directly blamed the presumed polluters, and in doing so engaged in boundary-work to separate scientific facts from knowledge claims based on the (diver) community's personal observations of altered coral reefs (Guston 2001). Such reductive and technocratic framings of environmental problems are a response to scientized political cultures, which entice communities to appropriate scientific practices and discourse to appear legitimate (Kimura and Kinchey 2016).

While moral/normative reasons were most conspicuous in the narratives that were constructed to gain legitimacy for the LMSP, over time, pragmatic reasons became 


\section{Chapter 6}

more important sources of legitimacy in the eyes of volunteers. Moreover, the presence of a community champion - the volunteer coordinator - was key in building trust and strengthening the informal accountability mechanisms among participants. These insights can be useful for initiators of participatory sensing projects, for which community engagement is obviously essential to realize "visions of bottom-up empowerment", but as shown by Balestrini et al. (2015:50), this engagement may be ephemeral. Identification of a community champion and sources of pragmatic legitimacy for volunteers can be conducive to more sustainable participation.

\subsubsection{The LMSP's internal legitimacy and the democratization of water quality monitoring}

In STS scholarship, the democratization of science entails not only community inclusion, but "deep and active participation" and community control of the entire knowledge production process (Kimura and Kinchey 2016; Wilderman et al., 2007). The inclusion of only (North American) scuba divers as LMSP participants signified the exclusion of non-divers (native Bonaireans and other residents) in the program, reflecting the elitist nature of scuba diving and historic patterns of inequality on Bonaire. Participation in and control of the LMSP can be considered "high" in problem definition, data collection and overall project management, "medium" in project design (i.e. deciding location of buoys, frequency of sensor servicing) and "null" in data analysis and interpretation. The latter required specialized skills, equipment and expertise and constituted the bottleneck in the path towards science democracy. As such, the use of the rainbow sensors did not liberate the community from the so-called expert-lay divide, but reproduced and reinforced this hierarchy, similar to observations raised in other studies on participatory sensing (Jalbert and Kinchey 2016; Balestrini et al., 2015). The case examined here, in addition, illustrates another type of divide in environmental knowledge: the global North/global South divide (Karlsson et al., 2007). While the sensors were characterized as "good", ultimately their data torrents became a handicap for the continuation of the LMSP. Arts et al., observe that "digital technology may best be reconceptualised by conservationists from something that is either good or bad, to a dual-faced force in need of guidance" (2015:S670).

While citizen science is often presented as emancipatory, critics point out that the growth of public participation in science can be interpreted as a result of neoliberal 
transformations to the funding and organization of science (Kimura and Kinchey 2016). Citizen science is seen under this neoliberal lens as a "low-cost" solution to the absence of environmental data, and volunteers as "picking up the slack" of their governments (Kinchey and Perry 2012). On Bonaire, there is no governmental monitoring program on seawater quality, nor have ambient standards been established. After Bonaire became a special municipality of the Netherlands in 2010, a discussion of whose responsibility it is to conduct environmental monitoring has arisen between the Dutch and Bonaire governments. Till today, no resolution exists to the question of who is responsible to monitor and manage the environmental quality of water on Bonaire, and efforts remain short-lived and fragmented, whereas long-term and integrated management approaches are deemed urgent (Slijkerman et al., 2019).

\subsubsection{The LMSP's external legitimacy and the democratization of water quality policy}

Democratization of wastewater policy was to a certain degree enabled by the LMSP. Although the influence exerted was limited in terms of the scope and short-term nature of the "Action Plan", it was effective in setting the issue of wastewater management on Bonaire's political agenda and putting pressure to commence construction of the wastewater treatment plant and sewerage system. Although the LMSP was producing "torrents of data", those data were not used in the formal sense to provide evidence of nutrient pollution, as data analysis was lacking. Yet, the expert authority of the foreign scientists who had visited Bonaire, the existence of the sensors and the act of data sensing on itself granted legitimacy to the environmentalists' claims.

In their study of the construction and use of sustainability indicators, Lehtonen et al. (2016) showed that the use of indicators in policy venues does not automatically imply influence, and that influence does not always require indicator use: "...influence denotes the ways in which dialogue and argumentation generated by indicators or indicator sets - or by the processes of designing and applying indicators [...] - influence various elements of the policy chain" (2016:4). The case of the LMSP shows that, indeed, despite the lack of data use, the process of designing and implementing the monitoring network was influential as it triggered dialogue and argumentation. 


\section{Chapter 6}

During the monitoring process, the 'algal growth' narratives proved to be powerful in instigating political action, whereby the media played an important role. The wide publicity generated around the LMSP through The Bonaire Reporter contributed to awareness raising among (a segment of) Bonaire's population. Public opinion on seafront water discharges turned into public pressure that reached a zenith in 2008. Positive media attention to projects where communities are involved in research about their environment seems to provide leverage to such projects' political reach. Evans et al. (2000) observed that the volunteer-based project described in their paper attracted wide media coverage, possibly influencing the policy debate about tributyltin contamination of the North Sea.

\subsubsection{Conceptual lens and future research}

The conceptual framework built for this study provided a useful lens for the analysis of legitimacy dynamics in the LMSP. Disambiguation of legitimacy into its internal and external perspectives, as well as its multiple dimensions, allowed for a rich understanding of the different sources of legitimacy and how they were relevant for distinct audiences. A chronological analysis based on the stages of building, maintaining and repairing legitimacy was helpful to ascertain how narrators and their audiences adaptively constructed meaning for the LMSP. Finally, the framework suggested a way to understand how legitimacy is related to the democratization of science and policy (potentially) brought about by participatory sensing.

This study focused on participatory sensing in a context where the importance of coral reef ecosystems for the island's economic wellbeing is recognized, and where an environmentalist ethic has a long history (Parker 1999). The Bonaire Reporter, for instance, is a pro-environment newspaper. Future research could focus on participatory sensing initiatives established in similar MPAs, but which lack media attention. This could provide additional insights regarding the role of the media in the construction of legitimacy for participatory sensing efforts (Evans et al., 2000). Moreover, on Bonaire, due to the absence of governmental monitoring data and of regulatory standards for (sea)water quality, the (lack of) results generated by the LMSP could not be scrutinized or contested by decision-makers and polluters. In future research, it would be interesting to investigate a case where seawater quality data generated by a participatory sensing project is pitted against "official" government data (Ottinger 2010), and examine the (de)legitimating role that water quality standards play in the narratives constructed by the various actors involved. 
Chronicle of a grassroots project to monitor seawater quality on Bonaire

\subsubsection{Conclusions}

Participatory sensing initiatives can potentially become a powerful agent of change in environmental governance. Providing affected communities with sensing technologies, however, will not automatically lead to community empowerment. The "Light and Motion Sensor Program" showed that these technologies can reproduce dependencies of communities on (foreign) experts to make sense of the data and to maintain custom-built sensors. Concurrently, the examined case also indicated that there are indirect pathways through which participatory sensing initiatives may exert influence on policy debates. In our risk society, the allure of novel, low-cost technologies to monitoring invisible environmental threats will most likely continue to grow among concerned communities. The dual-faced force of technology requires attention from researchers and practitioners to guide its use in participatory sensing initiatives in order to fulfil their democratization potential. 
CHAPTER

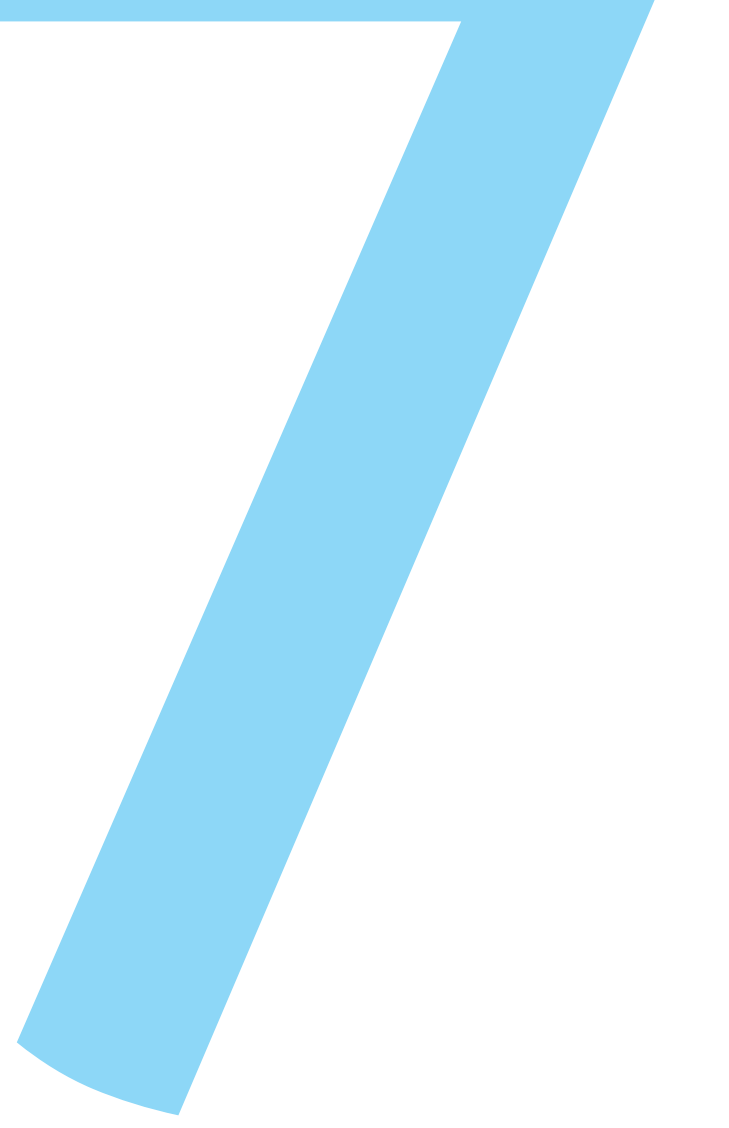


Conclusion 



\section{Conclusion}

\subsection{Introduction}

Debates about knowledge and expertise are often at the core of nature conservation and environmental governance processes. The ongoing digitization of conservation offers unprecedented opportunities for acquiring new data about the natural world, and creates and expands spaces for collaborative knowledge production by scientists and non-scientists. This $\mathrm{PhD}$ thesis critically assesses the proposition that digital innovations in nature conservation lead to more effective and legitimate conservation governance. I explore whether, and to what extent, digital conservation is fulfilling such promises for coral reef conservation in the Caribbean Sea. The aim of this thesis is to contribute to our understanding of knowledge production and use by multi-actor digital networks established for coral reef conservation in various Caribbean marine protected areas (MPAs). In order to achieve this aim, three research questions were formulated:

1) What features of multi-actor digital conservation networks in Caribbean coral reef MPAs are essential to understand processes of knowledge production and use by these networks?

2) What motivates, enables and constrains actors to participate in practices related to digital conservation in Caribbean coral reef MPAs?

3) Under which conditions do digital conservation networks in Caribbean MPAs contribute to effective and legitimate coral reef governance?

In this final chapter I first answer each research question in Sections 7.2 through 7.4. Subsequently in Section 7.5, I reflect on the interdisciplinary approach adopted and on the thesis' theoretical contributions. Finally, I close the thesis in Section 7.6 by proposing a research agenda to advance the field of digital conservation. Table 7.1 shows an overview of the research presented in the previous chapters. 
Table 7.1. Overview of the case studies.

\begin{tabular}{|c|c|c|c|}
\hline $\begin{array}{l}\text { Thesis } \\
\text { chapter }\end{array}$ & Case study & $\begin{array}{l}\text { Geographical } \\
\text { area }\end{array}$ & $\begin{array}{l}\text { Digital multi-actor conservation networks formed } \\
\text { around which technologies? }\end{array}$ \\
\hline Ch. 3 & $\begin{array}{l}\text { Information system } \\
\text { development (ISD) for } \\
\text { collaborative MPA } \\
\text { management }\end{array}$ & $\begin{array}{l}\text { Temperate and } \\
\text { tropical MPAs in } \\
\text { different } \\
\text { continents }\end{array}$ & $\begin{array}{l}\text { (Imagined) collaborative database for } \\
\text { participatory MPA management/governance }\end{array}$ \\
\hline Ch. 4 & $\begin{array}{l}\text { Scientific, media and } \\
\text { stakeholder discourses } \\
\text { about invasive lionfish }\end{array}$ & $\begin{array}{l}\text { US Eastern coast } \\
\text { and Caribbean } \\
\text { Sea }\end{array}$ & $\begin{array}{l}\text { USGS publicly accessible database and digital map } \\
\text { of lionfish spread; REEF fish database; various } \\
\text { online discussion groups, blogs and news outlets } \\
\text { about lionfish }\end{array}$ \\
\hline Ch. 5 & $\begin{array}{l}\text { Various types of citizen } \\
\text { science initiatives } \\
\text { around invasive } \\
\text { lionfish }\end{array}$ & $\begin{array}{l}\text { Dutch Caribbean } \\
\text { MPAs }\end{array}$ & $\begin{array}{l}\text { Early warning systems in all islands; digital maps; } \\
\text { science-driven citizen science (Bonaire, St. } \\
\text { Maarten); data forms for MPA authority (Saba, St. } \\
\text { Eustatius); independent data collection and } \\
\text { sharing using social media, e-mail and private } \\
\text { databases (Bonaire, Curaçao) }\end{array}$ \\
\hline Ch. 6 & $\begin{array}{l}\text { Grassroots water } \\
\text { quality monitoring } \\
\text { network }\end{array}$ & $\begin{array}{l}\text { Bonaire National } \\
\text { Marine Park }\end{array}$ & $\begin{array}{l}\text { A water quality monitoring network, comprised of } \\
\text { thirteen underwater stations, containing nine } \\
\text { sensors each }\end{array}$ \\
\hline
\end{tabular}

\subsection{Understanding knowledge production and use by multi-actor digital conservation networks in Caribbean coral reef MPAs}

In this section I will answer the first research question:

What features of multi-actor digital conservation networks in Caribbean coral reef MPAs are essential to understand processes of knowledge production and use by these networks?

Based on a synthesis of the empirical findings and theoretical insights gleaned throughout this $\mathrm{PhD}$ thesis, I have identified five interlinked features of multi-actor digital networks that are essential to understanding processes of knowledge production and use for coral reef conservation. These features refer to the dynamics of digital networks, the voluntary nature of these arrangements, the diversity of stakeholders and goals involved, the level of specialized skills required to participate, and the type and polarization level of the nature conservation issue being addressed. Below, each feature is briefly explained and related to the opportunities and challenges it represents for digital conservation of Caribbean coral reefs. 


\subsubsection{Dynamics of multi-actor digital networks}

The emergence and development of digital conservation networks around coral reef conservation in the Caribbean is a highly dynamic process. The lionfish case (Chapters 4 and 5) showed that numerous networks co-existed at the regional and local levels, whereby some were entirely virtual networks and others comprised faceto-face interactions among actors, and where different digital technologies were used to collect, share, analyze and disseminate data. As time passed by, sub-networks were formed around new-found goals; while some networks endured, others disappeared. Moreover, actors can be members of multiple networks simultaneously, engage in a variety of data practices (i.e. data production in one network, data sharing in another one, data use in another) and use technologies and data in different ways. The seawater quality monitoring case (Chapter 6) illustrated how network membership and the intended use of data changed in time, as key actors left the network and new practices - lionfish monitoring and culling - were incorporated into the routines of the volunteer divers. These dynamics entail that networks are flexible, their formation is swift and therefore knowledge production is responsive to perceived needs at different scales. By the same token, this flexibility makes networks more unpredictable than other formalized knowledge arrangements (i.e. government or academic-led research/monitoring projects).

\subsubsection{Voluntary arrangements}

Participation in digital conservation networks is mostly conducted on a voluntary basis. This has implications for the durability of the network and the perceived legitimacy of the knowledge claims based on data produced by volunteer nonscientists. In terms of durability, the lionfish study presented in Chapter 5 provided insights into volunteers' multiple and changing motivations to engage in various networks, and of the conditions that enable and constrain participation in the different islands examined. Regarding the legitimacy of data produced by volunteers, it was clear from the seawater monitoring study (Chapter 6) that the intended use of such data places demands on the procedural legitimacy of the monitoring effort for this case it meant using novel sensing technologies, scientific methods and the backing of scientific experts to enhance the credibility of the monitoring effort in the eyes of the public and of decision-makers. Also important in voluntary collaborations for knowledge production for conservation purposes is the question 


\section{Chapter 7}

of accountability, or feedback legitimacy, as demonstrated by Chapters 3 and 6 . Given the lack of formal accountability mechanisms, steering and maintaining digital conservation networks relies on a joint effort based on trust and goodwill from heterogeneous actors. The voluntary nature of participation in digital conservation networks endows them with the possibility to gather large amounts of data at various scales efficiently, which would not be possible by means of traditional academic research/monitoring projects due to the high costs involved. On the other hand, the quality of data collected by volunteers is often questioned, and the durability of the network is uncertain.

\subsubsection{Stakeholder and goal diversity}

Chapter 3 highlighted that, in the context of information system development (ISD) for collaborative MPA management, different stakeholder groups hold divergent interpretations of data attributes and may have different ISD requirements. Similarly, the heterogeneity of actors with distinct ways of knowing, values, interests and norms engaged in multi-actor digital networks established for coral reef conservation underscores the importance of negotiating and re-negotiating the goals of such initiatives. Chapters 4-6 indeed showed that, given this actor diversity and the dynamic conditions that characterize digital conservation networks, revisiting the goals of data production and use and adapting the network accordingly was commonplace in the cases studied, with both positive and negative outcomes for different stakeholder groups. While collaborative efforts offer numerous opportunities in terms of efficiency and mutual learning, challenges include potential miscommunication and incompatible goals that result in premature network exit of key actors and/or volunteers.

\subsubsection{Specialized skills}

Key tasks for coral reef conservation entail presence underwater, which in turn requires participants to possess scuba diving skills. In the Caribbean, only a small proportion of local populations engage in scuba diving, an expensive activity mainly practiced recreationally by tourists. In the Dutch Caribbean, scuba diving is practiced professionally by (mostly foreign) tour operators, scientists and MPA staff. Other necessary specialized skills such as spearfishing (for lionfish management) and analysis of sensor data (for seawater quality monitoring) delimit participation to 
certain elite and expert groups and influence network performance. As such, digital conservation networks for coral reef conservation in the Caribbean can be said to occupy a particular niche within nature conservation practices, with implications for the (input) legitimacy of such networks and the potential to reproduce expert hierarchies and historical patterns of inequality. On the other hand, such expert / elite activities can evolve into communities of practice that provide stability to selforganized, effective networks. One example is the lionfish hunter group on Bonaire, which has endured for ten years and effectively uses social media to organize and coordinate activities. This network has specialized on lionfish culling - with seemingly positive results in terms of decreasing lionfish densities in nearshore areas - whereas lionfish research and monitoring activities are conducted by professional researchers and/or MPA staff.

\subsubsection{Type of nature conservation issue and issue polarization}

The type of conservation issue addressed by the network is important as this will have consequences for the type of skills and technologies required for data acquisition and analysis, and therefore for the tasks that volunteer non-scientists can fulfil, as stated above. Whereas lionfishes are observable and their abundance underwater can be "measured" by divers, seawater nutrient concentrations cannot. In the latter case, sensing technologies mediate such assessments. Moreover, the perception of the issue's driving force and impacts has a bearing on how the problem and solutions are defined by network members and perceived by decision-makers. While lionfish was predominantly framed as a common enemy that threatened reefbased human activities, in the seawater monitoring case, coastal development was identified as a threat to coral reefs. Specifically, Bonaire's hotels and businesses along the sensitive zone were pinpointed as culprits, which created conflict between these groups and the island's environmentalists. The level of issue polarization shapes how actors respond to calls to join digital conservation networks and how knowledge is used. Roughly stated, knowledge use ranges from conceptual in situations of low issue polarization to political when issue polarization is high. 


\subsection{Drivers and barriers for participation in multi-actor digital networks for conservation of Caribbean coral reefs}

In this section I will answer the second research question:

What motivates, enables and constrains actors to participate in practices related to digital conservation in Caribbean coral reef MPAs?

\subsubsection{Actor types and their motivations}

The empirical chapters uncovered the multiple and dynamic motivations held by the different actors participating in the various digital networks studied. Chapter 3 demonstrated the importance of the actors' identities, affiliations, interactions and environments in shaping their interpretations of data attributes and their data practices. Chapters 4 through 6 built on these insights and confirmed the crucial role that these factors played in actors' decisions to participate in data collection, data analysis and data sharing practices. In the cases studied, four main actor types who engage in digital conservation in the Caribbean were identified: scientists, MPA managers and staff, NGOs and "citizens." The latter type mostly consists of the marine user categories of recreational and professional divers.

Scientists in environmental science and conservation play different roles, depending on how they interact with society. In the cases presented here, scientists worked intensely with non-scientists, which corresponds to the role of participatory expert described by Turnhout et al. (2013). Within this role, many scientists engaged in advocacy (Turnhout et al., 2008), as shown by the analysis of scientific discourses presented in Chapter 4.

As can be expected, the main motivation of MPA managers to participate in the networks was to answer management questions, which changed in time. Because MPAs often focus on conservation issues, the underlying motive that guided MPA management was to protect the environment. The data generated by the digital networks partly helped MPA managers to answer these questions. NGOs' main motivation to participate in digital networks was likewise to generate data in order to address conservation issues faced by the MPAs. NGOs are initiators or co- 
creators of a variety of digital conservation networks in the Caribbean and elsewhere, partnering with MPA staff and/or (visiting) scientists.

Citizens' motivations are not as straightforward as those driving participation of the groups discussed so far. Whereas the identities and affiliations (including norms, values, beliefs and interests) of scientists, MPA managers and NGOs explain the main motives that drove them to action, the identities of citizen volunteers are more dynamic, and their motivations were influenced by their local contexts.

Chapters 4-6 indicated that strong conservation values guided most actors who engaged in the various initiatives examined in this thesis, at least initially, but as time passed by other motivations became important as well. In the Dutch Leeward islands, networks (re)-assembled around the lionfish-hunter relation. In the Windward islands, networks dissolved as no enduring human-lionfish relation was established, or alternatively, because the relation was based on human acceptance of lionfish in its new ecosystem, no human intervention was deemed necessary. The seawater quality monitoring case showed that the network endured, despite the withdrawal by the scientists, based on a combination of factors: volunteers engaged in pragmatic exchanges with other actors (i.e. free air from dive operators for help with their clients); a convincing narrative of a new intended use for the data conferred a sense of purpose to the monitoring network; and volunteers incorporated new practices related to lionfish into their diving routines.

\subsubsection{The various logics of participation, enabling and constraining conditions}

Three distinct logics help to understand the dynamics of participation in digital conservation networks: the logic of consequences, the logic of appropriateness and the logic of practice (Emilsson 2017; Arts et al., 2014; Schatzki 2012). The three logics are based on distinct theoretical understandings of actors and their behaviors. The logic of consequences, informed by rational choice theories, follows from a view of individuals as self-interested utility maximizers that are driven by extrinsic motivators (e.g. commodification of lionfish). The logic of appropriateness, informed by (neo)institutional theories, is based on an understanding of individuals as guided primarily by shared norms and values and driven by intrinsic motivators (e.g. helping the environment). The logic of practice, informed by social practice 


\section{Chapter 7}

theories, views behavior as situated in webs of practices (i.e. volunteers incorporated new lionfish spearfishing practices into their sensor servicing routines). I argue that these different theoretical understandings of individuals are not mutually exclusive, but complementary, as they help to understand dynamics of (aspects of) behavior as people, their roles and situations change. Conditions that enabled and constrained participation were identified at the individual and systemic level, which included personal, interpersonal, organizational and technological factors, as established in chapters 3,5 and 6 .

\subsubsection{On the nature of participation in digital conservation networks}

To understand what "participation" of scientists and non-scientists entails in digital networks for coral reef conservation, awareness of the various project types is important. Digital conservation overlaps in this sense with the field of citizen science. The citizen science literature differentiates among community-driven, collaborative and science-driven projects (Dillon et al., 2016; Wilderman 2007; Bonney et al., 2009). The models vary according to the project goals and to the nature of participation of scientists and non-scientists in these projects (Schäfer and Kieslinger 2016).

In terms of project goals, community-driven projects are set in motion by public concerns related to a nature conservation issue and are thus action-oriented, which can lead to issue polarization between communities and decision-makers or resource users/polluters. In contrast, scientific-driven projects focus on answering research questions posed by academics (Dillon et al., 2016). The nature of participation in digital conservation networks refers to the roles and responsibilities of participants in terms of problem definition, design and implementation of the project, including data collection, analysis, interpretation and use (Wilderman 2007). Broadly speaking, scientific-driven projects in the context of multi-actor digital conservation of coral reefs in Caribbean MPAs focus on issues for which polarization in society is low, while the other two project types tend to be more prevalent when issue polarization is medium to high.

The purpose of knowledge production within community-driven and collaborative projects is to bring about change in socio-ecological systems (e.g. Bonaire's participatory sensing project), and as such fit with the trend of a shifting social 
contract between science and society (Hessels and van Lente 2008). This shift has the potential to democratize knowledge production, which has effects on the perceived legitimacy of knowledge and the accountability of scientists, who interact in different and new ways with society (van der Hel 2016; Ladd et al., 2009; Cash et al., 2003). As Chapter 6 illustrated, the trade-off between representation-based legitimacy and credibility-based legitimacy can be eased when low-cost, modern sensing technologies are developed and used collaboratively between scientists and local communities. This case also showed, however, that communities often face data analysis challenges, which reproduces expert-lay hierarchies and may exacerbate dependence on (foreign) scientists. Using low-cost sensing technologies offers opportunities to democratize scientific knowledge production, but technological innovations should be accompanied by the development of local capacity for data analysis and interpretation. Figure 7.1 summarizes the insights discussed above.

\begin{tabular}{|l|l|l|l|l|l|l|l|}
\hline $\begin{array}{l}\text { Type of multi- } \\
\text { actor digital } \\
\text { conservation } \\
\text { networks }\end{array}$ & $\begin{array}{l}\text { Who } \\
\text { defines } \\
\text { the } \\
\text { problem? }\end{array}$ & $\begin{array}{l}\text { Who } \\
\text { designs } \\
\text { the } \\
\text { project? }\end{array}$ & $\begin{array}{l}\text { Who } \\
\text { collects } \\
\text { the data? }\end{array}$ & $\begin{array}{l}\text { Who } \\
\text { analyzes } \\
\text { \& } \\
\text { interprets } \\
\text { the data? }\end{array}$ & $\begin{array}{l}\text { Who } \\
\text { uses the } \\
\text { data? }\end{array}$ & $\begin{array}{l}\text { Issue } \\
\text { polarization } \\
\text { is } \\
\text { typically... }\end{array}$ & $\begin{array}{l}\text { Knowledge } \\
\text { democratization } \\
\text { is potentially... }\end{array}$ \\
\hline $\begin{array}{l}\text { Community- } \\
\text { driven }\end{array}$ & $\begin{array}{l}\text { Non- } \\
\text { scientists }\end{array}$ & $\begin{array}{l}\text { Non- } \\
\text { scientists }\end{array}$ & $\begin{array}{l}\text { Non- } \\
\text { scientists }\end{array}$ & $\begin{array}{l}\text { Scientists } \\
\text { \& non- } \\
\text { scientists }\end{array}$ & $\begin{array}{l}\text { Primarily } \\
\text { non- } \\
\text { scientists }\end{array}$ & High & High \\
\hline Collaborative & $\begin{array}{l}\text { Scientists } \\
\text { \& non- } \\
\text { scientists }\end{array}$ & Primarily & scientists & $\begin{array}{l}\text { Primarily } \\
\text { non- } \\
\text { scientists }\end{array}$ & $\begin{array}{l}\text { Primarily } \\
\text { scientists }\end{array}$ & $\begin{array}{l}\text { Scientists } \\
\text { \& non- } \\
\text { scientists }\end{array}$ & \\
\hline $\begin{array}{l}\text { Science- } \\
\text { driven }\end{array}$ & Scientists & Scientists & $\begin{array}{l}\text { Non- } \\
\text { scientists }\end{array}$ & Scientists & $\begin{array}{l}\text { Primarily } \\
\text { scientists }\end{array}$ & & \\
\hline
\end{tabular}

Figure 7.1. Typology of multi-actor digital conservation networks for Caribbean coral reef MPAs, according to the nature of participation of scientists and non-scientists in the problem definition, design and implementation of the project (adapted from Dillon et al., 2016; Bonney et al., 2009; Wilderman 2007). Issue polarization and knowledge democratization potential are shown as a continuum that runs from 'high' to 'low' across the community-driven to science-driven network types. 


\subsection{Effective and legitimate multi-actor digital networks for conservation of Caribbean coral reefs}

In this section I will answer the third research question:

Under which conditions do digital conservation networks in Caribbean MPAs contribute to effective and legitimate coral reef governance?

The preceding sub-sections have shown that the diversity of actors with different stakes that characterize many digital networks for coral reef conservation signify that often multiple goals are pursued. Given that effectiveness is a judgement of the degree to which intended goals are achieved, perceptions of the effectiveness of digital networks often differ among stakeholders. In addition, effectiveness can be assessed at various levels (output, outcome, impact). Similarly, legitimacy perceptions vary according to the perspective (internal, external), the sources of legitimacy for different groups (cognitive, moral, pragmatic) and the stage of the governance process examined (input, throughput, output).

Notwithstanding the multifaceted and relational nature of these concepts, some generalizations can be made regarding the performance of multi-actor digital conservation networks, in terms of their effectiveness and legitimacy. Drawing from empirical and theoretical insights garnered through the research presented in this thesis, I have identified three conditions under which multi-actor digital conservation networks can contribute to effective and legitimate coral reef governance:

- A perceived crisis unites and mobilizes key actors to join and participate in a digital conservation network that produces actionable data

- Solution-oriented frames/narratives bind the networks together after the initial crisis

- Win-win situations are fostered for participants of digital conservation networks

\subsubsection{Responding to a perceived crisis}

It is clear from the lionfish case that the rapid spread of this foreign fish in the Western Atlantic and Caribbean coasts was widely perceived as a crisis. The rapid dissemination of scientific information by the media catalyzed the mobilization of 
scientists and non-scientists who were concerned about the implications of the invasion. The digital network that originated in Florida, the epicenter of the invasion, played a key role in collating sightings data, and soon after numerous digital and nondigital networks assembled as a first line of defense against the perceived enemy. These data became actionable information, institutionalized in lionfish management plans, and had a transformative effect on the scientific understanding of marine fish invasions. At this point in time, the multi-actor digital networks that formed around the lionfish issue delivered on their promise of effective and legitimate governance for coral reef conservation in the Caribbean. Nonetheless, as time passed by and the costs and risks of lionfish monitoring and control became apparent, many actors started to exit the original network and new networks formed, albeit with new purposes.

This dynamic reminds us of Anthony Downs' issue attention cycle (1972), which posits that alarmed discovery of a perceived environmental threat is followed by an enthusiastic response by the public - who exerts political pressure on decisionmakers to address the novel threat -, only to realize that the costs of continued engagement with the issue are too high, after which attention fades and shifts to a new issue. Indeed, my findings corroborated that after the initial spur of activity, attention on lionfish waned in various sites studied. In other sites, a shift in the meanings of lionfish and new practices changed the nature of the attention that actors were paying to the issue. Moreover, public attention in the region has turned to emerging pressures affecting reefs worldwide, such as increased incidence of coral bleaching events, plastic pollution and the discovery of deleterious effects of sunscreen on corals (Slijkerman and Bol 2018; NOAA 2018; Debrot et al., 2013).

\subsubsection{Using solution-oriented frames}

How then can digital conservation networks that contribute to effective and legitimate governance of issues affecting coral reefs be sustained? Research has shown that the call for action in conservation, when based on fear, can result in paralysis, as people think that their efforts will not make a difference (Gobster 2005). The dire straits in which coral reef ecosystems find themselves has the world's coral reef conservation community "oscillating between hope and despair" (Braverman 2016). Gloom and doom narratives that predict the demise of corals by the mid- $21^{\text {st }}$ 


\section{Chapter 7}

century based on climate change projections, alternate with narratives that express hopes for coral futures (ibid).

In the cases examined in this thesis, catastrophe frames were complemented with solution frames that spoke to network participants - who felt that their efforts were useful - and to decision-makers - who endorsed the solutions proposed as these were deemed as acceptable and feasible. The lionfish case showed that framing lionfish as an enemy that could be defeated by hunting and human consumption strengthened a sub-set of networks in the Leeward islands. In the seawater quality monitoring case, a narrative that presented the foreign scientists and their sensors as protagonists helped to infuse trust among volunteer divers and the wider public that the monitoring effort would actually help to alleviate the island's wastewater issues. The solution to truck away wastewater to a small, temporary plant was acceptable to decision-makers and achievable within a short timeframe. After the scientists left the project, a new (potential) use for the collected data was found, which provided the volunteers with a sense of purpose to continue data retrieval from the sensors.

\subsubsection{Fostering win-win situations}

Finally, the empirical chapters showed that digital networks tend to endure in situations where 1) practices brought about by these networks are compatible with pre-existing and/or new practices and 2) when the benefits of participation are perceived to exceed the perceived costs. The lionfish case (Chapters 4 and 5) provided insights regarding how the new recreation and commercial practices changed the goals of some digital networks, which specialized in certain aspects of lionfish management and can be considered effective to this date (e.g. Bonaire's lionfish hunters group, see https://www.facebook.com/groups/bonairelionfish/). In the seawater monitoring case (Chapter 6 ), the volunteers could merge their diving practices with both the sensor servicing practices, and later with the lionfish monitoring and control practices. Moreover, the reciprocal relation with the dive operators who provided free air to a set of these volunteers in exchange for their help with cruise tourists ensured that the diving costs were kept low. These sources of pragmatic legitimacy strengthened the monitoring program's original intent and its moral legitimacy. Overall, a win-win situation was created among network participants. 
I acknowledge that these cases are idiosyncratic and the exact conditions are not amenable to replication everywhere. However, initiators of digital conservation initiatives should take into account the aforementioned elements of win-win situations, including the three types of logic that guide people's decisions discussed in the previous section, as well as the various sources of legitimacy at play, when designing conservation initiatives around coral reef ecosystems.

\subsection{Reflection and theoretical contribution}

In this section I reflect on the methodology adopted in this $\mathrm{PhD}$ thesis and on the theoretical contribution of my research to debates about changing science-society relations, and the role of multi-actor digital conservation networks herein.

\subsubsection{Reflection on interdisciplinarity}

The complexity of today's global environmental problems requires thinking across disciplinary boundaries to adequately understand human-environment interactions and their consequences. In this $\mathrm{PhD}$ thesis, I adopted a sociological perspective to investigate the challenges and opportunities of digital conservation in Caribbean coral reef MPAs. Nonetheless, my background in the natural sciences proved very valuable in complementing this social science perspective. I could draw from a set of skills and insights stemming from my training in marine science that informed my $\mathrm{PhD}$ research, from the conceptual design of my empirical chapters up to the synthesis stage. The systematic approach to study design and the explicit description of methods that characterize the natural sciences combined well with the rich and contextualized analyses offered by the social sciences. By blending the methodological strengths from both disciplines, I was able to ensure the quality of the technical design of my research and achieve a more integrative understanding of the socio-ecological phenomena under study than would have been possible when relying solely on a mono-disciplinary perspective (Tobi and Kampen 2018).

This disciplinary boundary-crossing, however, also presented several challenges. At the start of my $\mathrm{PhD}$ journey, I was confronted with an identity crisis: was I a biologist, a sociologist, both or neither? Learning and reflecting about different paradigms in the philosophy of science stirred my ontological and epistemological assumptions. I found myself moving from a positivist towards a realist social constructionist paradigm, which resulted in the reformulation of my research questions and overall research approach. Engaging with Gadamerian hermeneutics 


\section{Chapter 7}

early on enabled me to make sense of this evolution in my thinking and of my research process. The importance of introspection and self-reflexivity as a researcher, of testing my pre-understandings and of embracing the 'breakdowns of meaning' and the iterative nature of the critical hermeneutics research framework were very useful insights.

Furthermore, interpretive and critical streams of literature such as science and technology studies and sociology of knowledge provided me with the theoretical underpinning and vocabulary to articulate my research in my newly found voice. Once comfortable in my new identity as an interpretive researcher studying interdisciplinary phenomena, however, new challenges arose. In writing down my research, I had trouble picturing who exactly my audience was and in selecting the appropriate academic journal. Even after choosing journals that claimed to promote interdisciplinary research, the peer review process was not always based on interdisciplinary reviewers, or on a balanced set of reviewers from different disciplinary backgrounds. I learned that being meticulous in the technical design of my research and transparent in its description is crucial to communicate about my research and my findings across disciplinary divides.

Moreover, clear and detailed descriptions of the research are important elements that allow other researchers to decide whether the findings of one's study are applicable to other situations, in other words, to judge their generalizability potential (Onwuegbuzie and Leech 2007; Schofield 2002), as I have explained in Chapter 2. I believe that I have provided clear and transparent descriptions of my research that will allow other researchers to judge whether findings are generalizable to similar settings. Moreover, the research presented in this $\mathrm{PhD}$ thesis has generated a number of analytical generalizations and working hypotheses that can be tested in future research, which leads me to the next sub-section.

\subsubsection{Theoretical contribution}

This $\mathrm{PhD}$ thesis adds to our understanding of knowledge production and use by multi-actor digital networks in the field of coral reef conservation. The theoretical contribution of this thesis is three-fold.

First, the thesis adds to the interpretive Information Systems (IS) development literature by unpacking the multiple and overlapping meanings of five desirable data attributes: data availability, accessibility, quality, consistency and security (Chapter 3). 
By understanding the IS user as a social actor, Chapter 3 not only shows that different actors interpret data attributes differently due to their organizational background, but posits that their interpretations and actions are guided by the perceived legitimacy and accountability of their own and each other's data practices.

Second, the thesis contributes to the conservation biology literature that focuses on invasive species, by incorporating a social scientific perspective to understand the lionfish invasion in the Western Atlantic Ocean (Chapter 4). The social construction of the lionfish invasion by natural scientists, the media and Caribbean MPA stakeholders drew from data (digital and non-digital, scientific and non-scientific) and used metaphors of nature to make sense of the various facets of the invasion through their lionfish discourses. Chapter 4 showed that species invasions should be understood not only as an ecological occurrence, but as a socio-ecological phenomenon.

Third, the thesis adds to the citizen science - and related literatures - that focus on (public) participation in the production of scientific knowledge in the field of nature conservation (Chapters 5 and 6). Two key aspects related to participation are theorized: (1) motivations, drivers and barriers to participation in various data practices and (2) the potential and limits of participatory sensing to democratize the production of policy-relevant scientific knowledge. Regarding the first point, chapter 5 offers an integrative conceptual framework of participation that recognizes the interplay between individualistic and systemic factors, as well as temporal dynamics, in actors' motivations and possibilities to participate in citizen science initiatives. Regarding the second point, the thesis contributes to the theorizing of legitimacy and science democracy in the context of participatory sensing. Chapter 6 builds from chapter 3's insights on the importance of legitimacy (and accountability) relations among different actors engaged in data practices. Chapter 6 provides conceptual clarification of the legitimation dynamics at play around participatory sensing projects, and suggests a way to understand how legitimacy is related to the democratization potential of science and policy through these emerging monitoring practices and technologies.

These theoretical elaborations are based on inductively generated insights obtained from cross-case analyses, which provided robust evidence to support analytic generalizations to the "truth space" (Onwuegbuzie and Leech 2007) of information 


\section{Chapter 7}

system development, invasive species discourses, (volunteer) participation in nature conservation and legitimacy dynamics at the knowledge-governance interface, respectively. These additions refine existing theories in the aforementioned fields of scholarship. Working hypotheses based on the empirical and theoretical findings can be generated, as illustrated below.

\subsection{Research outlook}

In this final section of the thesis I lay out a research agenda for the field of knowledge co-production and use in multi-actor digital conservation networks. I distinguish between three research dimensions that would benefit from attention: the empirical, methodological and ethical dimensions.

Regarding the empirical dimension, research that focuses on the knowledgegovernance nexus manifested through digital conservation networks established around coral reef MPAs in other geographical areas of the world would provide interesting points of comparison for the research presented in this thesis. Identifying commonalities and differences in the sociomaterial practices of the heterogeneous actors that compose the networks, and the consequences of these practices for reef conservation governance, would enhance our understanding of which 'enabling and constraining' factors are inherent to this mode of collaborative knowledge production, and which are external and contextual. By taking a working hypothesis derived from the research presented in this $\mathrm{PhD}$ thesis as a point of departure, such comparison would allow us to make more general statements about the challenges and opportunities of digital conservation for governing coral reef conservation.

One working hypothesis derived from this thesis is that technologically mediated collaboration requires accountability mechanisms that are different from mechanisms in face-to-face collaboration. A line of enquiry that could be pursued refers then to the different accountability mechanisms at work in digital conservation initiatives. Digital technologies allow for various types of multi-actor networks to emerge: networks where hybrid collaboration takes place among actors who are colocated and interact face-to-face, but also through telecommunication technologies; collaboration between co-located and distant actors; or entirely virtual collaborations. Mechanisms to manage multiple accountability relations among 
actors who collaborate in various modalities require different conditions to function properly, and research is necessary to elucidate such conditions.

Furthermore, it would be useful to study patterns of digital conservation initiatives at the global scale in terms of numbers, types and goals of such initiatives. As discussed in Chapter 6, the North-South knowledge divide in conservation science persists, and there is evidence that a similar bias is emerging in conservation citizen science (Chandler et al., 2017). Given that the digitization of nature conservation and citizen science are seen by many as powerful agents of change in terms of democratizing knowledge of the natural world and empowering local communities for conservation action, elucidating current trends and the reasons underlying those trends seems pertinent.

Regarding the methodological dimension, research that incorporates interdisciplinary and transdisciplinary approaches to studying the design and implementation processes, as well as the outcomes of digital conservation initiatives would be valuable. Natural and social scientists, together with software developers, could jointly set up multiple methods frameworks to conduct (action) research in the field of digital citizen science. Moreover, the citizen science evaluation literature has called for the development of methodologies to study the "complex sciencesociety" relations brought about by citizen science (Bonney et al., 2016). The use of social media to explore mutual learning among science and non-science participants of citizen science projects in longitudinal studies would generate interesting insights in this respect.

Finally, the ethical aspects of the use of digital technologies for conservation are important to consider in further research. Tracking and surveillance technologies used for anti-poaching purposes have lately gained media attention due to the ethical dilemmas they bring to the fore by confronting wildlife conservation values with human rights through the militarization of conservation. In addition, the widespread use of tracking technologies has led to what some call the "commodification of spectacular nature" and the automatization of data analysis to "conservation by algorithm" (Adams 2019), which require ethical assessments. Digital conservation offers a treasure trove of tools and possibilities to improve the governance of nature conservation, but it should not be seen as a panacea. The social innovations required to make digital conservation work should receive as much research attention as the technological innovations claiming the spotlight. 
Chapter 7 


\section{References}

Ackoff, R. (1989). From data to wisdom. Journal of Applied Systems Analysis, 16(1), 3-9.

Adams, W. M. (2019). Geographies of conservation II: Technology, surveillance and conservation by algorithm. Progress in Human Geography, 43(2), 337-350.

Agardy, T. (2000). Information needs for marine protected areas: Scientific and societal. Bulletin of Marine Science, 66(3), 875-888.

Agardy, T., Bridgewater, P., Crosby, M. P., Day, J., Dayton, P. K., Kenchington, R., .. Peau, L. (2003). Dangerous targets? Unresolved issues and ideological clashes around marine protected areas. Aquatic Conservation: Marine and Freshwater Ecosystems, 13(4), 353-367.

Agardy, T., Di Sciara, G.N. and Christie, P., 2011. Mind the gap: addressing the shortcomings of marine protected areas through large scale marine spatial planning. Marine Policy, 35(2), .226-232.

Aguilar-Perera, A. (2013). Eating Lionfish: An Effective Solution to Control its Invasion?

AIDEnvironment. (2004). Integrated marine and coastal area management (IMCAM) approaches for implementing the Convention on Biological Diversity. Retrieved from https://www.cbd.int/doc/publications/cbd-ts-14.pdf

Albins, M., \& Hixon, M. (2008). Invasive Indo-Pacific lionfish Pterois volitans reduce recruitment of Atlantic coralreef fishes. Marine Ecology Progress Series, 367, 233-238.

Aleccia, J. (2012, June 27). Eat lionfish? Sure, but beware of the nasty toxins. NBC News. Retrieved from https://www.nbcnews.com/healthmain/eat-lionfish-sure-beware-nasty-toxins-848510

Allan, B. M., Nimmo, D. G., Ierodiaconou, D., VanDerWal, J., Koh, L. P., \& Ritchie, E. G. (2018). Futurecasting ecological research: the rise of technoecology. Ecosphere, 9(5), e02163.

Almany, G. R., Hamilton, R. J., Williamson, D. H., Evans, R. D., Jones, G. P., Matawai, M., ... Sawynok, B. (2010). Research partnerships with local communities: two case studies from Papua New Guinea and Australia. Coral Reefs, 29(3), 567-576.

Al-Rawas, A., \& Easterbrook, S. M. (1996). Communication Problems in Requirements Engineering: A Field Study. Proceedings of the First Westminster Conference on Professional Awareness in Software Engineering, Royal Society, London, (February), 1-12.

Alter, S. (2008). Defining information systems as work systems: implications for the IS field. European Journal of Information Systems, 17(5), 448-469.

Alvarez-Filip, L., Gill, J. A., Dulvy, N. K., Perry, A. L., Watkinson, A. R., \& Côté, I. M. (2011). Drivers of region-wide declines in architectural complexity on Caribbean reefs. Coral Reefs, 30(4), 1051-1060.

Angen, M. J. (2000). Evaluating Interpretive Inquiry: Reviewing the Validity Debate and Opening the Dialogue. Qualitative Health Research, 10(3), 378-395.

Anguillian. (2012, December 7). Lionfish researcher looks at invasive species. Dispels fears, tells of lionfish as nonpoisonous delicacy. The Anguillian. Retrieved from http://theanguillian.com/2012/12/lionfishresearcher-looks-at-invasive-species-dispels-fears-tells-of-lionfish-as-non-poisonous-delicacy/

Anwar, F., Razali, R., \& Ahmad, K. (2011). Achieving Effective Communication during Requirements Elicitation - A Conceptual Framework.

Arias-González, J. E., González-Gándara, C., Luis Cabrera, J., \& Christensen, V. (2011). Predicted impact of the invasive lionfish Pterois volitans on the food web of a Caribbean coral reef. Environmental Research, 111(7), 917-925.

Arts, B., Behagel, J., Turnhout, E., de Koning, J., \& van Bommel, S. (2014). A practice based approach to forest governance. Forest Policy and Economics, 49, 4-11.

Arts, K., Fischer, A., \& van der Wal, R. (2012). Common stories of reintroduction: A discourse analysis of documents supporting animal reintroductions to Scotland. Land Use Policy, 29(4), 911-920.

Arts, K., van der Wal, R., \& Adams, W. M. (2015). Digital technology and the conservation of nature. Ambio, 44(S4), 661-673.

Arts, K., Webster, G., Sharma, N., Melero, Y., Mellish, C., Lambin, X., \& Van der Wal, R. (2013). Capturing mink and data: Interacting with a small and dispersed environmental. Framework for Responsible Research and Innovation 


\section{References}

in ICT FRRIICT - Case Study, 1-5. Retrieved from http://responsible-innovation.org.uk/torrii/resourcedetail/1059

Associated Press. (2008, August 14). Poisonous lionfish invade Caribbean, head up Eastern Seaboard. Fox News. Retrieved from http://www.foxnews.com/story/2008/08/14/poisonous-lionfish-invadecaribbeanhead-up-eastern-seaboard.html

Aswani, S., Basurto, X., Ferse, S., Glaser, M., Campbell, L., Cinner, J. E., ... Pollnac, R. (2018). Marine resource management and conservation in the Anthropocene. Environmental Conservation, 45(2), 192-202.

Attride-Stirling, J. (2001). Thematic networks: an analytic tool for qualitative research. Qualitative Research, 1(3), 385405 .

Austen, K. (2015). Environmental science: Pollution patrol. Nature News, 517(7533), p.136.

Avila, E. (2013, April 8). Pez León, peligrosidad redituable. El Quintanarroense. Retrieved from http://issuu.com/ elquintanarroense/docs/edicion_digital_08-04-13/1

Bakker, K., \& Ritts, M. (2018). Smart Earth: A meta-review and implications for environmental governance. Global Environmental Change, 52, 201-211.

Balestrini, M., Diez, T. and Kresin, F. (2015). From Participatory Sensing to Making Sense. In Proceedings of the Workshop Environmental Infrastructures and Platforms for Environmental Crowd Sensing and Big Data.

Balmford, A., Gravestock, P., Hockley, N., McClean, C. J., \& Roberts, C. M. (2004). The worldwide costs of marine protected areas. Proceedings of the National Academy of Sciences, 101(26), 9694-9697.

Baltais, S. (2013). Citizen Science, the benefits and challenges : How do you make citizen science both fun and useful ? 4th Queensland Coastal Conference. Townsville.

Barbour, A. B., Allen, M. S., Frazer, T. K., \& Sherman, K. D. (2011). Evaluating the Potential Efficacy of Invasive Lionfish (Pterois volitans) Removals. PLoS ONE, 6(5), e19666.

Barlow, K. C. (2012, October 25). Divers to be honored for lionfish kills. Northwest Florida Daily News. Retrieved from http://www.nwfdailynews.com/article/20121025/NEWS/310259974/0/

Barry, D., \& Oelschlaeger, M. (1996). A Science for Survival: Values and Conservation Biology. Conservation Biology, 10(3), 905-911.

Belfiore, S., Cicin-Sain, B., \& Ehler, C. (2004). Incorporating Marine Protected Areas into Integrated Coastal and Ocean Management : Principles and Guidelines. In Fortune. Retrieved from http://www.iucn.org/dbtwwpd/edocs/PDF-2004-001.pdf

Bell, C. D., Blumenthal, J. M., Austin, T. J., Ebanks-Petrie, G., Broderick, A. C., \& Godley, B. J. (2008). Harnessing Recreational Divers for the Collection of Sea Turtle Data Around the Cayman Islands. Tourism in Marine Environments, 5(4), 245-257.

Bellwood, D. R., Hughes, T. P., Folke, C., \& Nyström, M. (2004). Confronting the coral reef crisis. Nature, 429(6994), 827-833.

Bentley, R., Hughes, J. A., Randall, D., Rodden, T., Sawyer, P., Shapiro, D., \& Sommerville, I. (1992). Ethnographically-informed systems design for air traffic control. Proceedings of the 1992 ACM Conference on Computer-Supported Cooperative Work - CSCW'92, 123-129.

Berente, N., Gal, U., \& Hansen, S. (2011). Ethical implications of social stratification in information systems research. Information Systems Journal, 21(4), 357-382.

Bergman, M., King, J. L., \& Lyytinen, K. (2002). Large-Scale Requirements Analysis Revisited: The need for Understanding the Political Ecology of Requirements Engineering. Requirements Engineering, 7(3), 152171.

Bertzky, M., \& Stoll-Kleemann, S. (2009). Multi-level discrepancies with sharing data on protected areas: What we have and what we need for the global village. Journal of Environmental Management, 90(1), 8-24.

Bervoets, T. (2010). St. Maarten Nature Foundation Lionfish Response Plan. Nature Foundation of St. Marteen, 1-30.

Betancur-R., R., Hines, A., Acero P., A., Ortí, G., Wilbur, A. E., \& Freshwater, D. W. (2011). Reconstructing the lionfish invasion: insights into Greater Caribbean biogeography. Journal of Biogeography, 38(7), 1281-1293.

Bharwani, S. (2006). Understanding Complex Behavior and Decision Making Using Ethnographic Knowledge Elicitation Tools (KnETs). Social Science Computer Review, 24(1), 78-105.

Biermann, F. and Gupta, A. (2011). Accountability and legitimacy in earth system governance: a research framework. Ecological economics, 70(11), 1856-1864.

Bindoff, N.L., Cheung, W.W.L., Kairo, J.G., Arístegui, J., Guinder, V.A., Hallberg, R.,...Williamson, P. (2019). 


\section{References}

Changing Ocean, Marine Ecosystems, and Dependent Communities. In: IPCC Special Report on the Ocean and Cryosphere in a Changing Climate [H.-O. Pörtner, D.C. Roberts, V. Masson-Delmotte, P. Zhai, M. Tignor, E. Poloczanska, K. Mintenbeck, A. Alegría, M. Nicolai, A. Okem, J. Petzold, B. Rama, N.M. Weyer (eds.)]. In press.

Bird, R. (2008, December 13). Lionfish: born in the wrong sea. Turks and Caicos Weekly News. Retrieved from http://tcweeklynews.com/lionfish-born-in-the-wrong-sea-p1027-1.htm

Black, J. (2008). Constructing and contesting legitimacy and accountability in polycentric regulatory regimes. Regulation \& Governance, 2(2), 137-164.

Blagescu, M., de Las Casas, L., \& Lloyd, R. (2005). Pathways to Accountability: The GAP Framework, London: One World Trust, London.

Bodilis, P., Louisy, P., Draman, M., Arceo, H. O., \& Francour, P. (2014). Can Citizen Science Survey Non-indigenous Fish Species in the Eastern Mediterranean Sea? Environmental Management, 53(1), 172-180.

Bogdanoff, A. K., Akins, J. L., Morris, J. A., \& 2013 GCFI Lionfish Workgroup. (2014). Invasive Lionfish in the Marketplace : Challenges and Opportunities Invasor Pez León en el Mercado: Retos y Oportunidades Lionfish Envahissantes sur le Marché: Défis et Opportunités. Gulf and Caribbean Fisheries Institute, November 4-8, 2013, 66, 140-147.

Bonney, R., Shirk, J. L., Phillips, T. B., Wiggins, A., Ballard, H. L., Miller-Rushing, A. J., \& Parrish, J. K. (2014). Next Steps for Citizen Science. Science, 343(6178), 1436-1437.

Bonney, R., Ballard, H., Jordan, R., McCallie, E., Phillips, T., Shirk, J., \& Wilderman, C. C. (2009). Public Participation in Scientific Research: Defining the Field and Assessing Its Potential for Informal Science Education. A CAISE Inquiry Group Report. Science Education, (July). Retrieved from http://www.birds.cornell.edu/citscitoolkit/publications/CAISE-PPSR-report-2009.pdf

Bonney, R., Cooper, C. B., Dickinson, J., Kelling, S., Phillips, T., Rosenberg, K. V., \& Shirk, J. (2009). Citizen Science: A Developing Tool for Expanding Science Knowledge and Scientific Literacy. BioScience, 59(11), 977984.

Bonney, R., Phillips, T. B., Ballard, H. L., \& Enck, J. W. (2016). Can citizen science enhance public understanding of science? Public Understanding of Science, 25(1), 2-16.

Boonman-Berson, S., Turnhout, E., \& van Tatenhove, J. (2014). Invasive species: The categorization of wildlife in science, policy, and wildlife management. Land Use Policy, 38, 204-212.

Bovens, M. (2007). Analysing and assessing accountability: A conceptual framework 1. European Law Journal, 13(4), 447-468.

Braverman, I. (2016). Biopolarity: Coral Scientists between Hope and Despair. Anthropology Now, 8(3), $26-40$.

Bremner, A., \& Park, K. (2007). Public attitudes to the management of invasive non-native species in Scotland. Biological Conservation, 139(3-4), 306-314.

Brown, J. H., \& Sax, D. F. (2004). An Essay on Some Topics Concerning Invasive Species. Austral Ecology, 29(5), 530 536.

Brown, L. D., \& Jagadananda, L. (2007). Civil society legitimacy and accountability: Issues and challenges. Centre for Youth \& Social Development. (January), 1-43.

Browne, G. J., \& Ramesh, V. (2002). Improving information requirements determination: a cognitive perspective. Information \& Management, 39(8), 625-645.

Bruno, J. F., Valdivia, A., Hackerott, S., Cox, C. E., Green, S., Côté, I., ... Precht, W. (2013). Testing the grouper biocontrol hypothesis: A response to Mumby et al., 2013. PeerJ PrePrints, 1, e139v1.

Bruyere, B., \& Rappe, S. (2007). Identifying the motivations of environmental volunteers. Journal of Environmental Planning and Management, 50(4), 503-516.

Bryce, R., Oliver, M. K., Davies, L., Gray, H., Urquhart, J., \& Lambin, X. (2011). Turning back the tide of American mink invasion at an unprecedented scale through community participation and adaptive management. Biological Conservation, 144(1), 575-583.

Bryman, A. (2008). Social Research Methods (3rd ed.). Oxford University Press.

Bryner, J. (2013, July 12). Even sharks are no match for invasive lionfish. NBC News. Retrieved from https://www.nbcnews.com/science/even-sharks-are-no-match-invasive-lionfish-6C10621635

Buchanan, D. (2009, August 23). Influx of lionfish a threat to native marine life, experts say. St. Croix Source. Retrieved from https://stcroixsource.com/2009/08/24/influx-lionfish-threat-native-marine-life-experts-say/ 


\section{References}

Buijs, A. (2009). Lay People's Images of Nature: Comprehensive Frameworks of Values, Beliefs, and Value Orientations. Society \& Natural Resources, 22(5), 417-432.

Burke, B. J., \& Heynen, N. (2014). Transforming participatory science into socioecological praxis: Valuing marginalized environmental knowledges in the face of the neoliberalization of nature and science. Environment and Society, 5(1), 7-27.

Burke, L., Reytar, K., Spalding, M., \& Perry, A. (2011). Reefs at Risk Revisited. In Reefs at Risk Revisited.

Bustamante, G., Vanzella, A., Glazer, R., \& Collado-Vides, L. (2018). The evolution of the Caribbean Marine Protected Area Management Network and Forum (CaMPAM): 20 years of the Regional Multidimensional Program for Strengthening MPA Practitioners. Gulf and Caribbean Research, 29(1), GCFI1-GCFI9.

Butler, T. (1998). Towards a Hermeneutic Method for Interpretive Research in Information Systems. Journal of Information Technology, 13(4), 285-300.

Byrd, T. A., Cossick, K. L., \& Zmud, R. W. (1992). A Synthesis of Research on Requirements Analysis and Knowledge Acquisition Techniques. MIS Quarterly, 16(1), 117.

Cado Van Der Lely, A., Warning, A., \& Van Beukering, P. (2014). Total Economic Value of Nature of St Eustatius: Intitute for Environmental Issues. VU University of Amsterdam.

Callicott, J. B., Crowder, L. B., \& Mumford, K. (1999). Current Normative Concepts in Conservation. Conservation Biology, 13(1), 22-35.

Canessa, R., Butler, M., Leblanc, C., Stewart, C., \& Howes, D. (2007). Spatial Information Infrastructure for Integrated Coastal and Ocean Management in Canada. Coastal Management, 35(1), 105-142.

Carballo-Cárdenas, E. C. (2015). Controversies and consensus on the lionfish invasion in the Western Atlantic Ocean. Ecology and Society, 20(3).

Carlton, J. T., \& Geller, J. B. (1993). Ecological Roulette: The Global Transport of Nonindigenous Marine Organisms. Science, 261(5117), 78-82.

Carpenter, K. E., Abrar, M., Aeby, G., Aronson, R. B., Banks, S., Bruckner, A., ... Wood, E. (2008). One-Third of Reef-Building Corals Face Elevated Extinction Risk from Climate Change and Local Impacts. Science, 321(5888), 560-563.

Carr, A. J. L. (2004). Why do we all need community science? Society \& Natural Resources.

Carrizo, D., Dieste, O., \& Juristo, N. (2008). Study of elicitation techniques adequacy. WER08 XI Workshop Em Engenharia de Requisitos, 104-114. Retrieved from http://www.math.yorku.ca/ cysneiro/4040_2005/Choosing Elicitation Techiniques.pdf

Carrozza, C. (2015). Democratizing expertise and environmental governance: Different approaches to the politics of science and their relevance for policy analysis. Journal of Environmental Policy \& Planning, 17(1), 108-126.

Carton, L. \& Ache, P. (2017). Citizen-sensor-networks to confront government decision-makers: Two lessons from the Netherlands. Journal of Environmental Management, 196, 234-251.

Cash, D. , Clark, W. C., Alcock, F., Dickson, N. M., Eckley, N. \& Jäger, J. (2002). Salience, Credibility, Legitimacy and Boundaries: Linking Research, Assessment and Decision Making. KSG Working Papers Series RWP02046.

Cash, D., Clark, W. C., Alcock, F., Dickson, N., Eckley, N., \& Jager, J. (2003). Salience, Credibility, Legitimacy and Boundaries: Linking Research, Assessment and Decision Making. SSRN Electronic Journal.

Cassey, P., Blackburn, T. M., Duncan, R. P., \& Chown, S. L. (2005). Concerning invasive species: Reply to Brown and Sax. Austral Ecology, 30(4), 475-480.

Castells, M. (1996). The information age: Economy, society and culture (3 volumes). Blackwell, Oxford.

Catlin-Groves, C. L. (2012). The citizen science landscape: from volunteers to citizen sensors and beyond. International Journal of Zoology, 2012.

CBS News. (2013, February 21). Lionfish: Invasive species devastating reefs, experts say. CBS News. Retrieved from https://www.cbsnews.com/news/lionfish-invasive-species-devastating-reefs-expert-says/

Chandler, M., See, L., Copas, K., Bonde, A. M. Z., López, B. C., Danielsen, F., .. Newman, G. (2017). Contribution of citizen science towards international biodiversity monitoring. Biological Conservation, 213, 280-294.

Checkland, P. (2000). Soft systems methodology: A thirty year retrospective. Systems Research and Behavioral Science, 17 , 11-58.

Chew, M. K. \& Laubichler, M.D. (2003). Natural enemies - metaphor or misconception? Science, 301(5629), 52-53.

Christie, P., \& White, A. T. (2007). Best practices for improved governance of coral reef marine protected areas. Coral Reefs, 26(4), 1047-1056. 


\section{References}

Christie, P. (2011). Creating space for interdisciplinary marine and coastal research: five dilemmas and suggested resolutions. Environmental Conservation, 38(2), 172-186.

Chuan-Chuan Lin, J., \& Lu, H. (2000). Towards an understanding of the behavioural intention to use a web site. International Journal of Information Management, 20(3), 197-208.

Chughtai, H., \& Myers, M. (2014). Ethnographic field research: Interpreting one's entrance into the field as thrownness. In ECIS 2014 Proceedings - 22nd European Conference on Information Systems.

Clary, E. G., \& Snyder, M. (1999). The Motivations to Volunteer. Current Directions in Psychological Science, 8(5), $156-159$.

Clavero, M., \& García Berthou, E. (2005). Invasive species are a leading cause of animal extinctions. Trends in Ecology \& Evolution, 20(3), 110-110.

Claydon, J., Calosso, M., \& Traiger, S. (2012). Progression of invasive lionfish in seagrass, mangrove and reef habitats. Marine Ecology Progress Series, 448, 119-129.

Cocking, S. (2013, October 26). Florida starts planning to attack invasive lionfish. Miami Herald.

Colautti, R. I., \& MacIsaac, H. J. (2004). A neutral terminology to define 'invasive' species. Diversity and Distributions, 10(2), 135-141.

Colautti, R. I., \& Richardson, D. M. (2009). Subjectivity and flexibility in invasion terminology: too much of a good thing? Biological Invasions, 11(6), 1225-1229.

Cole, M., \& Avison, D. (2007). The potential of hermeneutics in information systems research. European Journal of Information Systems, 16(6), 820-833.

Comisión Nacional de Áreas Naturales Protegidas (CONANP). (2012). La Invasión del pez. león. Retrieved from https://www.youtube.com/watch?v=bYKHubHVl6Y

Conrad, C. C., \& Hilchey, K. G. (2011). A review of citizen science and community-based environmental monitoring: issues and opportunities. Environmental Monitoring and Assessment, 176(1), 273-291.

Conserve.IO. (2015). Technology for a better planet. Retrieved from http://conserve.io/tech-for-a-better-planet

Contandriopoulos, D., Lemire, M., Denis, J., \& Tremblay, É. (2010). Knowledge Exchange Processes in Organizations and Policy Arenas: A Narrative Systematic Review of the Literature. Milbank Quarterly, 88(4), 444-483.

Conti, L. A., Fonseca Filho, H., Turra, A., \& Amaral, A. C. Z. (2018). Building a local spatial data infrastructure (SDI) to collect, manage and deliver coastal information. Ocean \& Coastal Management, 164, 136-146.

Corrigan, C. M., \& Kershaw, F. (2008). Working Toward High Seas Marine Protected Areas: An Assessment of Progress Made and Recommendations for Collaboration. LTNEP-World Conservation Monitoring Centre, (October).

Costello, M. J., Vanhoorne, B., \& Appeltans, W. (2015). Conservation of biodiversity through taxonomy, data publication, and collaborative infrastructures. Conservation Biology, 29(4), 1094-1099.

Côté, I. M., Darling, E. S., Malpica-Cruz, L., Smith, N. S., Green, S. J., Curtis-Quick, J., \& Layman, C. (2014). What Doesn't Kill You Makes You Wary? Effect of Repeated Culling on the Behaviour of an Invasive Predator. PLOS ONE, 9(4), e94248.

Côté, I. M., Green, S. J., \& Hixon, M. A. (2013). Predatory fish invaders: Insights from Indo-Pacific lionfish in the western Atlantic and Caribbean. Biological Conservation, 164, 50-61.

Côté, I. M., Akins, L., Underwood, E., Curtis-Quick, J., \& Green, S. J. (2014). Setting the record straight on invasive lionfish control: Culling works. PeerJ PrePrints, 2, e398v1.

Courtenay, W. R. J. (1995). Marine fish introductions in southeastern Florida. American Fisheries Society Introduced Fish Section Newsletter, 14(1), 2-3.

Cousteau, P., \& Knight, M. (2012, April 26). Taming the lionfish: Florida fights back against invasive species. CNN. Retrieved from https://edition.cnn.com/2012/04/24/us/lionfish/index.html

Crabbé, A., \& Leroy, P. (2008). Policy Evaluation and Environmental Policy \& Problems and Limitations of Environmental Policy Evaluation. In The Handbook of Environmental Policy Evaluation, 1-43. Routledge.

Crall, A. W., Newman, G. J., Jarnevich, C. S., Stohlgren, T. J., Waller, D. M., \& Graham, J. (2010). Improving and integrating data on invasive species collected by citizen scientists. Biological Invasions, 12(10), 3419-3428.

Crall, A. W., Renzl, M., Panke, B., \& Newman, G. J. (2012). Is there a role for the public in monitoring invasive species? Plant Sciences Reviews, 2011, 41-47.

Crudge, S. E., \& Johnson, F. C. (2007). Using the repertory grid and laddering technique to determine the user's evaluative model of search engines. Journal of Documentation, 63(2), 259-280. 


\section{References}

Cruz, R. (2013, September 20). Tiene Cozumel “ceviche de pez león” más grande del mundo. Público.Mx. Retrieved from http://www.publico.mx/nota/51986/

Cuddington, K. (2001). The "Balance of Nature" Metaphor and Equilibrium in Population Ecology. Biology \& Philosophy, 16(4), 463-479.

Cuthill, M. (2000). An Interpretive Approach to Developing Volunteer-based Coastal Monitoring Programmes. Local Environment, 5(2), 127-137.

Cvitanovic, C., Hobday, A. J., van Kerkhoff, L., Wilson, S. K., Dobbs, K., \& Marshall, N. A. (2015). Improving knowledge exchange among scientists and decision-makers to facilitate the adaptive governance of marine resources: a review of knowledge and research needs. Ocean \& Coastal Management, 112, 25-35.

Daehler, C. (2001). Two Ways to Be an Invader, but One Is More Suitable for Ecology. Bulletin of the Ecological Society of America, 82, 101-102.

Dalton, T., Forrester, G., \& Pollnac, R. (2015). Are Caribbean MPAs making progress toward their goals and objectives? Marine Policy, 54, 69-76.

Danielsen, F., Burgess, N. D., Balmford, A., Donald, P. F., Funder, M., Jones, J. P. G., ... Yonten, D. (2009). Local Participation in Natural Resource Monitoring: a Characterization of Approaches. Conservation Biology, 23(1), 31-42.

Danielsen, F., Jensen, A. E., Alviola, P. A., Balete, D. S., Mendoza, M., Tagtag, A., ... Enghoff, M. (2005). Does Monitoring Matter? A Quantitative Assessment of Management Decisions from Locally-based Monitoring of Protected Areas. Biodiversity \& Conservation, 14(11), 2633-2652.

Davis, A., Dieste, O., Hickey, A., Juristo, N., \& Moreno, A. M. (2006). Effectiveness of Requirements Elicitation Techniques: Empirical Results Derived from a Systematic Review. 14th IEEE International Requirements Engineering Conference (RE'06), 179-188.

Davis, J. B. (2011). What Are the Main Challenges Facing the MPA World? Marine Affairs Research and Education (MARE).

Davis, M. A., Chew, M. K., Hobbs, R. J., Lugo, A. E., Ewel, J. J., Vermeij, G. J., .. Briggs, J. C. (2011). Don’t judge species on their origins. Nature, 474(7350), 153-154.

Davis, M., \& Thompson, K. (2000). Eight Ways to be a Colonizer; Two Ways to be an Invader: A Pro- posed Nomenclature Scheme for Invasion Ecology. In Bulletin of the Ecological Society of America (Vol. 81).

*Davis, S. (2016). Bonaire's Wastewater Treatment System Reaches a Milestone. The Bonaire Insider.

Day, J. (2008). The need and practice of monitoring, evaluating and adapting marine planning and managementlessons from the Great Barrier Reef. Marine Policy, 32(5), 823-831.

de Freitas, D. M., Kininmonth, S., \& Woodley, S. (2009). Linking science and management in the adoption of sensor network technology in the Great Barrier Reef coast, Australia. Computers, Environment and Urban Systems, 33(2), 111-121.

de Leeuw, E. D. (1992). Data Quality in Mail, Telephone and Face to Face Surveys. Amsterdam: Vrije Universiteit.

de León, R., Vane, K., Bertuol, P., Chamberland, V., Simal, F., Imms, E., \& Vermeij, M. (2013). Effectiveness of lionfish removal efforts in the southern Caribbean. Endangered Species Research, 22(2), 175-182.

De Meyer, K., \& MacRae, D. (2006). Bonaire National Marine Park Management Plan 2006. STINAPA Bonaire.

De'ath, G., \& Fabricius, K. (2010). Water quality as a regional driver of coral biodiversity and macroalgae on the Great Barrier Reef. Ecological Applications, 20(3), 840-850.

Debrot, A. O., Meesters, H. W. G., Bron, P. S., \& de León, R. (2013). Marine debris in mangroves and on the seabed: Largely-neglected litter problems. Marine Pollution Bulletin, 72(1), 1.

Delaney, D. G., Sperling, C. D., Adams, C. S., \& Leung, B. (2008). Marine invasive species: validation of citizen science and implications for national monitoring networks. Biological Invasions, 10(1), 117-128.

Devictor, V., Whittaker, R. J., \& Beltrame, C. (2010). Beyond scarcity: citizen science programmes as useful tools for conservation biogeography. Diversity and Distributions, 16(3), 354-362.

Di Minin, E., Tenkanen, H., \& Toivonen, T. (2015). Prospects and challenges for social media data in conservation science. Frontiers in Environmental Science, 3, 63.

Dickie, I. A., Bennett, B. M., Burrows, L. E., Nuñez, M. A., Peltzer, D. A., Porté, A., ... van Wilgen, B. W. (2014). Conflicting values: ecosystem services and invasive tree management. Biological Invasions, 16(3), 705-719.

Díez, E., \& McIntosh, B. S. (2009). A review of the factors which influence the use and usefulness of information systems. Environmental Modelling \& Software, 24(5), 588-602. 


\section{References}

Diez, E., \& McIntosh, B. S. (2011). Organisational drivers for, constraints on and impacts of decision and information support tool use in desertification policy and management. Environmental Modelling \&o Software, 26(3), 317327.

Diller, J. L., Frazer, T. K., \& Jacoby, C. A. (2014). Coping with the lionfish invasion: Evidence that naïve, native predators can learn to help. Journal of Experimental Marine Biology and Ecology, 455, 45-49.

Dillon, J., Stevenson, R. B., \& Wals, A. E. J. (2016). Introduction to the special section Moving from Citizen to Civic Science to Address Wicked Conservation Problems. Corrected by erratum 12844. Conservation Biology, 30(3), 450-455.

Donlan, C. J., \& Martin, P. S. (2004). Role of Ecological History in Invasive Species Management and Conservation. Conservation Biology, 18(1), 267-269.

Downs, A. (1972). Up and Down with Ecology: The Issue-Attention Cycle. Public Interest, 28.

Drori, I., \& Honig, B. (2013). A process model of internal and external legitimacy. Organization Studies, 34(3), 345-376.

Dudley, N. (2008). Guidelines for applying protected area management categories.

Dyer, B., \& Millard, K. (2002). A generic framework for value management of environment data in the context of integrated coastal zone management. Ocean \& Coastal Management, 45(1), 59-75.

Ecott, T. (2011, May 7). 'Godzilla' lionfish threatening Cayman paradise. BBC News. Retrieved from http://news.bbc.co.uk/2/hi/programmes/from_our_own_correspondent/9477235.stm

Edelenbos, J., van Buuren, A., \& van Schie, N. (2011). Co-producing knowledge: joint knowledge production between experts, bureaucrats and stakeholders in Dutch water management projects. Environmental Science \& Policy, 14(6), 675-684.

Eilperin, J. (2010, July 7). How to conquer the invasive lionfish? Saute it. Washington Post. Retrieved from https://www.washingtonpost.com/gdpr-consent/?destination= $\% 2 \mathrm{Fwp}-$

dyn $\% 2$ Fcontent $\% 2$ Farticle $\% 2$ F $2010 \% 2 F 07 \% 2 F 06 \% 2 F A R 2010070601003$.html $\% 3$ F\&utm_term $=.7 \mathrm{c} 01$ 4f93caaf

Elder-Vass, D. (2012). Towards a realist social constructionism. Sociologia, problemas e práticas 70, 9-24.

Eleveld, M. A., Schrimpf, W. B. ., \& Siegert, A. G. (2003). User requirements and information definition for a virtual coastal and marine data warehouse. Ocean \& Coastal Management, 46(6-7), 487-505.

Elise, S., Urbina-Barreto, I., Boadas-Gil, H., Galindo-Vivas, M., \& Kulbicki, M. (2015). No detectable effect of lionfish (Pterois volitans and P. miles) invasion on a healthy reef fish assemblage in Archipelago Los Roques National Park, Venezuela. Marine Biology, 162(2), 319-330.

Emilsson, K. (2017). Accountability in a Compact Governance Context: A Good or Bad Marriage? MSc thesis at Dept. of Political Science, Lund University, Sweden.

Estévez, R. A., Anderson, C. B., Pizarro, J. C., \& Burgman, M. A. (2015). Clarifying values, risk perceptions, and attitudes to resolve or avoid social conflicts in invasive species management. Conservation Biology, 29(1), 19-30.

European Commission SCU. (2013). Science for Environment Policy In-Depth Report: Environmental Citizen Science. Report Produced for the European Commission DG Environment, (9), 32.

Evans, J. M., Wilkie, A. C., \& Burkhardt, J. (2008). Adaptive Management of Nonnative Species: Moving Beyond the "Either-Or" Through Experimental Pluralism. Journal of Agricultural and Environmental Ethics, 21(6), 521539.

Evans, S. M., Birchenough, A.C. \& Fletcher, H. (2000). The value and validity of community-based research: TBT contamination of the North Sea. Marine Pollution Bulletin, 40(3),. 220-225.

Fabricius, K. E. (2011). Factors determining the resilience of coral reefs to eutrophication: a review and conceptual model. In Coral reefs: an ecosystem in transition, 493-505. Springer, Dordrecht.

Falk-Petersen, J., Bøhn, T., \& Sandlund, O. T. (2006). On the Numerous Concepts in Invasion Biology. Biological Invasions, 8(6), 1409-1424.

Farinha, C., \& da Silva, M. M. (2013). Requirements Elicitation with Web-Based Focus Groups. In Information Systems Development, 443-455.

Fauzi, A. (2011). Understanding the lionfish invasion in Bonaire to develop the best strategy for Trinidad and Tobago. Proceedings of the 64th Gulf and Caribbean Fisheries Institute, 57-64. Puerto Morelos, Mexico.

Feldman, M. S., Sköldberg, K., Brown, R. N., \& Horner, D. (2004). Making sense of stories: A rhetorical approach to narrative analysis. Journal of Public Administration Research and Theory, 14(2), 147-170. 


\section{References}

Fereday, J., \& Muir-Cochrane, E. (2006). Demonstrating Rigor Using Thematic Analysis: A Hybrid Approach of Inductive and Deductive Coding and Theme Development. International Journal of Qualitative Methods, 5(1), 80-92.

Ferretti, F. (2019). Mapping do-it-yourself science. Life sciences, society and policy, 15(1), p.1.

Festa, J. (2014, July 30). Caribbean crisis: how eating lionfish can help save the planet. Epicure \& Culture. Retrieved from https://epicureandculture.com/lionfish/

Ford-Thompson, A. E. S., Snell, C., Saunders, G., \& White, P. C. L. (2012). Stakeholder Participation in Management of Invasive Vertebrates. Conservation Biology, 26(2), 345-356.

Foster, J., \& Sandberg, L. A. (2010). Friends or foe? Invasive species and public green space in Toronto. Geographical Review, 94(2), 178-198.

Foundation, N. (2011, November 21). Nature Foundation recommends population not eat lionfish; study shows toxins found in lionfish caught in St. Maarten waters. St. Maarten Island Time. Retrieved from http://sxmislandtime.com/component/k2/item/16465-nature-foundation-recommends-populationnot-eat-lionfish-study-shows-toxins-found-in-lionfish-caught-in-st-maarten-waters.html

Frazer, T. K., Jacoby, C. A., Edwards, M. A., Barry, S. C., \& Manfrino, C. M. (2012). Coping with the Lionfish Invasion: Can Targeted Removals Yield Beneficial Effects? Reviews in Fisheries Science, 20(4), 185-191.

Freitag, A., Meyer, R. \& Whiteman, L. (2016). Strategies employed by citizen science programs to increase the credibility of their data. Citizen Science: Theory and Practice, 1(1).

Freshwater, D. W., Hines, A., Parham, S., Wilbur, A., Sabaoun, M., Woodhead, J., .. Paris, C. B. (2009). Mitochondrial control region sequence analyses indicate dispersal from the US East Coast as the source of the invasive Indo-Pacific lionfish Pterois volitans in the Bahamas. Marine Biology, 156(6), 1213-1221.

Friess, D. A., Kudavidanage, E. P., \& Webb, E. L. (2011). The digital globe is our oyster. Frontiers in Ecology and the Environment, 9(10), 542-542.

Fuentes-Fernández, R., Gómez-Sanz, J. J., \& Pavón, J. (2010). Understanding the human context in requirements elicitation. Requirements Engineering, 15(3), 267-283.

Funtowicz, S. O., \& Ravetz, J. R. (1993). Science for the post-normal age. Futures, 25(7), 739-755.

Gabrys, J., Pritchard, H., \& Barratt, B. (2016). Just good enough data: Figuring data citizenships through air pollution sensing and data stories. Big Data \& Society, 3(2), 2053951716679677.

Gabrys, J. \& Pritchard, H. (2018). Just Good Enough Data and Environmental Sensing: Moving Beyond Regulatory Benchmarks toward Citizen Action. International Journal of Spatial Data Infrastructures Research, 13, 4-14.

Gadamer, H.-G. (1975). Truth and Method. Trans. W. Glen-Dopel. London: Sheed and Ward

Gadamer, H.-G. (1988). On the circle of understanding. In Hermeneutics versus science, 68-78.

Gallivan, M. J., \& Keil, M. (2003). The user-developer communication process: a critical case study. Information Systems Journal, 13(1), 37-68.

Gane, N., \& Back, L. (2012). C. Wright Mills 50 years on: The promise and craft of sociology revisited. Theory, Culture \& Society, 29(7-8), 399-421.

García-Llorente, M., Martín-López, B., González, J. A., Alcorlo, P., \& Montes, C. (2008). Social perceptions of the impacts and benefits of invasive alien species: Implications for management. Biological Conservation, 141(12), 2969-2983.

Garcia-Soto, C., \& van der Meeren, G. I. (2017). Advancing citizen science for coastal and ocean research. European Marine Board IVZW.

Genovesi, P., \& Bertolino, S. (2001). Human dimension aspects in invasive alien species issues: the case of the failure of the grey squirrel eradication project in Italy.

Gibbons, M. (1999). Science's new social contract with society. Nature, 402(6761supp), C81.

Giddens, A. (1984). The constitution of society: Outline of the theory of structuration. Univ of California Press.

Giddens, A. (1990). The Consequences of Modernity. In Stanford University Press.

*Gijzen, H. J., \& van der Steen, P. (2004). Sewage management in Bonaire. UNESCO-IHE, Delft.

Gill, D. A., Mascia, M. B., Ahmadia, G. N., Glew, L., Lester, S. E., Barnes, M., .. Fox, H. E. (2017). Capacity shortfalls hinder the performance of marine protected areas globally. Nature, 543(7647), 665-669.

Gill, E. (2012, July 2). Florida Sea Grant says not to eat lionfish. TCPalm. Retrieved from https://eu.tcpalm.com/ 


\section{References}

Glader, P. (2010, November 15). No TitleThe lionfish creates an uproar, bringing out the hunters. Voracious intruders stalked with spears; doing your part by eating them. Wall Street Journal. Retrieved from https://www.wsj.com/articles/SB10001424052748704658204575610721532882174

Glaser, B. G., \& Strauss, A. L. (1967). The discovery of grounded theory: Strategies for qualitative research. New York, NY: Aldine De Gruyter.

Glasersfeld, E. (1991). An Exposition of Constructivism: Why Some Like it Radical. In Facets of Systems Science, 229_ 238).

Gobster, P. H. (2005). Invasive Species as Ecological Threat: Is Restoration an Alternative to Fear-based Resource Management? Ecological Restoration, 23(4), 261-270.

Goffredo, S., Pensa, F., Neri, P., Orlandi, A., Gagliardi, M. S., Velardi, A., ... Zaccanti, F. (2010). Unite research with what citizens do for fun: "recreational monitoring" of marine biodiversity. Ecological Applications, 20(8), $2170-2187$.

Golani, D., \& Sonin, O. (1992). New record of the Red Sea fishes Pterois miles (Scorpaenidae) and Pteragogus pelycus (Labridae) from the eastern Mediterranean Sea. Japanese Journal of Ichthyology, 39, 167-169.

Golant, B. D., \& Sillince, J. A. A. (2007). The constitution of organizational legitimacy: A narrative perspective. Organization Studies, 28(8), 1149-1167.

Golfashani, N. (2003). Understanding Reliability and Validity in Qualitative Research. The Qualitative Report, 8(4), $597-$ 607. Retrieved from https://nsuworks.nova.edu/tqr/vol8/iss4/6

Gómez Lozano, R., Anderson, L., Akins, J. L., Buddo, D. S. A., García-Moliner, G., Gourdin, F., ... Torres, R. (n.d.). Regional Strategy for the Control of Invasive Lionfish in the Wider Caribbean. International Coral Reef Initiative, 31.

Gómez, Y. (2010). Status of the lionfish (Pteroris sp.) in the Sian Ka'an and the Sian Ka'an reefs biosphere reserves. In I. S. S. Group (Ed.), Global Invasive Species database. Aukland, New Zealand: University of Auckland.

Gorman, J. (2010, December 31). A diet for an invaded planet: invasive species. New York. Times. Retrieved from https://www.nytimes.com/2011/01/02/weekinreview/02gorman.html

Graham, N. A. J., \& Hicks, C. C. (2015). Adaptive Management for Novel Ecosystems. In Adaptive Management of Social-Ecological Systems, 123-146.

Graham, N. A., Cinner, J. E., Norström, A. V, \& Nyström, M. (2014). Coral reefs as novel ecosystems: embracing new futures. Current Opinion in Environmental Sustainability, 7, 9-14.

Green, S. J., Tamburello, N., Miller, S. E., Akins, J. L., \& Côté, I. M. (2013). Habitat complexity and fish size affect the detection of Indo-Pacific lionfish on invaded coral reefs. Coral Reefs, 32(2), 413-421.

Green, S. J., \& Côté, I. M. (2009). Record densities of Indo-Pacific lionfish on Bahamian coral reefs. Coral Reefs, 28(1), 107-107.

Green, S. J., Akins, J. L., Maljković, A., \& Côté, I. M. (2012). Invasive Lionfish Drive Atlantic Coral Reef Fish Declines. PLOS ONE, 7(3), e32596.

Green, S. J., Dulvy, N. K., Brooks, A. M. L., Akins, J. L., Cooper, A. B., Miller, S., \& Côté, I. M. (2014). Linking removal targets to the ecological effects of invaders: a predictive model and field test. Ecological Applications, 24(6), 1311-1322.

Gulf and Caribbean Fisheries Institute (GCFI). (2014). Book of Abstracts. Proceedings of the 67th GCFI.

Gurevitch, J., \& Padilla, D. (2004). Are invasive species a major cause of extinctions? Trends in Ecology \& Evolution, 19(9), 470-474.

Guston, D. H. (1996). Principal-agent theory and the structure of science policy. Science and Public Policy, 23(4), 229240 .

Guston, D. H. (2001). Boundary Organizations in Environmental Policy and Science: An Introduction. Science, Technology, \& Human V alues, 26(4), 399-408.

Hackerott, S., Valdivia, A., Green, S. J., Côté, I. M., Cox, C. E., Akins, L., .. Bruno, J. F. (2013). Native Predators Do Not Influence Invasion Success of Pacific Lionfish on Caribbean Reefs. PLoS ONE, 8(7), e68259.

Haider, S., \& Jax, K. (2007). The application of environmental ethics in biological conservation: a case study from the southernmost tip of the Americas. Biodiversity and Conservation, 16(9), 2559-2573.

Hajer, M. A. (1995). The Politics of Environmental Discourse: Ecological Modernization and the Policy Process. Oxford: Claredon Press.

Hajer, M. A. (2002). Discourse Analysis and the Study of Policy Making. European Political Science 2 (1): 61-65. 


\section{References}

Hajer, M., \& Laws, D. (2006). Ordering through discourse. The Oxford Handbook of Public Policy, 251, 268.

Haklay, M. (2013). Citizen Science and Volunteered Geographic Information: Overview and Typology of Participation. In D. Sui, S. Elwood, \& M. Goodchild (Eds.), Crowdsourcing Geographic Knowledge: Volunteered Geographic Information (VGI) in Theory and Practice (pp. 105-122).

Hall, M. (2003). Editorial: The Native, Naturalized and Exotic-plants and animals in human history. Landscape Research, 28(1), 5-9.

Halpern, B. S., Lester, S. E., \& Kellner, J. B. (2009). Spillover from marine reserves and the replenishment of fished stocks. Environmental Conservation, 36(4), 268-276.

Hamner, R. M., Freshwater, D. W., \& Whitfield, P. E. (2007). Mitochondrial cytochrome b analysis reveals two invasive lionfish species with strong founder effects in the western Atlantic. Journal of Fish Biology, 71(sb), 214-222.

Hansen, M. D., \& Wang, Y. R. (1991). Managing Data Quality: A Critical Issue for the Decade to Come. Cambridge, MA: Massachusetts Institute of Technology.

Hare, J., \& E. Whitfield, P. (2003). An Integrated Assessment of the Introduction of Lionfish (Pterois volitans/miles complex) to the Western Atlantic Ocean. NOAA Technical Memorandum NOS NCCOS.

Hargreaves-Allen, V., Mourato, S., \& Milner-Gulland, E. J. (2011). A Global Evaluation of Coral Reef Management Performance: Are MPAs Producing Conservation and Socio-Economic Improvements? Environmental Management, 47(4), 684-700.

Harvey, R. G., \& Mazzotti, F. J. (2015). Public Awareness and Attitudes toward Invasive Lionfish: Preliminary Results from Baseline Survey. Interim Report to the Florida Fish and Wildlife Conservation Commission.

Hastings, J. G., Gruby, R. L., \& Sievanen, L. S. (2012). Science-based coastal management in Fiji: Two case studies from the NGO sector. Marine Policy, 36(4), 907-914.

Heger, T., Saul, W.-C., \& Trepl, L. (2013). What biological invasions 'are' is a matter of perspective. Journal for Nature Conservation, 21(2), 93-96.

Hegger, D., Lamers, M., Van Zeijl-Rozema, A., \& Dieperink, C. (2012). Conceptualising joint knowledge production in regional climate change adaptation projects: success conditions and levers for action. Environmental Science \& Policy, 18, 52-65.

Hessels, L. K., \& Van Lente, H. (2008). Re-thinking new knowledge production: A literature review and a research agenda. Research Policy, 37(4), 740-760.

Hickey, A. M., \& Davis, A. M. (2004). A Unified Model of Requirements Elicitation. Journal of Management Information Systems, 20(4), 65-84.

Higgins, C., \& Walker, R. (2012). Ethos, logos, pathos: Strategies of persuasion in social/environmental reports. Accounting Forum, 36(3), 194-208. Taylor \& Francis.

Hirschheim, R. (1988). Information Systems and User Resistance: Theory and Practice. The Computer Journal, 31(5), 398-408.

Hjørland, B., \& Albrechtsen, H. (1995). Toward a new horizon in information science: Domain-analysis. Journal of the American Society for Information Science, 46(6), 400-425.

Hoegh-Guldberg, O., Kennedy, E. V., Beyer, H. L., McClennen, C., \& Possingham, H. P. (2018). Securing a Longterm Future for Coral Reefs. Trends in Ecology \& Evolution, 33(12), 936-944.

Hoegh-Guldberg, O., Pendleton, L. \& Kaup, A. (2019). People and the changing nature of coral reefs. Regional Studies in Marine Science, p.100699.

Hughes, J., \& Wood-Harper, T. (1999). Addressing Organisational Issues in Requirements Engineering Practice: lessons from action cases. Australasian Journal of Information Systems, 6(2).

Hughes, T. P., Barnes, M. L., Bellwood, D. R., Cinner, J. E., Cumming, G. S., Jackson, J. B. C., ... Scheffer, M. (2017). Coral reefs in the Anthropocene. Nature, 546(7656), 82-90.

Hughes, T. P., Kerry, J. T., Baird, A. H., Connolly, S. R., Dietzel, A., Eakin, C. M., ... Liu, G. (2018). Global warming transforms coral reef assemblages. Nature, 556(7702), 492.

Huus, K. (2010, August 10). Do your civic duty, eat this fish! NBC News. Retrieved from http://www.nbcnews.com/id/38632799/ns/us_news-environment/t/do-your-civic-duty-eatfish/\#.XR34KPZuLIV

Hyder, K., Townhill, B., Anderson, L.G., Delany, J. \& Pinnegar, J.K. (2015). Can citizen science contribute to the evidence-base that underpins marine policy?. Marine policy, 59, 112-120.

Irwin, A. (1995). Citizen Science: A study of people, expertise, and sustainable development. Psychology Press. 


\section{References}

Irwin, A. (2018). Citizen science comes of age. Efforts to engage the public in research are bigger and more diverse than ever. But how much more room is there to grow?. Nature, 562(7728), 480-482

Jackson, J., Donovan, M., Cramer, K., \& Lam, V. (2014). Status and trends of Caribbean coral reefs: 1970-2012. Global coral reef monitoring network. International Union for the Conservation of Nature Global Marine and Polar Program: Washington, DC.

Jackson, R. L., Drummond, D. K., \& Camara, S. (2007). What Is Qualitative Research? Qualitative Research Reports in Communication, 8(1), 21-28.

Jacobson, S. K., Carlton, J. S., \& Monroe, M. C. (2012). Motivation and satisfaction of volunteers at a Florida natural resource agency. Journal of Park and Recreation Administration, 30(1).

Jalbert, K. \& Kinchy, A.J. (2016). Sense and influence: environmental monitoring tools and the power of citizen science. Journal of environmental policy \& planning, 18(3), .379-397.

Jasanoff, S. (2003). Technologies of Humility: Citizen Participation in Governing Science. Minerva, 41(3), $223-244$.

Jasanoff, S. (2004). States of Knowledge: the co-production of science and the social order. Routledge.

Jentoft, S., van Son, T. C., \& Bjørkan, M. (2007). Marine Protected Areas: A Governance System Analysis. Human Ecology, 35(5), 611-622.

Jepson, P. (2005). Governance and accountability of environmental NGOs. Environmental Science \& Policy, 8(5), 515524.

Jepson, P., \& Ladle, R. J. (2016). Erratum to: Nature apps: Waiting for the revolution. Ambio, 45(2), $266-266$.

Johannessen, J., Olaisen, J., \& Olsen, B. (2002). Aspects of a systemic philosophy of knowledge: from social facts to data, information and knowledge. Kybernetes, 31(7/8), 1099-1120.

Johnson, A. E., \& Jackson, J. B. C. (2015). Fisher and diver perceptions of coral reef degradation and implications for sustainable management. Global Ecology and Conservation, 3, 890-899.

Johnston, M., \& Purkis, S. (2015). A coordinated and sustained international strategy is required to turn the tide on the Atlantic lionfish invasion. Marine Ecology Progress Series, 533, 219-235.

*Jones, B.H., Cetinic, I., Toro-Farmer, G., Herzog, K., Bianculli, A., De Leon, R., Ragan, W.T. \& Reynolds, W. (2008). The light and motion sensor program: low cost coral reef monitoring. In Proc 11th Int Coral Reef Symp (Vol. 16, 582-586).

Joppa, L. N. (2015). Technology for nature conservation: An industry perspective. Ambio, 44(S4), 522-526.

Jud, Z. R., Nichols, P. K., \& Layman, C. A. (2015). Broad salinity tolerance in the invasive lionfish Pterois spp. may facilitate estuarine colonization. Environmental Biology of Fishes, 98(1), 135-143.

Karlsson, S., Srebotnjak, T. \& Gonzales, P. (2007). Understanding the North-South knowledge divide and its implications for policy: a quantitative analysis of the generation of scientific knowledge in the environmental sciences. Environmental Science \& Policy, 10(7-8), .668-684.

Kelleher, G. (1999). Guidelines For Marine Protected Areas. IUCN, Gland, Switzerland and Cambridge, UK.

Kellert, S. R. (1985). Public perceptions of predators, particularly the wolf and coyote. Biological Conservation, 31(2), 167-189.

Kemp-Benedict, E. J., Bharwani, S., \& Fischer, M. D. (2010). Using Matching Methods to Link Social and Physical Analyses for Sustainability Planning. Ecology and Society, 15(3), art4.

Keulartz, J., \& van der Weele, C. (2008). Framing and Reframing in Invasion Biology. Configurations, 16(1), $93-115$.

Kimball, M., Miller, J., Whitfield, P., \& Hare, J. (2004). Thermal tolerance and potential distribution of invasive lionfish (Pterois volitans/miles complex) on the east coast of the United States. Marine Ecology Progress Series, 283, 269-278.

Kimura, A.H. \& Kinchy, A. (2016). Citizen science: Probing the virtues and contexts of participatory research Engaging Science, Technology, and Society, 2, 331-361.

Kinchy, A.J. \& Perry, S.L. (2011). Can volunteers pick up the slack-efforts to remedy knowledge gaps about the watershed impacts of Marcellus Shale gas development. Duke Envtl. L. \& Pol'y F., 22, p.303.

Klein, H. K., \& Myers, M. D. (1999). A Set of Principles for Conducting and Evaluating Interpretive Field Studies in Information Systems. MIS Quarterly, 23(1), 67.

Koss, R. S., Miller, K., Wescott, G., Bellgrove, A., Boxshall, A., McBurnie, J., ... Ierodiaconou, D. (2009). An evaluation of Sea Search as a citizen science programme in Marine Protected Areas. Pacific Conservation Biology, 15(2), 116-127.

Kuhn, T. S. (1962). The Structure of Scientific Revolutions. The University of Chicago Press. 


\section{References}

Ladd, J. M., Lappé, M. D., McCormick, J. B., Boyce, A. M., \& Cho, M. K. (2009). The "how” and "whys” of research: life scientists' views of accountability. Journal of Medical Ethics, 35(12), 762-767.

Lakoff, G. (1993). The contemporary theory of metaphor. In A. Ortony (Ed.), Metaphor and Thought, $202-251$.

Lamb, J. B., Willis, B. L., Fiorenza, E. A., Couch, C. S., Howard, R., Rader, D. N., ... Harvell, C. D. (2018). Plastic waste associated with disease on coral reefs. Science, 359(6374), 460-462.

Lamb, R. \& Kling, R. (2003). Reconceptualizing Users as Social Actors in Information Systems Research. MIS Quarterly, 27(2), 197.

Lambert, B. (2006, September 8). A spiny invader proliferates in L.I. waters, and scientists wonder about its impact. New York Times. Retrieved from https://www.nytimes.com/2006/09/08/nyregion/08fish.html

*Lapointe, B.E. \& Mallin, M.A. (2011). Nutrient enrichment and eutrophication on fringing coral reefs of Bonaire and Curaçao, Netherlands Antilles. Report to the United Nations Environment Programme for the NACRI Coral Reef Monitoring Program, Harbor Branch Oceanographic Institute, Ft. Pierce Fl.

Larson, B. M. H. (2005). The War of the Roses: Demilitarizing Invasion Biology. Frontiers in Ecology and the Environment, $3(9), 495-500$.

Larson, B. M. H., Nerlich, B., \& Wallis, P. (2005). Metaphors and Biorisks. Science Communication, 26(3), $243-268$.

Larson, B. M. H. (2007a). Who's invading what? Systems thinking about invasive species. Canadian Journal of Plant Science, 87(5), 993-999.

Larson, B. M. H. (2007b). An alien approach to invasive species: objectivity and society in invasion biology. Biological Invasions, 9(8), 947-956.

Larson, B. M. H. (2008). Entangled biological, cultural and linguistic origins of the war on invasive species. Frank, R.M., Dirven, R., Ziemke, T. and Bernárdez, E. Eds., 2008. Body, Language, and Mind: Sociocultural Situatedness. Berlin: Mouton de Gruyter., 169-197.

Lash, S. (2006). Life (Vitalism). Theory, Culture \& Society, 23(2-3), 323-329.

Latour, B. (2005). Reassembling the social. Politica y Sociedad, 43(3), 127-130.

Lavoie, C. (2010). Should we care about purple loosestrife? The history of an invasive plant in North America. Biological Invasions, 12(7), 1967-1999.

Lawrence, A. (2006). 'No Personal Motive?' Volunteers, Biodiversity, and the False Dichotomies of Participation. Ethics, Place \& Environment, 9(3), 279-298.

Lawrence, A., \& Stewart, A. (2011). Sustainable Forestry Decisions: On the Interface Between Technology and Participation. Mathematical and Computional Forestry \& Natural-Resrouce Sciences, 3(1), 42-52.

Lawrence, A., \& Turnhout, E. (2010). Personal meaning in the public sphere: The standardisation and rationalisation of biodiversity data in the UK and the Netherlands. Journal of Rural Studies, 26(4), 353-360.

Lehtonen, M., Sébastien, L. \& Bauler, T. (2016). The multiple roles of sustainability indicators in informational governance: between intended use and unanticipated influence. Current Opinion in Environmental Sustainability, 18, 1-9.

Lejano, R., Ingram, M., \& Ingram, H. (2013). The Power of Narrative in Environmental Networks. MIT Press.

Lesser, M. P., \& Slattery, M. (2011). Phase shift to algal dominated communities at mesophotic depths associated with lionfish (Pterois volitans) invasion on a Bahamian coral reef. Biological Invasions, 13(8), 1855-1868.

Lester, S., Halpern, B., Grorud-Colvert, K., Lubchenco, J., Ruttenberg, B., Gaines, S., ... Warner, R. (2009). Biological effects within no-take marine reserves: a global synthesis. Marine Ecology Progress Series, 384, 33-46.

Lewandowski, E., \& Specht, H. (2015). Influence of volunteer and project characteristics on data quality of biological surveys. Conservation Biology, 29(3), 713-723.

Liao, Y.-C., Chen, L.-S., \& Shao, K.-T. (2010). The predatory Atlantic red drum, Sciaenops ocellatus, has invaded the western Taiwanese coast in the Indo-West Pacific. Biological Invasions, 12(7), 1961-1965.

Lindop, A., Bultel, E., Zylich, K., \& Zeller, D. (2015). Reconstructing the former Netherlands Antilles marine catches from 1950 to 2010 .

Linendoll, K. (2013, October 19). Lionfish infestation in Atlantic Ocean a growing epidemic. CNN. Retrieved from https://edition.cnn.com/2013/10/18/tech/innovation/lionfish-infestation-atlanticlinendoll/index.html

*Littler, M. M., \& Littler, D. S. (2006). Bonaire National Marine Park-Algal Survey and Inventory. Unpublished Report to the Bonaire National Marine Park, Bonaire.

Lockridge, G., Dzwonkowski, B., Nelson, R. \& Powers, S. (2016). Development of a low-cost arduino-based sonde for coastal applications. Sensors, 16(4), p.528. 


\section{References}

López-Gómez, M. J., Aguilar-Perera, A., \& Perera-Chan, L. (2014). Mayan diver-fishers as citizen scientists: detection and monitoring of the invasive red lionfish in the Parque Nacional Arrecife Alacranes, southern Gulf of Mexico. Biological Invasions, 16(7), 1351-1357.

Lupton, D. (2014). Digital sociology. Routledge.

Lyytinen, K. (1988). Expectation failure concept and systems analysts' view of information system failures: Results of an exploratory study. Information \& Management, 14(1), 45-56.

Maasen, S., Mendelsohn, E., \& Weingart, P. (Eds.). (1995). Biology as Society, Society as Biology: Metaphors.

Mack, R. N., Simberloff, D., Lonsdale, W. M., Evans, H., Clout, M., \& Bazzaz, F. A. (2000). Biotic invasions: causes, epidemiology, global consequences, and control. Ecological Applications, 10(3), 689-710.

Maljković, A., Van Leeuwen, T. E., \& Cove, S. N. (2008). Predation on the invasive red lionfish, Pterois volitans (Pisces: Scorpaenidae), by native groupers in the Bahamas. Coral Reefs, 27(3), 501-501.

Márquez, H. (2009, December 2). New pirate of the Caribbean invades from Pacific. Inter Press Service News Agency. Retrieved from http://www.ipsnews.net/2009/12/environment-new-pirate-of-the-caribbean-invadesfrom-pacific/

Marres, N. (2017). Digital sociology: The reinvention of social research. John Wiley \& Sons.

Marshall, N. A., Friedel, M., van Klinken, R. D., \& Grice, A. C. (2011). Considering the social dimension of invasive species: the case of buffel grass. Environmental Science \& Policy, 14(3), 327-338.

Masalu, D. C. P. (2008). Coastal data and information management for integrated coastal management: The role of IODE. Marine Policy, 32(4), 544-550.

Mason, M. (2010). Sample size and saturation in $\mathrm{PhD}$ studies using qualitative interviews. Forum Qualitative Sozialforschung/Forum: Qualitative Social Research, 11(3).

Matthews, K. B., Rivington, M., Blackstock, K., McCrum, G., Buchan, K., \& Miller, D. G. (2011). Raising the bar? The challenges of evaluating the outcomes of environmental modelling and software. Environmental Modelling \& Software, 26(3), 247-257.

McAllister, C. (2006). Requirements Determination of Information Systems: User and Developer Perceptions of Factors Contributing to Misunderstandings. Minnesota: Capella University.

McCall, M. K., \& Dunn, C. E. (2012). Geo-information tools for participatory spatial planning: Fulfilling the criteria for 'good' governance? Geoforum, 43(1), 81-94.

McClanahan, T. R., \& Arthur, R. (2001). The Effect of Marine Reserves and Habitat on Populations of East African Coral Reef Fishes. Ecological Applications, 11(2), 559.

McConney, P., \& Pena, M. (2012). Capacity for (Co)Management of Marine Protected Areas in the Caribbean. Coastal Management, 40(3), 268-278.

McCormick, S. (2007). Democratizing science movements: A new framework for mobilization and contestation. Social Studies of Science, 37(4), 609-623.

McGeoch, M. A., Butchart, S. H. M., Spear, D., Marais, E., Kleynhans, E. J., Symes, A., ... Hoffmann, M. (2010). Global indicators of biological invasion: species numbers, biodiversity impact and policy responses. Diversity and Distributions, 16(1), 95-108.

McIntosh, B. S., Ascough, J. C., Twery, M., Chew, J., Elmahdi, A., Haase, D., ... Voinov, A. (2011). Environmental decision support systems (EDSS) development - Challenges and best practices. Environmental Modelling \& Software, 26(12), 1389-1402.

McIntosh, B. S., Giupponi, C., Voinov, A. A., Smith, C., Matthews, K. B., Monticino, M., ... Assaf, H. (2008). Chapter Three Bridging the Gaps Between Design and Use: Developing Tools to Support Environmental Management and Policy.

McNie, E. C. (2007). Reconciling the supply of scientific information with user demands: an analysis of the problem and review of the literature. Environmental Science \& Policy, 10(1), 17-38.

Meiner, A. (2010). Integrated maritime policy for the European Union - consolidating coastal and marine information to support maritime spatial planning. Journal of Coastal Conservation, 14(1), 1-11.

Mellin, C., Aaron MacNeil, M., Cheal, A. J., Emslie, M. J., \& Julian Caley, M. (2016). Marine protected areas increase resilience among coral reef communities. Ecology Letters, 19(6), 629-637.

Messing, R. H., \& Wright, M. G. (2006). Biological control of invasive species: solution or pollution? Frontiers in Ecology and the Environment, 4(3), 132-140.

Miami Herald. (2008, January 18). Newcomer to Keys is unwelcome, uncouth. Miami Herald. 


\section{References}

Mickwitz, P. (2003). A framework for evaluating environmental policy instruments: context and key concepts. Evaluation, 9(4), 415-436.

Millerand, F., \& Baker, K. S. (2010). Who are the users? Who are the developers? Webs of users and developers in the development process of a technical standard. Information Systems Journal, 20(2), 137-161.

Miller-Rushing, A., Primack, R., \& Bonney, R. (2012). The history of public participation in ecological research. Frontiers in Ecology and the Environment, 10(6), 285-290.

Miller-Taei, S., \& Kostka, W. (2012). Paying for MPAs: Examples of Large-Scale Fundraising for Planning and Management. MPA News, 13(6), 1-8.

Miloslavich, P., Díaz, J. M., Klein, E., Alvarado, J. J., Díaz, C., Gobin, J., ... Ortiz, M. (2010). Marine Biodiversity in the Caribbean: Regional Estimates and Distribution Patterns. PLoS ONE, 5(8), e11916.

Mingers, J. (2000). The contribution of critical realism as an underpinning philosophy for OR/MS and systems. Journal of the Operational Research Society, 51(11), 1256-1270.

Mol, A. P. J. (2008). Environmental Reform in the Information Age. The Contours of Informational Governance. Cambridge University Press.

Molina, B. (2009, March 24). Pez León: se busca vivo o muerto. Mundo Náutico. Retrieved from http://www.revistamundonautico.com/pez-leon-se-busca-vivo-o-muerto/

Moore, A. (2012). The aquatic invaders: Marine Management Figuring Fishermen, Fisheries, and Lionfish in The Bahamas. Cultural Anthropology, 27(4), 667-688.

Mora, C. (2006). Coral Reefs and the Global Network of Marine Protected Areas. Science, 312(5781), 1750-1751.

Morell, V. (2010, April 29). Mystery of the lionfish: don't blame Hurricane Andrew. ScienceInsider. Retrieved from https://www.sciencemag.org/news/2010/04/mystery-lionfish-dont-blame-hurricane-andrew

Morris, J. A. (2011). Invasive lionfish: a guide to control and management. In Special Publication Series Number 1. Marathon, Florida: Gulf and Caribbean Fisheries Institute.

Morris, J. A., \& Whitfield, P. E. (2009). Biology, ecology, control and management of the invasive Indo-Pacific lionfish: an updated integrated assessment. National Oceanic and Atmospheric Administration (NOAA) Technical Memorandum NOS NCCOS, 99. Beaufort, North Carolina, USA: NOAA/National Ocean Service/Center for Coastal Fisheries and Habitat Research.

Morris, J. A., \& Akins, J. L. (2009). Feeding ecology of invasive lionfish (Pterois volitans) in the Bahamian archipelago. Environmental Biology of Fishes, 86(3), 389-398.

Morris, J. A., Thomas, A., Rhyne, A. L., Breen, N., Akins, L., \& Nash, B. (2011). Nutritional properties of the invasive lionfish: A delicious and nutritious approach for controlling the invasion. AACL Bioflux, 4(1), 21-26.

Morris, J. A., Shertzer, K. W., \& Rice, J. A. (2011). A stage-based matrix population model of invasive lionfish with implications for control. Biological Invasions, 13(1), 7-12.

Mouillot, D., Parravicini, V., Bellwood, D. R., Leprieur, F., Huang, D., Cowman, P. F., ... Guilhaumon, F. (2016). Global marine protected areas do not secure the evolutionary history of tropical corals and fishes. Nature Communications, 7(1), 10359.

Müller, M. (2015). Assemblages and Actor-networks: Rethinking Socio-material Power, Politics and Space. Geography Compass, 9(1), 27-41.

Mumby, P. J., Harborne, A. R., \& Brumbaugh, D. R. (2011). Grouper as a Natural Biocontrol of Invasive Lionfish. PLOS ONE, 6(6), e21510.

Mumby, P. J., Brumbaugh, D. R., Harborne, A. R., \& Roff, G. (2013). On the relationship between native grouper and invasive lionfish in the Caribbean. PeerJ PrePrints, 1, e45v1.

Mumby, P. J., Harborne, A. R., Raines, P. S., \& Ridley, J. M. (1995). A critical assessment of data derived from Coral Cay Conservation volunteers. Bulletin of Marine Science, 56(3), 737-751.

Myers, M. D. (1994). A disaster for everyone to see: An interpretive analysis of a failed is project. Accounting, Management and Information Technologies, 4(4), 185-201.

Nature Foundation. (2011, November 21). Nature Foundation Recommends Population not eat Lionfish; Study shows toxins found in Lionfish caught in St. Maarten Waters. Saint Maarten News Network. Retrieved from https://smn-news.com/st-maarten-st-martin-news/10100-nature-foundation-recommends-populationnot-eat-lionfish-study-shows-toxins-found-in-lionfish-caught-in-st-maarten-waters.html

Neighbors, J. M. (1980). Software construction using components (Doctoral dissertation, University of California, Irvine).175. 


\section{References}

Nerlich, B., \& James, R. (2009). "The post-antibiotic apocalypse" and the "war on superbugs": catastrophe discourse in microbiology, its rhetorical form and political function. Public Understanding of Science, 18(5), 574-590.

Newig, J., \& Kvarda, E. (2012). Participation in environmental governance: legitimate and effective. Environmental Governance: The Challenge of Legitimacy and Effectiveness, 29-45.

Newman, G., Zimmerman, D., Crall, A., Laituri, M., Graham, J., \& Stapel, L. (2010). User-friendly web mapping: lessons from a citizen science website. International Journal of Geographical Information Science, 24(12), 18511869.

Newman, J., \& Head, B. W. (2017). Wicked tendencies in policy problems: Rethinking the distinction between social and technical problems. Policy and Society, 36(3), 414-429.

NOAA. (2018). Coral Bleaching During \& Since the 2014-2017 Global Coral Bleaching Event. Retrieved February 1, 2019, from https://coralreefwatch.noaa.gov/satellite/analyses_guidance/global_coral_bleaching_201417_status.php

NOAA (2011). National Ocean Service (NOS) education. Retrieved from https://oceanservice.noaa.gov/education/ Norouzzadeh, M. S., Nguyen, A., Kosmala, M., Swanson, A., Palmer, M. S., Packer, C., \& Clune, J. (2018). Automatically identifying, counting, and describing wild animals in camera-trap images with deep learning. Proceedings of the National Academy of Sciences, 115(25), E5716-E5725.

Nuñez, M. A., Kuebbing, S., Dimarco, R. D., \& Simberloff, D. (2012). Invasive Species: to eat or not to eat, that is the question. Conservation Letters, 5(5), 334-341.

Nursey-Bray, M. J., Vince, J., Scott, M., Haward, M., O’Toole, K., Smith, T., ... Clarke, B. (2014). Science into policy? Discourse, coastal management and knowledge. Environmental Science \& Policy, 38, 107-119.

Nuseibeh, B., \& Easterbrook, S. (2000). Requirements engineering. Proceedings of the Conference on The Future of Software Engineering - ICSE '00, 35-46.

Olsen, E. (2010, November 22). Florida Keys declare open season on the invasive Lionfish. New York Times. Retrieved from https://www.nytimes.com/2010/11/23/science/23lionfish.html

Onwuegbuzie, A., \& Leech, N. (2007). Sampling Designs in Qualitative Research: Making the Sampling Process More Public. Qualitative Report, 12(2), 19-20. Retrieved from http://files.eric.ed.gov/fulltext/EJ800181.pdf

Orlikowski, W. J. (2007). Sociomaterial Practices: Exploring Technology at Work. Organization Studies, 28(9), 14351448.

Otero, M., Cebrian, E., Francour, P., Galil, B., \& Savini, D. (2013). Monitoring marine invasive species in Mediterranean marine protected areas (MPAs): a strategy and practical guide for managers. Malaga, Spain: IUCN, 136.

Ottinger, G. (2010). Buckets of resistance: Standards and the effectiveness of citizen science. Science, Technology, \& Human Values, 35(2), 244-270.

Ottinger, G. \& Zurer, R. (2011). Drowning in data. Issues in Science and Technology, 27(3), 71-82.

Paddack, M. J., Reynolds, J. D., Aguilar, C., Appeldoorn, R. S., Beets, J., Burkett, E. W., ... Côté, I. M. (2009). Recent Region-wide Declines in Caribbean Reef Fish Abundance. Current Biology, 19(7), 590-595.

Padilla, D. ., \& Williams, S. . (2004). Sources of invasive species in aquatic ecosystems. Frontiers in Ecology and the Environment, 2(3), 131-138.

Palaniappan, M., Gleick, P. H., Allen, L., Cohen, M. J., Christian-Smith, J., Smith, C., \& Ross, N. (2010). Clearing the waters: a focus on water quality solutions. Nairobi, Kenya: UNEP/Pacific Institute.

Pan, Z., \& Kosicki, G. (1993). Framing analysis: An approach to news discourse. Political Communication, 10(1), 55-75.

Panian, Z. (2009). Recent Advances in Data Management. W. Trans. on Comp., 8(7), 1061-1071. Retrieved from http://dl.acm.org/citation.cfm?id=1639477.1639480

Parker, I. M., Simberloff, D., Lonsdale, W. M., Goodell, K., Wonham, M., Kareiva, P. M., ... Goldwasser, L. (1999). Impact: Toward a Framework for Understanding the Ecological Effects of Invaders. Biological Invasions, 1(1), 3-19.

*Parker, S. (1999). Collaboration on tourism policy making: Environmental and commercial sustainability on Bonaire, NA. Journal of Sustainable Tourism, 7(3-4), 240-259.

Patterson, J. J., Smith, C., \& Bellamy, J. (2013). Understanding enabling capacities for managing the 'wicked problem' of nonpoint source water pollution in catchments: A conceptual framework. Journal of Environmental Management, 128, 441-452. 


\section{References}

Pendleton, L. H., Hoegh-Guldberg, O., Langdon, C., \& Comte, A. (2016). Multiple stressors and ecological complexity require a new approach to coral reef research. Frontiers in Marine Science, 3, 36.

Peretti, J. H. (1998). Nativism and Nature: Rethinking Biological Invasion. Environmental Values, 7(2), $183-192$.

Perry, D., \& Perry, G. (2008). Improving Interactions between Animal Rights Groups and Conservation Biologists. Conservation Biology, 22(1), 27-35.

Petrik, M., \& Raemaekers, S. (2018). The Case for Supporting Small-Scale Fisheries Governance Through ICT. SAIIA. Policy briefing, June 2018.

Pickering, A. (1993). The Mangle of Practice: Agency and emergence in the sociology of science. American journal of sociology 99 , no. 3, 559-589.

Pickrell, J. (2004, June 1). Freed pet fish threaten native species, study says. National Geographic News. Retrieved from https://news.nationalgeographic.com/news/2004/05/0520_040520_aquariumescapees/

Pimentel, D., Zuniga, R., \& Morrison, D. (2005). Update on the environmental and economic costs associated with alien-invasive species in the United States. Ecological Economics, 52(3), 273-288.

Pimento, C., Monaco, E., Barbour, A., \& Silliman, B. R. (2013). Predation on Speared Red Lionfish, Pterois Volitans, By Spotted Moray, Gymnothorax Moringa. Florida Scientist, 76(3-4), 391-394.

Pimm, S. L., Alibhai, S., Bergl, R., Dehgan, A., Giri, C., Jewell, Z., ... Loarie, S. (2015). Emerging technologies to conserve biodiversity. Trends in Ecology \& Evolution, 30(11), 685-696.

Pipino, L. L., Lee, Y. W., \& Wang, R. Y. (2002). Data quality assessment. Communications of the ACM, 45(4ve).

Pocock, M. J. O., Tweddle, J. C., Savage, J., Robinson, L. D., \& Roy, H. E. (2017). The diversity and evolution of ecological and environmental citizen science. PloS One, 12(4), e0172579.

Pomeroy, R. S., Watson, L. M., Parks, J. E., \& Cid, G. A. (2005). How is your MPA doing? A methodology for evaluating the management effectiveness of marine protected areas. Ocean \& Coastal Management, 48(78), 485-502.

Pomeroy, R., \& Douvere, F. (2008). The engagement of stakeholders in the marine spatial planning process. Marine Policy, 32(5), 816-822.

Potts, C., \& Hsi, I. (1997). Abstraction and context in requirements engineering: Toward a synthesis. Annals of Software Engineering, 3, 23-61.

Pritchard, H. \& Gabrys, J. (2016). From citizen sensing to collective monitoring: Working through the perceptive and affective problematics of environmental pollution. GeoHumanities, 2(2), 354-371.

Quinn, N. (2010). Environmental Information Management Systems as Templates for Successful Environmental Decision Support. Proceedings International Environmental Modelling and Software Society, Ottawa, Canada.

Radio Nederland Wereldomroep. (2010). Fighting lionfish necessary for coral [translated from the Dutch Bestrijding lionfish noodzakelijk voor koraal]. Radio Nederland Wereldomroep.

Rasmus, W., D. (2018). What is the difference between Data, Information, Knowledge and Wisdom? Retrieved from Serious Insights website: https://www.seriousinsights.net/what-is-data-information-knowledge-andwisdom/

Rauschmayer, F., van den Hove, S., \& Koetz, T. (2009). Participation in EU Biodiversity Governance: How Far beyond Rhetoric? Environment and Planning C: Government and Policy, 27(1), 42-58.

Reed, M. S., Graves, A., Dandy, N., Posthumus, H., Hubacek, K., Morris, J., ... Stringer, L. C. (2009). Who's in and why? A typology of stakeholder analysis methods for natural resource management. Journal of Environmental Management, 90(5), 1933-1949.

Renkema, T. J. W., \& Berghout, E. W. (1997). Methodologies for information systems investment evaluation at the proposal stage: a comparative review. Information and Software Technology, 39(1), 1-13.

*Reynolds, W.T. and Jones, B.H., 2013. Device and process to measure water clarity and organic content. U.S. Patent 8,368,891.

Ricciardi, A., \& Cohen, J. (2007). The invasiveness of an introduced species does not predict its impact. Biological Invasions, 9(3), 309-315.

Richardson, D. M., Pysek, P., Rejmanek, M., Barbour, M. G., Panetta, F. D., \& West, C. J. (2000). Naturalization and invasion of alien plants: concepts and definitions. Diversity <btml_ent Glyph="@amp;"Ascii="Eamp;"/> Distributions, 6(2), 93-107.

Ricoeur, P. (1973). The Model of the Text: Meaningful Action Considered as a Text. New Literary History, $5(1), 91$.

Rife, A. N., Erisman, B., Sanchez, A., \& Aburto-Oropeza, O. (2013). When good intentions are not enough ... Insights on networks of "paper park" marine protected areas. Conservation Letters, 6(3), 200-212. 


\section{References}

Robbins, P. (2010). Comparing invasive networks: Cultural and political biographies of invasive species. Geographical Review, 94(2), 139-156.

Roberge, J. (2011). What is critical hermeneutics? Thesis Eleven, 106(1), 5-22.

Robertson, A., Garcia, A., Quintana, H., Smith, T., II, B., Reale-Munroe, K., ... Plakas, S. (2013). Invasive Lionfish (Pterois volitans): A Potential Human Health Threat for Ciguatera Fish Poisoning in Tropical Waters. Marine Drugs, 12(1), 88-97.

Rockström, J., Steffen, W., Noone, K., Persson, Å., Chapin, F. S. I., Lambin, E., ... Foley, J. (2009). Planetary Boundaries: Exploring the Safe Operating Space for Humanity. Ecology and Society, 14(2), art32.

Roe, E. M. (1989). Narrative analysis for the policy analyst: A case study of the 1980-1982 medfly controversy in California. Journal of Policy Analysis and Management, 8(2), 251-273.

Rosenthal, E. (2011, July 9). Answer for invasive species: Put it on a plate and eat it. New York. Times. Retrieved from https://www.nytimes.com/2011/07/10/science/earth/10fish.html

Rotman, D., Hammock, J., Preece, J., Hansen, D., Boston, C., Bowser, A., \& He, Y. (2014). Motivations Affecting Initial and Long-Term Participation in Citizen Science Projects in Three Countries. IConference 2014 Proceedings.

Roux, D. J., Rogers, K. H., Biggs, H. C., Ashton, P. J., \& Sergeant, A. (2006). Bridging the Science\&amp;\#8211;Management Divide: Moving from Unidirectional Knowledge Transfer to Knowledge Interfacing and Sharing. Ecology and Society, 11(1), art4.

Rowlands, B. (2009). A social actor understanding of the institutional structures at play in information systems development. Information Technology \& People, 22(1), 51-62.

Roy, H. E., Pocock, M. J. O., Preston, C. D., Roy, D. B., Savage, J., Tweddle, J. C., \& Robinson, L. D. (2012). Understanding citizen science and environmental monitoring: final report on behalf of UK Environmental Observation Framework.

Ruebottom, T. (2013). The microstructures of rhetorical strategy in social entrepreneurship: Building legitimacy through heroes and villains. Journal of Business Venturing, 28(1), 98-116.

Ruiz-Carus, R., Matheson, R. E., Roberts, D. E., \& Whitfield, P. E. (2006). The western Pacific red lionfish, Pterois volitans (Scorpaenidae), in Florida: Evidence for reproduction and parasitism in the first exotic marine fish established in state waters. Biological Conservation, 128(3), 384-390.

Ryan, R. L., Kaplan, R., \& Grese, R. E. (2001). Predicting Volunteer Commitment in Environmental Stewardship Programmes. Journal of Environmental Planning and Management, 44(5), 629-648.

Safina, C. (2012, September 10). Scourge of the lionfish, part 3: the newest fish in the kitchen. New York. Times.

Safina, C. (2012, September 18). Scourge of the lionfish, part 4: from beautiful novelty to marine invader. New York Times. Retrieved from https://coastalscience.noaa.gov/news/scourge-of-the-lionfish-part-4-frombeautiful-novelty-to-marine-invader/

Sagoff, M. (2005). Do Non-Native Species Threaten The Natural Environment? Journal of Agricultural and Environmental Ethics, 18(3), 215-236.

Sala, E., Lubchenco, J., Grorud-Colvert, K., Novelli, C., Roberts, C., \& Sumaila, U. R. (2018). Assessing real progress towards effective ocean protection. Marine Policy, 91, 11-13.

Samkin, G., \& Schneider, A. (2010). Accountability, narrative reporting and legitimation: the case of a New Zealand public benefit entity. Accounting, Auditing \& Accountability Journal, 23(2), 256-289.

Sandberg, J., \& Tsoukas, H. (2011). Grasping the Logic of Practice: Theorizing Through Practical Rationality. Academy of Management Review, 36(2), 338-360.

Saunders, B., Sim, J., Kingstone, T., Baker, S., Waterfield, J., Bartlam, B., ... Jinks, C. (2018). Saturation in qualitative research: exploring its conceptualization and operationalization. Quality \& Quantity, 52(4), 1893-1907.

Schäfer, T., \& Kieslinger, B. (2016). Supporting emerging forms of citizen science: A plea for diversity, creativity and social innovation. Journal of Science Communication, 15(2), Y02.

Scharpf, F., (1999). Governing in Europe: effective and democratic? Oxford University Press, Oxford.

Schatzki, T. R. (2012). A primer on practices: Theory and research. In Practice-based education 13-26. Brill Sense.

Sche, S., Johnson, A., van Beukering, P., \& Wolfs, E. (2012). The fishery value of coral reefs in Bonaire. IVM Institute for Enironmental Studies, Amsterdam, The Netherlands.

Schep, S., van Beukering, P., Brander, L., \& Wolfs, E. (2012). The Tourism value of nature on Bonaire: Using choice modelling and value mapping. IVM Institute for Environmental Studies. 


\section{References}

Shirk, J., Ballard, H., Wilderman, C., Phillips, T., Wiggins, A., Jordan, R., ... \& Bonney, R. (2012). Public participation in scientific research: a framework for deliberate design. Ecology and society, 17(2).

Schofield, J. W. (2002). Increasing the Generalizability of Qualitative Research. In The Qualitative Researcher's Companion, 171-203.

Schofield, P. J., Morris, J. A., Langston, J. N., \& Fuller, P. L. (2015). Pterois volitans/miles. USGS Nonindigenous Aquatic Species Database. Retrieved from https://nas.er.usgs.gov/queries/FactSheet.aspx?speciesID=963

Schofield, P. (2009). Geographic extent and chronology of the invasion of non-native lionfish (Pterois volitans [Linnaeus 1758] and P. miles [Bennett 1828]) in the Western North Atlantic and Caribbean Sea. Aquatic Invasions, 4(3), 473-479.

Schofield, P. (2010). Update on geographic spread of invasive lionfishes (Pterois volitans [Linnaeus, 1758] and P. miles [Bennett, 1828]) in the Western North Atlantic Ocean, Caribbean Sea and Gulf of Mexico. Aquatic Invasions, 5(Supplement 1), S117-S122.

Schofield, P. J., Morris Jr, J. A., Langston, J. N., \& Fuller, P. L. (2009). Pterois volitans/miles. USGS Nonindigenous Aquatic Species Database, Gainesville, Florida.

Schultz, E. T. (1986). Pterois volitans and Pterois miles: Two Valid Species. Copeia, 1986(3), 686.

Schultze, U., \& Avital, M. (2011). Designing interviews to generate rich data for information systems research. Information and Organization, 21(1), 1-16.

Schüttler, E., Rozzi, R., \& Jax, K. (2011). Towards a societal discourse on invasive species management: A case study of public perceptions of mink and beavers in Cape Horn. Journal for Nature Conservation, 19(3), 175-184.

Schwartz-Shea, P., \& Yanow, D. (2013). Interpretive research design: Concepts and processes. Routledge.

Scobie, M. (2016). Policy coherence in climate governance in Caribbean Small Island Developing States. Environmental Science \& Policy, 58, 16-28.

Scyphers, S. B., Powers, S. P., Akins, J. L., Drymon, J. M., Martin, C. W., Schobernd, Z. H., ... Switzer, T. S. (2015). The Role of Citizens in Detecting and Responding to a Rapid Marine Invasion. Conservation Letters, 8(4), 242-250.

Selig, E. R., \& Bruno, J. F. (2010). A Global Analysis of the Effectiveness of Marine Protected Areas in Preventing Coral Loss. PLoS ONE, 5(2), e9278.

Semmens, B., Buhle, E., Salomon, A., \& Pattengill-Semmens, C. (2004). A hotspot of non-native marine fishes: evidence for the aquarium trade as an invasion pathway. Marine Ecology Progress Series, 266, 239-244.

Sharp, H., Finkelstein, A., \& Galal, G. (1999). Stakeholder identification in the requirements engineering process. Proceedings. Tenth International Workshop on Database and Expert Systems Applications. DEXA 99, 387-391.

Shine, R., \& Doody, J. S. (2011). Invasive species control: understanding conflicts between researchers and the general community. Frontiers in Ecology and the Environment, 9(7), 400-406.

Shirk, J., Ballard, H., Wilderman, C., Phillips, T., Wiggins, A., Jordan, R., .. Krasny, M. (2012). Public participation in scientific research: a framework for deliberate design. Ecology and Society, 17(2).

Shogren, E. (2013, April 17). Lionfish attacking Atlantic ocean like a living oil spill. WLRN. Retrieved from https://www.wlrn.org/post/invasive-species-hungry-lionfish-havent-gone-away

Shove, E., Pantzar, M., \& Watson, M. (2012). The Dynamics of Social Practice: Everyday Life and How it Changes.

Sian Ka'an Biosphere Reserve. (2010). Pez león, red lionfish (Pterois sp). A new threat for the Mesoamerican Reef [Title translated from the Spanish "Una nueva amenaza para el arrecife mesoamericano"]. Retrieved from http://siankaantours.com/page/2/

Silk, R. (2012, June 30). FDA wavers on ciguatera warning. Florida Keys News. Retrieved from https://keysnews.com/node/40782

Silvertown, J. (2009). A new dawn for citizen science. Trends in Ecology \& Evolution, 24(9), 467-471.

Simberloff, D. (2003). Confronting introduced species: a form of xenophobia? Biological Invasions, 5(3), $179-192$.

Slijkerman, D.M.E., van der Geest, M. \& Debrot, A.O. (2019). Nexus interventions for small tropical islands: case study Bonaire: Water. Wageningen Marine Research.

Slijkerman, D.M.E., and S. Bol. (2018). UV filter pollution Bonaire by tourism: Lac Bay monitoring and survey results 2017. No. C023/18. Wageningen Marine Research.

*Slijkerman, D.M.E., Smith, S., Koelemij, E. and Rippen, A., 2012. Water quality monitoring Bonaire. Identification of indicators, methods and locations. IMARES report $C, 27$.

*Slijkerman, D.M.E., de León, R. and de Vries, P., 2014. A baseline water quality assessment of the coastal reefs of Bonaire, Southern Caribbean. Marine pollution bulletin, 86(1-2), 523-529. 


\section{References}

Slim, H. (2002). By What Authority? The Legitimacy and Accountability of Non-governmental Organisations. The International Council on Human Rights Policy International Meeting on Global Trends and Human Rights. Retrieved from http://www.gdrc.org/ngo/accountability/by-what-authority.html

Sommerville, I., Rodden, T., Sawyer, P., Bentley, R., \& Twidale, M. (n.d.). Integrating ethnography into the requirements engineering process. (1993) Proceedings of the IEEE International Symposium on Requirements Engineering, 165-173.

Soule, M. (1985). What Is Conservation Biology? BioScience, 35(11), 727-734.

Soule, M. E. (1990). The Onslaught of Alien Species, and Other Challenges in the Coming Decades *. Conservation Biology, 4(3), 233-240.

Spalburg, J. (2014, January 9). Lionfish may have natural predator in the Caribbean. Saba-Nens. Retrieved from http://www.saba-news.com/lionfish-may-natural-predator-caribbean/

Spalding, M. D., Fox, H. E., Allen, G. R., Davidson, N., Ferdaña, Z. A., Finlayson, M., ... Robertson, J. (2007). Marine Ecoregions of the World: A Bioregionalization of Coastal and Shelf Areas. BioScience, 57(7), 573-583.

Spradley, J. P. (1979). The ethnographic interview. Holt, Rinehart and Winston.USA.

Steenweg, R., Hebblewhite, M., Kays, R., Ahumada, J., Fisher, J. T., Burton, C., ... Rich, L. N. (2017). Scaling-up camera traps: monitoring the planet's biodiversity with networks of remote sensors. Frontiers in Ecology and the Environment, 15(1), 26-34.

Steneck, R.S., Arnold, S.N. \& DeBey, H. (2009). Status and Trends of Bonaire's Coral Reefs. Repprt for STINAPA. University of Maine, School of Marine Sciences, USA.

Stevens, M., Vitos, M., Altenbuchner, J., Conquest, G., Lewis, J., \& Haklay, M. (2014). Taking participatory citizen science to extremes. IEEE Pervasive Computing, 13(2), 20-29.

Stojanovic, T., Green, D. R., \& Lymbery, G. (2010). Approaches to knowledge sharing and capacity building: The role of local information systems in marine and coastal management. Ocean \& Coastal Management, 53(12), 805-815.

Stromberg, J. C., Chew, M. K., Nagler, P. L., \& Glenn, E. P. (2009). Changing Perceptions of Change: The Role of Scientists in Tamarix and River Management. Restoration Ecology, 17(2), 177-186.

Subramaniam, B. (2001). The Aliens Have Landed! Meridians, 2(1), 26-40.

Suchman, M. C. (1995). Managing Legitimacy: Strategic and Institutional Approaches. The Academy of Management Review, 20(3), 571.

Sutherland, W. J., Clout, M., Côté, I. M., Daszak, P., Depledge, M. H., Fellman, L., .. Watkinson, A. R. (2010). A horizon scan of global conservation issues for 2010. Trends in Ecology \& Evolution, 25(1), 1-7.

Szaro, R. C., Berc, J., Cameron, S., Cordle, S., Crosby, M., Martin, L., ... Ruark, G. (1998). The ecosystem approach: science and information management issues, gaps and needs. Landscape and Urban Planning, 40(1-3), 89101.

Talbot, R. (2014). Is a ban on lionfish in Florida justified? Coral Magazine, 11(4), 9-12.

Theobald, E. J., Ettinger, A. K., Burgess, H. K., DeBey, L. B., Schmidt, N. R., Froehlich, H. E., ... Harsch, M. A. (2015). Global change and local solutions: Tapping the unrealized potential of citizen science for biodiversity research. Biological Conservation, 181, 236-244.

Thiel, M., Penna-Díaz, M. A., Luna-Jorquera, G., Salas, S., Sellanes, J., \& Stotz, W. (2014). Citizen scientists and marine research: volunteer participants, their contributions, and projection for the future. Oceanography and Marine Biology: An Annual Review, 52, 257-314.

Thornhill, D. J. (2012). Ecological impacts and practices of the coral reef wildlife trade. Defenders of Wildlife, (December 2012), 1-179. Retrieved from http://doczine.com/bigdata/1/1367018257_849680fd85/ecologicalimpacts-and-practices-of-the-coral-reef-wildlife-trade.pdf

Tim, Y., Pan, S. L., Bahri, S., \& Fauzi, A. (2018). Digitally enabled affordances for community-driven environmental movement in rural Malaysia. Information Systems Journal, 28(1), 48-75.

Tobi, H., \& Kampen, J. K. (2018). Research design: the methodology for interdisciplinary research framework. Quality \& Quantity, 52(3), 1209-1225.

Today's Xtra Media. (2019, July 4). Nature Foundation warns against consumption lionfish. Today's Xtra Media. Retrieved from http://www.todaysxm.com/nature-foundation-warns-against-consumption-lionfish/

Tolvanen, H., \& Kalliola, R. (2008). A structured approach to geographical information in coastal research and management. Ocean \& Coastal Management, 51(6), 485-494. 


\section{References}

Toonen, H. M., \& Bush, S. R. (2018). The digital frontiers of fisheries governance: fish attraction devices, drones and satellites. Journal of Environmental Policy \& Planning, 1-13.

Trégarot, E., Fumaroli, M., Arqué, A., Hellio, C., \& Maréchal, J.-P. (2015). First records of the red lionfish (Pterois volitans) in Martinique, French West Indies: monitoring invasion status through visual surveys. Marine Biodiversity Records, 8 .

Tuomi, I. (1999). Data is more than knowledge: implications of the reversed knowledge hierarchy for knowledge management and organizational memory. Proceedings of the 32 nd Annual Hawaii International Conference on Systems Sciences. 1999. HICSS-32. Abstracts and CD-ROM of Full Papers, 12.

Turnhout, E. (2018). The Politics of Environmental Knowledge. Conservation and Society, 16(3), 363.

Turnhout, E., \& Boonman-Berson, S. (2011). Databases, Scaling Practices, and the Globalization of Biodiversity. Ecology and Society, 16(1), art35.

Turnhout, E., Hisschemöller, M., \& Eijsackers, H. (2008). Science in Wadden Sea policy: from accommodation to advocacy. Environmental Science \& Policy, 11(3), 227-239.

Turnhout, E., Stuiver, M., Klostermann, J., Harms, B., \& Leeuwis, C. (2013). New roles of science in society: different repertoires of knowledge brokering. Science and Public Policy, 40(3), 354-365.

Turrini, T., Dörler, D., Richter, A., Heigl, F., \& Bonn, A. (2018). The threefold potential of environmental citizen science-Generating knowledge, creating learning opportunities and enabling civic participation. Biological Conservation, 225, 176-186.

UNCED. (1992). Agenda 21: Information for Decision Making. In International Documents on Corporate Responsibility.

UNEP-WCM. (2008). National and Regional Networks of Marine Protected Areas: A Review of Progress. In UNEPWCM.

UNEP-WCMC \& IUCN, (2019). Marine Protected Planet, March 2019. Cambridge: UNEP-WCMC and IUCN.

Valdivia, A., Bruno, J. F., Cox, C. E., Hackerott, S., \& Green, S. J. (2014). Re-examining the relationship between invasive lionfish and native grouper in the Caribbean. Peer], 2, e348.

Valéry, L., Fritz, H., Lefeuvre, J.-C., \& Simberloff, D. (2008). In search of a real definition of the biological invasion phenomenon itself. Biological Invasions, 10(8), 1345-1351.

Valusek, J. R., \& Fryback, D. G. (1985). Information requirements determination: obstacles within, among and between participants. Proceedings of the Twenty-First Annual Conference on Computer Personnel Research - SIGCPR '85, 103-111.

Van de Kerkhof, S., Schep, S. W., van Beukering, P., Brander, L., \& Wolfs, E. (2014). The Tourism Value of Nature on Saba. Netherlands Ministry of Economic Affairs Report, Amsterdam.

van der Hel, S. (2016). New science for global sustainability? The institutionalisation of knowledge co-production in Future Earth. Environmental Science \& Policy, 61, 165-175.

van der Wal, R., \& Arts, K. (2015). Digital conservation: An introduction. Ambio, 44(S4), 517-521.

*van Kekem, A. J., Roest, C. W. J., \& van der Salm, C. (2006). Critical review of the proposed irrigation and effluent standards for Bonaire. Alterra.

van Lamsweerde, A. (2000). Requirements engineering in the year 00. Proceedings of the 22nd International Conference on Software Engineering - ICSE '00, 5-19.

van Tatenhove, J. P. M. (2011). Integrated marine governance: Questions of Legitimacy. Maritime Studies, 10(1), 87113.

van Wyk, E., Roux, D. J., Drackner, M., \& McCool, S. F. (2008). The Impact of Scientific Information on Ecosystem Management: Making Sense of the Contextual Gap Between Information Providers and Decision Makers. Environmental Management, 41(5), 779-791.

Verweij, P., Hennekes, S. M., Meulebrouk, B., Gijzen, S., Dijkman, E., Meesters, H., \& Vermaas, T. (2013). Dutch Caribbean Biodiversity Database. Retrieved from Online website: http://www.dcbd.nl/

Vidgen, R. (1997). Stakeholders, soft systems and technology: separation and mediation in the analysis of information system requirements. Information Systems Journal, 7(1), 21-46.

Viller, S., \& Sommerville, I. (n.d.). Social analysis in the requirements engineering process: from ethnography to method. Proceedings IEEE International Symposium on Requirements Engineering (Cat. No.PR00188), 6-13.

Vitousek, P. M., D’Antonio, C. M., Loope, L. L., \& Westbrooks, R. (1996). Biological invasions as global environmental change. American Scientist, 84(5), 468-478. Retrieved from http://ddr.nal.usda.gov/bitstream/10113/61/1/IND20537951.pdf 


\section{References}

Volk, C. J., Lucero, Y., \& Barnas, K. (2014). Why is data sharing in collaborative natural resource efforts so hard and what can we do to improve it? Environmental Management, 53(5), 883-893.

Voultsiadou, E., Gerovasileiou, V., Vandepitte, L., Ganias, K. \& Arvanitidis, C. (2017). Aristotle's scientific contributions to the classification, nomenclature and distribution of marine organisms. Mediterranean Marine Science, 18(3), 468-478.

Wagner, C. S., Whetsell, T. A., \& Leydesdorff, L. (2017). Growth of international collaboration in science: revisiting six specialties. Scientometrics, 110(3), 1633-1652.

Wagner, D. E., Kramer, P., \& Van Woesik, R. (2010). Species composition, habitat, and water quality influence coral bleaching in southern Florida. Marine Ecology Progress Series, 408, 65-78.

Walsham, G. (2006). Doing interpretive research. European Journal of Information Systems, 15(3), 320-330.

Wand, Y., \& Wang, R. Y. (1996). Anchoring data quality dimensions in ontological foundations. Communications of the ACM, 39(11), 86-95.

Wang, R. Y. (1998). A product perspective on total data quality management. Communications of the ACM, 41(2), 5865.

Wang, R. Y., \& Strong, D. M. (1996). Beyond Accuracy: What Data Quality Means to Data Consumers. Journal of Management Information Systems, 12(4), 5-33.

Wang, R. Y., Kon, H. B., \& Madnick, S. E. (1993.). Data quality requirements analysis and modeling. Proceedings of IEEE 9th International Conference on Data Engineering, 670-677.

Wang, R. Y., Storey, V. C., \& Firth, C. P. (1995). A framework for analysis of data quality research. IEEE Transactions on Knowledge and Data Engineering, 7(4), 623-640.

Warren, C. R. (2007). Perspectives on the ‘alien’ versus ‘native' species debate: a critique of concepts, language and practice. Progress in Human Geography, 31(4), 427-446.

Weeks, P., \& Packard, J. (2009). Feral Hogs: Invasive Species or Nature's Bounty? Human Organization, 68(3), 280292.

Weingart, P. (1999). Scientific expertise and political accountability: paradoxes of science in politics. Science and Public Policy, 26(3), 151-161.

Weiss, C. H. (1979). The Many Meanings of Research Utilization. Public Administration Review, 39(5), 426.

Welp, M., de la Vega-Leinert, A., Stoll-Kleemann, S., \& Jaeger, C. C. (2006). Science-based stakeholder dialogues: Theories and tools. Global Environmental Change, 16(2), 170-181.

Wetherell, M., Taylor, S., \& Yates, S. J. (2001). Discourse as data: a guide for analysis. London: SAGE Publications Ltd.

Wheeler, P., \& Peterson, J. (2010). Exploring Stakeholder Views Regarding Spatial Information and Enabling Technology Use for ICZM: A Case Study from Victoria, Australia. Coastal Management, 38(1), 1-21.

Whitfield, P. E., Hare, J. A., David, A. W., Harter, S. L., Muñoz, R. C., \& Addison, C. M. (2006). Abundance estimates of the Indo-Pacific lionfish Pterois volitans/miles complex in the Western North Atlantic. Biological Invasions, 9(1), 53-64.

Whitfield, P., Gardner, T., Vives, S., Gilligan, M., Courtenay Ray, W., Ray, G., \& Hare, J. (2002). Biological invasion of the Indo-Pacific lionfish Pterois volitans along the Atlantic coast of North America. Marine Ecology Progress Series, 235, 289-297.

Wiggins, A., \& Crowston, K. (2011). From Conservation to Crowdsourcing: A Typology of Citizen Science. 201144 th Hawaii International Conference on System Sciences, 1-10.

Wilcove, D. S., Rothstein, D., Dubow, J., Phillips, A., \& Losos, E. (1998). Quantifying Threats to Imperiled Species in the United States. BioScience, 48(8), 607-615.

Wilcox, C. L., \& Hixon, M. A. (2015). False positive tests for ciguatera may derail efforts to control invasive lionfish. Environmental Biology of Fishes, 98(3), 961-969.

Wilderman, C. C., McEver, C., Bonney, R., \& Dickinson, J. (2007). Models of community science: design lessons from the field. Citizen Science Toolkit Conference, C. McEver, R. Bonney, J. Dickinson, S. Kelling, K. Rosenberg, and JL Shirk, Eds., Cornell Laboratory of Ornithology, Ithaca, NY.

Willcocks, L., \& Mingers, J. (2004). Social Theory and Philosophy for Information Systems. John Wiley \& Sons Ltd.

Willette, D. A., Chalifour, J., Debrot, A. O. D., Engel, M. S., Miller, J., Oxenford, H. A., .. Védie, F. (2014). Continued expansion of the trans-Atlantic invasive marine angiosperm Halophila stipulacea in the Eastern Caribbean. Aquatic Botany, 112, 98-102. 


\section{References}

Wong, W. Y. (2002). The scientific and media discourse of biological invasion. Providence, Rhode Island, USA: Brown University.

Wood, L. J. (2007). MPA Global: A Database of the World's Marine Protected Areas. Sra Around Us Project. UNEP-WCMC $\& \mathrm{WWF}$.

Wood, L. J., Fish, L., Laughren, J., \& Pauly, D. (2008). Assessing progress towards global marine protection targets: shortfalls in information and action. Oryx, 42(03).

WPBT. (2011). Changing seas, alien invaders. Retrieved from https://video.wpbt2.org/video/changing-seas-alieninvaders/

Wu, J., \& Loucks, O. L. (1995). From Balance of Nature to Hierarchical Patch Dynamics: A Paradigm Shift in Ecology. The Quarterly Review of Biology, 70(4), 439-466.

Yin, R. K. (2009). Case study research: Design and methods (4th Ed.). The Canadian Journal of Action Research, 14(1), 69-71. Retrieved from http://journals.nipissingu.ca/index.php/cjar/article/view/73

Young, A. M., \& Larson, B. M. H. (2011). Clarifying debates in invasion biology: A survey of invasion biologists. Environmental Research, 111(7), 893-898.

Zinken, J. (2007). Discourse metaphors: The link between figurative language and habitual analogies. Cognitive Linguistics, 18(3). 


\section{Appendices}

\section{Appendix 1: Interview schedule (Chapter 3)}

\section{Introduction:}

Introduced myself and my project; asked the informant about his/her background.

Working activities.

Q: Would you please describe your function within [organization]?

Probing: Could you tell me more about the different activities you perform(ed) [there/then]?

What is your role regarding [issue/MPA/dataset]?

How long have you worked [there]?

\section{Data availability}

Q: What is your opinion about data availability regarding [species/habitat/issue]?

Probing: Talking about [MPA/monitoring], do you have an overview of all the data pertaining to [MPA/species/issue]?

Are you familiar with all research conducted?

You mentioned that data availability on [issue/species] was [bad], but you said that a lot of monitoring data exists on that [issue/ species], what do you mean then with "availability"?

\section{Data accessibility}

Q: In your opinion, how accessible are the data from [organization]?

Probing: Do you know the procedure to request access to [dataset/database]?

Could you please give me an example of how often [they] request information from you, is it on a monthly basis or more frequently or less frequently?

You said that accessibility had to [be improved], could you elaborate?

\section{Data quality}

Q: So you are familiar with [data], in your opinion how is the quality of this dataset?

Probing: What's important for you so that you can judge that a dataset is of high quality?

Any more components of data quality that you can think of?

\section{Data consistency}

Q: If we talk about the consistency of the data, what can you tell me about [dataset/monitoring data on species/habitat/ survey]?

Probing: You said that the consistency of the data was [not good], could you please elaborate on that?

You were talking about [monitoring data], that it has been consistently good. What do you think makes this monitoring so good? 


\section{Appendices}

\section{Data security}

Q: I would like to know what you think about data security. How do you define data security and how secure do you think your own data is?

Probing: What is your opinion about data security within [organization]?

What measures are taken to ensure that data is secure?

\section{Data use and general (self) assessment and finalizing the interview}

Q: Could you describe how data on [species/issue] has been used in [organization/MPA]? Probing: Can you give an example?

In your opinion, what are the strengths and weaknesses of the way data is produced and handled in [MPA/organization]?

How would you assess the way data is produced and handled in your organization? Probing: for example, on a scale from 1 to 10?

Is there anything else that would you like to add about the topics we talked about? 


\section{Appendix 2: Overview of informant groups, MPAs selected and interviews conducted in 2010-2011 (Chapter 3)}

\begin{tabular}{|c|c|c|c|}
\hline Informant & Definition & Informants associated to MPAs (MPA, cour & ry) \\
\hline \multirow[t]{5}{*}{ Academics } & \multirow{5}{*}{$\begin{array}{l}\text { Scientists (from the natural and } \\
\text { social sciences), employed by } \\
\text { academic institutions, who } \\
\text { conducted research or } \\
\text { monitoring activities in or near } \\
\text { the MPA on a regular basis or } \\
\text { had done so in the recent past. }\end{array}$} & $\begin{array}{l}\text { Lake Superior National Marine } \\
\text { Conservation Area, Canada }\end{array}$ & \multirow{5}{*}{$\begin{array}{l}\text { Interviews } \\
\qquad \mathrm{n}=7\end{array}$} \\
\hline & & $\begin{array}{c}\text { Schiermonnikoog National Park, } \\
\text { Netherlands }\end{array}$ & \\
\hline & & $\begin{array}{l}\text { Bonaire National Marine Park, Netherlands } \\
\qquad \text { Antilles }^{a}\end{array}$ & \\
\hline & & $\begin{array}{c}\text { Sian Ka'an Reefs Biosphere Reserve, } \\
\text { Mexico }\end{array}$ & \\
\hline & & Galapagos Marine Reserve, Ecuador & \\
\hline \multirow{9}{*}{$\begin{array}{l}\text { MPA } \\
\text { management } \\
\text { staff }\end{array}$} & \multirow{9}{*}{$\begin{array}{l}\text { Representatives of the MPA } \\
\text { management entity who } \\
\text { fulfilled management functions, } \\
\text { including decision-making and } \\
\text { (administration of) } \\
\text { research/monitoring activities. }\end{array}$} & $\begin{array}{c}\text { Schiermonnikoog National Park, } \\
\text { Netherlands }\end{array}$ & \multirow[t]{9}{*}{$n=13$} \\
\hline & & Great Barrier Reef Marine Park, Australia & \\
\hline & & $\begin{array}{c}\text { Sian Ka'an Reefs Biosphere Reserve, } \\
\text { Mexico }\end{array}$ & \\
\hline & & Cozumel Reefs National Park, Mexico & \\
\hline & & Galapagos Marine Reserve, Ecuador & \\
\hline & & $\begin{array}{l}\text { Bonaire National Marine Park, Netherlands } \\
\qquad \text { Antilles }^{a}\end{array}$ & \\
\hline & & $\begin{array}{l}\text { Musquash Estuary Marine Protected Area, } \\
\text { Canada }\end{array}$ & \\
\hline & & $\begin{array}{l}\text { Florida Keys National Marine Sanctuary, } \\
\text { USA }\end{array}$ & \\
\hline & & $\begin{array}{l}\text { St. Eustatius Marine Park, } \\
\text { Kingdom of the Netherlands }\end{array}$ & \\
\hline \multirow[t]{4}{*}{$\begin{array}{l}\text { Government } \\
\text { officials }\end{array}$} & \multirow{4}{*}{$\begin{array}{l}\text { Representatives of government } \\
\text { agencies who were either } \\
\text { directly involved in policy- } \\
\text { making or in (administration of) } \\
\text { research/monitoring activities } \\
\text { in the MPA. }\end{array}$} & $\begin{array}{c}\text { Schiermonnikoog National Park, } \\
\text { Netherlands }\end{array}$ & \multirow[t]{4}{*}{$n=8$} \\
\hline & & Great Barrier Reef Marine Park, Australia & \\
\hline & & $\begin{array}{l}\text { Florida Keys National Marine Sanctuary, } \\
\text { USA }\end{array}$ & \\
\hline & & Kingdom of the Netherlands & \\
\hline \multirow{5}{*}{$\begin{array}{l}\text { eNGO staff } \\
\text { (environmental } \\
\text { non- } \\
\text { governmental } \\
\text { organization) }\end{array}$} & \multirow{5}{*}{$\begin{array}{l}\text { Representatives of } \\
\text { environmentalist groups directly } \\
\text { involved in data production to } \\
\text { inform MPA management, or } \\
\text { who had worked closely with } \\
\text { MPA management during a } \\
\text { recent planning process. }\end{array}$} & National MPA System, Indonesia & \multirow{5}{*}{$\begin{array}{l}\text { Total } \\
\text { interviewed } \\
n=35\end{array}$} \\
\hline & & Great Barrier Reef Marine Park, Australia & \\
\hline & & $\begin{array}{c}\text { Florida Keys National Marine Sanctuary, } \\
\text { USA }\end{array}$ & \\
\hline & & $\begin{array}{c}\text { Sian Ka'an Reefs Biosphere Reserve, } \\
\text { Mexico }\end{array}$ & \\
\hline & & Galapagos Marine Reserve, Ecuador & \\
\hline
\end{tabular}




\section{Appendix 3: Interviews with MPA stakeholders conducted in 2013 (Chapter 4)}

\begin{tabular}{|c|c|c|}
\hline $\begin{array}{c}\text { MPA } \\
\text { location }\end{array}$ & Affiliation, profession & $\begin{array}{l}\text { Interview mode } \\
\text { (Tel.: T, } \\
\text { Face-to-face: } \mathrm{F} \text {, } \\
\text { Email: E) }\end{array}$ \\
\hline \multirow[t]{8}{*}{ Florida Keys } & Commercial fishing (aquarium industry) & $\mathrm{T}$ \\
\hline & Recreational fisher (angler) & $\mathrm{T}$ \\
\hline & Artificial reef industry / recreational fishing & $\mathrm{T}$ \\
\hline & MPA staff (NOAA) & $\mathrm{T}$ \\
\hline & REEF (NGO) & $\mathrm{T}$ \\
\hline & Marine Science lecturer \& recreational diver & $\mathrm{T}$ \\
\hline & The Nature Conservancy (NGO) & $\mathrm{E}$ \\
\hline & Florida Fish and Wildlife Conservation Commission (FWCC) & $\mathrm{E}$ \\
\hline \multirow[t]{3}{*}{ Sian Ka'an } & Commercial fishing (president fishing cooperative) & $\mathrm{T}$ \\
\hline & MPA staff (CONANP) & $\mathrm{T}, \mathrm{E}$ \\
\hline & Recreational fishing industry & $\mathrm{E}$ \\
\hline \multirow[t]{10}{*}{ Bonaire } & $\begin{array}{l}\text { Dive operators (managers } \& \text { instructors) } \\
\text { Total: } 15 \text { individuals from } 12 \text { different dive shops }\end{array}$ & $\mathrm{F}$ \\
\hline & Scientist & $\mathrm{F}$ \\
\hline & MPA staff (STINAPA) Total: 3 individuals & $\mathrm{F}$ \\
\hline & Local government, senior official & $\mathrm{F}$ \\
\hline & Local government, junior official & $\mathrm{F}$ \\
\hline & Local government (Dutch Caribbean level), senior official & $\mathrm{F}$ \\
\hline & Dutch Caribbean Nature Alliance (NGO) & $\mathrm{F}$ \\
\hline & Educator (teaching scuba at schools) & $\mathrm{F}$ \\
\hline & $\begin{array}{l}\text { Retiree, recreational diver } \\
\text { Total: } 7 \text { individuals }\end{array}$ & $\mathrm{F}$ \\
\hline & Retiree, recreational diver & $\mathrm{E}$ \\
\hline \multirow[t]{6}{*}{ Curaçao } & $\begin{array}{l}\text { Dive operators (managers } \& \text { instructors) } \\
\text { Total: } 8 \text { individuals from } 6 \text { different dive shops }\end{array}$ & $\mathrm{F}$ \\
\hline & Restaurant owner, dive instructor & $\mathrm{F}$ \\
\hline & Local government, senior official & $\mathrm{F}$ \\
\hline & Coast guard, senior official & $\mathrm{F}$ \\
\hline & Coast guard, junior official & $\mathrm{F}$ \\
\hline & Scientist CARMABI & $\mathrm{F}$ \\
\hline \multirow[t]{2}{*}{ Saba } & $\begin{array}{l}\text { Dive operators (managers } \& \text { instructors) } \\
\text { Total: } 4 \text { individuals from } 3 \text { different dive shops }\end{array}$ & $\mathrm{F}$ \\
\hline & MPA staff (Saba Conservation Foundation) & $\mathrm{F}$ \\
\hline \multirow[t]{3}{*}{ St. Eustatius } & MPA staff (STENAPA) Total: 3 individuals & $\mathrm{F}$ \\
\hline & $\begin{array}{l}\text { Dive operators } \\
\text { Total: } 4 \text { individuals from } 2 \text { different dive shops }\end{array}$ & $\mathrm{F}$ \\
\hline & Commercial fishing (president fisheries association) & $\mathrm{F}$ \\
\hline \multirow[t]{2}{*}{ St. Maarten } & MPA staff (The Nature Foundation) & $\mathrm{F}$ \\
\hline & $\begin{array}{l}\text { Dive operators (managers } \& \text { instructors) } \\
\text { Total: } 10 \text { individuals from } 6 \text { different dive shops }\end{array}$ & $\mathrm{F}$ \\
\hline \multicolumn{3}{|c|}{$\begin{array}{l}\text { Total interviewees: } 80 \\
\text { Total interviews: } 52\end{array}$} \\
\hline
\end{tabular}




\section{Appendix 4: Interview schedule (Chapter 4)}

Topics were adapted to the individual respondent according to his/her function or profession in the MPA. By asking respondents to provide their "views", "perceptions" or "perspectives" about lionfish (LF) presence in MPA's waters - and about LF management in their MPAs- the meanings they attach to LF could be explored broadly. Probing questions attempted to elicit more specific responses.

\section{Introduction}

Q: I would like to start by asking if you could describe your daily activities related to (MPA). Q: In your daily life, how often do you have to do in any way with LF? For example, during work or recreational activities.

\section{Origin}

Q: How/when did you hear about the LF for the first time? Probing: Please describe the time when the first LF were sighted in (MPA). What type of information did you receive and from which source?

\section{Spread}

Q: In your view, are LF numbers (in MPA) increasing, decreasing or stable? Probing: How often do you go in the water? When you are in the water, how often do you see LF? When you see LF, what do you do and why? Q: Is LF monitoring carried out in (MPA)?

\section{Impact}

Q: I would like to hear your perspectives/perceptions/views about LF (in general and specifically in MPA). Q: What is your perception about the LF in terms of affecting your activities, your business, your health? Probing: I would like to have a general idea of what's going on at (MPA) regarding LF; how do you and your colleagues interact with LF; you say that personally you do/not encounter LF and/but you know that they're having an impact, could you elaborate? Q: Have you (or someone you know) been stung by a LF? How does it feel like? How did it happen?

\section{Control}

Q: How is LF managed in (MPA)? Probing: Who participates and how? What do you think about the way LF is managed in (MPA)? Q: Have you ever captured a LF? Why/not?

Probing: Who are the main groups involved in management? Do you need a permit to capture LF? Where is LF capture allowed in (MPA)? With what kind of gear? Is there sustained interest in LF tournaments/derbies? In LF workshops/trainings (required to apply for a capture permit in Florida Keys)?

Q: What can you tell me about the commercialization of LF? Probing: Have you eaten LF? Do you like it? How does it taste like? Who is harvesting LF commercially? Who is not, and why? How many LF are harvested for consumption? What do you think about this development? What can you tell me about ciguatera risk in (MPA)? 


\section{Appendices}

\section{Appendix 5: Interview schedule (Chapter 5)}

1. Demographic information: Name, Gender, Age, Nationality, Occupation

2. Are you scuba certified? What is your diving proficiency level? High, Medium, Low

3. When you dive, do you hunt/cull/remove lionfish? Yes/No/Sometimes

4. Since when? (approximate date)

5. What are your main motivations to engage/not engage in lionfish removals? Please elaborate; provide background; with whom do you hunt?

6. Do you collect and / or report data on lionfish? If so, what type of data? Since when?

7. To whom do/did you report/to? How? Have you ever reported to any lionfish database?

8. What are your main motivations to report/not report?

9. Would you be willing to report your data if a new initiative (i.e. digital map) would be implemented? Why/not?

You mentioned participating in the $\mathrm{PhD}$ research project. What are your tasks and your main motivations to participate?

10. Do you use the Internet for your work? Privately?

11. If you do, do you communicate about lionfish through this means? Why/why not?

12. If so, what kind of data/information do you share about lionfish? With whom? What tools do you use? Why this tool? 


\section{Appendix 6: Primary and secondary data sources (Chapter 6)}

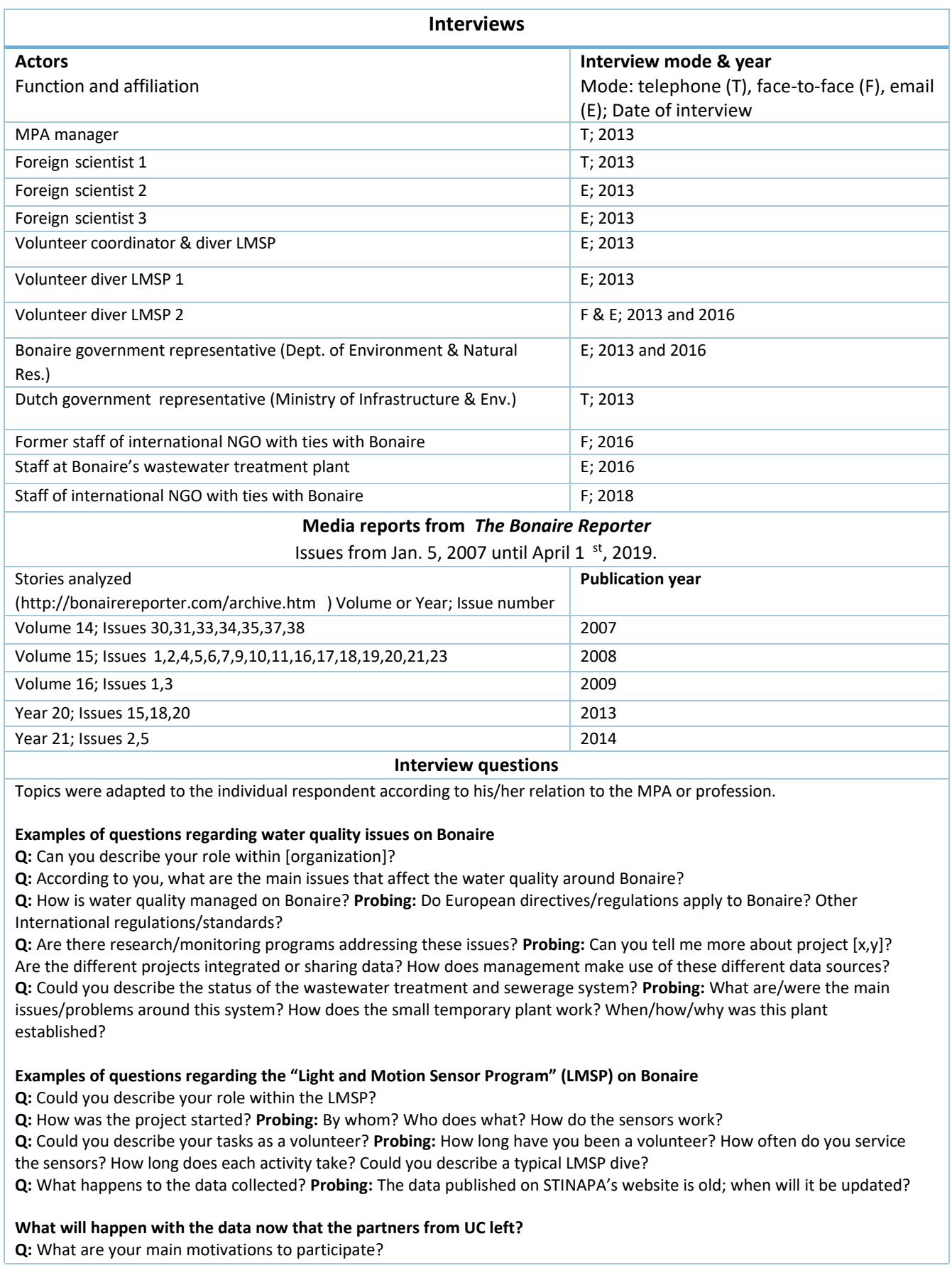


Appendices 


\section{Summary}

Coral reef ecosystems, which comprise the highest biodiversity of any ecosystem on Earth, are among the most threatened ecosystems in the world and are particularly vulnerable to the effects of global environmental change. As providers of livelihoods for approximately 500 million people worldwide, these ecosystems are regarded as an urgent conservation priority internationally. The term digital conservation has been coined to denote the rapid spread and impacts of innovations in Information and Communication Technologies (ICTs) on the science and practice of nature conservation. This $\mathrm{PhD}$ thesis sets out to investigate the opportunities and challenges brought about by digital conservation in governing coral reefs located in Caribbean marine protected areas (MPAs).

This thesis sheds light on how different multi-actor digital conservation networks arise and perform, focusing on the meanings that the participants of these networks assign to the various aspects of knowledge production and use in the context of Caribbean coral reef governance. The focus lies on questions of participation, as well as the perceived effectiveness and legitimacy of digital conservation initiatives.

The aim of this PhD thesis is three-fold. First, it seeks to provide a theoretical contribution to the novel field of digital conservation. Second, the thesis aims to understand actors' motivations to engage in various data practices related to coral reef conservation in Caribbean MPAs, as well as the conditions that enable and constrain them. Third, the thesis aims to enhance understanding of (perceptions of) effectiveness and legitimacy of digital conservation and coral reef governance.

To meet these objectives, the following research questions were formulated:

1. What features of multi-actor digital conservation networks in Caribbean coral reef MPAs are essential to understand processes of knowledge production and use by these networks?

2. What motivates, enables and constrains actors to participate in practices related to digital conservation in Caribbean coral reef MPAs?

3. Under which conditions do digital conservation networks in Caribbean MPAs contribute to effective and legitimate coral reef governance? 


\section{Summary}

This $\mathrm{PhD}$ thesis consists of seven chapters. Chapter 1 provides a general introduction, presents the research questions and my research strategy. Chapter 2 develops the methodological framework followed. The empirical chapters (chapters 3 through 6) were written as scientific papers, out of which three have been published in international scientific peer-reviewed journals and one is under review. Chapter 7 draws conclusions. Below, details are provided of the content of chapters 2-7.

The thesis is positioned within a realist social constructionist paradigm and takes a critical hermeneutics perspective to the study of knowledge production and use in multi-actor digital conservation networks. Chapter 2 builds the critical hermeneutic methodological framework that guided my research and presents the methods of data collection and analysis, which followed a qualitative case study approach. As a starting point for this thesis, I conducted an initial overview of several MPAs located in tropical and temperate regions of the world (Chapter 3). This exploratory study enabled the further delimitation of my research to one ecosystem type in one geographical region (coral reefs in the Caribbean), as well as the selection of two cases for which digital conservation instances had been developed to address salient governance issues: one focusing on invasive lionfish monitoring and management (Chapters 4 and 5) and the other on seawater quality monitoring (Chapter 6).

Chapter 3 is situated within the information systems (IS) development literature and presents an overview of how actors associated with eleven MPAs situated in eight different countries across three continents interpret desirable data attributes (availability, accessibility, quality, consistency and security). The chapter specifically contributes to IS interpretive research on the field of requirements elicitation for IS design. This chapter provides insights regarding how the organizational culture of the various actors shapes their interpretations and (inter)actions regarding the production and use of data in the context of collaborative MPA management and governance. Legitimacy and accountability are identified as important themes that cut across statements from all actor groups and guide their data practices.

Chapter 4 presents a chronological overview of discourse formation regarding the lionfish, a non-native fish species that has been accidentally introduced and rapidly spread throughout the Western Atlantic and has become a serious conservation concern in many Caribbean MPAs. In focus here is how discourse coalitions draw on scientific data to make themselves persuasive, and on metaphors of nature to convey meaning. The chapter examines how science and the media, powerful 
meaning-making actors in society, have socially constructed the lionfish invasion. The key role herein of a regional digital conservation initiative brought about by a large multi-actor network to map lionfish distribution is highlighted. In addition, the chapter elucidates the interpretations of local stakeholders associated with seven Caribbean MPAs. Stakeholders' discourses, based on their own lionfish data and local experiences, are juxtaposed against the dominant storylines about lionfish management circulating through the region, mainly through online maps, databases, news reports, Internet forums and social media.

Chapter 5 examines the drivers and barriers to participation in various digital and non-digital conservation initiatives built around lionfish in five Dutch Caribbean MPAs. The chapter contributes to the environmental volunteering literature related to conservation citizen science. It looks at actors' motivations to engage with and remain active in these initiatives, focusing on practices of data collection and data sharing. The personal meanings attached to both the data and the data collection experiences influenced actors' motivations to sustain or cease their participation in the various multi-actor networks operating regionally and locally. Moreover, enabling and constraining conditions at the personal, interpersonal, organizational and technological levels are identified.

Chapter 6 contributes to academic research of science-society relations in digital conservation, with legitimacy dynamics and the democratization of science and policy as central themes. The article assesses the social processes and outcomes of a participatory sensing initiative. A conceptual framework that explicates the multiple legitimacy relations forged among heterogeneous actors in collaborative knowledge production processes is presented. The framework is applied to describe and explain the processes and results of a community-based water quality monitoring project around Bonaire. The chapter offers a critical appraisal of digital technologies' promises of democratic knowledge production for use in coral reef conservation governance.

Chapter 7 concludes the thesis by synthesizing the findings of the four empirical chapters and answering the research questions posed in the introduction. The chapter moreover provides a reflection on interdisciplinarity and the theoretical contribution of the thesis, and closes with a research agenda proposed to advance the digital conservation field. 


\section{Summary}

First, I conclude that five features of multi-actor digital conservation networks are essential to understand processes of knowledge production and use: the dynamic nature of such networks; their voluntary character; the diversity of stakeholders and goals represented; the specialized skills required for participation; and the type of nature conservation issue at stake, as well as its level of polarization in society. These features confer multi-actor digital networks with opportunities such as flexibility and responsiveness to novel issues, efficiency and possibilities for mutual learning, as well as the formation of stable, effective and self-organized communities of practice. Challenges that these features pose include networks that are unpredictable, whose durability is uncertain and the quality of the data produced is questioned (affecting legitimacy in the eyes of decision-makers), potential miscommunication among heterogeneous actors and goal incompatibility. In general, the nature conservation issue addressed by these digital networks affects membership and the level of issue polarization shapes knowledge utilization (conceptual, instrumental, political).

Second, I conclude that multiple and changing motivations drive actors to participate in digital networks for coral reef conservation. Concern for the environment is initially important to drive collective action, but as time goes by other motives complement or even supersede environmental values. Three distinct logics - the logic of consequences, of appropriateness and of practice - help to understand dynamics of (aspects of) behavior as people, their roles and situations change. Factors at the individualistic (personal, interpersonal) and structural levels (organizational, technological) enable and constrain actors to sustain participation in networks. Building on the citizen science literature, a typology of digital conservation networks is presented, based on goals and the task division between scientists and non-scientists. Three types are identified: community-driven, collaborative and science-driven networks. The level of issue polarization and the democratization potential of these different types run on a continuum from 'high' for communitydriven, to 'low' for science-driven networks.

Third, I conclude that three conditions are necessary for multi-actor digital networks to contribute to effective and legitimate governance of coral reef conservation in Caribbean MPAs. These conditions include: a shared perception of a nature conservation issue as a crisis; use of solution-oriented frames; and fostering of winwin situations for project participants. While the first condition is key during the initial stage of network formation, the latter two are important for network durability. 


\title{
WASS Education Certificate
}

\author{
Eira Coralia Carballo Cárdenas \\ Wageningen School of Social Sciences (WASS) \\ Completed Training and Supervision Plan
}

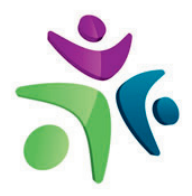

Wageningen School of Social Sciences

\begin{tabular}{|c|c|c|c|}
\hline Name of the learning activity & Department/Institute & Year & ECTS* \\
\hline \multicolumn{4}{|l|}{ A) Project related competences } \\
\hline Marine Protected Area Workshop & IMARES, Ijmuiden & 2010 & 0.2 \\
\hline Intro. to GIS (GRS-10306) & WUR & 2010 & 6 \\
\hline Int'l Marine Data and IS conference & Paris, France & 2010 & 0.6 \\
\hline Data Management (INF-21306) & WUR & 2010 & 6 \\
\hline World Ocean Day & TU Delft, Rotterdam & 2010 & 0.2 \\
\hline Qualitative Data Analysis (YRM-60806) & WUR & 2010 & 6 \\
\hline \multicolumn{4}{|l|}{ B) General research related competences } \\
\hline Introduction course & WASS & 2010 & n.a. \\
\hline Writing Research proposal & WUR & $2010-11$ & 6 \\
\hline $\begin{array}{l}\text { 'MPA stakeholders' perceptions of data } \\
\text { attributes' }\end{array}$ & $\begin{array}{l}\text { Int'l Marine Conservation Congress, } \\
\text { Victoria, Canada }\end{array}$ & 2011 & 1 \\
\hline $\begin{array}{l}\text { 'Stakeholder views on data attributes \& } \\
\text { data use for management of MPAs' }\end{array}$ & WASS PhD day, Wageningen & 2011 & 1 \\
\hline Poster & MARE conference, Amsterdam & 2011 & 1 \\
\hline Reviewing a scientific paper & Wageningen Graduate schools & 2012 & 0.1 \\
\hline $\begin{array}{l}\text { Sociology and political science of } \\
\text { environmental transformations }\end{array}$ & ENP & 2018 & 1.5 \\
\hline Article reviews & $\begin{array}{l}\text { Journals: Fish and Fisheries; } \\
\text { Management of Biological Invasions }\end{array}$ & 2019 & 2 \\
\hline \multicolumn{4}{|c|}{ C) Career related competences/personal development } \\
\hline $\begin{array}{l}\text { Coordination and teaching of course } \\
\text { Ocean and Coastal governance (ENP- } \\
52806)\end{array}$ & WUR & $\begin{array}{l}2012 \& \\
2014\end{array}$ & 4 \\
\hline $\begin{array}{l}\text { Convenor and Presenter at the } \\
\text { conference }\end{array}$ & $\begin{array}{l}2^{\text {nd }} \text { Wageningen } \mathrm{PhD} \text { symposium } \\
\text { "Connecting ideas, combining forces" }\end{array}$ & 2015 & 1.3 \\
\hline Seminar "Citizens for nature" & WASS & 2015 & 0.5 \\
\hline Accreditation of prior learning & $\begin{array}{l}\text { Various courses (i.e. statistics; writing } \\
\text { \& presenting a scientific paper; } \\
\text { bioinformation technology; } \\
\text { supervising thesis students) }\end{array}$ & & 3.2 \\
\hline Total & & & 40.6 \\
\hline
\end{tabular}




\section{About the author}

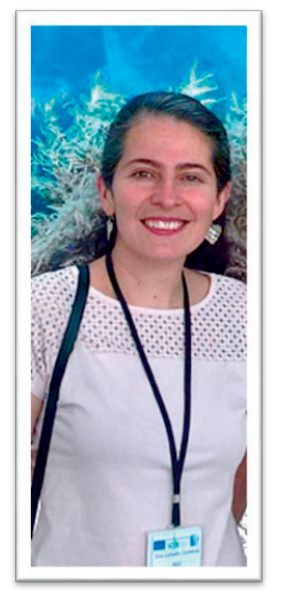

I was born on the $27^{\text {th }}$ of October, 1974, in Mexico City, as the oldest of four siblings. Growing up in sunny Mexico amidst a fairly large and close extended family, with numerous friends and neighbors constantly coming in and out of our home, my childhood was happy and carefree.

Although living far from the coast, I developed a love and fascination for the ocean during my early teenage years. After graduating from high school, I left for college in Florida, USA, to pursue my dream of studying marine biology. This was an uncommon and little understood thing to do in our social environment: an 18-year-old girl from a 'good' Mexican family going abroad on her own, to dive in the sea... Yet, my parents supported me unconditionally, and so a wonderful adventure began that took me beyond Florida - to the Netherlands, Belgium, Indonesia and back to the Netherlands. Throughout the years I have had the privilege of exploring the aquatic world from various academic perspectives and disciplines, including incursions into the labs of microalgal biotechnology and book editing for aquaculture extension in the tropics.

In Wageningen I have found a second home, and at the Environmental Policy group (ENP), a great community I have enjoyed being a part of for over a decade. First, as an MSc student, then as a PhD candidate, and since 2016 as a MERCES* researcher and a lecturer. I look forward to starting a new stage in my career at ENP in the summer of 2020. I live in the northwest area of town with my husband, two kids and our little fluffy dog.

\section{Eira Coralia Carballo Cárdenas}

Thomas A. Edison primary school and high school, Mexico City BSc in marine science, University of Tampa, Florida (cum laude) MSc in aquaculture and fisheries, Wageningen University (cum laude) MSc in environmental science - policy track, Wageningen University 
The PhD research was financially supported by IPOP Coast and Sea Program, Wageningen University.

Cover photographs by Erik Meesters.

Cover design by Emily Liang \& Eira C. Carballo Cárdenas.

Printed by Digiforce on recycled paper.

Financial support from Wageningen University for printing this thesis is gratefully acknowledged. 

